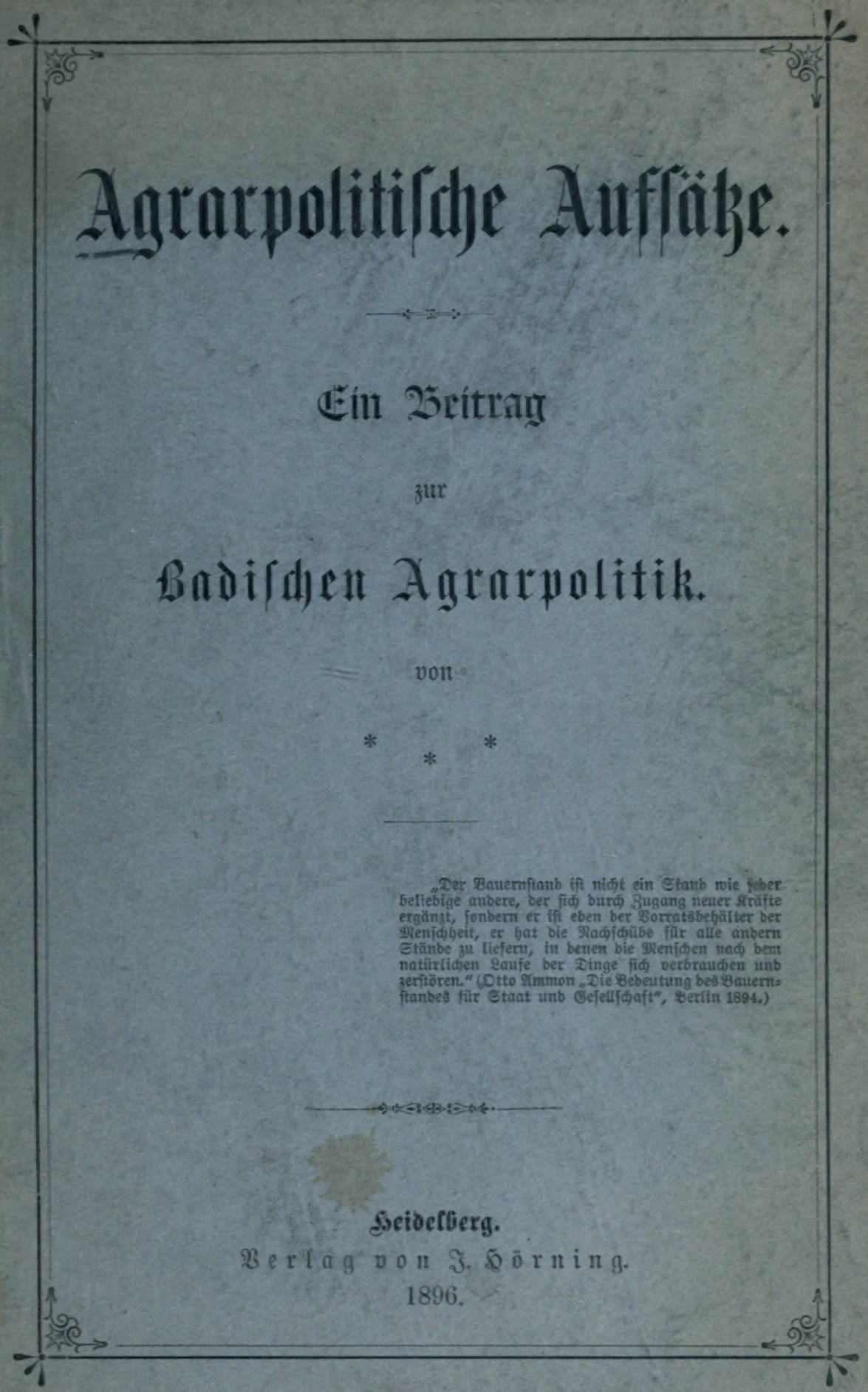







\title{
Anrarpolitildge Auffinge.
}

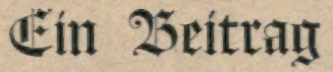

\author{
zur \\ Badifhen Agrarpolitik. \\ vont \\ * $\quad * \quad *$
}

Der Mauerntanb ift nidit ein Stanb wie ieber beliebige anbere, ber fid burd Bugang neuer Rrüfte ergängt, forbern et ift eben ber Borratsbejältet ber IRenídbeit, ex bat bie Radjidibe für alle anbern Stänbe ju liefern, in benen bie Mteníden nad beat natilitidien Qaufe ber Dinge fid verbrauden unb

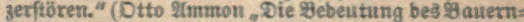
ftanbeß für Staat unb Sejelljdjaft", Đerlin 1894.)

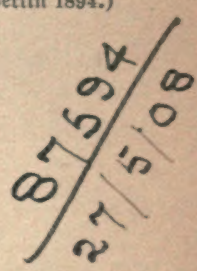

Şeidelberg.

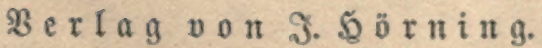

1896. 
not 20,2

(1)

(v)

$1818=$

$(4.44111+2$

$7 \cdot v^{2}$ 


\section{Dorwort und Ėinleitung.}

Daß̉ fich bie beutiche Ranbwirtichaft zur 3eit in einer fodmeren Rrifís befindet, wirb jeķt wohl von Riemanden, ber bie frühlung mit Derielfent nidgt volfftänoig verloren bat, mehr beitritten werben; bagegen gehen bie Meinungen ïber bie 2ufgaben, weldye ber Staatsregierung

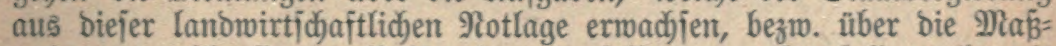
nabmen, weldi)e fie zur Befämpfung berjelben ergreifen foll, nod) weit auseintanber.

Sierin num zur Slärung Der öffentlidden Meinutng beizutragen, joll Der 3wed biejer $\mathfrak{B}$ roj̄düre jein.

2Afle biejenigen werben fid allerbings enttäujdot finden, weldje von

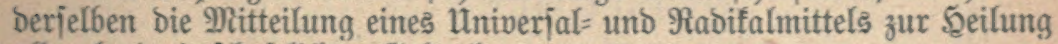
aller Ianowirtidaftlichen (Gebred)en erwarten.

Der Berfajier gehört, wenn man will, zu ben Berteibigern ber jo=

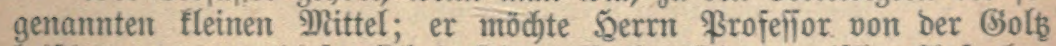
beiftimmen, went biejer fid in jeinem Budje "Die agrarifjent 24 ufgaben Der Gegentwart" (Seite 8) folgendermaß̧en äußert:

"Die Bejeitigung ber vorbandenten Uebelftände fann ohne groß̧e

Sdäbigung ber einzelnen Ranowirte wie ber ganzen lanowirtichaft= liden Froduftion nur gelingen, wenn man unter fteter \$eriidficd = tigung uno möglidffter Sdjomung ber gegebenten uno bittorifid ge= worbenen ßerbältnifife auf ben vorhanbenen (Srutudlagen weiterbaut."

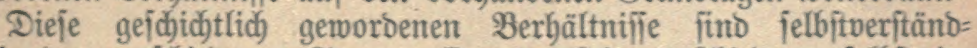
lid, in ben verfodjebenen Staaten Europas jebr verjdieden; jelbit im

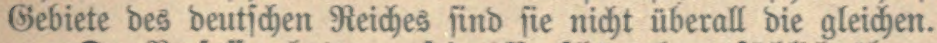

Der Berfafifer hat nun feine Brofidüre hauptiäddlid über unઠ für babifidge 2erbältnifife gejdjrieben uno zwar hat er fid bierbei, wie

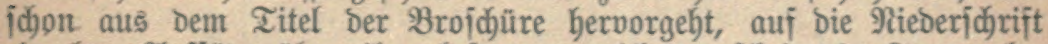
einzelner $\mathfrak{2}$ uffiäbe ¡d)ränft, ohne einen verbinbenden Text zwijdent Dent einzelnen 2tbjönitten einzujdalten.

Die ganze Entwidflung Der Ifgrarfrage uno bie Bebeutung berjelben

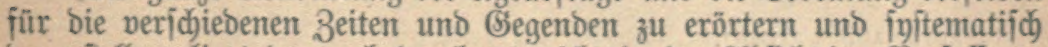

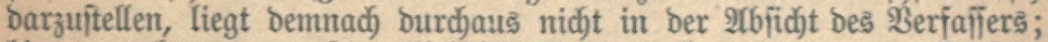

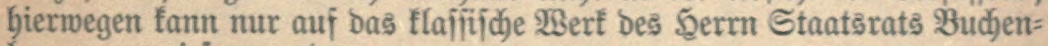
berger verwiejen werben.

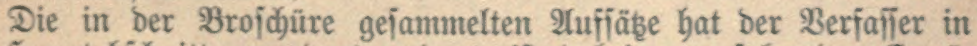
brei Қauptabjīnnitte georonet uno er ift Dabei von folgenden Erwä= gungen ausgegangen:

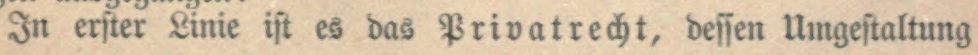


nac) Den Bebürfniffen ber Ranowirtichaft bie moberne 2Agrarpolitif in

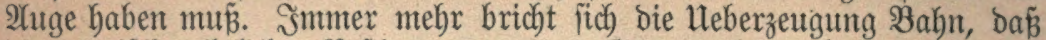
Die römijich=rechtlichen Beftimmungen Des Güterverfehrs (unter Rebenden uno von Iobes wegen), weldbe für den $\mathfrak{B a r e n h a n d e l}$ und Rapital= ımiak ganz geeignet fein mögen, für bie Ranomirtichaft nicht paffen; wie man in ben lebsten Sabren ein jelbititänoiges 2lrbeitsrecht zu

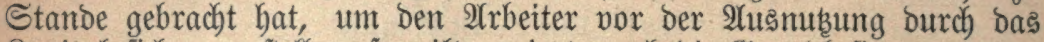
Rapital ficher zu ftellen, fo gilt es jebt, auch bie (Srunbbefitber vor ben

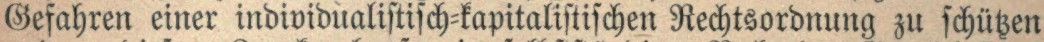

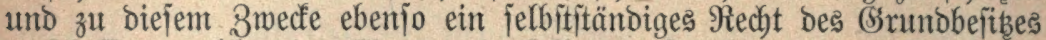
zu ichaffen, welches ber Eigenart besjelben entipridyt, ober bas beitebende Recht Den Beoürfniffen Der Ranbwirtichaft anzupafjen.

Reben ber Aenderung bes $\mathfrak{B}$ rivatred) $t$ s bleibt alleroings nod) ber inneren Bermaltung ein groper Wirfungsfreis und auch bie Finanzperwaltung fant im Domänen= uno Steuermejen Manches zur Befferung ber lanowirtickaftlicken 3uttände beitragen.

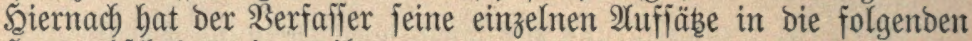
brei Şauptabichnitte eingeteilt:

I. B̧ereid bes Șutizminifteriums, II.

III. " Miniferiums des Śnnern, der rinanzen

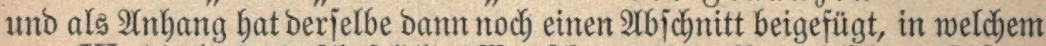

IV. bie landwirtjchaftlichen Wünjche aus dem Bereich bes Eijen= bahnmejens bejprocken werben jollen.

Der eine ober anbere ber \&ejer mödbte vielleidgt por Beginn ber Seftüre biejes Schriftchens noch wifien, meldber politifchen \$artei ber Berfafier benn eigentlich angebört; Gierauf fann berjelbe mur erwibern, daß̧ er fich bisher von bem ßarteileben immer möglichjt ferngebalten

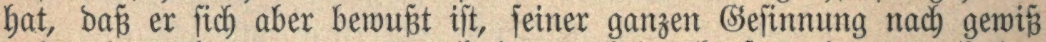
meber ber ultramontanen, noch ber orthodor:fonjervativen, nod) ber bemofratifchen ober gar jozialdemofratijchen \$artei anzugebören. Bon Dem bemofratijchen Stanopunft füblt fich ber Berfajier jogar jo weit

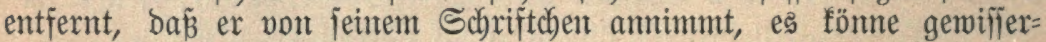
maken als ein nidbtomofratijdbes \$sendant zu ber 2Anfangs laufenden Sabres eridbienenen Muier'icten Brojdüre über "bie Âgrarfrage uno bie Stellung ber Demofratie zu Derjelben" angejeben merben.

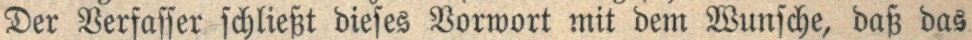
Sdyriftchen ber babijchen Ranowirtichaft in einer ober ber andern Meije zum Ruken gereidben, und da uno nachfichtige Beurteilung finden möge.

sim Dftober 1895. 


\section{T⿱宀 Taupfablthnniff.}

\section{Das băuterlid) (Erbredt)t.}

Bevor wir ber Frage näker treten, ob bą zur Beit bei unts geltende

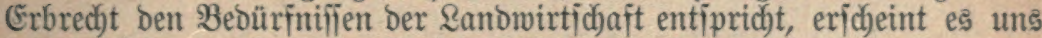
erforberlich), zuerjt biejes Rech)t in jeinter jebigen Beitaltung furz bar= zuiteller.

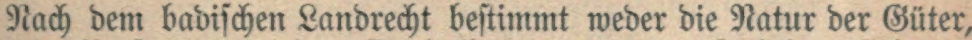
nod) Die ßerion, von ber fie Kerfommen, Den gejebzlichen Erbgang (Saß3 732); Das (Erbred)t ift aljo Das (Sleid)e für bewegliche uno un= beweglidje, für ftäbtifje und länolidje Sermögensbejtanoteile.

Beim Mangel eines Teitamentes erben in eriter Reibe bie Rinber uno zwar - auf bem Ranbe, wie in ber Stabt - zu gleidjen Teilen

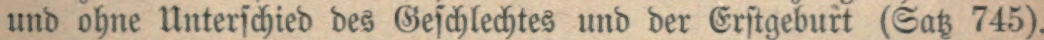

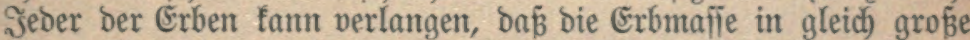
Soje eingeteilt miro, von benten jebes womöglicid gleidy viel an berweg= licjen und gleich) viel an unbeweglicjen (Sütern entbalten joll, und bá̉ Dann bieje soje burdh) Biehung verteilt merben (Sabi 826, 831 fi.); jente

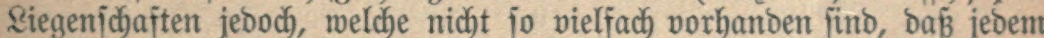
ber Erben ein äbnlidges Stüd werben fönnte, und weldbe aud burd) Berteilumg nid)t zu einer jold)en Mebrfad)heit gebradft werden fönten

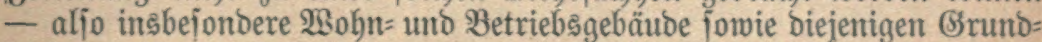

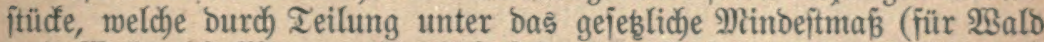

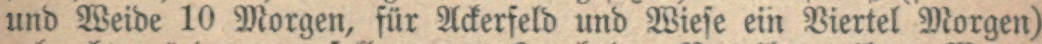
gebradjt wuirben -, jollen zum 3wed ber Berteilung ibres Wrertes veriteigert merben, fofern bie Beteiligten fid nidht über eine andere 2 rt

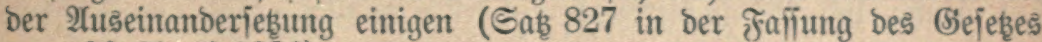
vom 26. Ipril 1886).

Dies find in wentigen Borten bie wejentlidjiten, Gier in Betradjt fommenden Beftimumingen bes gemeinen babijden Erbredtes.

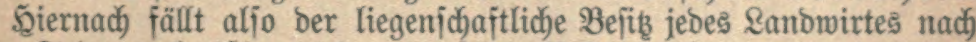
befien Tod regelmäß̧ig wieber in feine Bejtanoteile auseinander uno miro in einzelnen Stüden an bie veriddiebenen Erben verteilt.

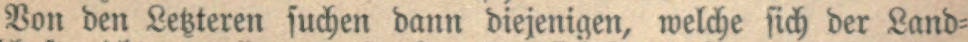
wirtidjaft nidjt zu mibmen gebenfen ober fid fortverbeiraten, ibre \$ar= zellen nad) und nad) möglidjit gut zu veräufern; biejenigen bagegen, weldje im Dorfe als Sanomirte zurüd6leiben, ftreben Dabin Durch Seirat 
Doer, went fie Eriparniffe madben fönnen, burd) 2lnlage berielben in (Srumbitücfen nack und nack wieber zu Dem Srunbbefib ibrer Eltern emporzufommen, morauf Dann beim nädbiten Generationsmechjel bie Ber= iplitterung von nettem beginnt.

Babifdees 2lnerbenredit.

Diejem Snftem entgegengejebst ift bas jogenannte $\mathfrak{A}$ nerbented) $t$; biernach bleibt ber Riegenj(c)aftsbejib eines Bauern nach befien Iod unzerteilt und geht als ein SGanzes auf einen ber Erben, Den 21nerben, über, währeno bie übrigen Erben Durch bares Gelo ober Schuldeinträge auf Den Sof abgefunden merben.

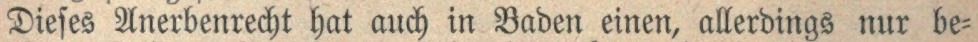

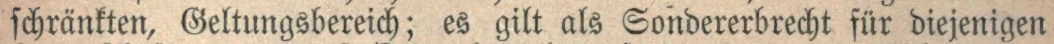
Riegenichaften, morauf Drtsgebraudb 4. 1. m. einem Der Erben eine Borteilgerechtigfeit geben, uno zwar erbält ber Sorteilserbe bas (s)ut zu eintem findlichen $2\left(n j\right.$ d)lag, welcher ${ }^{1 / 10}$ und in rauken Berggegenden ${ }^{1} / 8$, auf $\mathfrak{B}$ erorbnung Der Eltern aber bis z $11 / 4$ unter bem wabren laufenden

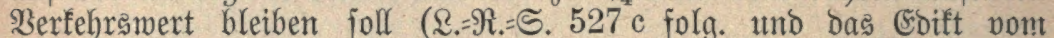
23. März 1808). Un 3weifel über Den (Seltungebraud) biejes 2tnerben= rechtes zu bejeitigen, murbe mittelft (Sejeb̧ vom 23. Mai 1888 beitimmt,

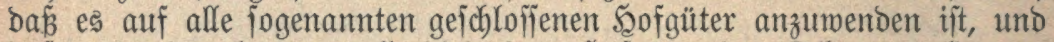

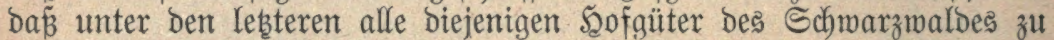
veriteben fino, welche jeit bem ermähnten Esift zu Folge Sgerfommens unzertrennt von einem Eigentümer auf ben andern übergegangen find.

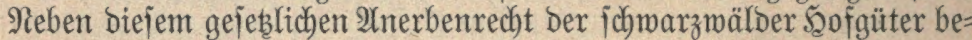
fteft übrigens in einzelnen Segenden Babens z. B. im Dbenwald, am

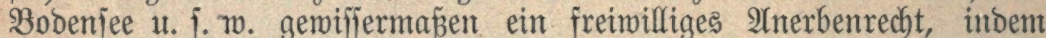

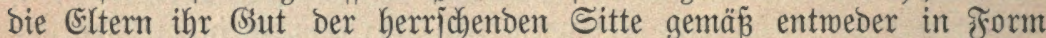
Des Sindsfaufes ober ntittelit Teftamentes für eines ibrer finder be= ftimmen ober basielbe bei eingetretenem Iobesfall unter alleitiger $3 \mathfrak{u}=$

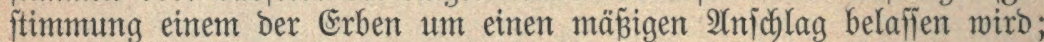
von bem gejeblicken Sorteils= und 2(nerbenrecht untericheidet fich bieje Sitte aber insbejonbere baburch), Daßj fie auf bem jebesmaligen

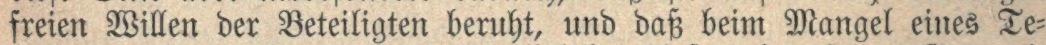
itaments feinem ber Erben ein recktlicker 2tnjpruch auf bas (Sit und insbejondere nicht zu einem findlichen Intrichlag zuftebt.

Bergleidiung beiber Mecht infteme.

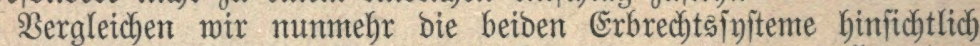
ibrer volfsmirtichaftlichen Bebeutung, jo rithmt man vor allem bem

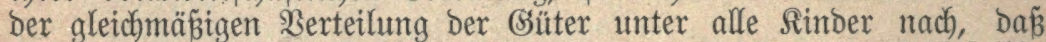
ber (stund und Boben bierourch auf eine möglidfit grofie Bahl jelbft=

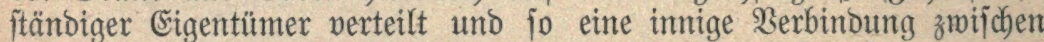
2Trbeit uno Eigentum gejchaffen merbe - bie beite Schranfe gegen bas

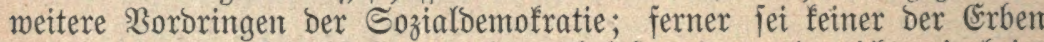
mit bebeutenden (Śleichitellungsgelbern belaitet, ba er ja nidbt mie beim Snitem bes $\mathfrak{A}$ nerbenrechts feine Miterben Durch bares (seld ober Sdbuld= einträge auf Den 5oof abzufinden bätte; immer gebe es in Den Gegenden biejes Erbrechtsingitents Rauf́shluftige uno Berfaufshuftige für einzelne

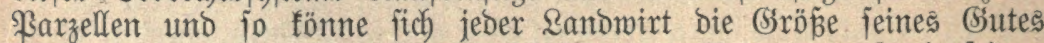
feinen indivibutllen Eharaftereigenichaften und Reigungen fowie jeinen Bermögensverbältniffen entiprecheno einrichten; Durch bieje ftändige 
(Biiterbemenum jei jerner and) bem Iaglöbner Gelegenbeit geboten,

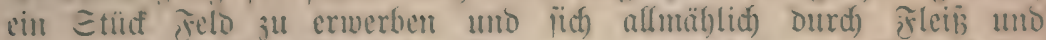

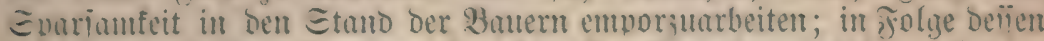

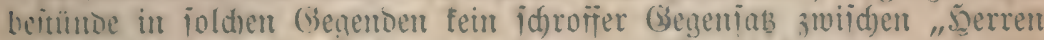
Imo Sinet)ten" uno cberiowenty ein eigentlidber 2frbeitermangel, eine

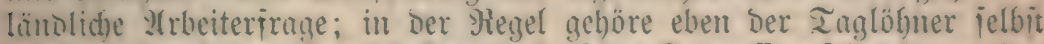

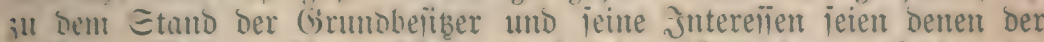

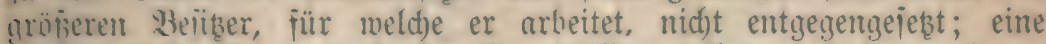
nüntige jolge Der weitnebennen Grmbbelibverteilung uno ber geringen

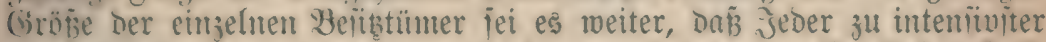
Bbemintid)aftung genötigt jei, un jeine uno jeiner Framilie 2rrbeitsfraft volfitänoig auszunuken.

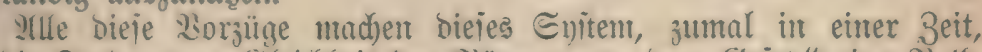

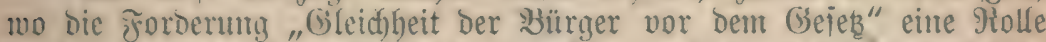
ipielt, populär uno es ijt nicht zu vertemen, Dấ es fejt uno tief in Dent Hed)tsuejühl eines groben Teils Der Bevölferming murzelt, und

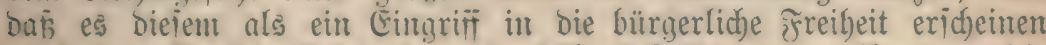
mürbe, wollte bie Gejebgehung Dașelthe bejeitigen ober ihm nur bie Eirrenichaft als gemeines, in eriter sinie geltendes Erbredft entjiehen; trobidem wollen wir umjere 2fugen gegeniiber Den Biadjteilen diejes Snitems nidjt veridhliépen:

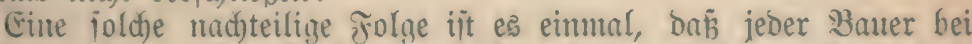

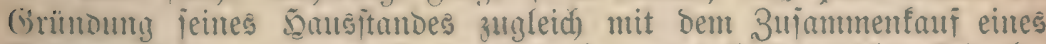
Butemutes von neuem benimen min, moourd) ihm nidgt allein be=

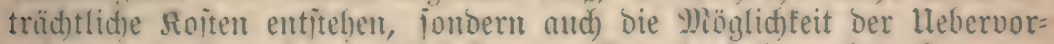

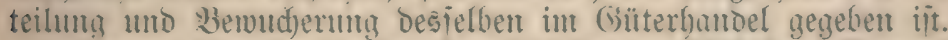

Ferner fann ja bie hei Grunditücfen Durthführbare Raturalteilung

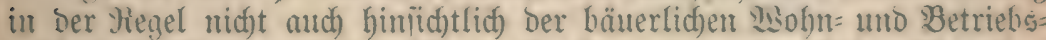
gehüube ituttfinton; Dieje milien vielmehr an einten ber Erben übergehen

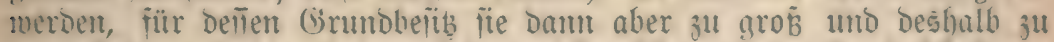

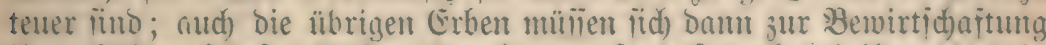

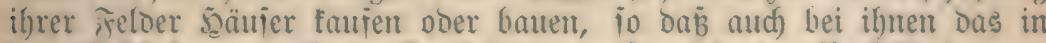

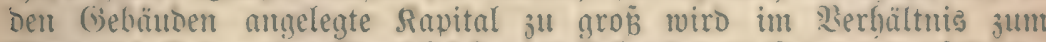

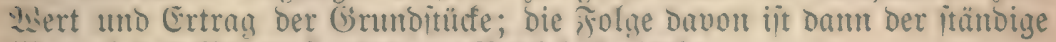
Wiannel Des Bamernitandes an Betriehstanital.

Ein brittes Bedenten liegt in ber immer weitergehenon Beriplitterung

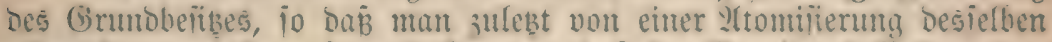

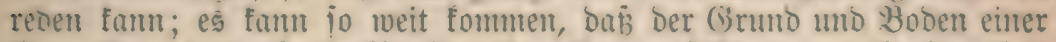
(Semarfung in tanjende fleiniter Fiariellen ierjüll, Deren Beritrentbeit

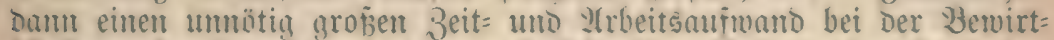

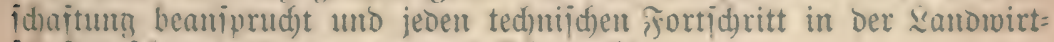
id)ait erichwert ober gans mmö̈glid) mad)t.

Iud) tritt wegen Der "Seid)tigfeit, fant jeberzeit ein ober zwei fleine

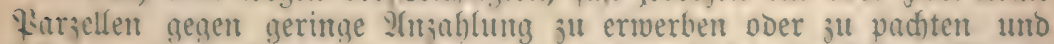

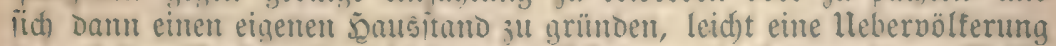

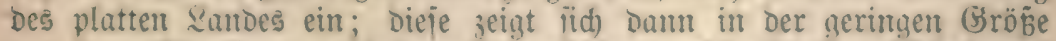

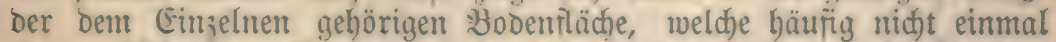

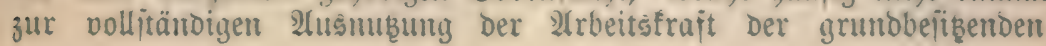


Familie hintreidjt, umb weiter in einem als Frolge bavon anftretentoen wahren Randhunger, ba jeber - menn nidjt gimftigenfalls einige rasa=

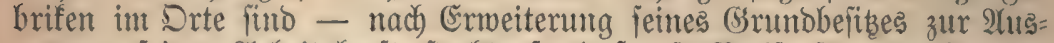

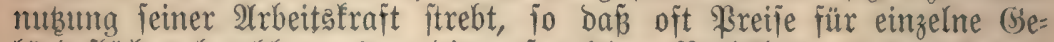
länbefläch)en bezahlt werben, bie außer jebem ßerbältnis zu Dem Ertrag berfelben itehen; da bewahrbeitet fich bann bas Bautern=Spridymort:

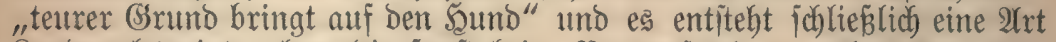
¿anoproletariat, ohne bie fonit beim Bauernitano zu rübmenoen titch= tigen Eigenjibaften und ohne Rraft und $\mathfrak{S}$ offnumg, in befiere Berbält= niffie emporzufrmmen.

Im Ǧegenjaß zu biejen bebenflichen Folgen bes gemeinen Erb:

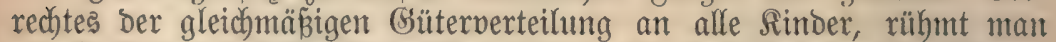

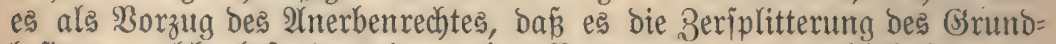

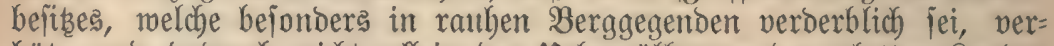
Güte und badurch nidyt allein ber Hebervölferung bes plattent Ranbes entgegenwirfe, fonbern auch bie Erbaltumg eines fräfitigent, leiittutrģ= fäbigen Bauternitandes gewährleifte, weldher boch bas Riucfgrat eines jeben Staatsmejents billde.

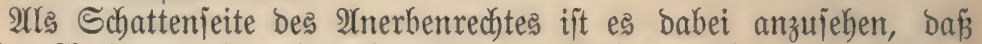
es eine 2lenberung ber einmal geworbenen Befibperteilung, aud wenn fie ben veränberten Sulturverbältniffen nicht mehr entipricht, erichivert,

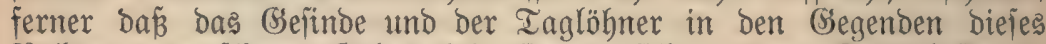

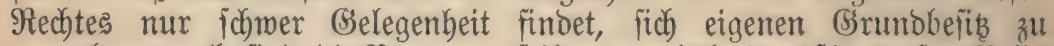

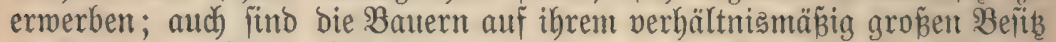
in Folge ber bohen Bhleidffellungsgelder an bie Miterben oft tief ver=

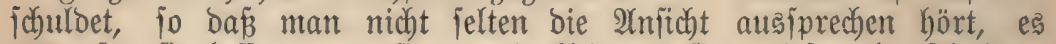
wäre für fie bejier, menn fie nur ein fleineres Gint, biejes aber idouldon= frei, ober menigitens mit geringerer Edhulbenlajt bejäßen.

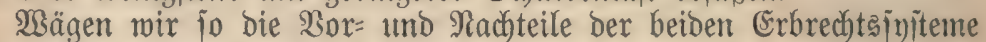

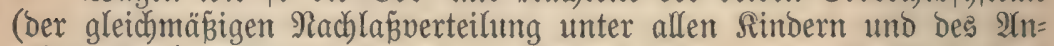
erbenrect)tes) gegeneinander ab, fo fommen wir zu bem Erngebuis, Da feines berjellben geeignet ift, Das andere vollitänoig zu verorängen; ins= bejonbere märe es ein großerer Feffler, mollte man foldyen Gegenden, in weldyen bas bisherige gemeine Erbrecht ber gleichen Behandlung ber

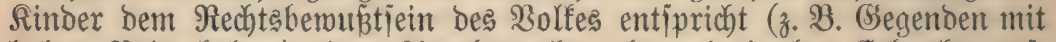
Goher Bobenfultur) das ânerbenrecht als prinzipales Erbrecht auf= brängen; Dagegen idgeint uns alferbings ein Bebürfnis vorzuliegen, bas

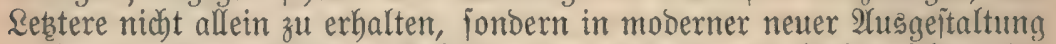
audd auf alle biejenigen (Bsebiete auszubehnen, wo bisher ichon eine

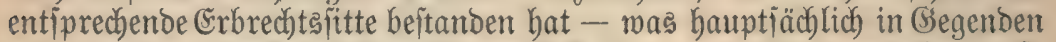

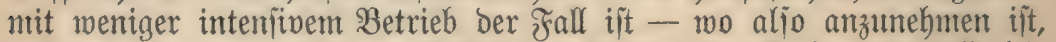
ba entipricht.

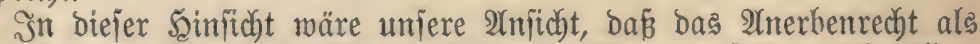
geiebliches Snteitaterbrecht fünftig Gieltung befommen jollte, nicht allein für bie 4942 geifhloffenen Şofgüter bes Schwarzmaldes, welche jeit bem Jahre 1808 unzertrennt von einem Eigentümer auf ben anbern über= gegangen find (Gsej. vom 23, Mai 1888) fondern auds: 
1. ïberfount für alle 5ofgüter, jei es im @dywarzmald, jei es in

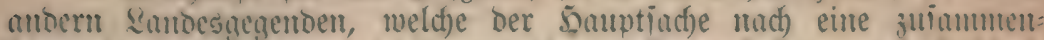

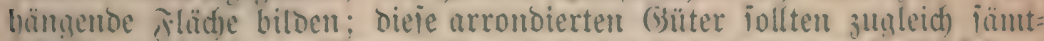

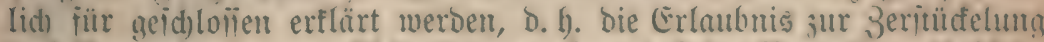

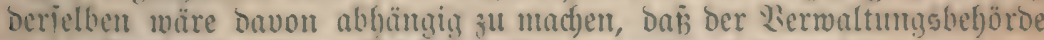

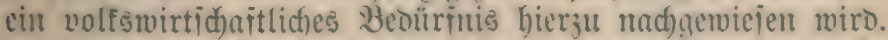

2. 3weitens wäre unieres (Erad)tens bas jòteitatanerhenrecht anเs= 3ubehnen auf Diejenigen nidht unter Bifïer 1 jallenden bäuerlichen Gïiter

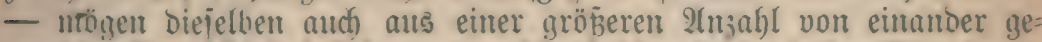
tremtter (Grunoitüde beiteben -, woldhe bei Den lesten beiden Eigentumts= ïbergängen (Bererbung ober 2ierfaui) als ein einfeitlidbes (Ganze be=

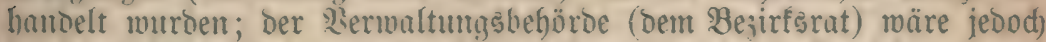

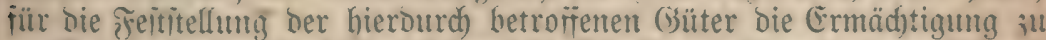

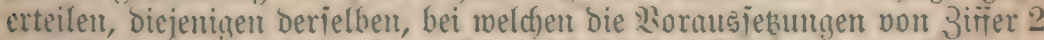

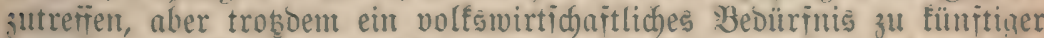
unsertremter siererbung nidht vorliegt, aui 2Antray von ber betr. Siite jul itreid)en, wie and) untgefebrt ioldbe (Biiter, bei welden mur ein ein= siger einbeitlicher Eigentumbïlbergang nadigemiejen wiro, aber eine 3er=

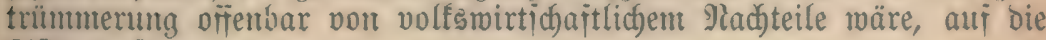
sipte zut jeben.

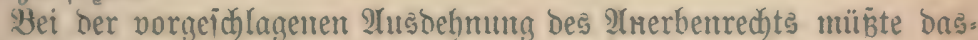
jelbe allerbings in moberner Geitaltung neufobifiziert werben, wohei utan von folgenden (Gejichtspunften ausgeben fömnte:

1. Dem Anerbenred)t wäre, wie bişher, Der Charafter als̈ J̈nteitat=

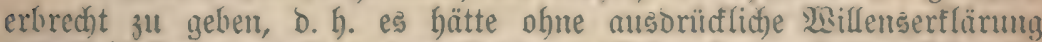
Des Erblallers z̆ll gelten; Dem Rebteren bliebe aber and) umgefebrt Die

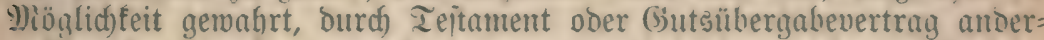

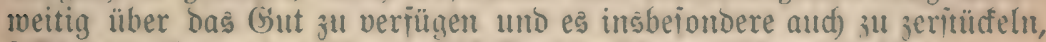

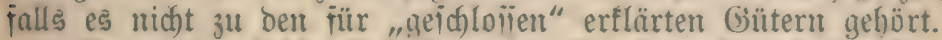

(Begen eine joldhe Geitaltung bes 2nerbenred)ts als jutteitaterbredit

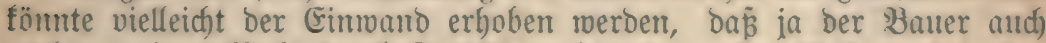

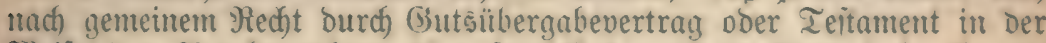

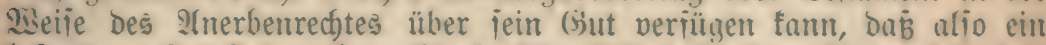
beionderes jutteitatanerbenred)t als bäterliches Eonderred)t umötia iei;

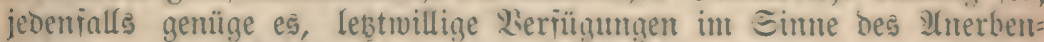

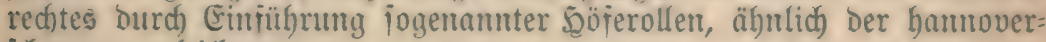
idjen, zu erleidjtern.

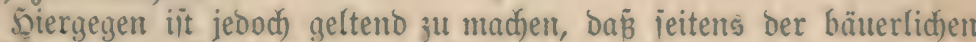
Benölferuty Die Erridtung eintes Teitantentes, ehenio wie Der Eintray

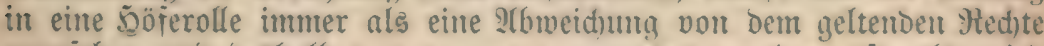
angeieben und beshalb mur ungern angemendet wurbe; oftmals wird 3ubem eine joldhe lebtwillige 2luorbmung von Tag 3u Tag binaughe= id)oben, uno wenn bann plöblid) Der Tod Des nofheiikers eintritt,

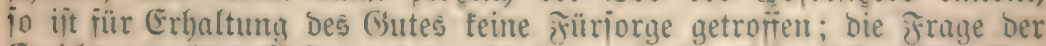
Errichtung eines Teitantentes gibt ferner in ben bäuterfichen foumilien Ieid)t 2tulä 3 allerlei Jutriguen ber Rinber gegenteinanber und auj

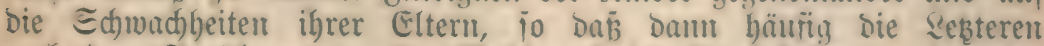
mad) Dem Epridmort zu ber \$siugl auch Die Dual baben, und unter 
IImftänoen Streit smo Saber in vorber friebliche Fantilien ein= zieken; wozu aber ïberbaut einen folchen Bwang zur Errichtung vou Ieftamenten ausüben, wo man mit einem ber bäuerlichen Eitte ent= ipred)enden Snteitaterbrecht viel leid)ter und befier zum Biele foummt?

Fï̈r biejenigen Fälle bagegen, wo Das 2̂nerbenredbt nach) Dem

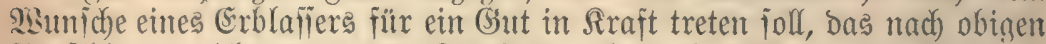
Sorjchlägen nicht unter das Snteitatanerbenrecht fällt, märe allerbinge bas Seftehen einer Sobferolle zur Erleidjterung einer entiprechenden lebt=

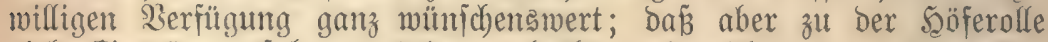
viele Einträge erfolgen wïrben, glauben wir nicht; Denn, von alfen

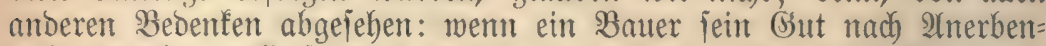
recht vererben will, io wiro er fich in ber Regel nicht Damit begnitgen, leniglich bie Bererbung nach biejem Rechte anzuoronen, fondern ex wirb

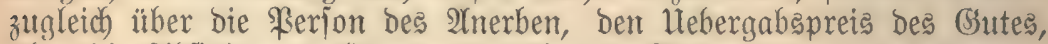
ither bie arbfindungagelder an bie ïbrigen Rinder, bie Unterbaltsrente

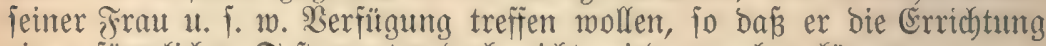
eines förmlichen Ieftamentes Doch nidht wiro umgehen fönnen.

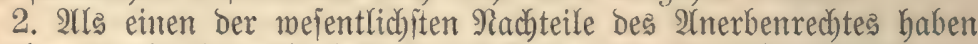
mir oben bie häufig recht hoke Beridhuldung Des Gutsübernehnters an= gefülyrt uno, daß̧ eine folche wirflich bei Den Schwarzmälder 5̧ofbautern nichts jeltenes ift, haben bie babijchen landwirtichaftlichen Erhebungen oom Sahre 1883 Deutlich gezeigt.

Der (Srumb biejer Berjouldung liegt vor allem in ber zu teuren

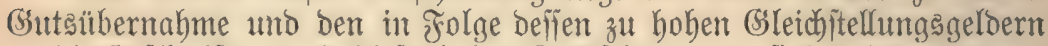

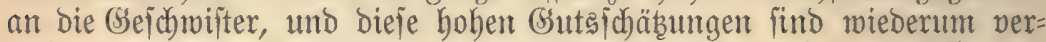

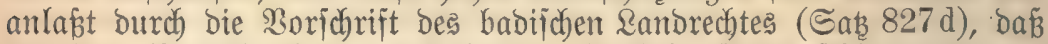

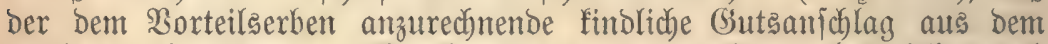
wahren laufenden Berfauferwert bes (sutes (nämlich) ourch)

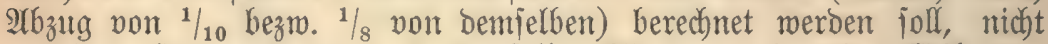
aus bem Ertrags wert; in Demjelben Sinne veroronet bas Esift vom

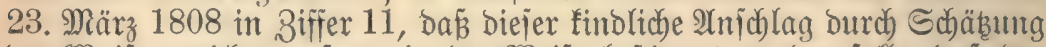

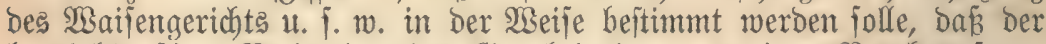

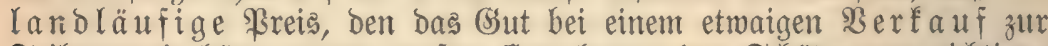
Ieilungszeit hätte, unter erniter Ermahnung ber Schäber zur richtigen uno vollen Scfäbung erboben und bavon ${ }^{1 / 10}$ bezm. ${ }^{1} / 8$ als Erleidbterung für ben Butsithernehmer abgezogen werben.

Bei biefen Beftimmungen hat man fich mohl pon bem Sebanten

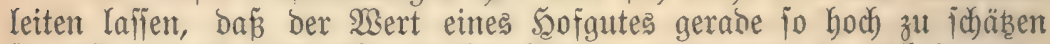
jei, als man für basjelbe erzielen fönnte, menn man es nach bem ge= wöhnlidben Erbrecht "erbteilungshalber" einer Beriteigerung" ausjeb̌en mürbe.

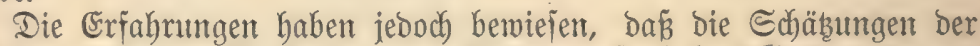

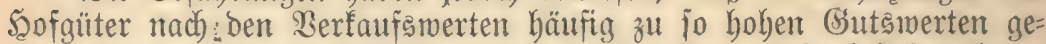
fübrt haben, bá ber Gutsübernehner Dabei faum mehr bejtehen fant.

Der Fall einer zu hohen Sdjäbung wiro z. B. häufig vorliegen, wenn man biejenigen Raupreije zur \$ergleidfung heranzieht, weldje bas

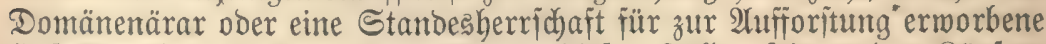
Sofgüter bezahlt hat; Denn Die in Diejen Fällen jeitens Des Räufers 


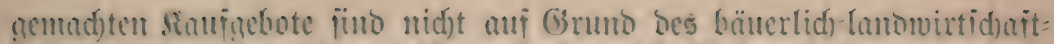

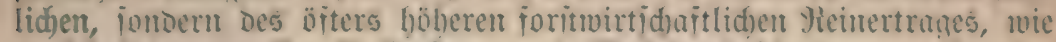

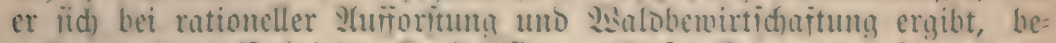

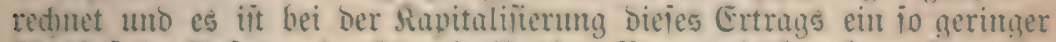

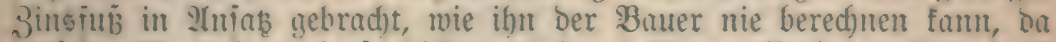
er ieine Rapitalien nie in billig gelieben betäme. Prod) unrid)tiner iit

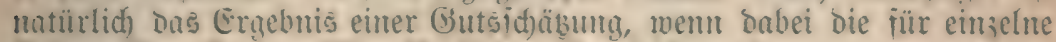

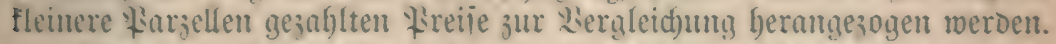

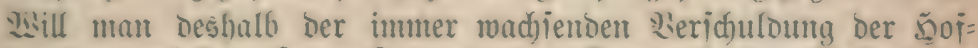
aüter entgegenmirfen, io muB man por allem mit bem Enitem Der Echätumg Derielben nad) Den siserfauistnerten vollitänotg bred)en

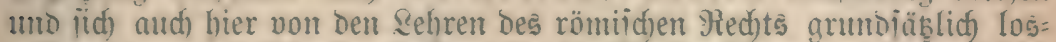

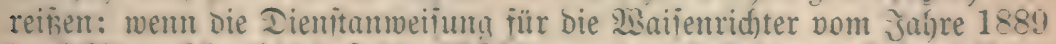

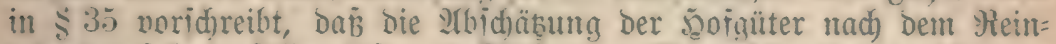

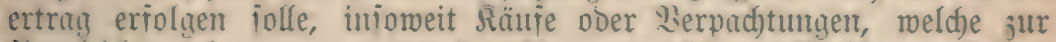

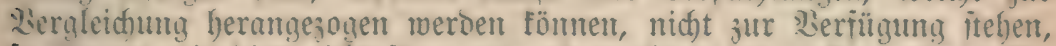
io föment wir bies nidht für genïgendo eradten; es jollte unieres Er=

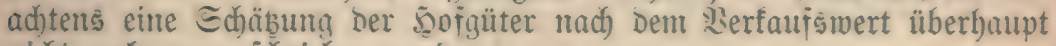
nidot mefr vorgejdrieben werben.

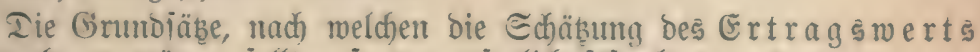
vorzunebmen wären, jollten jerner geieblid ieitgelegt merben.

Den (Śmuditenterreinertray zur Grundage oer sisertbered)mungen

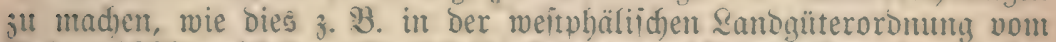
jabre 1882 geidhehen ijt, bürite bei uns nidjt antgeben, da ja bie

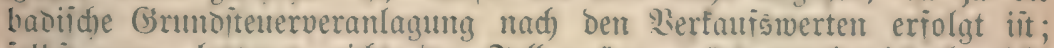

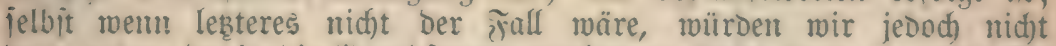
Daju raten, da ja bie (irmubitenerveranlagung jahriehnte lang bieielbe bleibt, währemo fïh Der Ertragswert aud Der Ẽofgüter mit Den Seit= verbältnifien erböht unઠ vermindert.

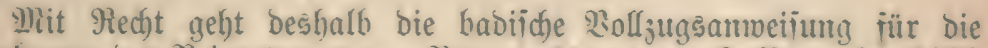
Beredmung bes Peinertrages von Bauennütern vom 2. Povember 1889

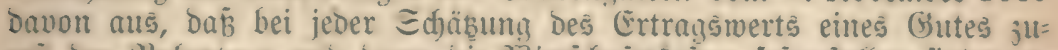

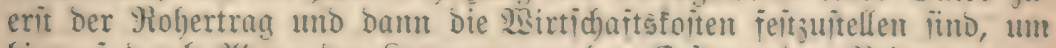

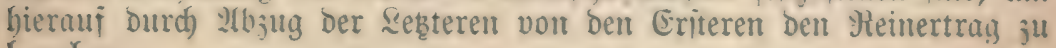
berectinen.

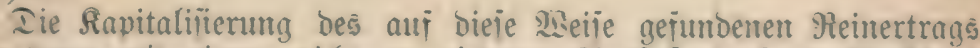
bätte Dum mit cinem nicht ju niederen 3insfü (แmjeres Erad)tens beller $5 \%$ als $4 \%$ ) zu erfolgen.

In Dem io bered)neten Siapital twäre ber ganje Ertragswert Des 5ुopes enthalten, nid)t beionders bintjuzuredhen wäre:

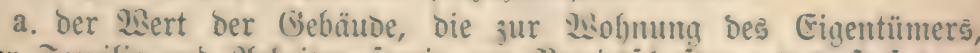
ieiner Fantile und Arbeiter iomie sur Bewirtidartung Des frojes er=

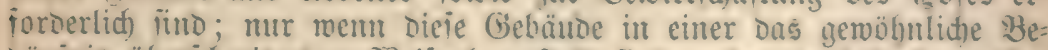
Dürmis überiareitenden Niseije hergejtell jino, wäre ein bejonberer $3 u=$ idjlag für biejelben geredtiertigt;

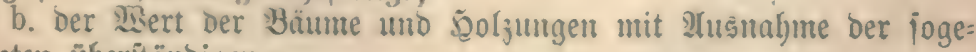
nannten über|întoigen; 


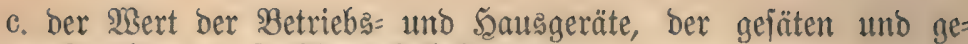
ernteten Frür)te ind fonftiger Zubehörben.

Dagegen wäre in 2rbzug zu bringen, ber 2(njoblag aller Rajten, bie auf bem (Gute haften, mie Grundbienitbarfeiten, Reibrenten, Arltenteile.

Sobald einmal autch für Baben ein länbliches \$cypothefenfrebit= infittut auf genoffenichaftlicber (Srundlage errichtet fein wiro, wäre bie Teilnahme des Bertrauensmannes biejer Baant bei ber Ssutsjobäbung vorzuidreiber.

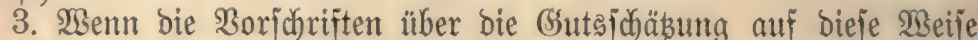
gejeblich neu geregelt mürben, müroe es umjeres Erachtens genügen, Das bem 2Inerben zu Siute fommende Boraus allgemein auf 10\% (bis= her 10 bezm. 12,5\%) bes für bas (Sitt berechneten Ertraggmerts feit= zuftellen; ja es würoe fich vielleidyt empfeblen, zu Gunten ber Bse=

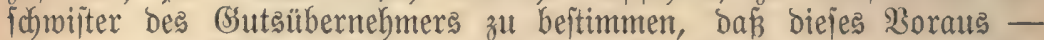
jofern ber Erblaffer nicht auङbriidfich eine andere Ânoromung getroffen hat - nicht mebr als $40 \%$ bes gejanten Riegenjichafts= uno Fabrnis= vermögens des Erblafiers betragen jolle, da jonit bie Geiddrifter bei ftarf verichulbetem Befit allzu geringe 2 (bfindungabeträge erfielten.

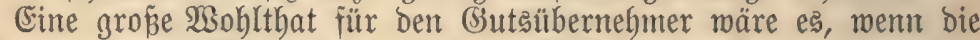

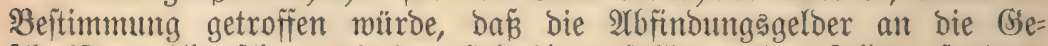
idfwifter nidbt fidfon mit ber Erbteilung fällig werben follen, fonbern erit nach Erreichung ber Bollährigfeit (oder beffer nod) eines Rebens= alters von 25 sabren), uno baßs fie aud bann mur bei ben 2(nerben

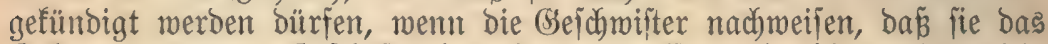
Gelb zu eigenem Bejchäfte braucben, es aljo nicht blos anbermeitig ausleiken wollen.

Aluf bieje Meife wäre bem (sutgübernebmer die Möglichfeit ge= geben, fich rubig unt allmtählid) zur Zahlung ber artofinoungageloer vorzubereiten, jedenfalls aber märe er gegen plöblicje unbegrïndete ober gar lediglich dhifanöje Ründigungen, weldhe ifn leidyt in bie Şand bes Şucherers fübren fönnten, gefichert.

Arls rsegenleiftung für bie mancherlei ifm zugutefommenden $3 o r=$ teile und insbejondere für bie - abweicheno vom gemeinen Recht Ginausgejhobene Bahlungspflid)t ber 2 fofindungsgelder wäre anderjeits bem 2lnerben eine Erziehungspflicht für jeine Gsejdymifter aufzuerlegen; autd) märe e马 ber Ermägung wert, ob man bem 2Anerben nicdt über= haupt zur \$fficht machen joulte, jeinen (Sejchmiftern im Falfe ber Inter= ftübungsbeoürftigfeit Bufluddt uno Unterfunft auf bem Sूofe zu gemähren, wogegen bieje nadb Rräften auf bem Sofe mitzuarbeiten hätten; auf bieje \$seije wurbe das Gut bes "Stammbalters" wieber zu einer wahren "Seimitätte" für die Familie, "wie bies früher Der Fall war, allerbings "eime Sceimitätte" in anderem Sinne, als man jonit mit biejent 2Utsonud im Scinblict auj bie amterifanijhe Sdhulogejebgebung zu veriteben pflegt.

4. Die von uns vorgejchlagenen Begünitigungen bes Ânerben ficheinen uns für ein Snteftatanerbenredgt vollauf genïgeno zu jein; fie nod) bebeutent meiter auszubebnen, wie mandymal verlangt mirs, müroen wir für eimen groben volfsmirtichaftlid)en Fegler halten.

Die non ber (s)utsübernabme ausgejd)lofienen Srüber bes 2tnerben 


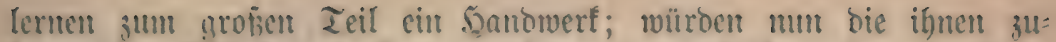
fonmenton sthintoungegeloer gar io gering ausfallen, io wäre ibnen

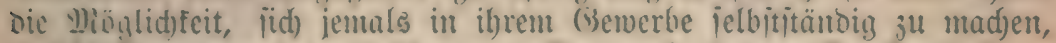
verid)loilen; Dent baju gehört vor allem aud) ein gewilles Rapital.

Ier Etant bat aher nidgt allein ein jutterefie an ber Erfbaltung cincs fräftigen Butuernitutbes, jondern and) an Den Bejteben eines tïd)tinen, gewerblidzen 1$)$ itttelitandes.

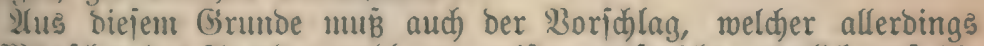

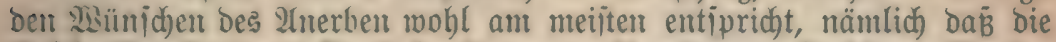
(Geich)witer itatt mit Rapital mit immermäbrenden, unfündbaren Henten abgejunden werden jollen, als zumeitgeheno zurïdgewiejen werben; mit

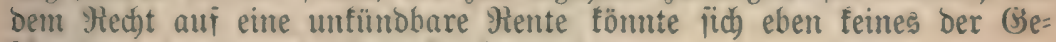
idjwitter ein eigentes (j)etwerbe begründen.

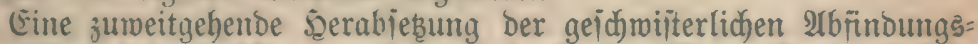
geliner liegt fermer nicht eimmal im interefie bes Bauernitandes ielbit;

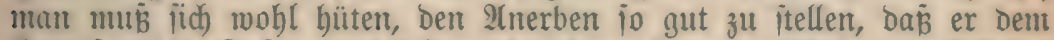
Sampi un's Dajein entrïdt wirb; Denn bann entitünde bie Gefabr, bub nit Dem Bwang zur 2 (rbeit uno ber હorge um bie Bufunit auch bie Jreube an zielbewujter Ihätigfeit und Das Etreben nad) Jortid)ritt

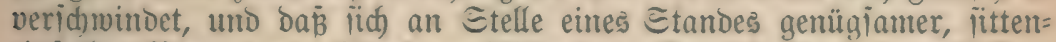
einjacher Bauern, ein ङtand wohllehender "Grumbbeliker" herausbilnet.

Iem Erblailer allerbings jollte bie Freiheit gelallen werben, ben Anerben noch weiter, als bas sntejtatamerbenrecht bejtimunt, zu bevor= âugen und beshalb wäre für bie $\$$ fiflichtteilsbered)mutg vorzuid)reiben,

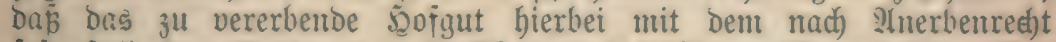

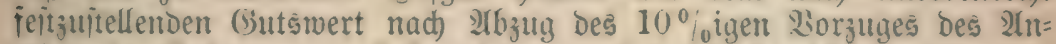
erben in Hed)mung zu ftellen jei; wir jüb jeood) nicht im 3reifel, Dấ von Dieier Freibeit, den $\mathfrak{A}$ nerben noch weiter zu begünjtigen, пur jelten (Gebraud gemacht würoe.

5. Ilm bie Eduldonlajt bes Anerben bei ber Gintenthernahme möglichit zu minbern, bat man in neuerer 3eit öjter vorgeichlagen,

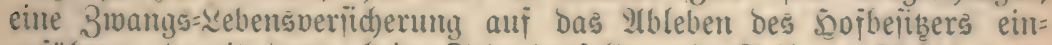

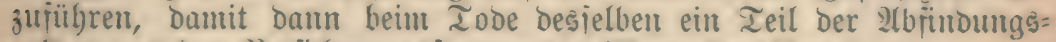

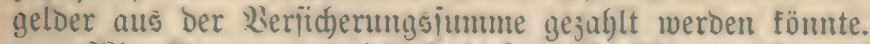

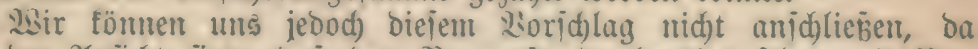

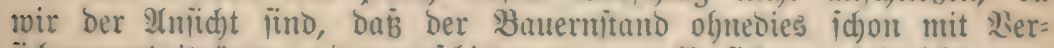

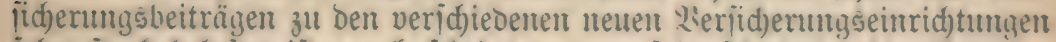

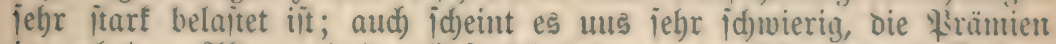

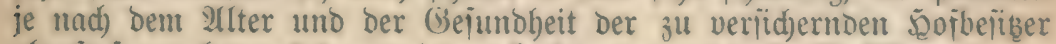
abjuitujen; eber würben wir nod) bie zmangsweije Einführm!n von

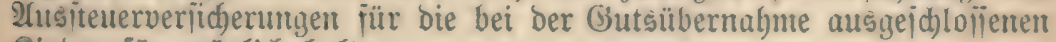
Rintor für möglid, halten.

6. Eimer $\mathcal{A b a ̈ n d e r u n g}$ oringend bebürtig eridjeint uns bie jur 3eit noch) geltende Beitimmuna in Bifier 7 bes mehrerwähnten EDiftes

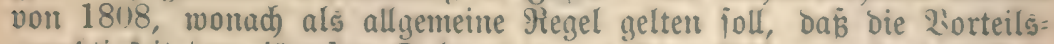
gered)tigfeit bem jüngiten Eohn oder, mo teine Eöhne vorbanden jint, Der ältejten Todjter zu (Bute fommen jolle.

3war ijt es ein Borteil biejes Mlinoratsredtes, daß̄ bie (Ettern 


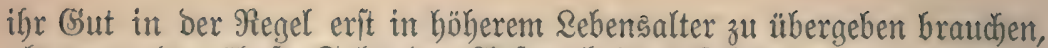
als wenn ber älteite Sohn ben 2 njprud barauf hätte, und aus biejem

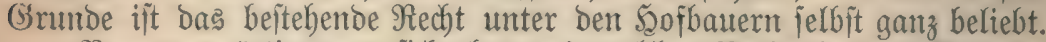
Bergegenwärtigt man fid) aber, mit welchen Machteilen Das Minorat verbunden ift, fo jollte man trobem nicht zögern, es burch bas Majorat zu erietzen.

Defters ift der jüngite Sokn bei bem Iobe bes Baters nod jo jung, Dá̧ eitre Sormundidhaft für benjelben eintreten mußs, was für bas Gut

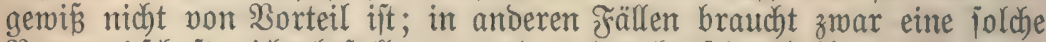

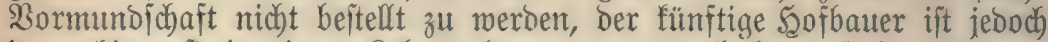
immerbin erit in einem Rebensalter, wo er noch feine Gelegenbeit ge= Gabt hat, fict) in ber 23 elt ordentlich umzujeben und etwas tüchtiges zu lernen; als Süngiter hat er ferner gegenüber ben (Şeichwiftern natür= lich) lange nidjt bie 2 untorität als etma ber 2 (elteite, auf beffen (Erziebung ja audf) bäıfig mefr Sorgfalt und gröpere Solten vermendet werben.

Sofort nach) ber (sutsibbernahme heiratet nun ber junge Sofbejizer uno je mehr Sinder ifm bann geboren werben, bejto länger barf er auf bem Sofe bleiben!

Wärbe Der Aelteite in Den Beịtz bes Şojes gelangen, fo wäre ex jebenfalls bei ber Guts̈übernabme jubon älter und erjahrener unt jeine Berbeiratung würbe bann aud mieder in reiferem sebensalter itattfinden.

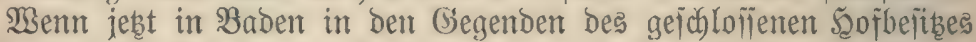
bie Ranbwirtichaft in vieler Sheziehung gegen andere Randesteile jo be= beuteno zunid ijt, jo hängt bies umjeres (sradytens audd mit ben ge= idcilderten Machteilen bes Mintorates zujammen uno es wïrde alio mit Der Bejeitigung besjelben ein Semmiduh bes Fortidyrittes megfallen.

Sicbt untermähnt möchten wir nod) ben nidyt jo ganz feltenen Fall

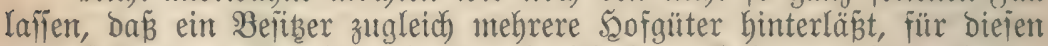
Fall jollte das Alnerbenrecht die Boridhrift enthalten, daß̧ bie beiden 5̧öfe getrennt von einander an bie beiden älteiten Rinder zu vererben wären.

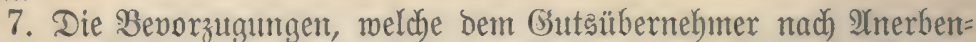
recht zu Teil werben jollen, baben natürlich nur ben eimen 3wect, dem 5ofbauernitand bie fichere Exijtenz auf feinen (Siitern felbit bei gewöbn= licher Mirtichaftsmeije zu ermöglichen; ganz gegen bie 2übïcht bes 2Un= erbenrechtes aber wäre es, wern ein 2 nerbe bie ifm als Siertreter ber Fantie, als Stammbalter, nidbt feiner \$ierion megen zugejtandenen Sergünítigungen Durch Serfauf Des (Gutes zu Geld machen mürde.

$\mathfrak{H m}$ joldjes möglichit zu verbüten und aljo auf Erbaltung bes Giutes in ein und berielben familie binzumirfen, ericheint es uns not=

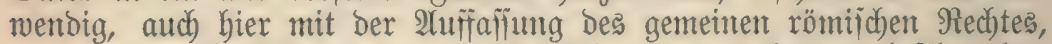

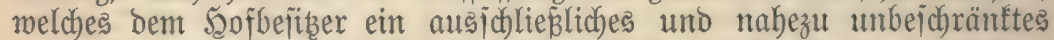
Sndividualeigenthum an feinem Sof verleigt, zu brechen und bie Dem

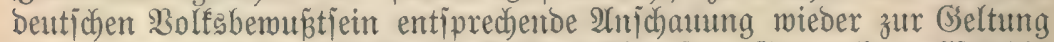

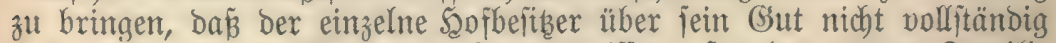

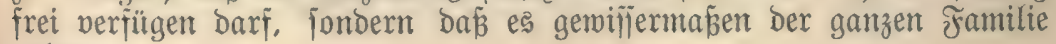
gebört.

Īn biejem Sinne möchten wir voridhlagen, einmal ben Sinbern 


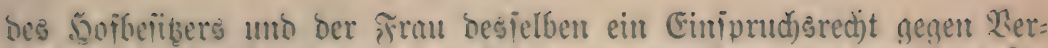

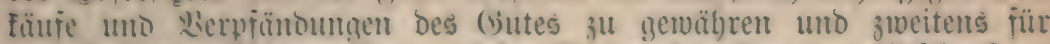

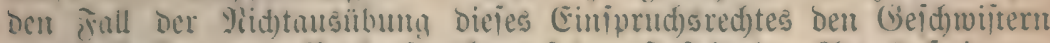

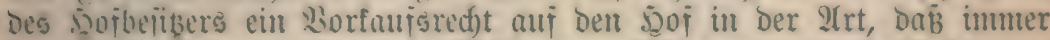
Der älteite Enhn - ober beim rethlen von Eöbnen die ältejte Tod)ter -

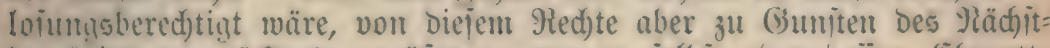

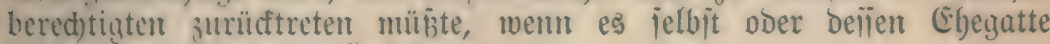
id)on in Belibe eines \$ofgutes wäre.

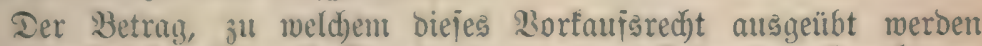

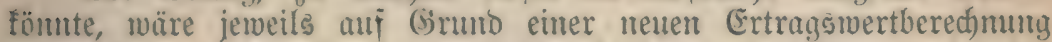

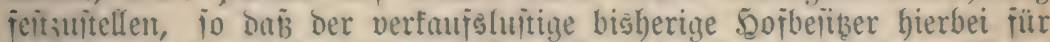

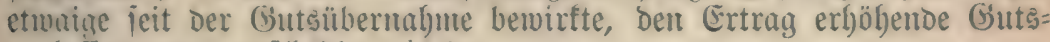
verbejerungen entīdäbigt wiurbe.

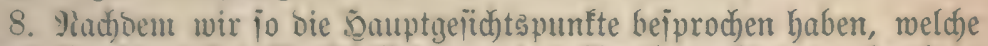

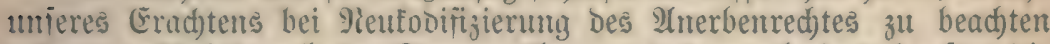
wärent, erilbrigt nod) Der Frage näber zu treten, ob bas ja fïr bie

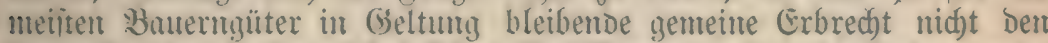

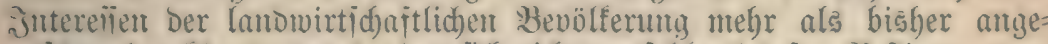

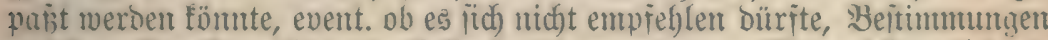

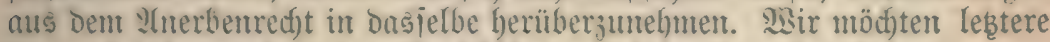
Frage bejahen uno umiere Liorid)läge mit folgentem begrïnden:

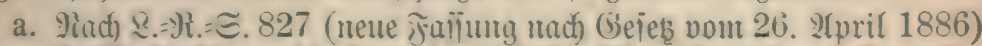

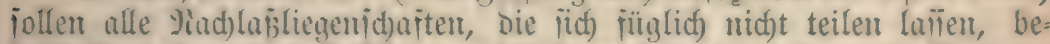

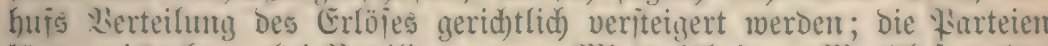

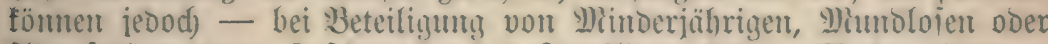

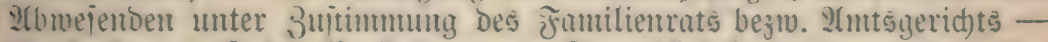

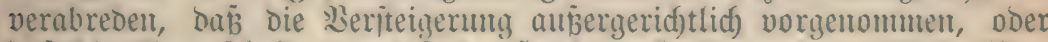

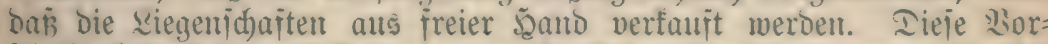
id)rijt bebentet zweifelfos einten wejentlidjen Fortidgritt gegen bie bis zum Jahre $1880^{3}$ giltig gemeiene, Dem Code Napoleon entipredjende

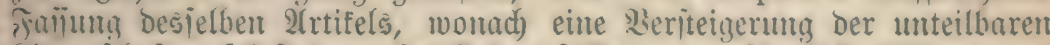
Siegenichajten jelbji baun itattrintoen jollte, wenn fäntlidje Erben gerne

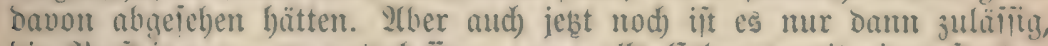

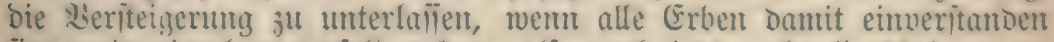
ïno; ein einjelner berjellben fant alio and jegt nod) alle übrigen zur Weriteigerung Der betr. unteilbaren Siegenichajt zivingent.

Sidjerlich) wiberipridjt es aber bod bem gejunten Wienidenneritano,

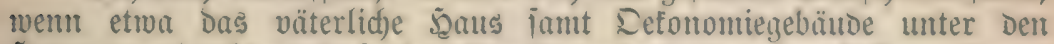
fammer gebradst uno io ber Familie entjoggen merben foll, weil mur

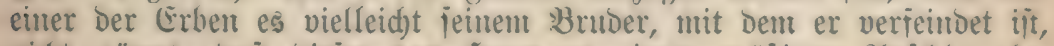

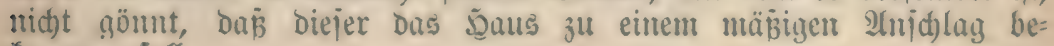
fommen foll.

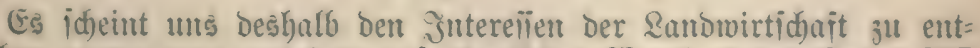
ipred)en, wern man von Dem uriprüntulidjen 230 rtlant bes Enteges 827

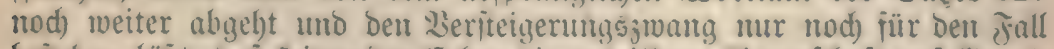

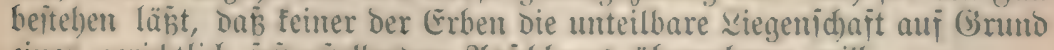
eines gerid)tlid) ieitzuitellenden Anidhlages übernebmen will. 
Itnter mefreren Erben wäre Dabei jeweils bem älteiten Eohn

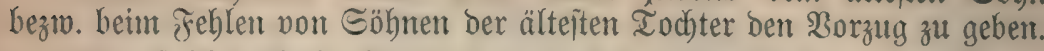

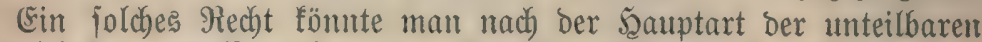
Riegenichaften gewiffermaß̈en als "Ģebäubeanerbenrecht" bezeidynen.

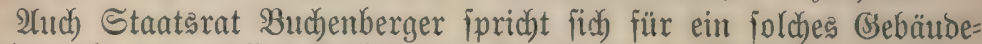

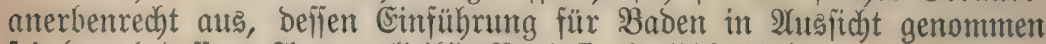
fei (vergl. Deffen „2tgrarpolitif", Baand I, S. 510,511).

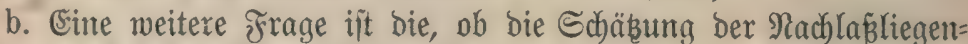
idjaften, aud fofern jie nidyt bem 2tnerbenredgt, fondern bem gemeinen Erbrecht unterliegen, fünftig nad) Ertragswert ober wie bisher nad) Serfehrsmert vorgenommen werben follte.

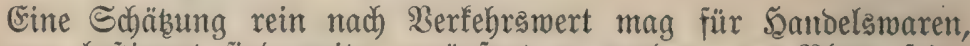

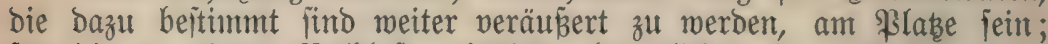

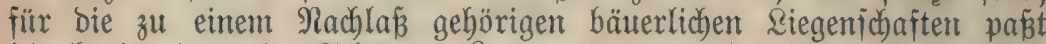
jebod) eine berartige Echäb̨ung banz uno gar nidht; Riegenichaften finto eben Eeine F̧andelswaren unt ganz verfehrt wäre es, wollte man bei

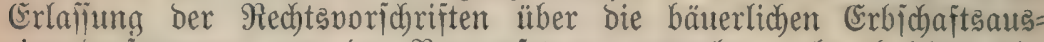

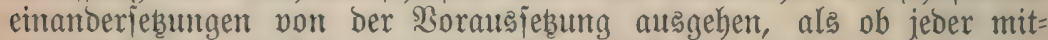
erbenbe Bauter bie ihm zugeteilten (Srunoftücfe mögliçit bald und tenter

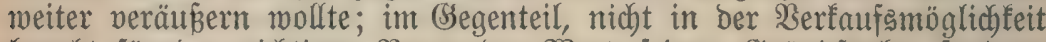
berugt für ben richtigen $\mathfrak{B a u e r}$ ber $\mathfrak{B}$ ert jeiner Grünbitüdé, fondern in beren Ertragsfähigfeit.

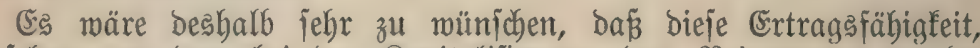
abgejehen von bem bei Der Rapitalifierung Des Reinertrags zu be=-

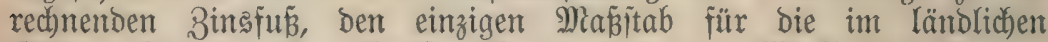

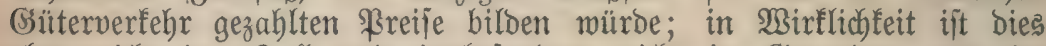

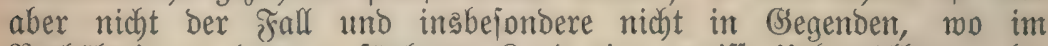
Berbältnis zu dem verfügbaren Rand eine gemiffe Ueberwälferung be=

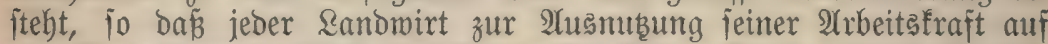

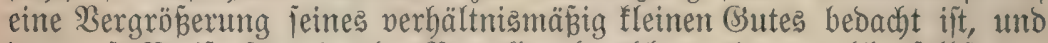
Dam oft Preije für einzelne \&arzellen bezahlt werden, welche jelbít bas Megrjadje bes wirflichen, Dem Ertrag entiprechenden $23 e r t e s$ erreichen; aud) rechnet ja befamntlich ber Ranowirt bei jeinen mirtichaftlichen

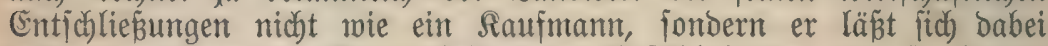
methr von einem gewiffen unbeitimmten Géfühl leiten, unt fo fonmt es, Dấ bie (süterpreife, vor allem bie von fleinen \$arzellen, autch von

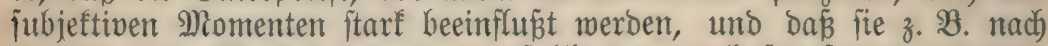
einigent guten Ernten, inbemt man folche num audi für fpäter erwartet,

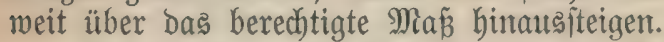

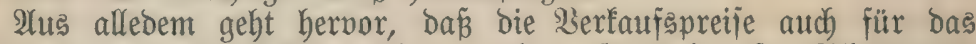

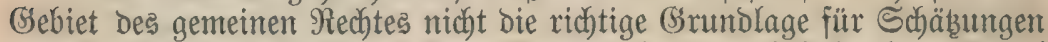

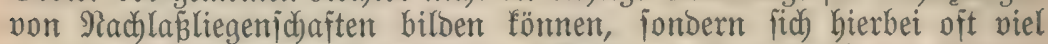
zu hohe Sdäbungswerte angeben nülïen; es iit beshalb ben 230 ortent Des Serrn Staatsrats Budjenberger in Bano I jeiner ",2lararpolitif" S. 510 volfftänbig beizuftimmen:

"Die gruntöäbliche $2 \mathfrak{A n n a h m e ~ b e s ~ E r t r a g s w e r t s p r i n z i p g ~ f u ̈ r ~ a l l e ~}$

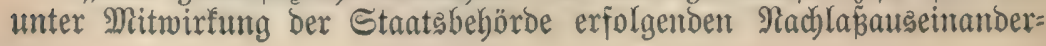


iebungen bari als einer ber widhtigiten Pejormpunfte gerabe aud bei

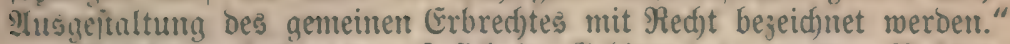

jniviern allerbings muB fich im Gebiete Des gemeinten Pechtes bie

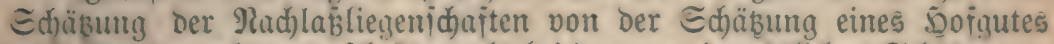
nact) 2tuerbenred)t untericheiden, als bei ben gemeinred)tlid)en Edäbungen

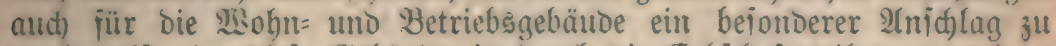
madien ijt, ba bieje Gebäube ja Durdh die (Erbjofajtsteilung von bem Berbano mit ben einselnen Ginmbitüden losgetrennt werden.

c. Fïur rejormbeoüritig Galten wir jerner bie Bejtimmung bes babiichen

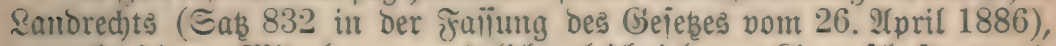
wonad) jebem IXiterben momöglid) gleidjviel an Siegenidjaiten und Frabrnilien jugerwiejen werben joll, uno hierbon nur abgegangen werben buri, wenn feitter ber Beteiligten 2Biberiprud bagegen erhebt.

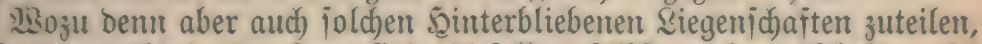
weldbe gar nicht in ber Rage ïno, biejelbent jelbit zu bemirtichaften, jei es Dấ ite jidh in einem andern Srte als Sambwirte niebergelalien haben,

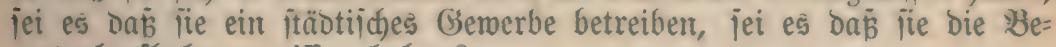
amtenlaufbabn ergriffen baben?

Ier Geijt ber Seit geht im allgemeinen bahin, ben 3withenhandel möglidjit einjuid)ränfen uno zwar inshejondere in jenten Serfehrsgebieten,

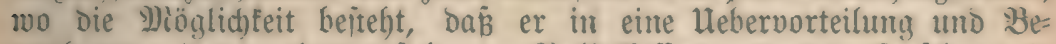
wutherung Der meniger erfabrenten siolf́staijen ausartet; foridjen wir

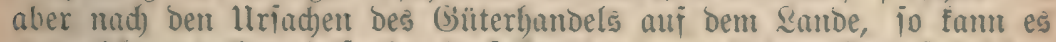
uns nidjt entgeben, Dä́ eine Derielben Darin zu finten iit, Dä́ bei Den

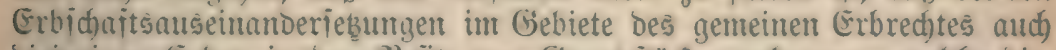
Diejenigen Erben in Den Bejib von Grunditücen gelangen, meld)e bie= ielben unmöglich jelbit bervirtic)ajten fönnen uno jie besbalb mider bejt= möglide verfaufen wollen.

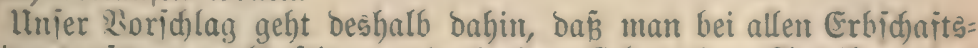

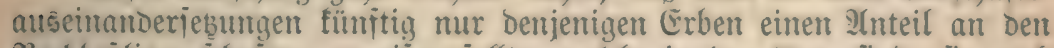

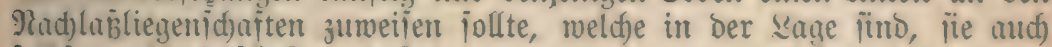

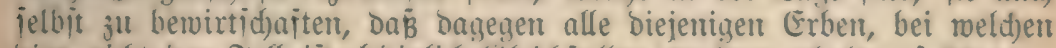
bies nidat ber Fall iit, lebiglid) Gleidjitellungsgelder erbalten iollten.

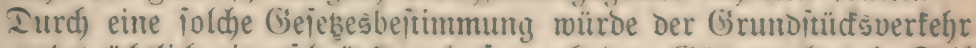
nidgt unbeträd)tlid) eintyeid)räntt und io aud) Dem (Bütterıudder ein Zeil feiner Brundlage entzogen. 


\section{Rentenidulo unt (exbpadit.}

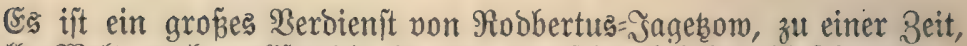

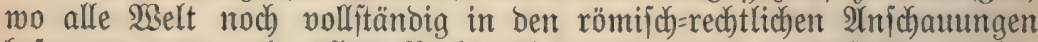
befangen war, mit allem Rachbrud immer wieber barauf hingemiejen

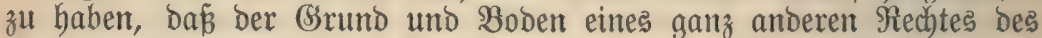
Eigentumsüberganģ, ber $\mathfrak{B}$ ererbung und des Schulbenmejens bebarf, als bas berweglide Rapital.

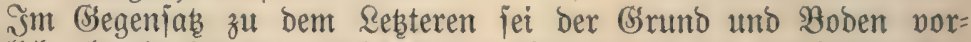
nehmlich als ein immermährender Rentenfond anzujeben; ber= jelbe werfe jeinem Befizer mur eine ftänoige jährlicte Rente ab, feinen= falls aber jei ber Brumbeigentümer in ber Rage, burch feiten Wirt= ja)aftsbetrieb jeberzeit Rapitalien aus jeinen Riegenichaften herauszuziehen,

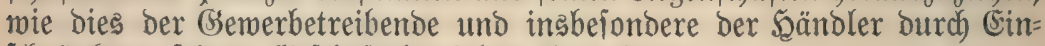
jchränfung jeines (şejchäftsbetriebes thun fönne.

Daraus folge, ba $\tilde{\beta}$ bas bisherige Berichuldoungsfyitem, wonady ber

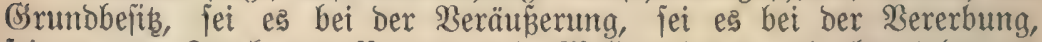
jei es zum Zwed von Bauten uno Meliorationen mit fünobaren Rapitaljd)ulden belaftet werbe, dem bejonderen Wejen bes (Strund

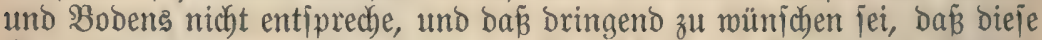
Rapitaljdulden - entiprecheno ber Eigenidgaft Des Grunb uno \$obens

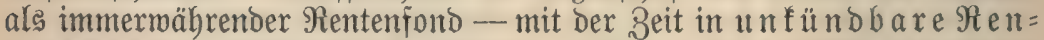
tenjdulden umgewandelt roürben; Rebteres jei zugleich bas einzige Mittel, ben Grunbbefiber vou ben Schmanfungen des Binsfües un= abhängig zu machen.

Dies ijt unter Meglafinung alles minder 2 Bidftigen ber hier in

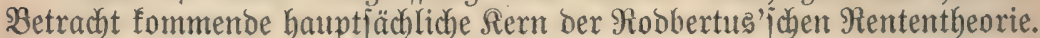

Es ift nidbt zu verfenten, daß̧ bieje Theorie nach und nach eine nette Betrad)tungsmeije bes ganzen 2 grarrechtes und insbejondere bes lanbwirtidjaftlicken Sdjulbredtes angebahnt hat; won feiner Seite

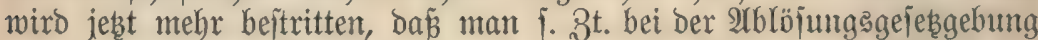

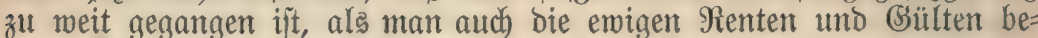
jeitigte uno beren Reubeitellung für bie 3ufunft verbot, aus Furcht, e马 fönnten fich aus jolchen Rentenpflichten mit ber Beit wieber neue Erbunterthänigfeiten entwidełeln.

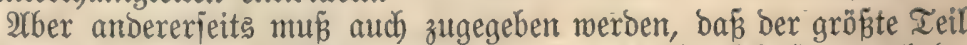

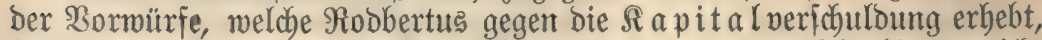
hinfällig miro, wenn bie Rapitalidbulden jeitents bes Gläubigers nidjt 


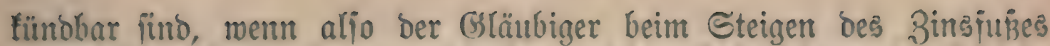
jeine Sinsforberung an bent Eduloner nicht erböben fant; bie jo iebr

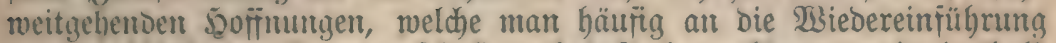
her unablösbaren Mentenjohld gefnupft hat, tönnen wir beshalb nidet teilen.

Wisenn ein Ranbwirt jährlich einen bejtimmten Betrag als Bins einer ieitens Des (Stäubigers unfüntbaren $R$ apitalid)uld zu zahlen bat, iitt er feineșuege jolechter geitellt, als went er ebenjoviel als jährliche Hentenid)ulo zu entrid)ten hätte; im (Begenteil er hat jogar in eriterem

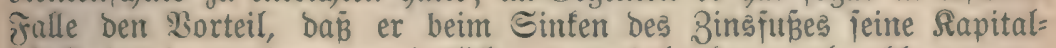
id)uld in eine geringer verginglicke ummandeln fann, obrobl er gegen

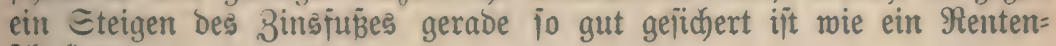
idulloner.

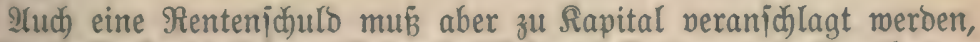

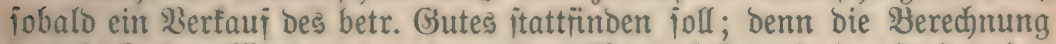
Des Laufenden Sertes einer Derartigen ßentenlait uno Damit bes Der

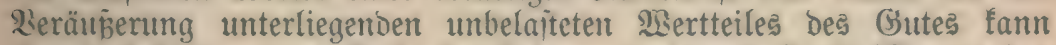
eben auf teine andere \$2eije itattrinten, als burch Sapitalijierung bes jabreshetrags ber Sajt mit bem zur 3eit giltigen 3insjü; und

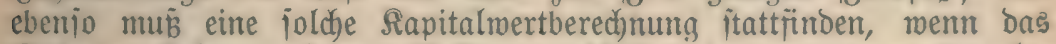
Gut im Erbwege jeinen Bejißer wedjelt, ober wenn zu ber be=

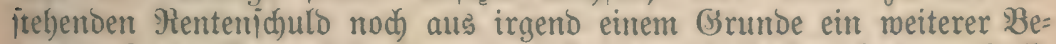
trug auf Das (isut geliehen werben joll; Denn in biejem lebteren fralle

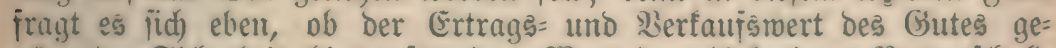

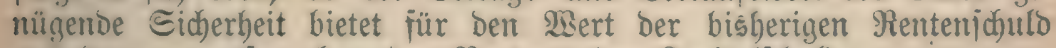
uno ber neu aufiumehmenden Renten= ober Rapitalichuld.

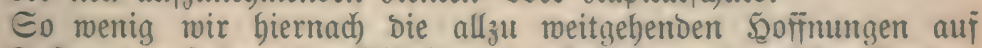

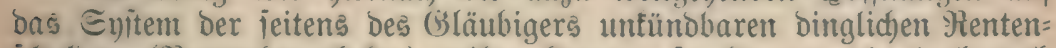
id)ulden (Rentenbypotbefen) teilen fönmen, fo fömnen wir bod) auch anbererieits feinen (Srumb einjehen, warum Dașelbe volfsmirtidaitlid) id)(ïlid) wirfen fönnte; mir glauben beshalb mohl befürnorten zu fön=

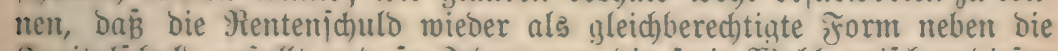

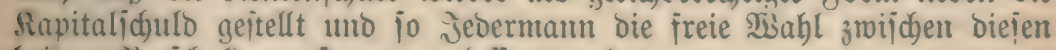
beiden Lieridulbungsformen gelalien merde.

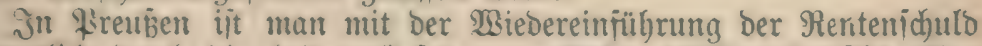
befanntlich Durch bie beiben (bejebe vom jabre 1890 uno 1891 über bie BilDung von Rentengütern vorangegangen; Das Biel, Das man mit Diejen (Gejeben veriolgt, ijt bauptiäd)lid) Das, mit Şilipe joldher Penten= güter in ben (Gegenten bes (Brobigrumbbelizes, aljo bauptiäd)lid) Den öjtlichen \$rovinzen, neue Bauerntolonien zu id)afien, und baraus erflärt jich aud) manche Bejtinmung ber beiben (Beiebe, meldje für unjere badiichen 2erbältnilie, wo bie 2 grarpolitif ganz andere 2 Higaben zu eriüllent hat, weniger geeignet erid)einten.

Ier Code civil uno Das Babiid)e Ranbrecht untericheidet befannt=

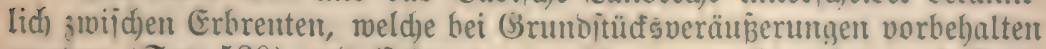
surrben (Sat3 530) uno Erbrenten, weld)e gegen Singahe eines Rapi=

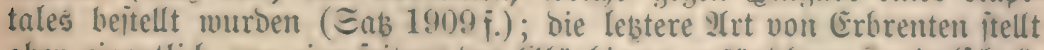
aber eigentlid) mur eine ieitens bes (släubigers untünbbare Japitalidguld 
bar; Denn eine "A̛tblöjung" Derjelben ift mur gegen Rïdgabe bes ge= zablten Rapitales vorgejeben, währent bei einer wirfliden Fenten= jchullo ber fapitalwert nach ben Zinsverbältniffen fteigt ober fällt.

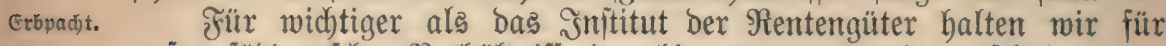
uniere jübdeutjoben ßerbältnifie bas biervon mur menig verjcbiebene ber Erbpadt.

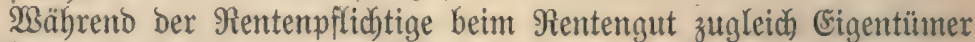
bes Butes ijt und Dem Rentenberechtigten mur ein Durd) Grunbbud

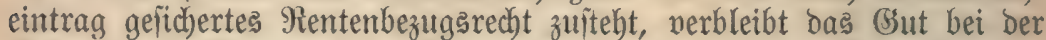
Erbpacht im Eigentum Des Erbzingberecbtigten, und ber Erbpädbter hat mur ein, alferbings menig bejdränftes, vererblides Nukungsredgt an Demielben.

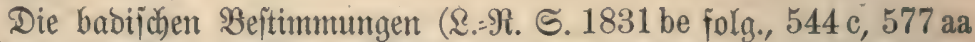
folg.) über bie (Erbpacht find vollitänoig veraltet und für das wirflidje Reben fo gut mie unbraubbar; eine Siereinfachutg und Erneuerung berjelben in

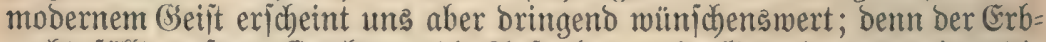

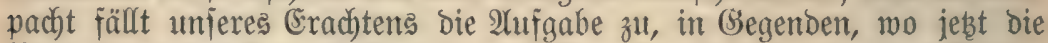
Serpadytung des Srundbefibes jei es in Parzellen jei es in einzelnen Giütern vorberricht, einen allmählichen Hebergang bes Gruno und Bobens in das

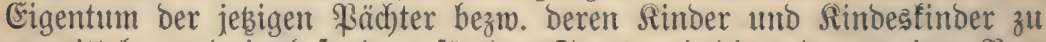
vermitteln, und insbefondere für den Staat und bie andern ewigen $\mathfrak{B} e r=$ waltungen roäre ein modern auझgejtaltetes Erbpachtred)t häufig bie zur Beit volfsmirtict)aftlich richtigite Frorm ber Bemirtichaftung bes nicht in Selbitabminiftration berinolidben lanomirtichaftlichen Bejizes.

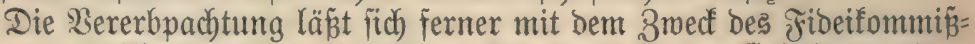
rechtes - Feitlegung einer länolicben Ertraggquelle zur Erhaltung eines abeligen Familiengejd)ledtes - vobl vereinigen und es wäre beshalb

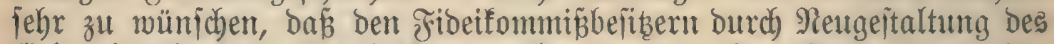
(Erbpad)trechtes die Mëglidffeit gegeben werbe, ihre Gïter ganz ober teilmeife in Sarzellen ober größeren Stücten zu vererbpadten; Der Borteil für fie beitünoe babei barin, daß́ fie fich ber meiften Miüben ber Gutsverwaltung entichlagen uno bierbei doch bie finanziefle Sicheritellung ifrer Fantlie und bantit ben 3weef bes Fineifommiß̈rechtes feineswegs in Frage ftellen witroen, währeno das âfgemeinwohl anderer= jeits burch bie Srünoung neuer Bauernftellen geföroert würoe. 


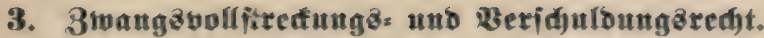

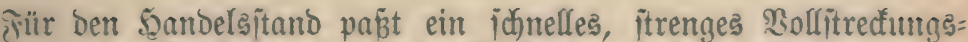
recht; Dent Der Raujmann erbält in Berfaufspreis jeiner 2 saren jemeils

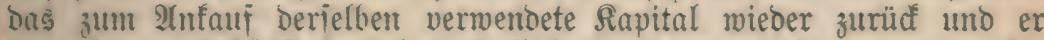

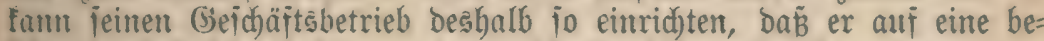
itimunte Beit bie Bahlung einter Echuld jejt veriprechen foun; aus biejent (Srunde ijt aud) eine idnelle Erefution gegen benjelben, falle er ieinen Berpflid)tungen nidat nad)fonmt, mohl geredtfertigt; iein Wermögen bejteht zudem grobenteils in 5ुandelsartifeln, welche ohne=

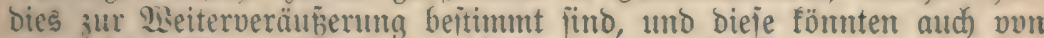
cinem bösmilligen Ed)uloner leid)t bei Seite gejdaritt und jo bem $3 \mathrm{u}=$ griff ber B̋läubiger entzogen merben.

Gans anders ijt bagegen bie Rage bes Grumbheithers; biejer erzielt von ieinem (Gruno uno Boden - wie id)on erwähnt - lebialid) eine jäbrlidje Rente; z̆u feiner Zeit Des Jabres fomm berielhe aber in ben Belib bes Rapitales, weldjes jein (Brund und Boben wert ijt; ja es ijt ifm jogar ummöglidh, jein \$sermögen ganz ober teil=

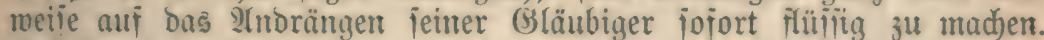
Eelbit auj ben Ertrag ber Ernte fann er fich nidjt jidjer verlallen; bettn bie Ernte ijt mad) Euantität แno Eualität von ber $13 i t t e n u n$ ahbängig

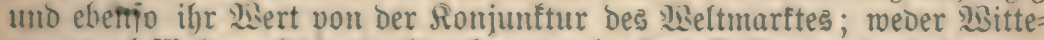
rung nod) \$iseltmarfts fonjumttur fann er aber beeiniluilen, nod) mur voraus= bered)nen. Iafür braud)t aber andererieits ber Gsläubiger bes Grundbeitbers

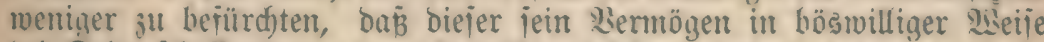
bei Eeite idarfen und bent Bugrifi entgiefen werbe; Dent es it ja

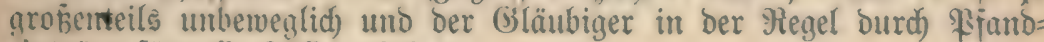
einträge für alle Fälle gejïdert.

Qhis alledem geht vorerit joviel hervor, babi ein itrenges, idfnel=

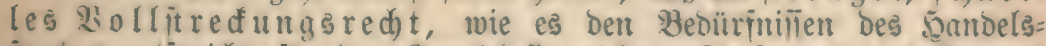

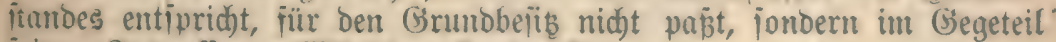
ieinen Interefien volfiändoig miberinrid)t.

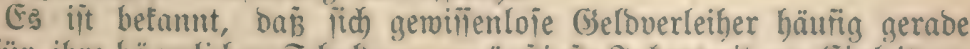

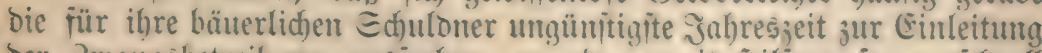
ber 3wantyghetreibung ausjuden, um bann mit bilfe unierer „idnell

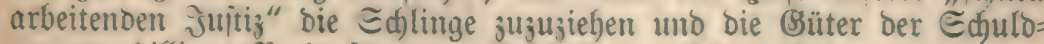

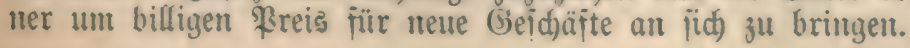




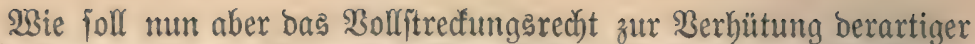
2Yusbentungen einer oft mur vorübergebenden Rotlage bes Echuldners

Erfestung bes Rectits bes (Slänbiger:s auf żmangs = verfauf burd ein foldies auf 3 wang vermaltung.

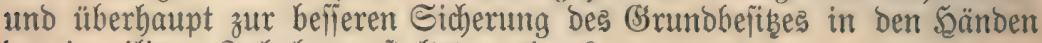
ber jeweiligen Inthaber gejtaltet werben?

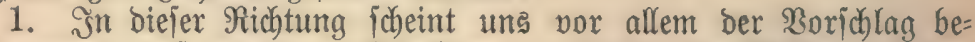
merfenswert, daß̉ man Dem (s)läubiger an Etelle bes Rechts aui ben

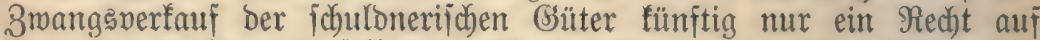
Bmangswerwaltung Derjelben gewähren folle; den 3ują möchten wir

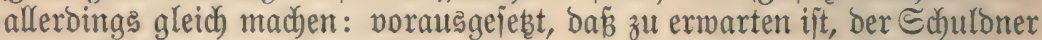
merbe fich baburd in nicht zu ferner Beit in jeinen wirtjchaftlicken Berbältniffen wieber erbolen.

Denn für ganz veriehlt mürben wir es halten, wemn man Sand wirte, welche offenfundig abgemirtichaftet haben uno aller Borausfitht nach zur 2rbtragung ifrer Schulden nie im Stande jein werben, fünft= lich im nominellen SBejts ihrer Ssüter erbalten wollte; fie würben fich als lebenslängliche Ilntergebene ihrer Bläubiger boch nie zufrieben fühlen, feineswegs aber fönnte man fie einem unabhängigen, vorwärtsitrebenden Bauernitano zuzählen, welcher bie feiteite Stübe bes Staatstörpers bil= bet, und auf meldben beshalb bie Sauptiorge jeder 2 grarpolitif gerichtet jein foll.

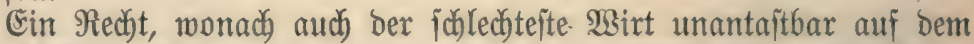
Gute bleibe, würbe ferner - wie Rorenz von Stein fich auborïct wie eine \$rämie auf ben Stillitand in ber Randroirtichaft, ja auf Un= oromung, Unzuverläifitgfeit und Faulbeit bes Şauern wirfen.

"Iur jenes mirtjchaftliche (Sut, melches bei Bernachläifitgung ver= loren gebt, miro mit Riebe uno Fleiß gepflegt, mit Sorgiamfeit und

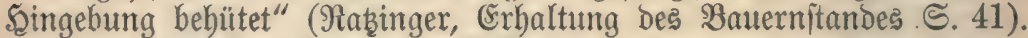

2Im leidhtejten wäre bas Syitem ber 3mangswermaltung bei bem Grokzgrundbefiz burdzuführen, welcher ja die Bemirtichaftung feiner

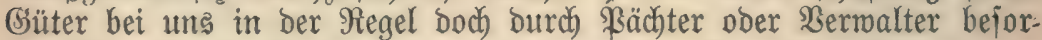
gen läbt; für ein Bauernaut mirb Dagegen eine 3wangsperwaltung nur viel Feltener am \$labe jein; benn, menn man einem Bauer, ber jeinen Berpflichtungen nicht nachfommen fann, nodb einen Berwalter zur Seite jest, fo miro ja aud beifen Unterbalt noch aus bem Gut beitritten wer= ben müliten, uno bie sage bes Echuldners wirb fich beshalb in ber Regel nur nod idjwieriger geitalten als vorker; immerbin ift aber boch ein ober ber andere Fall möglidf, wo ein Bauter, ber z. $\mathfrak{B}$. Durch

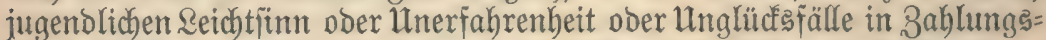
idbwerigfeiten geraten ift, baburd) auf feinem Befitbthum erbalten wer= ben fönnte, Daß̧ man jeine Grunditüde alle ober mur zum Teil z $\mathfrak{m a n g} s=$ weije in $\mathfrak{B a d}$ t giebt und von einem 3 wangs verfauf berjelben porerit abjiebt.

Es joheint uns Deshalf wohl empfeblensmert, Dem Geridete bie $\mathfrak{B e}=$ fugnis zu geben, in geeigneten Fällen an Stelle bes 3wangsverfauf́s vorläufig nur bie 3wangsverwaltung anzuoronen; wir wieberbolen aber, Dá̉ bies mur bann gejdbehen jollte, wenn eine Beflerung ber Lage bes Echuldners wäbreno ber furzen 3eit Der 3wangsverwaltung init ziem=

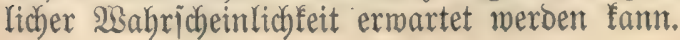


2. Tod cine meitere Ermächtignng an bie Geriç)te mtöhten wir

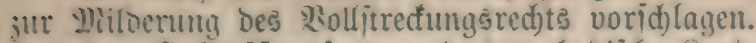

Iir Code Napoleon uno Das babiiche Sambred)t gewährten ur=

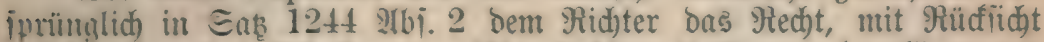

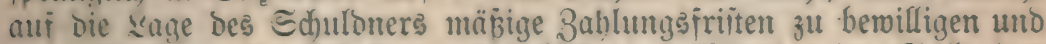

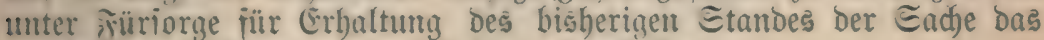
gerid)tlidhe Dherfabren eine Beit lang eimultellen.

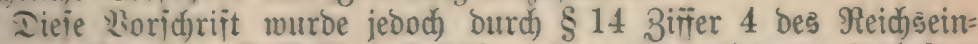

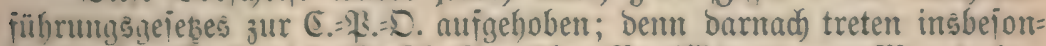

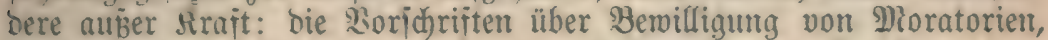

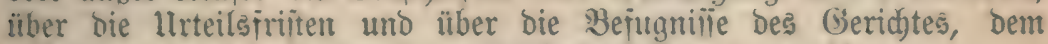

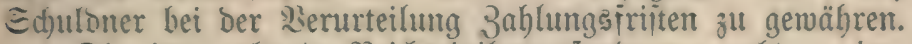

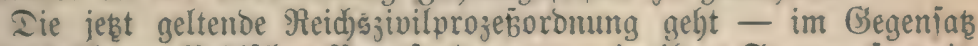

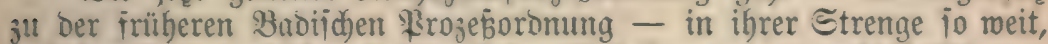

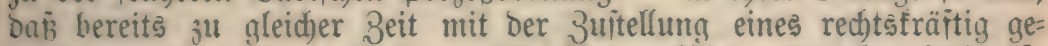
morbenen ober tür vorläıtịg vollitredbar erflärten Urteiles f̧abrnib̈= piündung heim schulbner erfolgen fann.

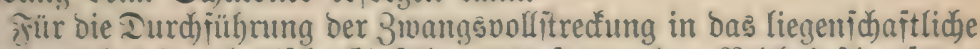

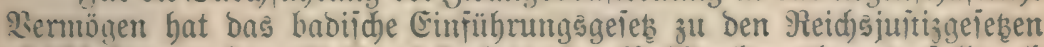
aleidfalls nur furze Friften feitgeiest: Der $\$ 3$ ollitredungsbeamte foll nad)

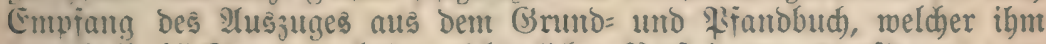
immerhalb 15 Tagen nad) ber ridjterlidjen Berjteigerungsverfïgung vor=

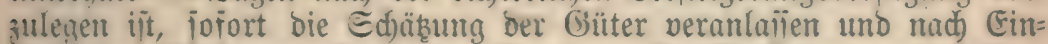
fumit Der Edäbungsurfunde ben Tag ber eriten Beriteigerung io beitim= men, baß́ bie 3wijhenjeit nom Tage ber Bejtimmung an bis zum Sieriteigerungstan nicht unter einem uno nidgt über zroei Diontate beträgt. Sutr mit ridhterlicher (3entebmigung fann ber erje Berjteigerungstag

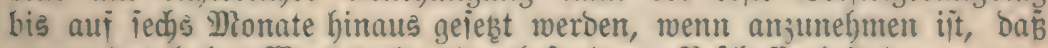
megen bes hohen Mertes ober ber bejonderen Bejdaifenheit ber ju ver= iteigernben (B̈itter feine ober wenige Bieter fich in ber Piähe berinden mögen. Sebterer Fall wirb aber bei ber zmangsweifen Weriteigenung von Farzellen - uno bieje bildet in Baben im Gegenjaßs zu Der \$eritei=

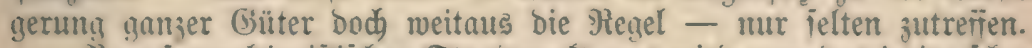

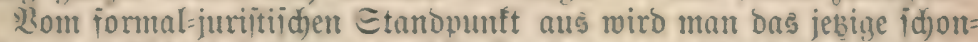

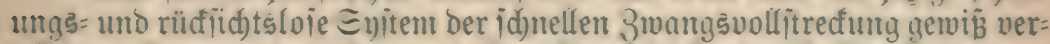

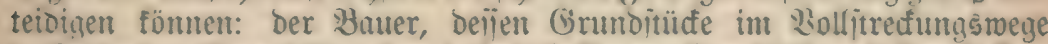
veriteinert merben, hätte eben bas Ed)uldenmadjen bleiben laijen iollen.

Etellt man rid aber auf einen böberen Stanopunft uno betrud)tet bie einjelne Medistovorid)rift nidht allein nad) Dem Miabitabe ber tonie= auenten Iurdfï̈brung bes eimmal angenommenen Şauptprinjipes, ion= bern aud bimid)tlid) ifrer volfsmirtid)aitlidjen und iojialen Msirfungen, io wird man von ber jebigen $\mathfrak{A}$ rt ber Bmantgenvollitredtung, meldbe auf

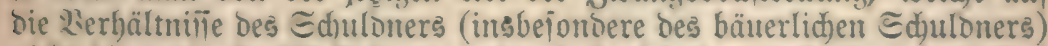

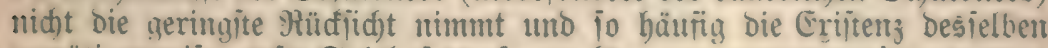
unnötigermeije auj̧ Epiel jeß̧t, jagen föntren: summum ius, summa iniuria.

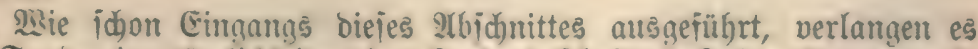

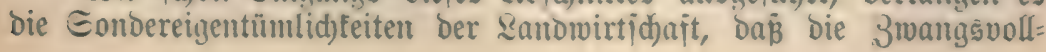


fitrectung in bas landwirtichaftlict) Bermögen eine langiamere fein jolle als in Das Sermögen faufmännificher Gejchäfte, uno mir möchten in biejer Şinficht vorichlagen, daß̧ eine 3wangפveriteigerung lanowirtichaft= licker Ssrunditüde vor allem fo lange autsgejebt bleiben jollte, als es

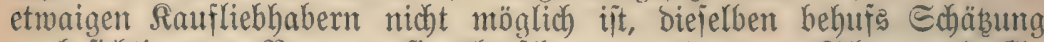
zu befichtigen, z. B. wenn fie überidbemmt ober von Echnee uno Eis beoecft fino.

Sor allem aber fobeint es uns notmendig, bem Richter wieber mie bis zum Sahre 1879 bie Ermächtigung zur Bervilligung von Zah= lungsfriften (Dloratorien) zu bewilligen, etwa bis einige Mochen nach ber nädditen unt ausnahmsımeije audh ber übernächiten Ernte; ntan fömnte bieje Ermädbtigung babei von ber Sorausjebeung $a b=$

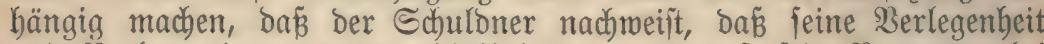
und Sotlage eirte nur augenblidfliche jei, o. h. baß̉ feir ßermögen bei Bewilligung entiprechender Bablungefriften zur Iilgung feiner Sdbulben Ginreicht, wäbrend er andererjeits Durch fitrenge Bolitredfung megen Der ihm obliegenden Berbindlichfeiten in bebeutenden Fachtheil veriebt wïrbe; man fömnte ferner ein eiblickes ßeriprechen von bem Schulbner ver= langen, daß̧ er feine Beftandteile feines Bermögeng auf bie Seite idjaffen werbe.

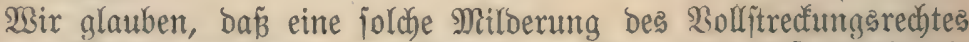
unierem Rlleinbauernitano zum Segen gereiden, uno baj bamit bie bäuerlichen Rlagen über bie unnötige Strenge und \$ärte besjelben in Der Saluptjacke bejeitigt wilroen.

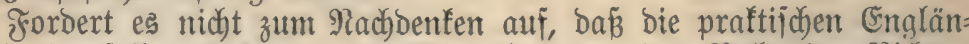

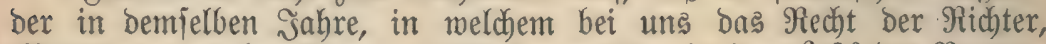
Moratorien zu bewilligen, aufgehoben murbe, in bem $\S 20$ bes Bauern= entlajtungsgejebes für $B$ ritij $=$ Sndien bejtimmt haben:

„Das Sericht fann zu jeber Beit verfügen, Dẩ Der Betrag eines vor ober nach dem Snfrafttreten biejes Gsejebes gejällten Urteils in Raten gezahlt werbe mit ober ohne Binjen"?

Beitatiung von 工eilzah)= lumgen

feitens bes Eduloners.

(Geftaftung Der 310angs volitredung in siegen= fóften mi aus 5ypo= thefentorber = unger.
3. Der unter Biffer 2 ermäbnte $\Omega_{0}=\Re .=\subseteq$. 1244 giebt uns ferner zu

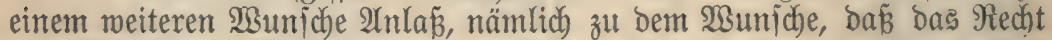
Des BSläubigers, Ieilzahlungen zurücfzumeijen, bejeitigt weroen möge. Wenn ein Bauer z. B. zur Bablung einer Schuld von 100 Mart ben $B e=$ trag von 60 Darf beijamnten hat, uno er muf benielben nun mebrere Modhen zu Sauje aufbeben, bis er aud bie reftlidyen 40 Marf bezahlen fann, io ift bock für ihn bie Berjuctung grofi, bie 60 Miarf inzwijchen für einen anderen 3wedf zu verwenden, uno gemifienloje Gläubiger rechnen

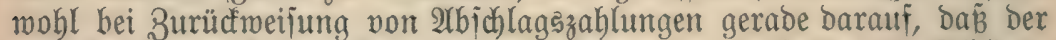
Edbulbner einer joldhen Berjudhung erliegt, um bann ipäter bie Echlinge um io feiter zuzieken zu fönnen. Deshalb jagen wir: $\mathfrak{B e g}$ mit bem

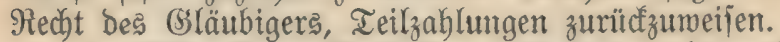

4. Mit anderen Borficlägen, Die man in lekter Beit zur Mildorung bes 3mangsollitrecfungs= uno Sdyllbenrechtes gemadht hat, fönnen wir uns bagegen weniger befreunben.

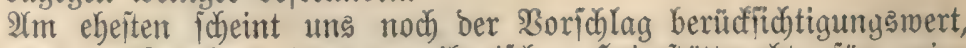

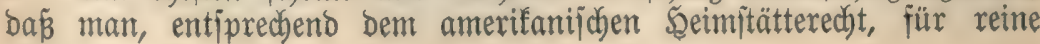




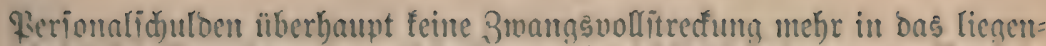

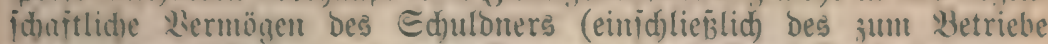
notmeitsigen lehentoen unb toten inventars) sulailen jolle, fondern mur

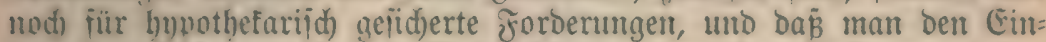

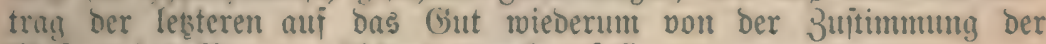
Eheirau bes Bumern abbäntuig madjen iolle.

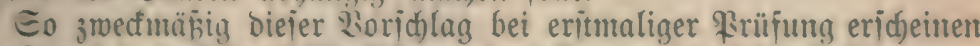

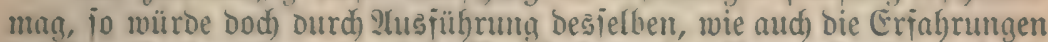
in 2lmerifa hemeijen, eine bohe Beridul(Dung bes Bauernjtandes uno bie

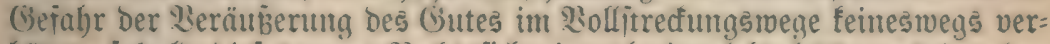
bütet; johalo biejes netue Red)t fidd) einmal eingelebt bätte, mürbe ebent niemand mefhr eitrem Bauern irgento einen Gielobetrag leiben, nod ihm ein Etüd Wieh oder eine Mlaidine auf Rrenit geben, ohne fid sugleid Durd) eine 5ypothef ali bas (jist jicher zu itellen.

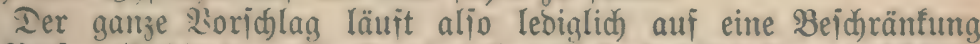

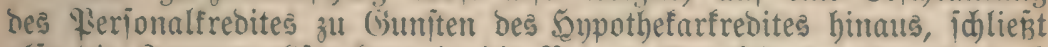
alio bie 3wangsvollitrefiung in bie Bauerngüter feinesmegs aus; bod แแ

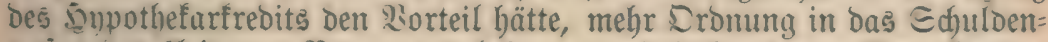
weiell Der fleineren Bauern zu bringen uno baher beren Bewudjertung

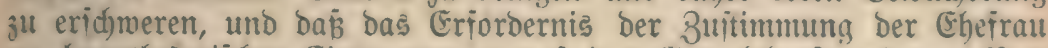

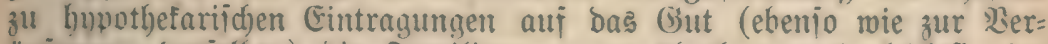

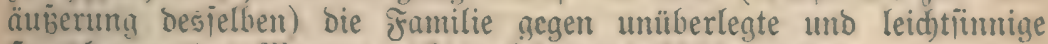

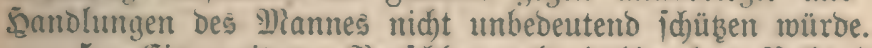

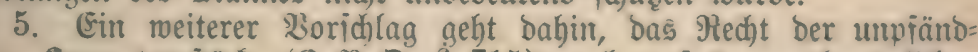

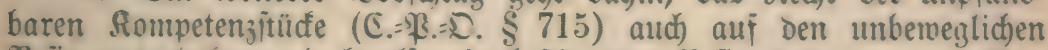

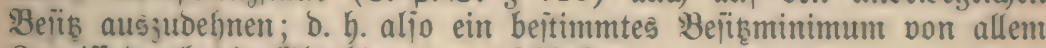

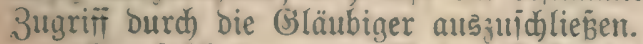

Ein ioldes untangreifhares Beitsminimum fönnte aber natürlid

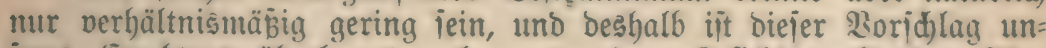
jeres Erad)tens itberhaupt mehr unter bem (Selichtspunfte ber F̂̉itr= jorge für den grundbejikenden ländlidjen Taglöhner uno Snoultrie=arbeiter als Dem Geiid)tรpuntte Des Banernidubes zu betrad)ten. Misir fömten es üherbaupt nidjt als das Biel einer geiumben 2lurar= politif aniegen, einem üheriduldeten Bauern alles bis auj ein fleines, unverlierbares Meitgut zu nehmen; auf Dem lekteren wirb er wegen diejer

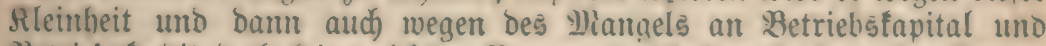
Betriebsfresit bod) feine ridjtige Bauternwirtida ât mebr betreiben fömnen

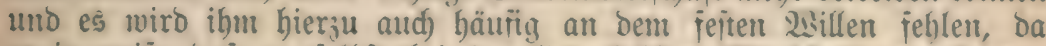

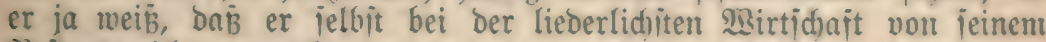
Beitgut nidb) vertrieben werben fann. Die Einfï̈lfung eirtes unan=

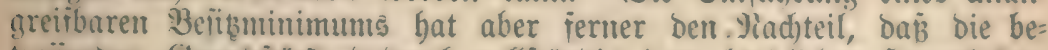
trefienden (Brunditücfe Daburd) vollitändig bem ländlident Suppothefur= frebit ent;ognen merden; Denn niemando wiro auf ein Belistum etwas

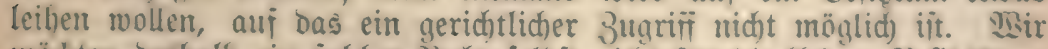

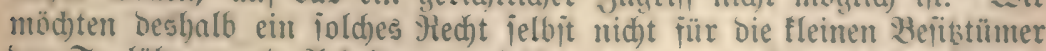
ber Iaglöhner uno Ifrbeiter emprehlen; Dem bie Rage biejer fleinen seute würbe burd) ein jolches Pedgt, welches man in gewifiem Einn 


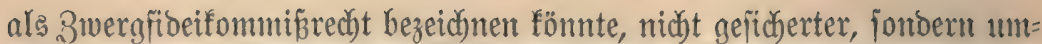

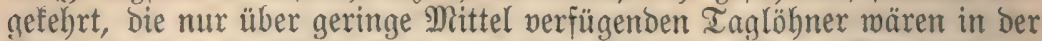

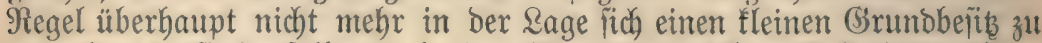
crwerben, ba fie benjelben ja bei bem Mangel eines Syppothefarfrebits (ltu= verpfänobarfeit ber betreffenden (Siiter) bar bezablen milßsten; an Stelle

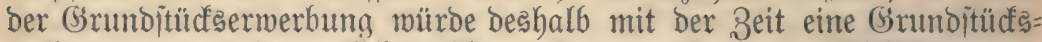
padytung treten, indem fidy wohl vermögendere Reute ein (Gejejhäft baraus machen mürben, fleine Grumbjtïcfe an 2Urbeiter zu verpachten, was gegen Den jebigen Zuitand gemí̄ feinen Fortichritt bedenten wïroe.

ஜeid) rüntutg ber2̧erifitulo=

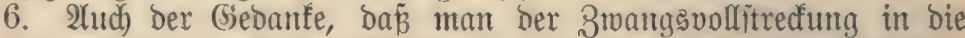

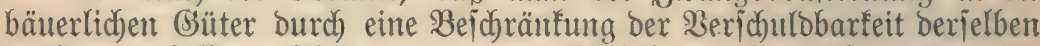
vorbeugen folle, ericheint uns undurchfïhrbar. Denn fest man bie

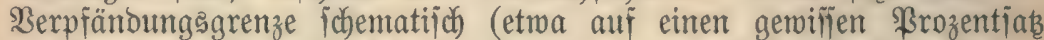

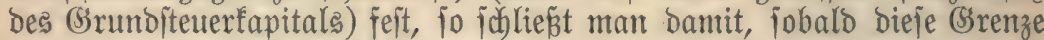
erreicht ift, zugleich jegliche fernere Belaitung für Meliorationen, wegen vorgefommenter Unglüctsfälle (z. B. Brandjchaben, Biebjeuchen, Srant= beiten in ber bäuerlicben Familie) uno ferner megen Rinberausitattungen,

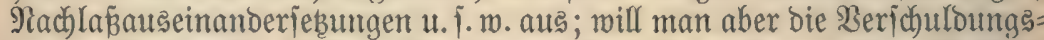
grenze für gemiffe sfälle nicht gelten laffen, fo mus man eine Bebörbe

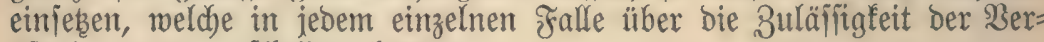
pfänoung zu enticheiben hätte.

Eine polcke polizeiliche Bevormunoung ift aber für bas moberne Seben eine reine Unmöglichleit; jelbit bie beitgeleitete Bermaltungs: behörbe wird nicht im Etande jein, in den taujendjach perjobiedenen Fällen bes Frebitbebürintiles jemeils zur ridjtigen Beit ihr "Sa" ober

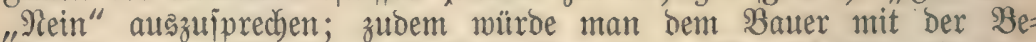

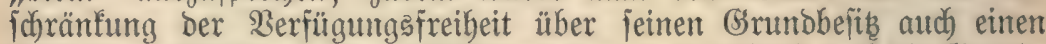
Teil feiner Selbitnerantwortlichfeit nefmen, und bieje ift bod) bie (Grumb= lage jebes erniten Mormärtsftrebens.

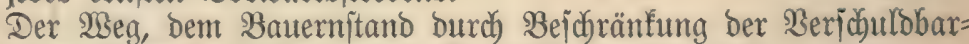
feit jeiner Gsuter zu helfen, wiro aljo nicht gangbar jein.

Beritaat= liďung bezro. Mionopoli= fierung bes sippothelar Irebits.
Sicht unermähnt möchten wir bier nod) einten weiteren Soridglag lafien, zu reldbem es nur ein fleiner Sdyritt ift, went man fidh ein= mal mit Dem Gedanfen befreundet hat, die 2Hufnahme von Seypothefen feitens ber Ranomirte von einer polizeilichen Genehmigung abbängig zu machen, nämlich ber Boridglag, ber betreffenden Beböroe aud bie

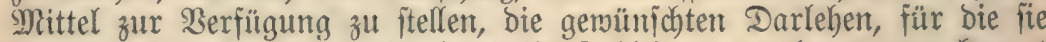
ihre Benehmiguntg zu erteilen bereit ift, jelb it zu gewähren; man fommt

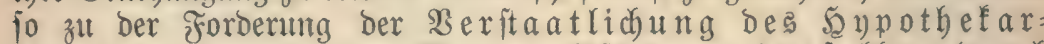
fredits und weiter ber Monopolifierung bespelben burd

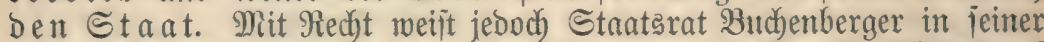

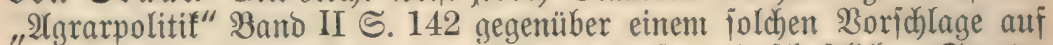
bie politificen Rachteile hin, bie fich aus biejer wirtidjaftlichen Staats=

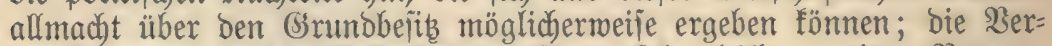
ftaatlichung bes Scnpothefarfrebites fönne jehr leicht zut einer Bureau= Eratifierung bes (sinumbbefikes führen, bie ber fozialen uno wirtichaftlicken

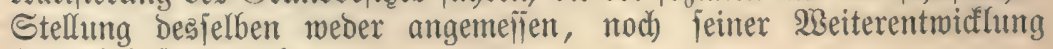
förberlic jein möd)te. 
Sieje Bebenfen genen ben ermähnten Reritantlid)ungsworid)lag find fidferlid) wohl gerediffertigt uno es icheint uns, bamit bie Unjwect=

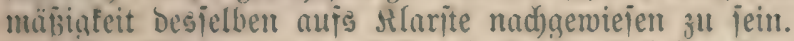

7. Wiit ben unter 3if̈er 4,5 uno 6 bejprod)enten \$orichlägen (iscitattung ber 3wangsvollitrectung in Siegenichaften fïnitig mur auts

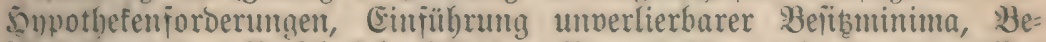
id)rälfung ber Sierichulbbarfeit ber Buterngüter auf einen gemilien

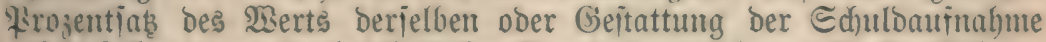
nuf biejelben mur mit obrigfeitlicher (Benehmigung, ferner \$ieritaatlichung des 5upothefarfrebites - fann, wie mir gejeben haben, bem Bamern= ftand nidgt geholfen werben.

SISill man gegen die Beriduldung bes Bauternjtandes porgehen, io farm bies mit Eriolg mur geid)eben, menn man ben eistzelnen Edhuld= uriadben nad)zuforjchen uno bieje bann einzeln zu befämpjen judtst.

Cinte 5aupturjacke ber machienden Seriäuldoung bes Bauternitandes ijt, mie wir im eriten Âbidnitt biejes Budbes bargelegt haben, bie bäutig зu teuere Guts̈ubernabme bei Erbfällen uno Rindstäujen uno als עittel biergegen erjobeint: ein zmedmäbiges $\mathfrak{A}$ nerbentrecht; meitere

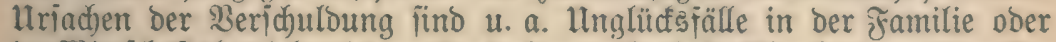

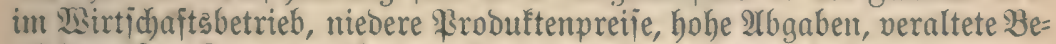

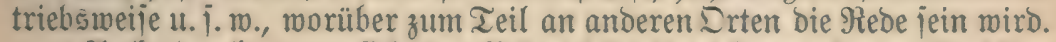

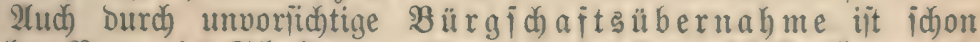

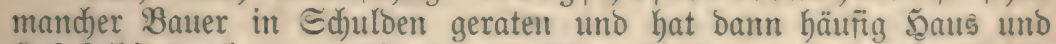

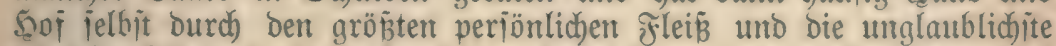
Eparjamfeit und Genügjamfeit nicht mehr por Dem 3wanggentauf retten förnen.

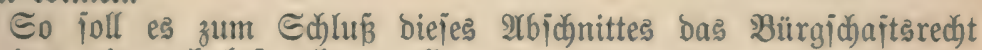
fein, bas wir nod beiprechen wollen:

Jabrbunberte lang war ber Bauer in Deutichlano unjelbitänoig

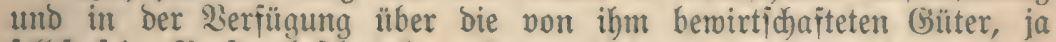
ielbit jeine \$erion beidoränft, uno von biejen Beiten bajtet immer nod etmas an feinem Charafter; formell ijt er jeood jebt frei von allen, ihm frïher aujerlegten Sieriügungshejobränfungen, uno bieje freiheit

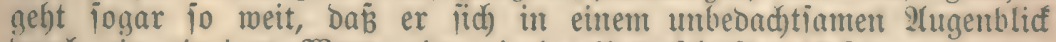
Durd) ein einziges Sort, eine einzige $\mathfrak{U n t e r i d ) r i f t ~ m i t ~ i e i n e m ~ g a n j e n ~}$ 2ermögen für eine frembe Perion verbürgen tam.

Su einer jolden freiheit liegt aber mieres Eradtents ein voltes= wirtichaftlidjes Bedurfnis burdjaus nidht vor; wir jeben eben audb bier,

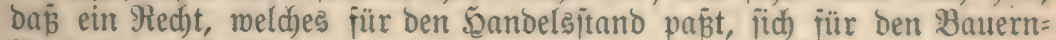

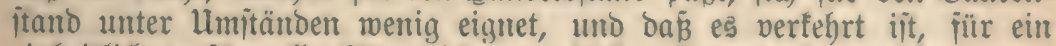

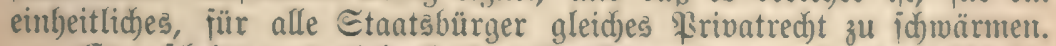

(Es eridfeint uns vielmebr ber Ermägung mert, ob man uidat bie

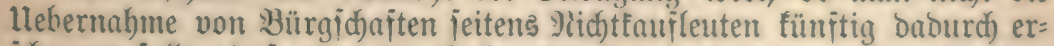

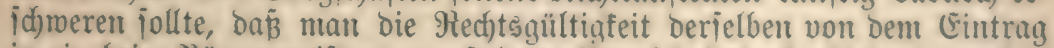
in ein beim Bürgermeijterant geführtes \$ïnrgichaftsbuch abbängig mad)en

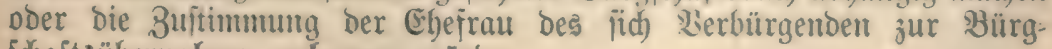
fobaftsübernahme verlangen würoe.

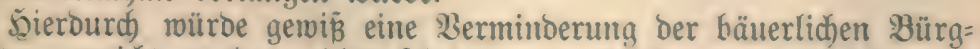
idgajten erreidft werben; bies joeint uns jeobd) mur ermiinjogt, uno 
ebenjo witrben wir es frettoig begriliken, wetn ber Gäterliche \$erjonal=

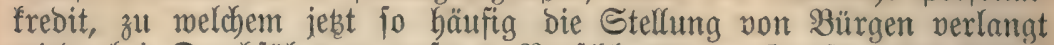
wirb, bei Durdfüührung unferes Borichlages zu Gunften bes Unter=

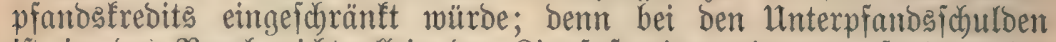

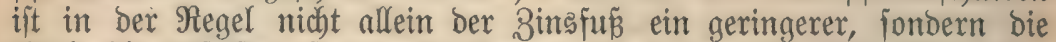

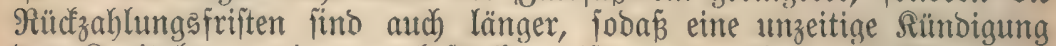

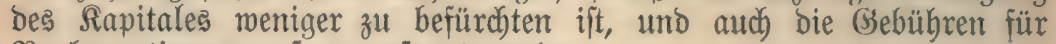
Frolongationen U. โ. w. eripart werben.

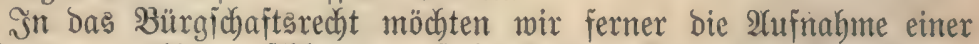

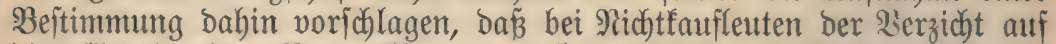
bie Einrede Der Borausflage Des Sauptichuldoners (Hebernabme ber

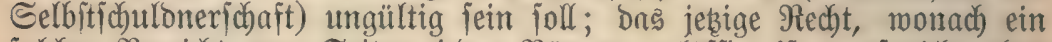
foldder Berzicht von Seiten jebes Bärgen zuläifiti ift, entipridot eben auch wieber mehr ben 2 Inforberungen bes Şandelsitanos an eine fidnelle Exefution als Den Sntereffen Der Bauernbevölferung auf Erbaltung in ihrem Esundbefitib.

SBenn wir oben uns Damit einveritanden erflärt haben, Daß fünftig

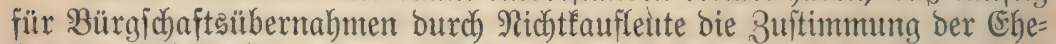

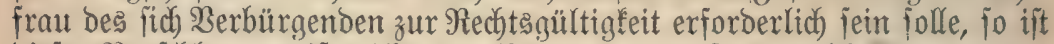

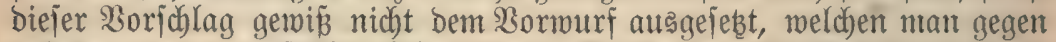
andere, von uns frither bejprochenen Berfoduldungabeidsränfungen mit

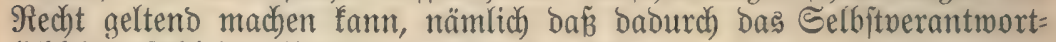
lichfeeitsgefühl Des Batern gemindert wïrbe.

Durd) unjeren Sorjajlag würbe allerbings vorerit mur eine einzige,

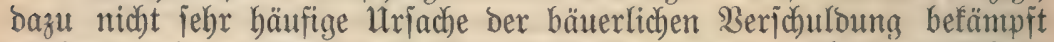
werben; wir mürben jebod, feine Bedenfen tragen, nod) einen S(d)ritt weiter zu gehen, und wären damit einveritanden, werm im (Seltungghereid)

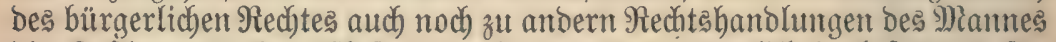
Die 3uftimmung ber Égefrau verlangt würbe, nämlid inthefondere für

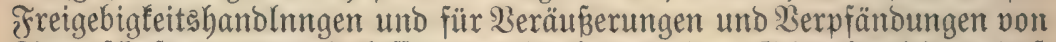

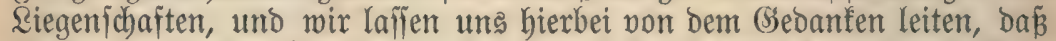

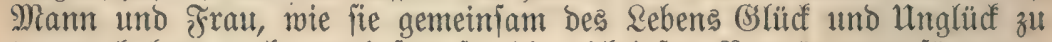
tragen Gahen, aud gemeinjam für bie widdtigiten Bermögensverfügııngen verantmortlich jein jollen.

Die Buitimmung Der Frau z̆ ßeräuß̈erungen und Berpfändungen von Riegenichaften if befanntlich in ber amerifanifichen Seimitättegejeb= gebung bereits vorgeidgriehen; Dabei findet bieje \$3oridgrift allerbings barin

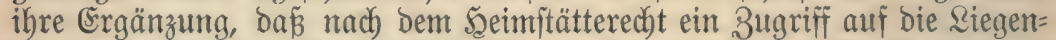

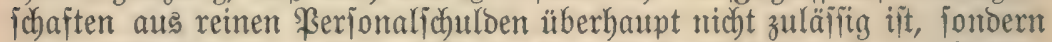

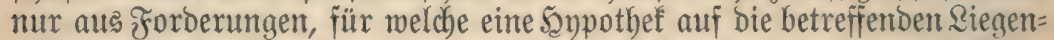
fchaften beftellt ift, was eben mur mit Buitimmung ber frau geideben

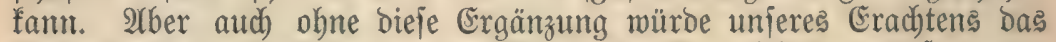
Erforbernis Der 3uittmmung Der Éhełrau zu Riegenichaftsveräuñerungen

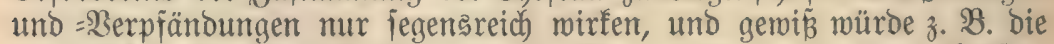

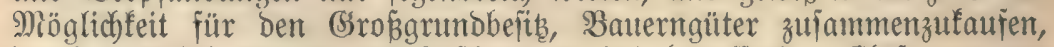
Durd) Das Erforbernis Der Buîtimmung ber betreffenden (Ébefrauen zur

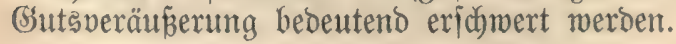




\section{Padtredt.}

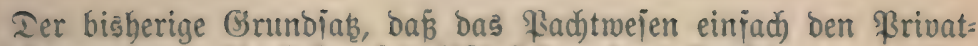

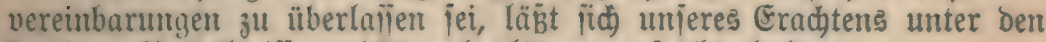
beutigen Berbältnilïen nidht mehr länger aujred)terhalten.

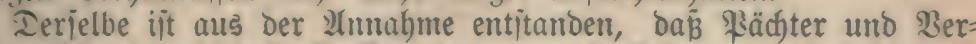
püd)ter jich als gleid) itarfe \$arteien gegenüberitehen, uno baß deshalb in ben siereinbarungen biejer untereinander regelmäB̈ig bas mahre volfs=

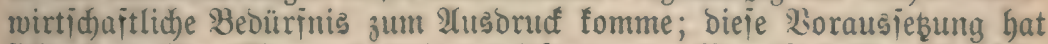
iid) aber als volltommen irrig ermiejen; zum Bemeịe belien iei leotg= lid) auj bie nidbt ielten vorfommenden ßad)tüberzablungen in (Śegenden mit einer getwilien llebervölferung in Folge bes bier oj̈t herridjenden mahren "Ranbhungers" vermiejen.

Es ericheint uns beshalb an ber 3eit, Den \$adhtwertrag ebenjo einer von jozialen Ermägungen getragenen, ö̈̈̈entlich)=rechtlichen Dronumg 3u unterwerjen, wie bies bereits bejüglich bes 2 rbeitsvertrages gejhehen iit.

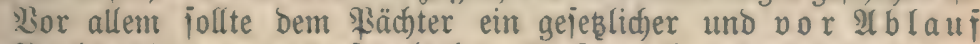

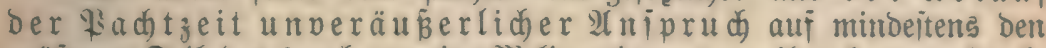
gröberen Zeil bes burd) etwaige \$leliorationen von ifm hervorgebrach=

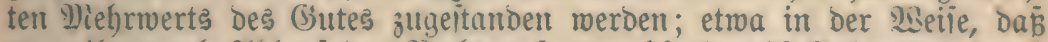
man ifut nad) Itblauf ber Yuadt auf etwa 10 ober 12 Jahre ben burch

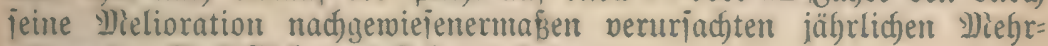
ertrag Der fiactiflädje jugeitehen wïrbe.

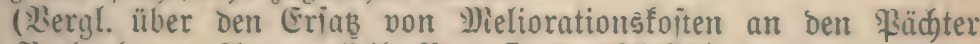
auch Bubbenberyer I(grarpolitif, Bant I, હ. 195 96.)

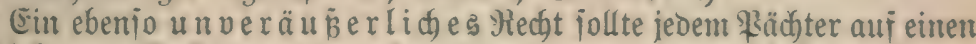
Rachla $\dot{B}$ am Pad)tjins eingeräumt werben, wenn mindeitens $1 / 3$ ber Ernte Durd) Sagelichlag ober Lleberidfwemmung zeritört wirb.

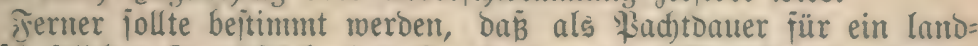
mirtid)aftlidjes Grumoitüd ohne (3)entehmigung bes Bezirfsrats nientals einte fiirzere 3eit als 9 Jal)re vereinbart werben bari.

\$äd)tern, welde ifgr Pachtitïd gut berwirtichajtet uno ifre Pacht: zinje ridtig entrid)tet baben, jollte ein Hed)t auj vorzugstweije Berüd= iid)tigung bei ipätern Jieuverpad)tungen eingeräumt verben.

Die 2 ierpadtungsbedingungen jollten bei allen Bierpad)tungen aui

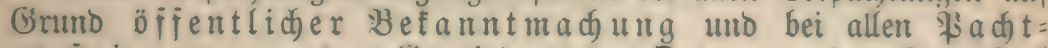
veriteigerungen Dem Gemeinderat des Ertes, wo bas Grumbitü gelegen iit, zur Genehmigung vorgelegt werben mülien, um biejem gleidjum als Dertreter Der Radhtlujtigen - Belegenbeit zu geben,

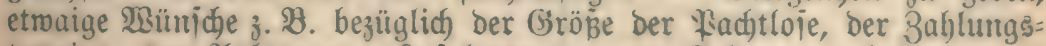
termine, Der 2 nnlage von Sujabrtswegen zur Geltung zu bringen.

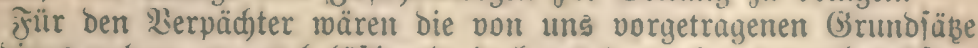
allerbings unbequem uno beläitigeno, dod) mürben wir es nur begrüben, menn baburd ber llebergang bes Eigentume in bie Santo bes Bewirt= idsafters mebr als bisher bejörbert würoe. 


\section{5. $23 e d j e(r e d) t$.}

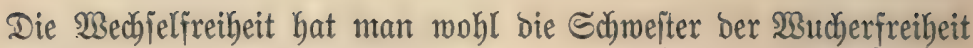
genannt.

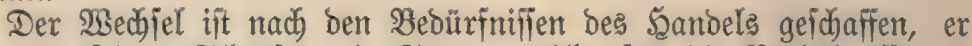
paß̈t mit feiner Schärje uno Strenge nidyt für die Berbältnifle der Ranbmirte, welche vor allem langfriftigen Rrebit brauchen, uno melchen

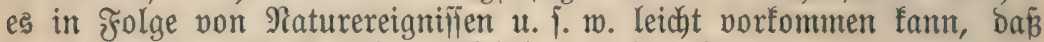
fie eine 3ablungsfrift nicht pünftlich einbalten fönnen.

Benn Ranotagsabgeoroneter Mujer in jeiner "IIgrarfrage" 5.65

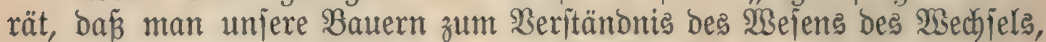
als eines modernen Serfehrs: und Belderjabmittels erzieben und über die relative Befäbrlichfeit mechjelmäbiger Berpflichtungen belebren folle, eine Rebraufgabe, zu Deren Senältigung einige Sdurfitunden genügen wïrben, fo fönnen wir bem nicht zultinmen.

Denn einmal hat bie Gdule auf bem Ranbe Denn boch midjtigere Äufgaben, als Belehrung über bas $\mathfrak{B e c h f e l r e c h t ~ z u ~ e r t e i l e n , ~ u n d ~ b a n n ~}$ mären audb einige menige Sdulfitunden hierüber vollitänoig ungenügeno unb deshalb zmedtos.

Was nüBen überbaupt dem Bauern etwaige geringe Renntnilie über Das Wejen des Wedjels, menn er fid in groper Beldverlegentheit

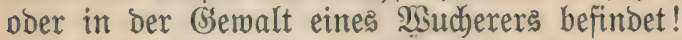

Man mag fich die Sacke überlegen, wie man mill, immer mú̈ man zu dem Ergebnis fommen, daß̧ Der Wechjel für die Berbältnijle ber Ranowirte und ingbejonbere ber Rleinbauern Durchaus ungeeignet ift.

Şm Snterefle Des Bauernjtandes hat man beshalb bäufig vorge= foblagen, Die jebige allgemeine $\mathfrak{B}$ edjelfähigfeit zu bejuränfen; unjerer $\mathscr{U}$ nficht nach mürde es jebod genügen, die Wedjelft renge

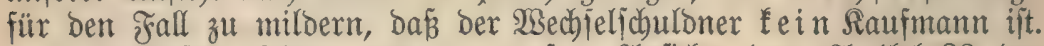

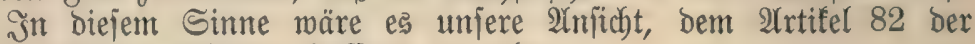
গ̉echjeloromung folgende Fafjung zu geben:

"Der Sechjelichuloner fann fich, fofern ex $R$ aufmann ift,

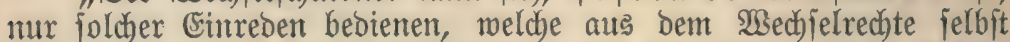
hervorgehen ober ihm unmittelbar gegen den jebesmaligen fiäger zuiteben.

Dem Raumann im Sinne biejes Artifels gelten gleid, diejenigen

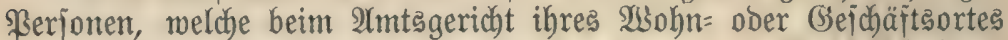

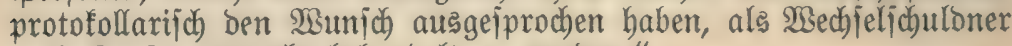
nach Siaufmannered)t behandelt zu merben."

IUf eine foldge Weije würbe unjeres Erachtens fomobl bem Be= bürniffe des \$gandelsftandes als Demjenigen des Pauernftandes genïgt merden. 


\section{Samuern fïr Sanbtwittidafiłiadjen.}

Sicht mit Ilnredht fann man behaupten, daß bie Gejebgebung bis=

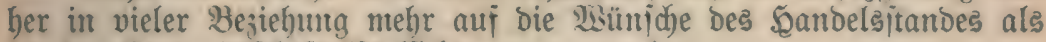
bie ber Lanbmirtid)aft Shïditcht genommen hat.

Eine ioldhe Bevorzugung Des Danbels fömnen bie Ranowirte unter

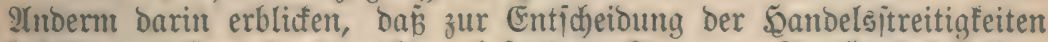
bei Den meiten \&amogerichten bejonbere Simmern für ફ̧andelsjachen,

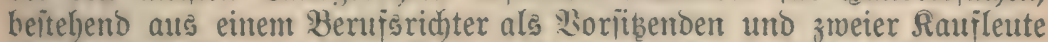
alş Sanbelşrid)ter, gebildet füto, währeno von ber Erridjtung bejonderer

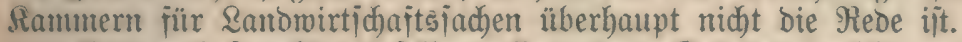

Ilno bod iprechen biejelben allgemeinten Grünbe, meldbe man für

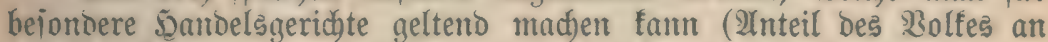
ber Med)tiprechung uno Deshalb volfstümliche Urteile, Serbreitung ber

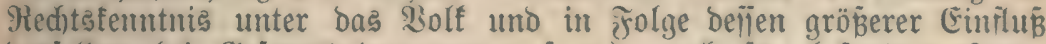
Desjelben bei Gejekesänoerungen u. ¡. w.), audh) für bejondere Rand= wirtichaftsgeridjte.

Wisill man nidjt Den Gebanten ber Şandelsgerid)te überhaupt auf

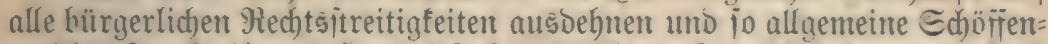

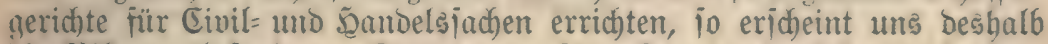
bie Bildung bejonderer Rammern fïr Ranbuirtichajtsjachen

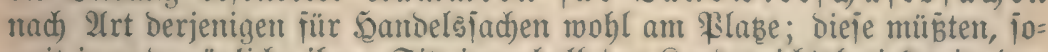

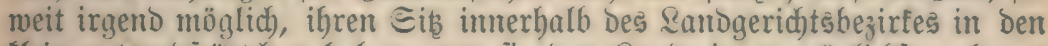
Eleinen Lambjtäotchen baben, um jie Den Ranbivirten möglidgit nahe zu brimgen und diejen alle ummötigen Roiten zu eriparen, oder es muipten bod) mindeitens 2Imtstage berielben in Den fleinen \&anoorten jtattfinden.

Ien Rammern für Rambrvirticjafitsjachen fönnten von ben ję̧t bent Civilfammern Der \&andgeridhte in eriter 'sntanj jugemiejenten Etreitigfeiten beiipielsmeije überlaijen werden: bie jämtlichen \$rozelje zwijhen Ranowir=

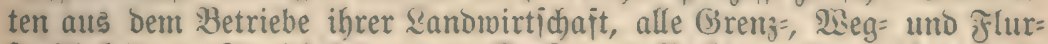
itreitigfeiten, Etreitigfeiten aus Rauf= uno Fachtverträgen über land=

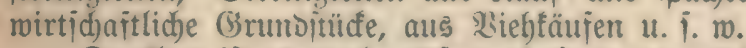

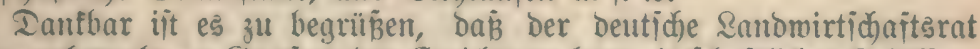

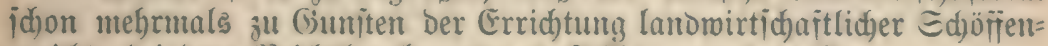
gerid)te bei bem seidjsfanleramte poritellig geworden ijt. 


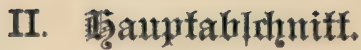

\section{Ta Innbwirtidaftlidie Sxebitweien.}

3weifellos ift im (S) ebiet bes ländliden Rreditwefens in

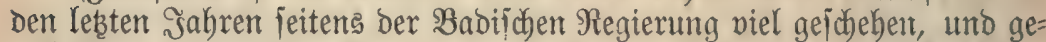

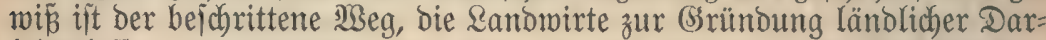

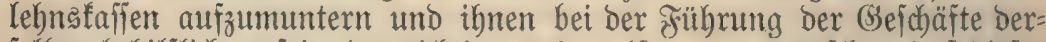
felben behilflich zu fein, Der richtige, und es ijt nur zu münichen, baß̉ biejer פBeg energifa) weiter verfolgt werbe; benn bieje (senoifenjafaften bilden mohl bas ficherfte Mittel gegen den ländlichen 19 sucher; aber andererieits ift Doch) ihre ganze Drganifation mur für furzfrifitige Darlehen einge= ridytet, Da ja ihre eigenen Schuldoverbindlidffeiten aud feine langfriftigen finto; wenn nut trokedom biefe Darlehnsfaffen jeitens ber Ranbwirte

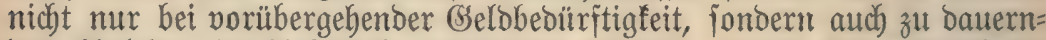
ben 2Ultehen in 22nipruch genommen merben, indem bie mebrjährige Berfallzeit event. noch mefrmals verlängert wiro, fo beutet bies barauf

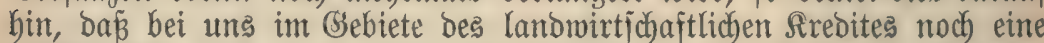

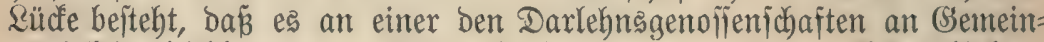

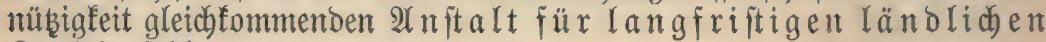
Arebit fehlt.

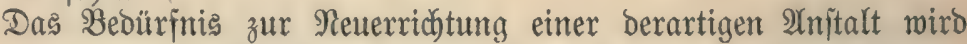

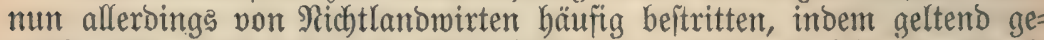

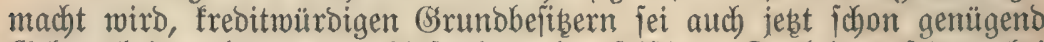
Gélegenheit geboten zur 2Aufnabme langíriftiger Darleben, fei es bei Frivaten, jei es bei Den zahlreichen Sparfajien uno Stiftungen, fei es

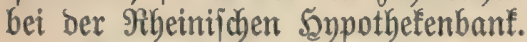

2lber alle bieje betreiben ja bas Darlebnggeidäät nidyt aus ge=

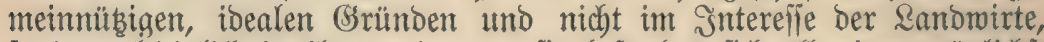
fondern lebiglidy in ihrem eigenen; fie beitreben fich alle einen möglidjit

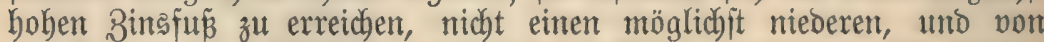

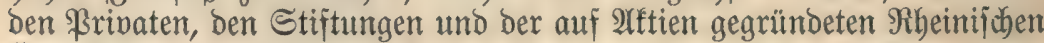
Szypothefenbanf wiro man bies audy gar nicht anders erwarten; went

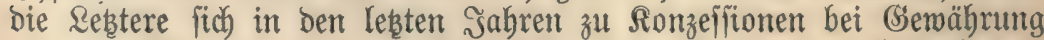
von ländichen Darlehen herbeigelaifen hat, io wiro ein Sauptbeweg= 
grumb wohl ber gemeien fein, baf man baburd bie Grünouna einer

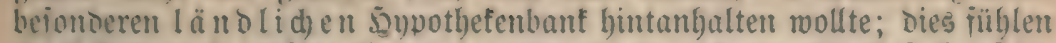
3meifellos and) uniere Butuern, uno es mag bam bie Uriade iein,

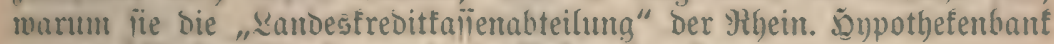

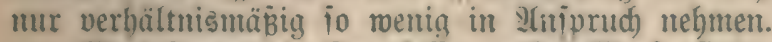

Isise jerner bie Eparfallen anbetrift, fo find aud bieje nidjt zur Unteritübung ber fresitbedïrfigen Sanotvirte, jonbern im Gegenteil im Juterelie ber Enarenten, D. h. Der Eleinen Rapitalijten gegründet, und für Die Gemeinden, welche bie Garantie für bie Lerbinolidfeiten ber= ielben ïbernommen baben, verjolgen ïe nod) ben weiteren gemeintoe=

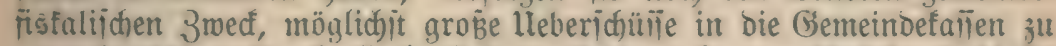
"gemeinmïbigen Zmeden" abzuliejern; Reb̨teres fann natürlidy gleidffalls mur auf Rojten ber \&anbwirte geidgehen, meldbe bie Edhulbzinjen auf= zubringen baben.

Die Landwirte find eben bei uns gegenüber ben Bertretern ber

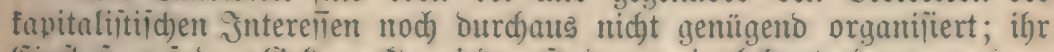

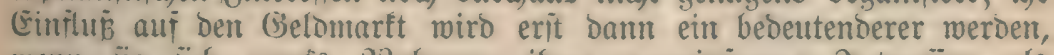

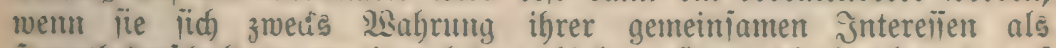

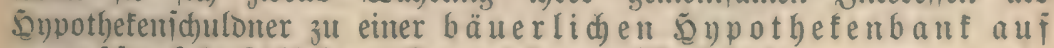
genolienidaftlid)er Grunolage (äbnlid) ben neteren norb= beutidjen samojidjaften) ieit juiammenid)lieben.

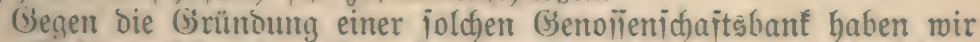

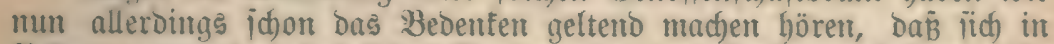
Baben megen Des ipärlicjen Borfommens Des (3rob̧urumobeikes nidgt genty gebiloete Santwirte fintoen wïrben, bie ïch zur Mitwirfung bei der Wiernaltung einer Genolienid)ajtsbanf eigneten; es jei Deshalb belier, ber Etaat nehme die Eache jelbititünoig in bie 5anto und grïnbe mit eigenen Witteln nad mitteldeutid)em Miuter eine 2 and frebitfaije, Deren (seichäite bant burd) gewijienhajte uno gentigeno vorgebildete itnatliche Beamte bejorgt mürden.

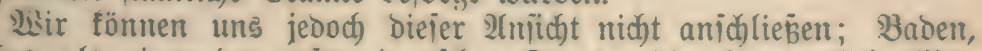
weldhes als einter ber eriten beutidhen Etaaten bie ebrenamtlidje Dit:

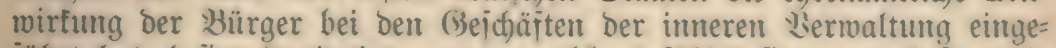

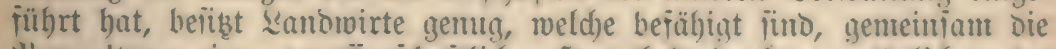
Lierwaltung einer gentolienid)aitlichen ફypotbetenbant - natürlid) unter Etantsaupiod - zu leiten und bierbei ibre bäuerlidien Etandesinterejien

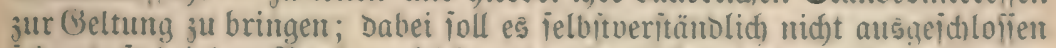
iein, Daś bei Der Banf zugleich) einige itaatliche oDer aus Den Etaats= Dienit bervorgegangene titd)tige Beante zur Beiorgung Der InuFenden Beichäite verwentot werien. Der Stantsregierung aber ben maß̈gehen= Den Eimflús auj bie Seitung Der Banf uno die Sauntverantwortlid)feit baïir zu übertragen, eridheint uns wentig zmedinäsig; Etautsheante hahen eben den Beruf, jmijhen ben Jinterenien ber veridienenten $B e=$

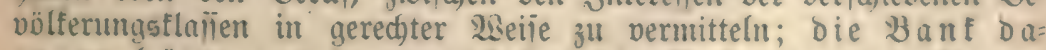
gegen batte gerabe umgefehrt bie $\mathbb{A} u f g a b e$, die finan= ziellen Eonderinterefien ber Sandwirte gegen die= jenigen anderer जtänoe nadorüdlid un unter $\|$ m= fiñoen rüfidatoros zertreten. 
Bei einem Stantsinfitut würoe ferner bie Berwaltung wohl ge= rabe io förnllich) und umitä̈tolid) eingerichtet veroen, roie bei ben fonitigen ftaatlid)en Bermögensverwaltungen; man würoe beshalb wobl bald Rlagent über bie "ichwerfällige Büreanfratie“, „über bie Reitung

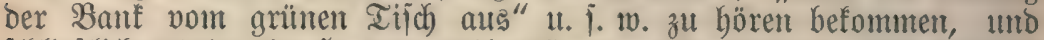

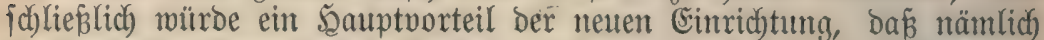
bie Ranbwirte immter mefhr Yernen umb barit geïbt werben, jelbititäntoig

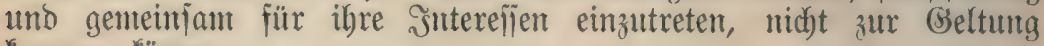
fommen föntuen.

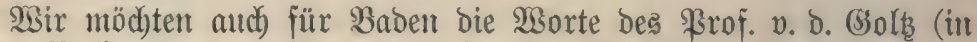

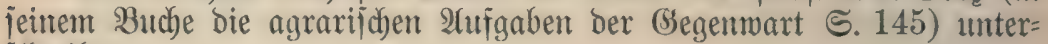
id)reiben:

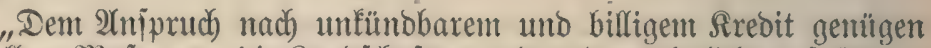

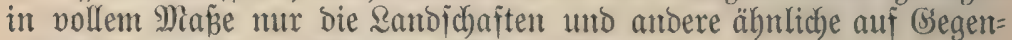
feitigfeit gegrïndete öffentliche Sreditinititute."

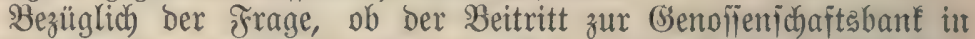
Das Belieben Der einzelnen Randwirte geitellt ober auf alle mit Echuldoen belajteten Grumbbefitzer ein 3 wang zum Beitritt ausgeïbt werben jollte,

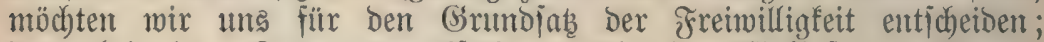
Denn bei einer 3wangsonganijation würbe Der Einfun bes Etaates auf bie Banfverwaltung wieberum ein größ̈erer werden; Der Etaat

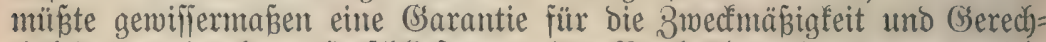

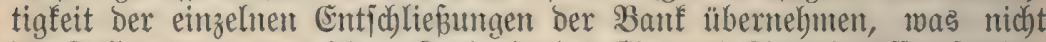

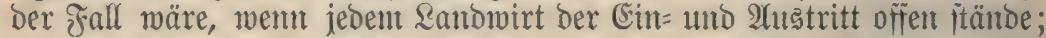
in ber \$olitif foll man ferner - fomeit irgeno möglich - bie

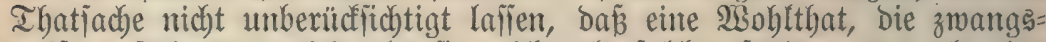
weije aufgeobrängt wiro, bäufig niedst als joldhe, fonoern mur als eine läitige Frreiheitşbeichräntung empfintoen wiró.

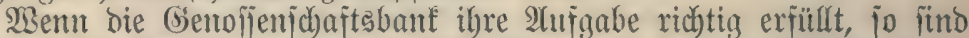

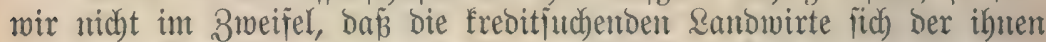
gebotenen Borteile wegen freimillig an biejelbe amjodießzent werben.

Errwägensmert wäre, ob bie şanf als einbeitliche 21njtalt für bas ganze Ranto ober als Sreishypothefenbant jemeils für ein ooer mehrere Sreije erridstet werben follte.

Zbätigteit einet foldien Bentolien= idjaftsbanf.

Die Saanttyätigfeit ber Banf Gätte in Der Bermittlung von lang= frifttigen lä̈ndichen Darlehen zu beittehen unb zwar vor allem gegen

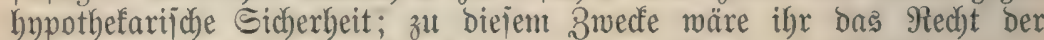

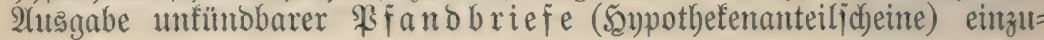
räument.

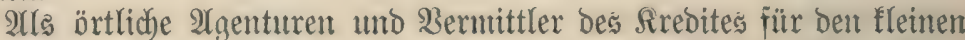

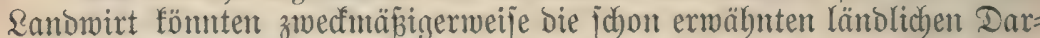

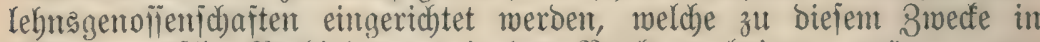
feite organifhe Serbindung mit ber Banf za bringen wären; mur Mitalieder ber örtlichen Darlehnstajien folltent bie segpothefentbant in $2 \mathfrak{A n j p r u d}$ nehmen bürien.

"Die örtlidjen Benofiemidaften", jagt Staatßrat Budhenberger bei Befpredfung einer foldhen Drganifation (ভ. 151 Des II. Bantoes jeiner

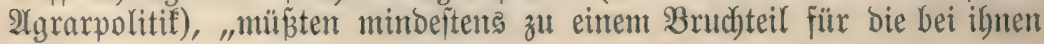


cintretenden Nerlufte für verbaftet erflärt werben, währeno für bent

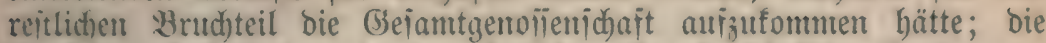

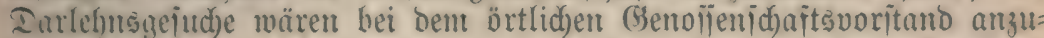
mefoen uno von biejem mit begutad)tendem 2 (ntrag bem Bentralvoritand voritulegen, bem bie Enbentidjeidung verbliebe; burdh bie aliquote Rer=

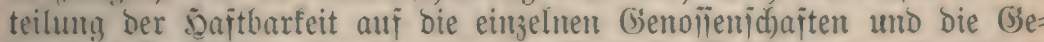

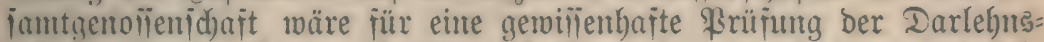
gefuche eine benfbar grop̈e Bürgïdaft gegeben; auth bie periönliche sirebitmintoigfeit ber Darlehnsbegehrer, ein gerabe bei Darleben ber bäıerlichen Bevölferuna nid)t unvejentliches (Element, fäme zur hin= reidjenden seltung."

Pieben Dem 5ypothefarfredit mü̈te bie (Senoīenid)ajtsbanf durd)

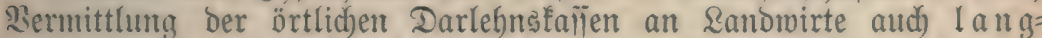
frijtigen \$gerionalf rebit gewäbren uno zwar beshalb, weil unjere flemteren Rambivirte uno barunter gerabe bie vermögenderen jelbit zu langifritigen Iarlehen häufig lieber ibren \$erionalfrebit als ihren

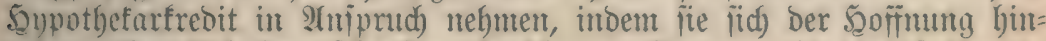
tiehen, ifre Edjulden idjneller abzahlen zu fönnen, als bies fpäter in Birtlidjteit ber Fall ift.

Tie örtlichen Darlehnsfaĩen, welche genentoärtig biejem Bedürfniढ nad) langirijigem Sherionalfrebit genitgen, haben in Folge belien jekt bedutento Betrüge joldjer Forderungen ausiteben, für meldje ibnen

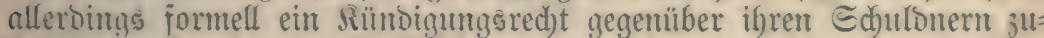
itebt, bas ïe aber in Ssirflidfeit io gut wie gar nidft geltento madjen

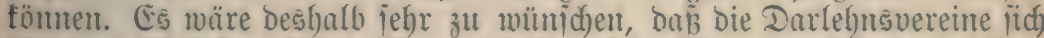
für ben jäbrlichen Dimbeitbetrag joldjer jebr idjwer realijerbarer For= berungen ourd) entipred)enden langirijtigen uno untümbbaren fresit bei

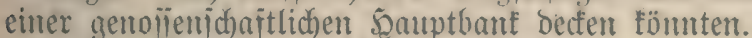

Die 2iorteile, weldhe den sambwirten burd) bie vorgejd)lagene gilliger nno Banforganifation geboten wittben, wären vor allem billiger uno un=

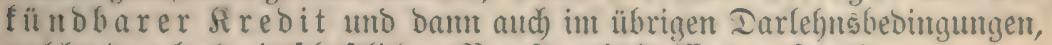
weldhe ben lanbwirtid)aitlidhen Berntisverhältnilien entipred)en.

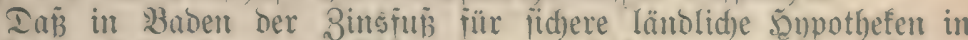
Den lebten Jubrzebnten Durd)ichnittlid) ein höherer war als in Jiord=

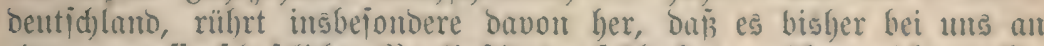

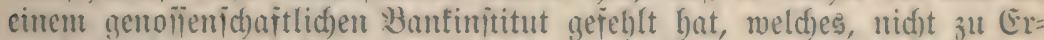
werbşzuecten geyründet, ben samowirten Iarleben zum Eelbitfojteupreis gemährt båtte.

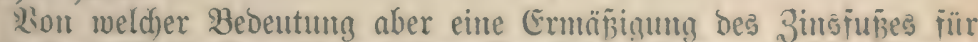
bie Rambuirtid)ait ijt, acht aus einer Bered)mun berwor, meld)e Etauts=

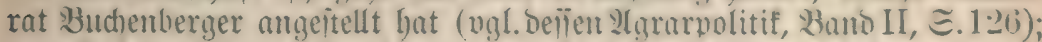
banad) bedeutet eine Serabminderung des Dopothefensingfunes um nur $1 / 2 \%$ für Waben eine bem Betray Der ituatlid)en (ínumbitener gleid)= fommente jabreseriparnis von $2^{1}, 2$ )illionen Marf.

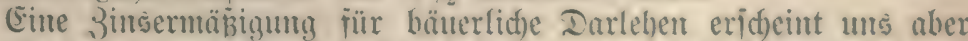

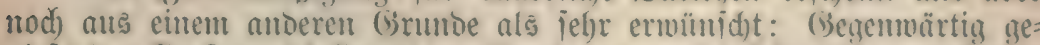

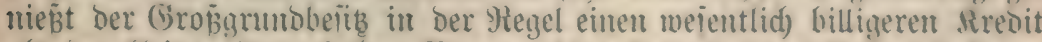
als ber fleite oder mittlere Bauer; Dies bat aber jur Jolge, Daß Der 


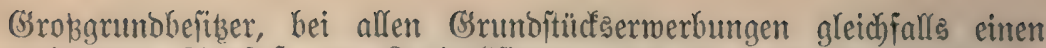
geringeren 3insfú zur Sapitalifierung des für bas Grumbitücd be= red)neten Reintertrags zu (Śnumbe legen uno jo ein böheres Rapital als Raufpreis bieten fann als ein Batter.

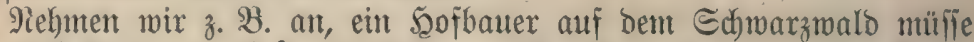
jeine Sdyulden zu $4,5 \%$ verzimjen, wäbreno der angrenzende Broß̈= grunbbefizer mur $3,5 \%$ zu zahlen braucke, fo bebentet bas, on

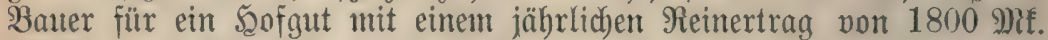

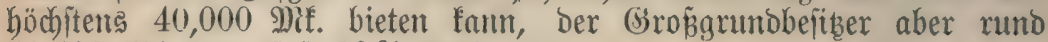
51,400 Mif. poer fajt $29 \%$ mebr.

Der Borteil des niebrigeren Binjes wiro jo zur jüärfiten Baffe

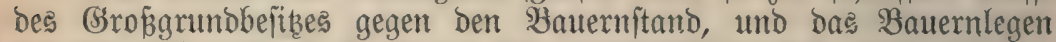
auf bem Edwwarzmald ift mit auf bieje Bingneridfiebenbeit zuriidzufübren; auch im Rampfe zmijhen Şanomerf uno Frabrif giebt ja oft leoiglich

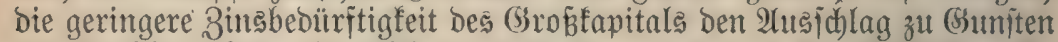
Des Grop̉betriebes. Es ericheint beshalb aud aus bicjem (Sejictspunfte als ein jebr eritrebensmertes 3iel, auj eine Szerabjekung bes Zinsfubes für bäuerlidje Darleben hinzumirfen.

Der zmeite Borteil, Den bie gennfienjofaftliche Brundfrebitbant dem Bauer bieten fömnte, wäre bie Unffindbbarfeit ber Gäuerlichen Darleben.

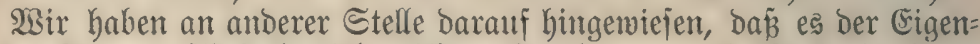
art bes Ranowirtichaftsbetriebe nicht entipricht, wenn ein Ranowirt füno= bare Schuldoen auf fein Giut aufnimmt. Der Sanomirt erzielt eben von jeinem Gut nur einte jährliche Siente, alio bie Binjen eintes Sapitales, nie aber wiro ihm bas lebstere währeno des Wiridaftebetriebes frei

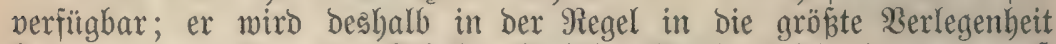

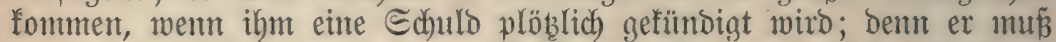
Dann entweber ein neues, unter Unitänden höher verzinslides Darleben aufnehmen ober pon jeinem Sint einzelne Grunbitüde lostrennen und veräıßern, was aber, wenn üherhaupt, in Der Fiegel mur mit Serluit mög= lich ijt, ba es eben gerabe plöz̧lic) umb zu ungelegener Beit gejcheben mup.

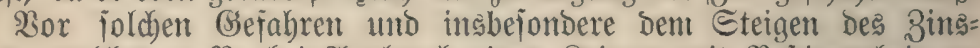

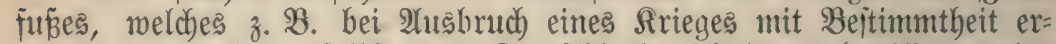
wartet werben fann, jelbit wenn Deutic) land nicht baran beteiligt würbe, follte ber Santowirt Durd) eine immer gröpere Serbreitung ber unfünd= baren Darlehngidhulben an Etelle Der tünbaren gefichert werben. Die Boransjebung hiernon ift allerbings wieber bie Grünbung eines gemein=

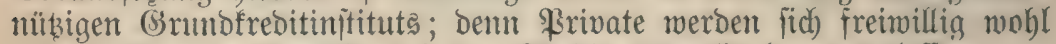

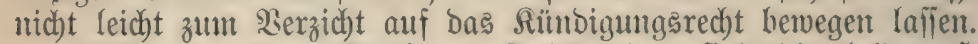

Billiger und unfümbbarer Rrebit, bas find bie beiden Şaupt=

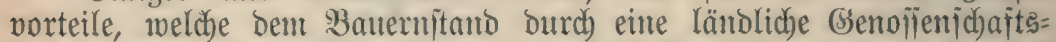
banf mebr als bisher gewäbrt werben fönnten; basteben wäre es

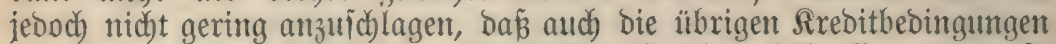

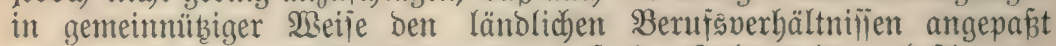
mïrben; io wären bie Zinstermine auf eine Sabreszeit zu beftimmen, mo ber Bauer ant ehejten Geld hat; es minften auch fleinere Darlehen von einigen 100 Marf zu Demjelben 3ingfuß zugelafien werden wie größzere; e马 müß̧ten Ânunitätenoarleben gewäbrt merben; aud bie ge= 


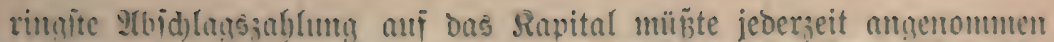

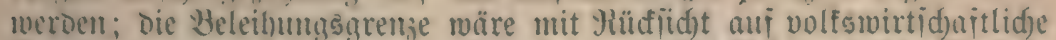

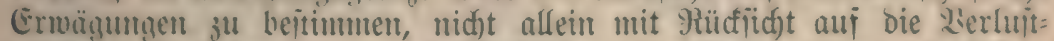
gerabr; Durlehen su umbirtj(jaftlichen 3wecten mïbten abgelehnt, bagenen mübte umugfehrt bei unverid)ufoeten Zahlungsidgwierigteiten bie mïalidjite Mï̈dicd)t geülot werben แ. i. w.

Zlus 2fllenem geht zur (Senüge hervor, wie jehr es zu münidjen wäre, Daß̉ Der Etaat Die Grünbumg einer ländliden Sypothefenbanf

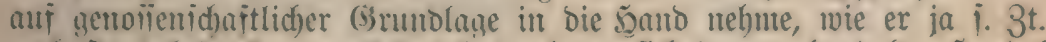

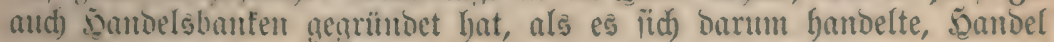
und Gererbe it bie 5öbe zu bringen.

2isober aber foll bie zu arünoende Bant bos erite Sapital ju ifrer

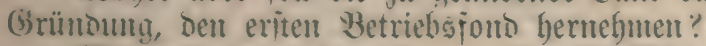

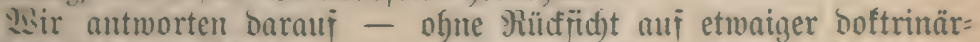
Eriter \%e:
triebsfond fiir bie neue Bant.

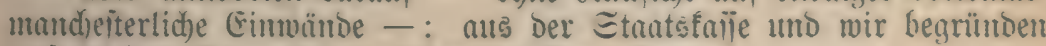
Dieie uniere 2lntmort mit jolgenden Benterfungen:

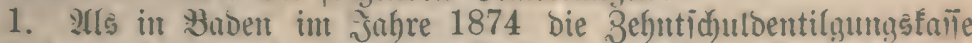
aufgehohen wurne, wurbe Der Sapitalbejtano, Den fie im sauje ber 3eit antueianmelt batte, in ber 5öbe von nuto 274,000 y)if. an bie General=

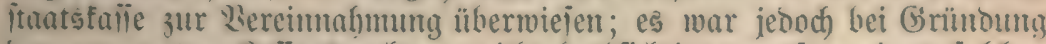
ber gentanten siaje Durd)ans nicht beabïidstigt gemeien, einten joldhen Betrag vou Den zebutpflidgtinen sanowirten einjuiparen, und es eridheint

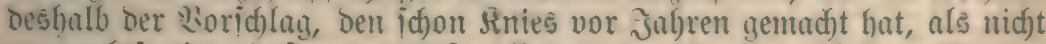

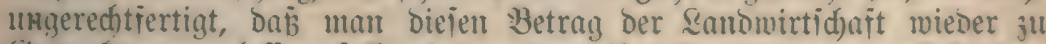

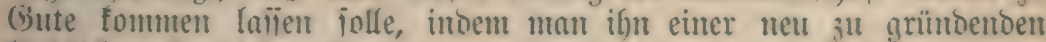

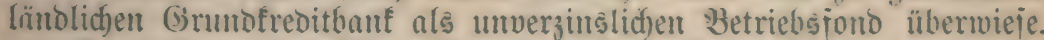

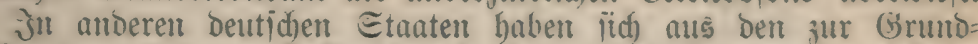

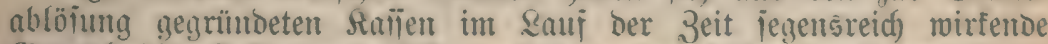
(istundfreditumitalten entwidelt, uno es wiurbe Daher burd) Den obigen

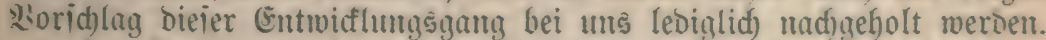

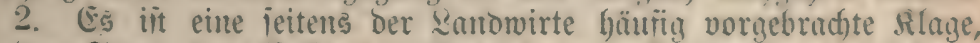

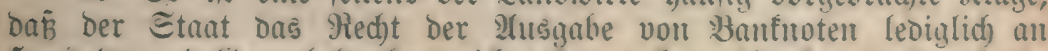

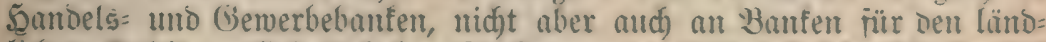

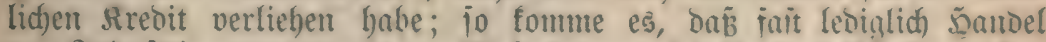

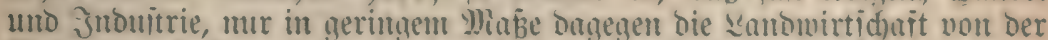

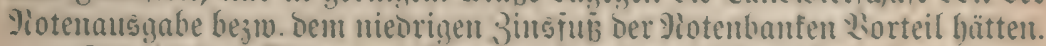

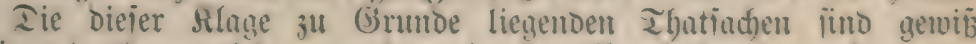

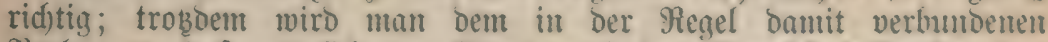

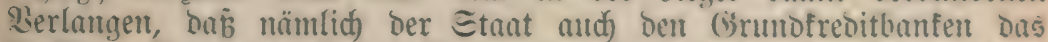
Hecht jur 9rotenansunabe bewilligen oner meniajtens bie beitehenden Mioten= banfen sur (Gemäbrumg billigen Sonpothefortredites an Zanbivirte ver= anlanien jollte, nid)t juitimmen fömen. Ein joldhes Nerlangen ị̄t eben

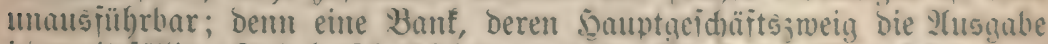
jederjeit fälliger Jnhaberidhulbidjeine wie Der Bunfnoten itt, würoc genen

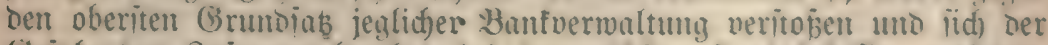

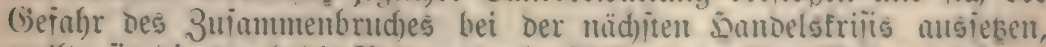

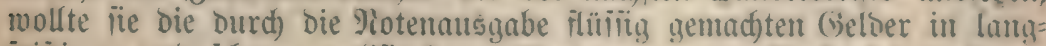
frijtigen und idjwer realipiterbaren Forbernigen an sanbwirte anlegen. 


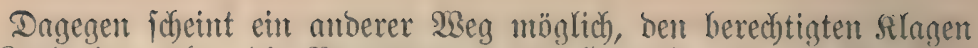

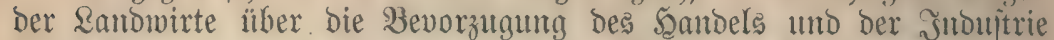
abzuhelfen; und bies wäre ber, Dá̉ ber Staat Den hejtehenden Sioten= banfen bie \$erpffichtung auferlegte, von ben Durch Die Rotenanggabe fliififig gemachten Bseldern - etwa nach dem Durdhichuitt Der lebten fïnf sabre - einen gewifien prozentualen Teil als unverzitstichen

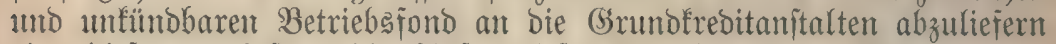
poer biejen menigitens bie Binjer biejes Ânteiles z̆ vergüten.

Die babiface Bant bat 3 . $\mathfrak{B}$. in Den Sahren 1891 und 1892 als (Seminnanteil ben Betrag von jeweils ïber 20,000 Mf. an Den Babijchen Staat abgeliejert; würoe mun ber lebtere auf biejen Betrag zu Gimiten

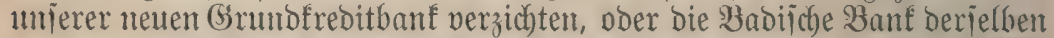

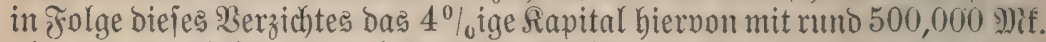
als unverzinslichen Betriebsfono zur Berfïgung itellen, fo fönnte unieres Erachtens Darin Piemtand eine bejondere Bevorzugung ber Ranomirtichart erblicfen; bieje wïrbe vielmehr baburch linfidhtlich ber. Sorteile aus ber Potenausgabe lebiglich bem Şandel uno ber Snouitrie gleidggeitellt.

Dieje (Sleichitellung wäre aber für bie \&anbwirtichaft ım fo wich= tiger, als fie es ber (Srundfrebitbanf ermöalichen würoe, unt jo reichter

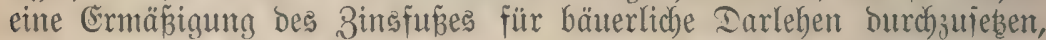
wobei man nod) gar nicht babin zu itrehen braudst, benielben bis zu

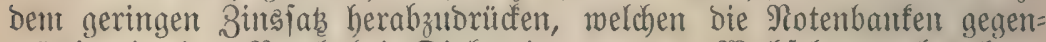

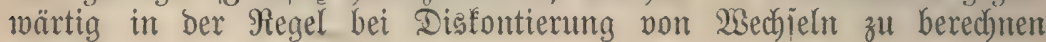
pflegen.

2tudc) bezüglich des Geminnanteiles an ber Reidbshanf, weldher allerbings in eriter sinte bem Reich, durch biefes aber in Folge Sier= minberung ber Miatrifularbeiträge auch) Dem Einzelitaate Baben zu Gute fommt, eridheint uns eine Siermentoung, äbnlid mie oben vorgejchlagen, mohl zu rechtfertigen.

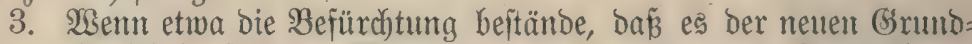
frebitgenofienichaft für ben 2lnfang an bem genïgenben Rrebit bezw.

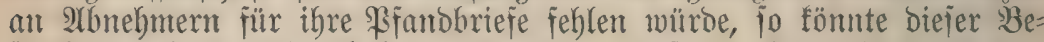

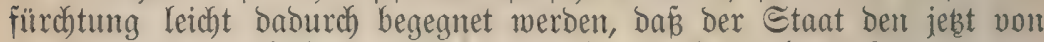
ber 2 tnortifationsfafie verwalteten, in barem Gelde bezm. Forberungen bejtebenden Teil bes Domänengrunbitodes - z. 3t. über 10,000,000 פj) - ganz oder zum Teil bei ber netten Banf anlegen würbe.

Dieje Gelder rübren - abgejehen von neueren Einnabmen für Baupläke uno Brunditü df ablöjutg her, bei melcher fie von bem Bautermitano als arblöjungsfapi= talien für bie bomänenärarijchen Bebnten แ. ¡. w. aufgebradbt wurben.

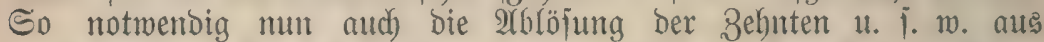
politifiden uno jozialen (Srümben war, fo mitijen boch aud) bie eifrigiten

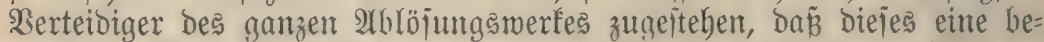
trächtliche Rapitalverichuldoung ber Ranbwirtichaft an Stelle ber frïberen 3ehnt= uno (siältenpflichtigfeiten zur Folge hatte. Es würoe uns mun nicht unbillig ericheinen, wenn bos Domänenärar jeine (Śnumbjtod'sgelder,

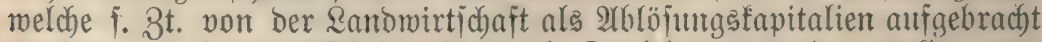
wurben, ber Sandwirtichaft wieber als Darlehen zumenden wollte, was 


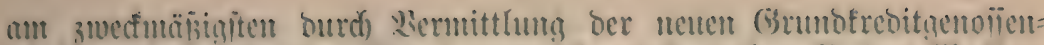

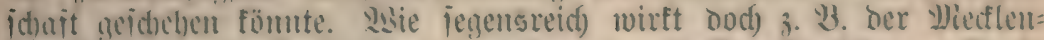
buraiidge Ionmutalfopitalfonto, ans bem ummittelbar Darleben an zano=

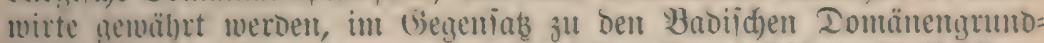

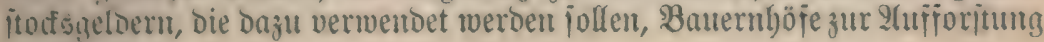
artzufaufen!

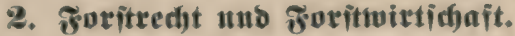

Lisic in allen Gebirganegenden, io gebörten uriprïnglid) auch im Ed)marzmalde su jedem soje - modite berielbe mu von frreien ober

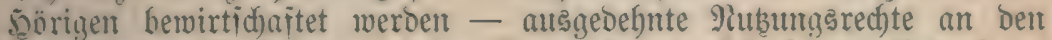
benudbarten Malommen: jeber Baner fomte iid) jemen Bebari an

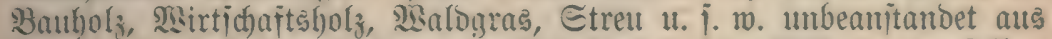

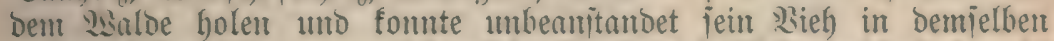

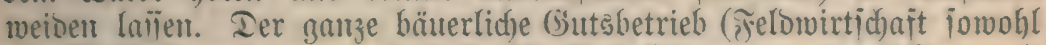

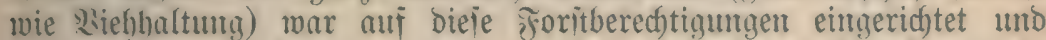

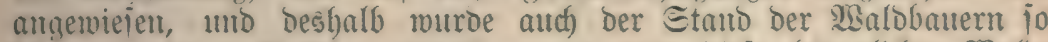
id) wer in ieinter Exiftentz getrofien, als man bieje bäterlid)en $\mathfrak{B a l}=$

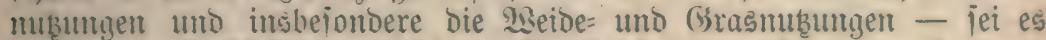

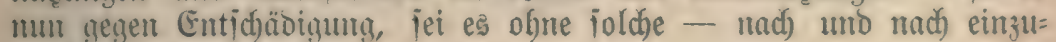
¡̈̆ränfen uno zu bejeitigen begann.

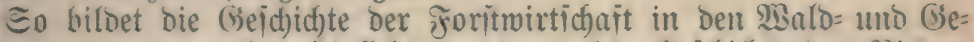

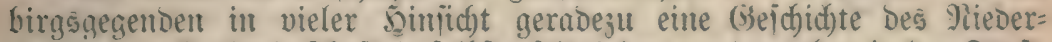
ganges ber Lantowirtichaft bajelbit: leit jeher murben eben in ben Frorit=

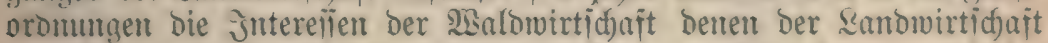
vorgejest, und es erid)eint uns bies aud) gantz erflärfid), went wir be= benfen, Daß́ bie Foritpoliseibehörben, weldye die Foritoromungen ver= faśten, früber - wie aud) jebt nod) - sugleid) פBalseigentümerinnen waren uno Deshalb ein eigenes Sntereife an der Bejd)rüntung Der bäuerlidhen

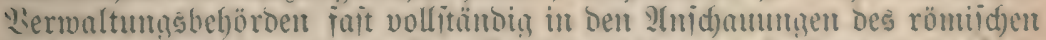

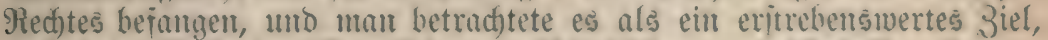
and) bein cigentums zu möglidfiter Slarbeit zu bringen, war aljo ben beutid)=

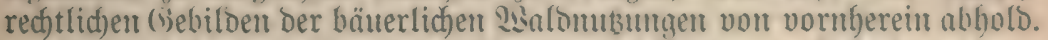

jebt itehen wir mu im Ed)warjwalde shitten in Enve ber ganjen Entwicflung, bie allerbinge nod) Durd) mande andere ltmitünde, vie Niermebrung ber bäterlid)en Itbnahen, Steigen ber (ijeïnbelöhne, ㄹer= änderungen in Den 9laturalienureifen แ. ¡. w. bejörbert murbe: Dem

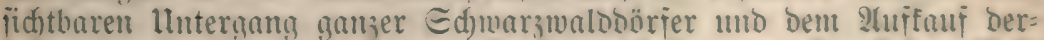

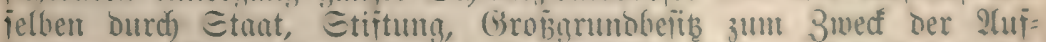
forjung.

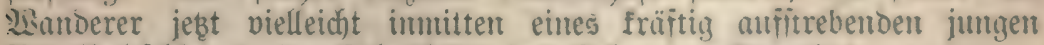

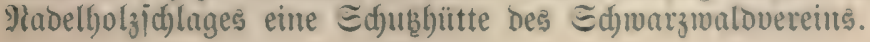


Slle man in Rorboftbentiaclanto ben Bantern bie gemeinfamen

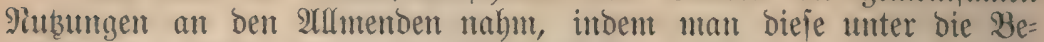
rechtigten aufteilte, ba zeigten fich bie Folgen alghald in eintem bebent= Yichen Zurüdfgehen ber Bahl ber Bauternfböfe; fie wurben vom benad)=

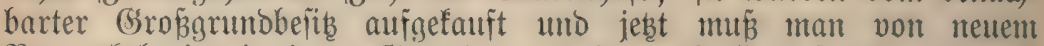
Bauternfolonien in jenen Gegenten grïnden. Eoll es joweit auds auf bem Sdiwarzmald fommen?

Aflerbings ift es unmöglich, Den ganzen Entwicflungsgang ber lekgten Jaghrbunderte wieber rüffgängig zu maden; aber bar über jollte unferes Eraditens feine Meinungeveridebenbeit beftehen, dá̉ es für ben Staat eine heilige grflicht ift, bell 5ofballernitand auf bem Sdwarzwald, foweit ex nidht idon untergegangen ift, zu ergalten; nur bariber,

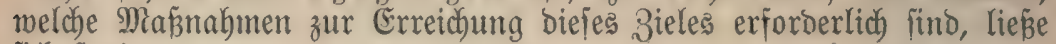
fich fitreiten.

2ieberaus=

behtumg ber lastblvirt=

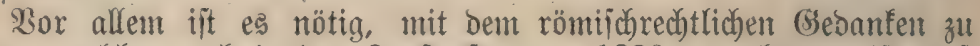
bredten, weldher aud in bem foritgejeb von 1833 zu erfennen ijt, dás

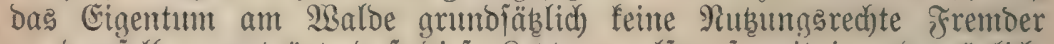
an bemjelben verträgt, dä dieje Reßteren aljo, jomeit irgend möglich, zu bejeitigen jeien, uno neue nicht mehr entiteben bürfen. Unjeres Er adbteng fömnte ber $93 a l d$, obne weitere Gefabr fïr benjelben, mieder mehr als bisher ber 2 Beibe= und Grasmubung geöfïnet merben; in diejer Sinfidgt mödbten wir um Berallgemeinerung ber während bes Futter= notjahres 1893 ergangenen \$erfïgung Groß̧h. Domänendireftion vom 10. Suli গr. 15564 bitten; dieje lautet:

"Die Malowetbe ijt zuzulaijen, too dies von der landvirtidarit= ricken Bevölferung verlangt uno ein mirfliches Bebilrfnis dafür für begründet eradbtet roird; Dabei werden bie Beftummungen Des Forit= gejebes in folgenber Weije ermeitert: $\$ 32$ : Die 2 fbteilungen ber Sodbualoungen jomie die Edyläge ber Mittel= uno Niebermalbungen

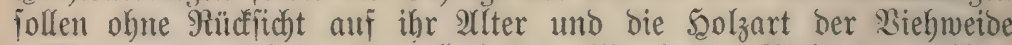
geöintut werben, jofern das \$ol3 bem Diaule bes Siebs entwachjen,

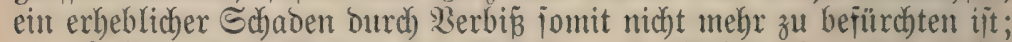

\$36: Das SBeiden Der Schafe und Geijen ijt unter diejer Borausjebung gleichfalls zuzulailen;

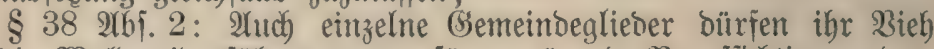

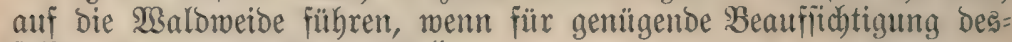
felben Sorge getragen wirb."

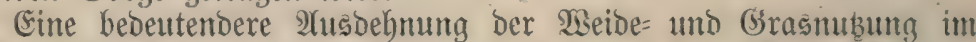
Walde mirs aber mur möglich fein, wenn man bei ber Bewirtidyaftumg bes Sebteren nicht allein einen möglichit groben Reinertrag aus bem Solzermad) s zu erzielen jucht, jonbern zu bem (Srutbją zurïdfebrt,

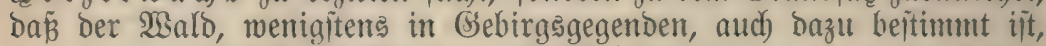

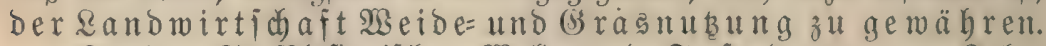

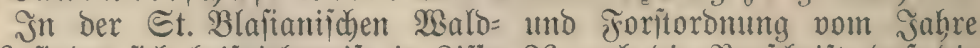

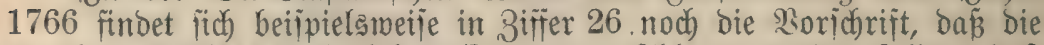

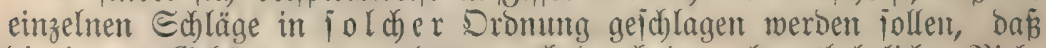
die jungen (Siebäue unter anderm aud burch Den obnentbebrlidgen Bieb= 


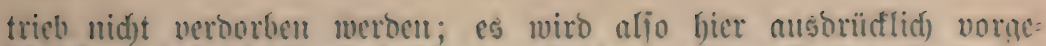

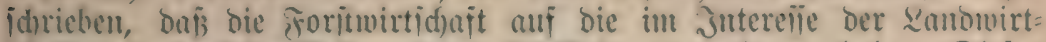

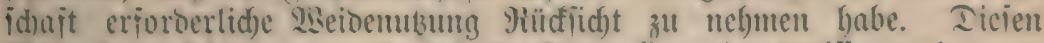

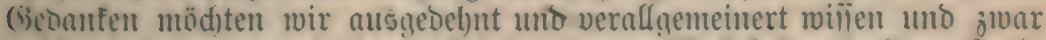
Dubiu, Dẩ fünttig überbaupt bei ber ganzen sibalofultur bahiu gejtrebt

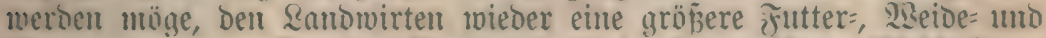

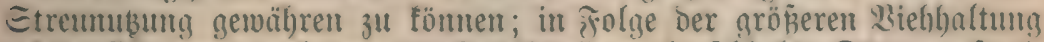

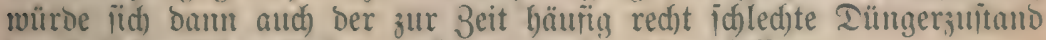
ber bofbäuerlid)en Felber nad) uno nad) wieder heliern.

Reil 3meifel fan barüber bejtehen, dab gerabe bie moserne, lebing= (id) auf 5oljerzeugung gerichtete Foritmirtichajt eine \$ierminderung Des

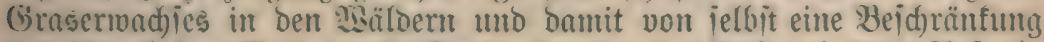
ber bäuerlidben Siseide= uno Grasmubutgen zur Folize hatte; Auinabe

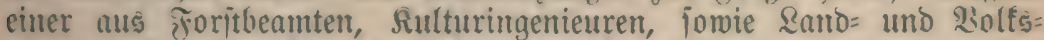
wirten sujammentzuescnden bejontoren Rommifïion wäre es, barïber

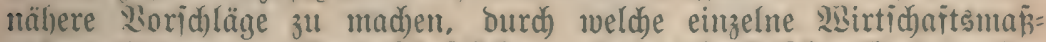
nabuen bas aus volfswirtichaftlid)en und jojialpolitij̄ben (Sründen ins

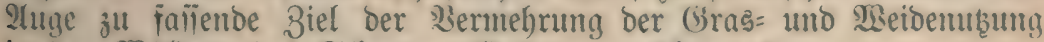

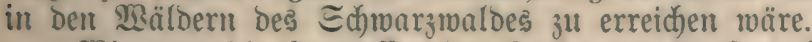

Mie man bie Snterelien ber Rand= und Forjtwirtidaft vereinigen fann, hiezu bietet aroß̉es ìntereije ein von bem Froritmeijter Bierau entmorfener Sulturplan, weldher anf bie beliere Bewirtichaftuna ber in

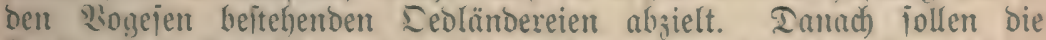

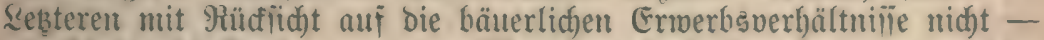
wie bish)er bäufig bei uns - vollitändig aufgeforitet, fonbern, wo bię ihre Sage irgeno gejtattet, burd) E(tupflanjen $5-6$ Wieter breiter

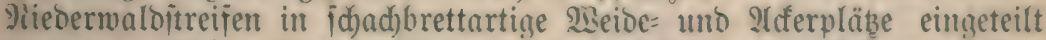

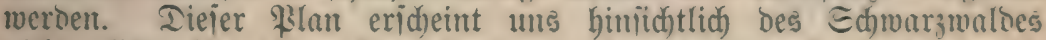
nidjt allein für bie nod) vorbandenen "Dedlänbereien", jonbern aud) für bie in ben lebten Jahrhumberten bereits aujgejoriteten 21 cfer= uno

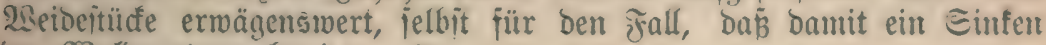
ber Balbernte verbunben wäre.

Soldje Gedanfen werben allerbings von allen benen von vornberein für verwerflid) erflärt wernen, weldhe von ber W(nïd)t aușnehen, bußs

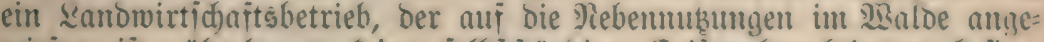

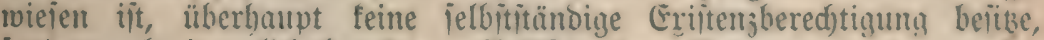
jonbern als interlich) franf unaupaltian bem llntergang entgegengebe.

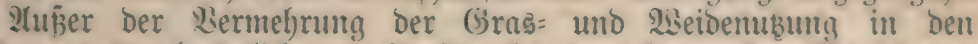

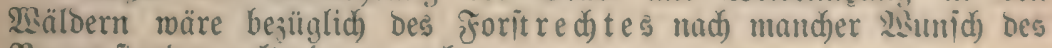
Bauernitandes gelteno zu madjen.

Sn $\$ 57$ jolg. Des joritgeiebes von 1833 ift heitimunt, baf feine Misobn= ober andere Gebümbe in einer Entjermung von wentiger als

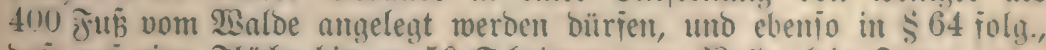

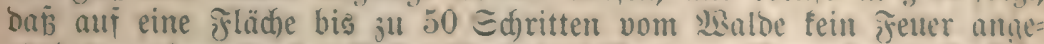
zündet werden Dari. Beide Pierbote bilden gemilïermatien geicklid)e

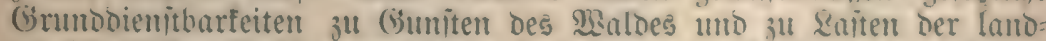

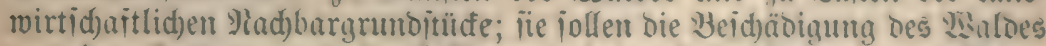
von ben sebeteren aus burd) jener und Durd) jorjtvergeben verbüten. 


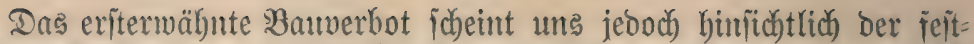

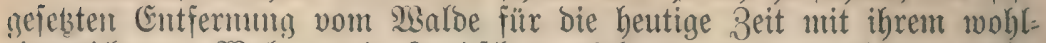

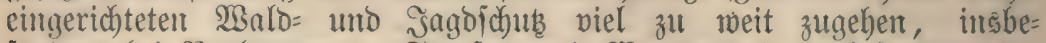

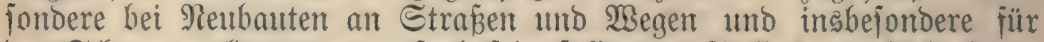
ben Echwarzmald, wo man froh iein jollte, an Stelle ber aufgejoriteten

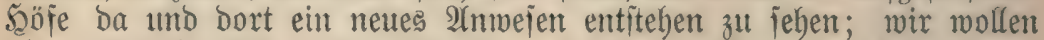
aber Gieranf nicht näher eingehen, jonbern ftellen uns bie Frage: warum hat man zwar zu Giuniten bes $\mathfrak{B a l b e s}$ folche Servituten ge=

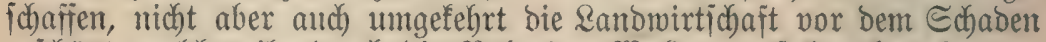

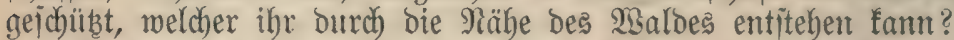

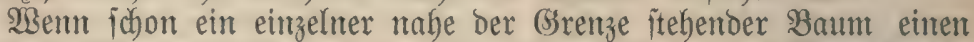

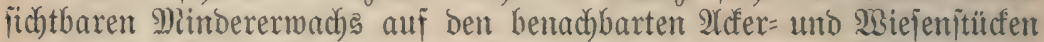
hervorrufen fant, fo fam bie Reutanlage eines ganzen 13 aldes unter

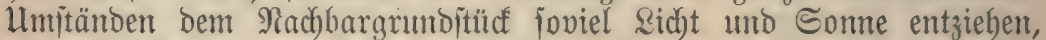

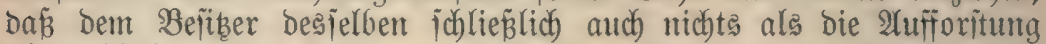
übrig bleibt. 2Sir fragen ung beshalf: wäre hier nticht ein Servitut zu Raiten bes Sisaldes und zu Guniten ber Ranomirtichajt am \$lake, ähnlid) wie fie umgefefrt in bem obenerwähnten Baunerbot uno Berbot

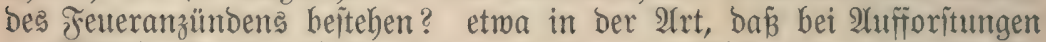

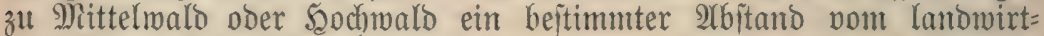

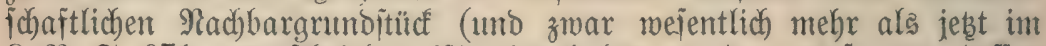

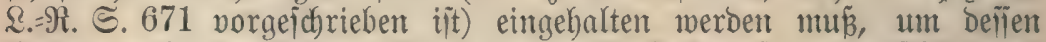

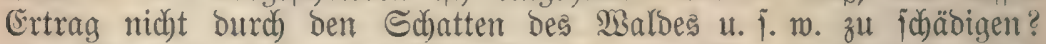

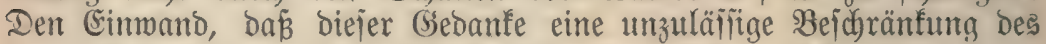

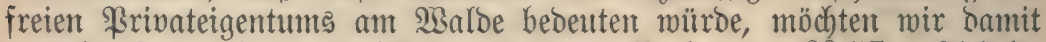
zurüctweijen, Dá̧ ja bie beiden ermähnten Berbote ber $\$ \S 57$ u. 64 folg.

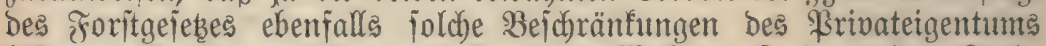
bilben, allerbings nicht zu Rajten bes $23 a l b e s$, jonbern ber Rand= wirtidafaft.

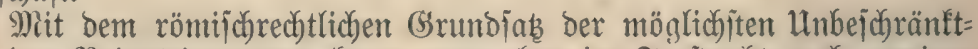
heit bes Srivateigentums farn man eben im Froritredgt noch wentiger als fonft ausfommen; bies lehrt uns aud ein anoerer (șegenitand, zu

Vied)t ber Frivatforit= 4. 23alowege. beffen Bejprectumg wir uns jebst wenden wollen, nämlich das $\Re$ ech $t$ Der Privatforit= uno $\mathfrak{B}$ aldwege. Ein bejonoeres Recht für bieje

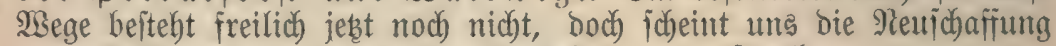
eines folchen einem bringenden Beoürijuis za entiprectben.

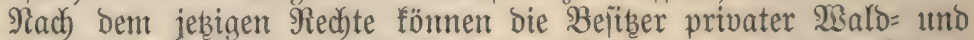
Foritmege das Begehen und Befahren Derielben gerabe jo verbieten,

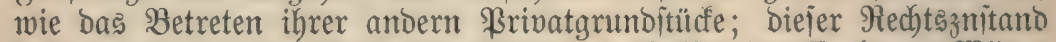

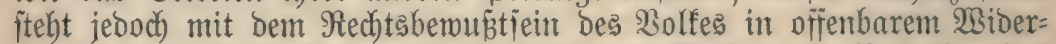
ipruch; Das Bolf hat gerabe bezüglich bes Waldes die Rezeption bes römifichen Rechtes am wenigiten anerfannt; es hat es nie begreifen

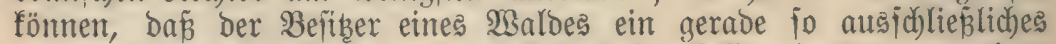
und unbeichränftes Redbt an bemielbeu haben jolle wie etroa an einer 5ofraithe oder gar an einem Fabrniżgegenitano. Alber nidht allein bas

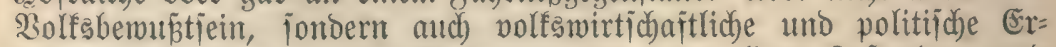
mägungen verlangen eine 2Aenberung bes bermaligen 3uftandes, uno

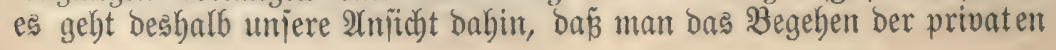




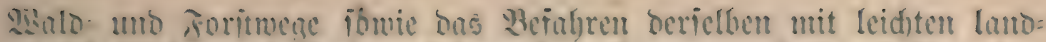

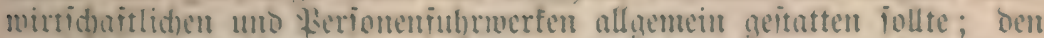

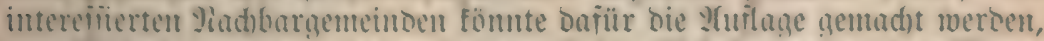

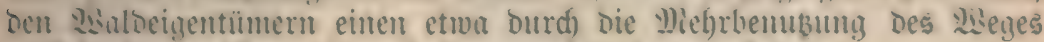

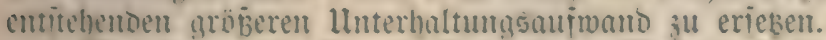

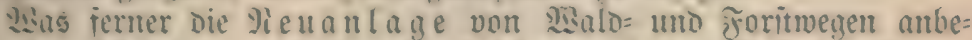

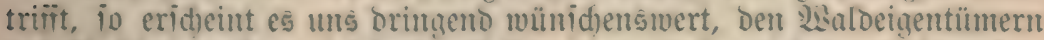

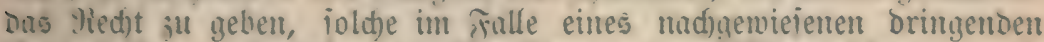
Redurintiles - woribber Der Besirfs̆rat su entidjeiden bätte - aud

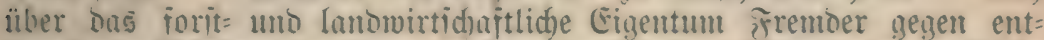

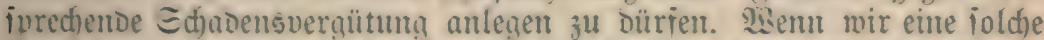

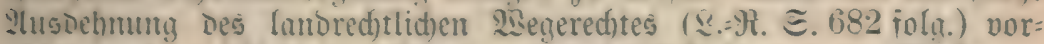

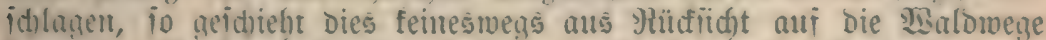

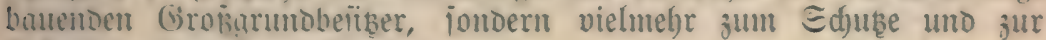
Erbaltung bes Bauernitanbes.

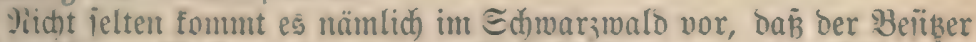

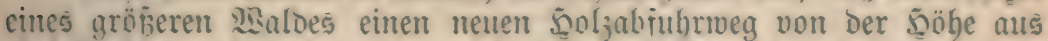

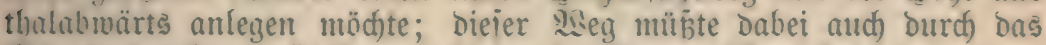
Eigentum mehrerer s.ofbauern hindurd) geben, welde jidh aber - itarr=

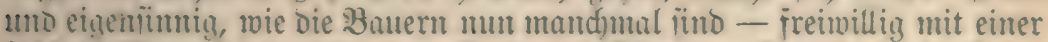
iold)en sienanlage nidgt cinveritanben erflären mollen, uno jo findet

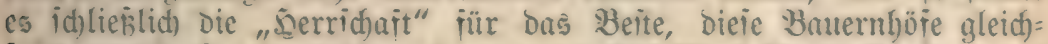

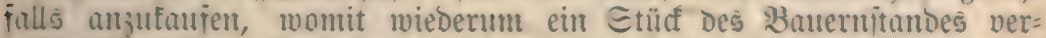
nidhtet iit. Ient Lerfaijer ijt ein Fall befannt, wo Das firojeft ber

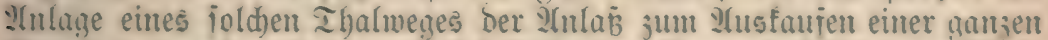
(Bemeinbe gegehen bat, meil fïh) fajt jeber Bauernthoi bis sum Ihale

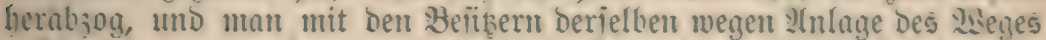
nid)t eimig werben fonte ober wollte. Fütte bie "Derrichaft" Damals

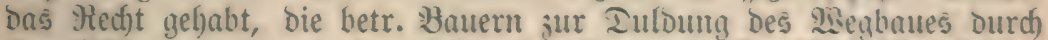

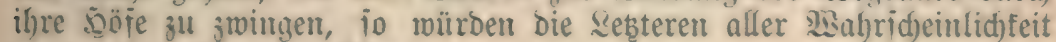
nad) audi jest nod beitehen.

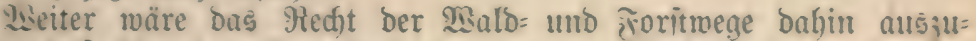
bifoen, Dab̉ bie eimual vorbanbenen priwaten sisulowege von Den Be=

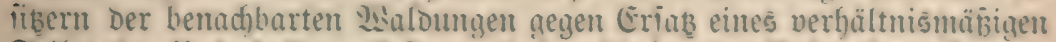

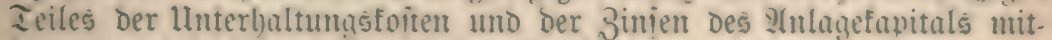

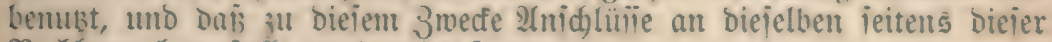
Radbarn bergeftellt werben burren.

Zluch biejer S:orid)lag bat lediglich die Erhaltung bes Bantern=

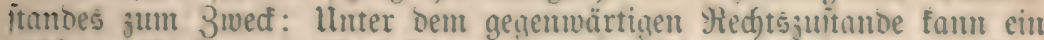

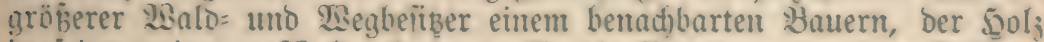
in ieinem eigenen $2 \mathrm{~s} a l d e$ banten mill, bie Bembung Der Dem Eriteren

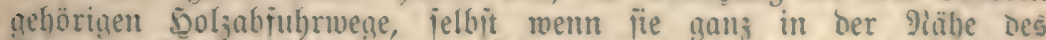
ibanermualdes vorbeizichen, unterianen, uno er hat jo ein fräitines

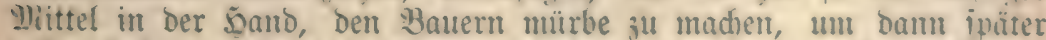

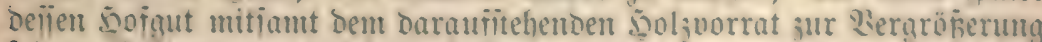

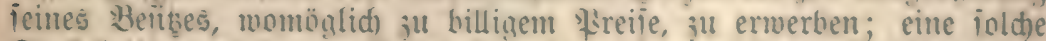
Epefulation mürbe gemiß Durd) uniern obenermähnten voridglag un= möglid gentadjt werbet. 


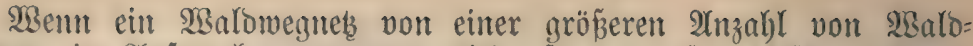
befibern in 2 (nfprud) genommen wirb, fo wäre für bicjen frall ge=

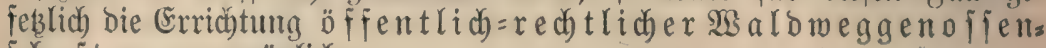
id aften zu ermöglichen.

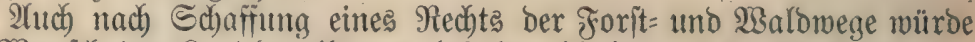

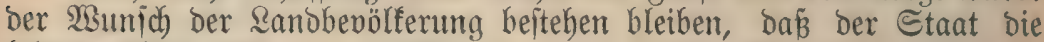
bebeutenditen und an meiten benubten biejer Frivatwege ganz in öffentliche Gemeintoe = Doer Rreismege ummandeln möge.

शewirtidiaf tung lleiner IIaIb = parzellen.

Ein meiterer von uns zu beiprechender \$unft fildet bie Eorge

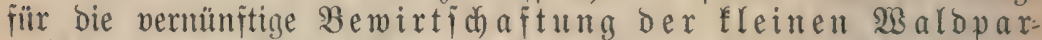
zellen; häırig ift bieje Bemirtichaftung jeitens ber bäuerlichen Befitber eine redbt foblechte, und es pflegt bies Daun vou bent Dumänenärar unto

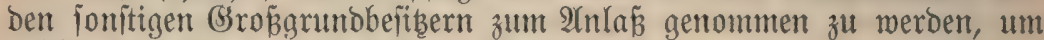
jolche Sarzellen - ber befleren Bewirtichaftung wegen, wie man jagt - zujammenzufaufen; Giermit ijt bem Bauernitano aber nicht gebolfen; im Gegenteil es ift ifm wieberum ein Stïc jeines I Tätigfeits= uno Rebenggebietes entzogen.

Die zeriplitterten Eigentuntsverbältnifie am 2 ald find mut in

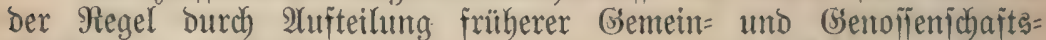
Waldungen entitander, indem man von ber Sorausjekung ausging, ber Einzelne werbe jeinen Anteil am beften bewirtichaften, went er allein über benfelben zu verfïgen hake; aud beitand ja bisher für ben

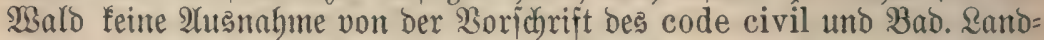

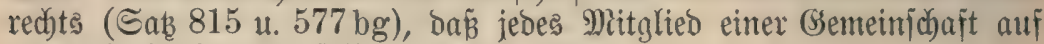
naturale Ieilung berielben bringen fann.

Die ermäbnte Sorausjebung ift mun aflerbings nidyt eingetrofien

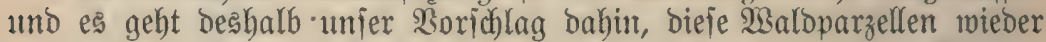
zu gemeinjamer Bemirtichaftung zujammenzufafien, mit andern 18 orten, wir möd)ten, um biejelben bem Banternitand zu erhalten, die Erlafilumg

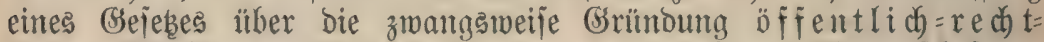

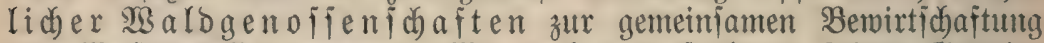
von 2 Galloparzellen anregen. $W_{0}$ noch von früheren Beiten (Semein=

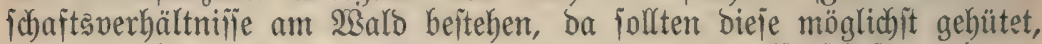
zugleid aber aud in moberne wohlgeoronete Genofienjidjaften überge=

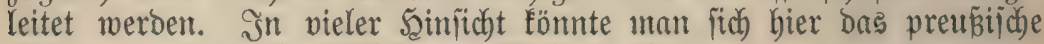
Gejeb vom.6. Suli 1875 zum Muiter nehmen.

Der Errwägung wert idbeint e马, ob man nidjt ben Mitgliebern joldher sBalogenofienjhaften, jofern fie Bauern füt, bei Berfäufen von

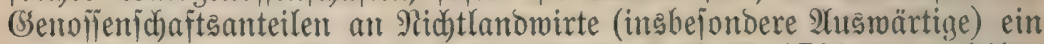

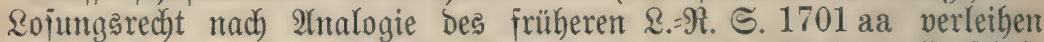

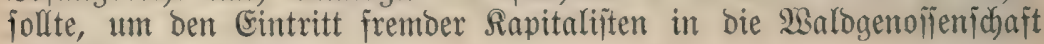
möglichit zu erjobreren.

Inlage von Etanweiern itt bent Gebirgs= gegenben.

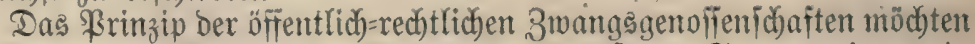

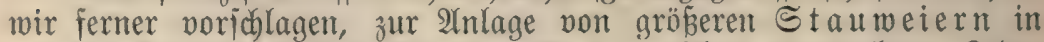
ben Suellengebieten bes Edfwarzmaldes bienthar zu madhen. Seber Freund der Lanowirtichaft follte foldjen Unternebmungen jeine energijajte Unterftüßung angebeiben laijen und zwar nicht alfein beshalb, weil ba=

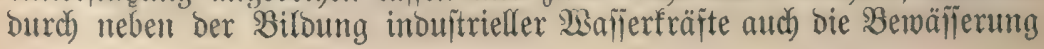


Der Iloulwicien helier cintuerid)tet werben fant, fonthern vor allem, weil

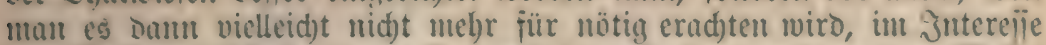

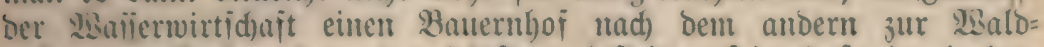
anlauge anjufaujen; benn bus bürfte unhejtritten jein, baß̃ ein einz̧iger

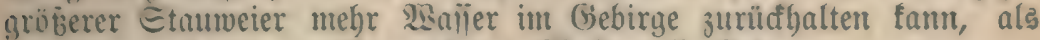

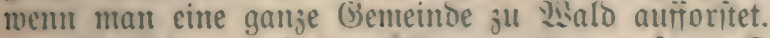

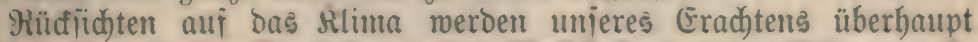

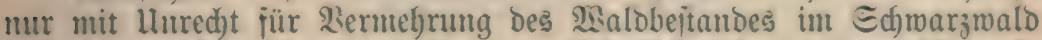

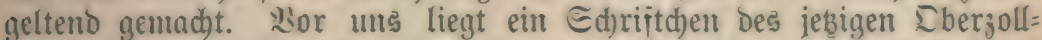
inipeftors uno früheren Ebereinnehmers und Domänenverwalters $\Omega$. (Sräfi

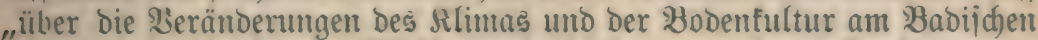
"Sherrhein", (Rarlsrube 1886), worin biejer - unjeres Eradhtens mit

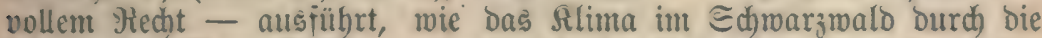

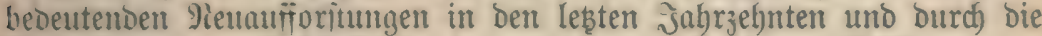

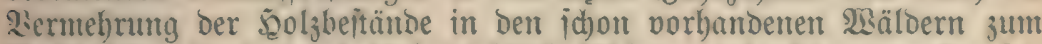

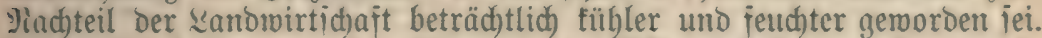

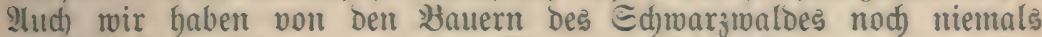

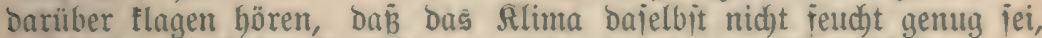
wohl aber, baj ber istribling in Folge bes langen 3uritubleibents bes હdnnees in den bebenteno pergröberten Saldungen immer ipäter ein-

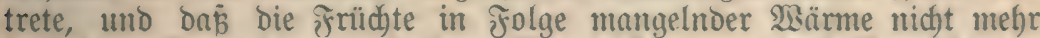
jo fidher reif mürbent wie frither. Misir müchten uns bešhalb vollitäntoig

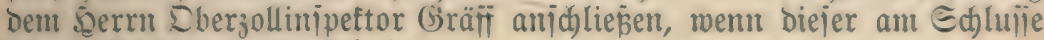
jeintes Büdjleins (ङ. 45) jagt:

,2

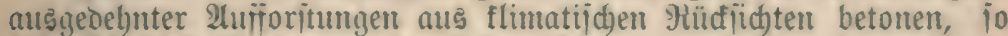

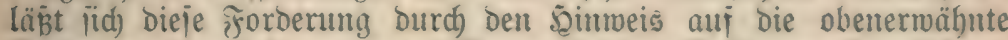

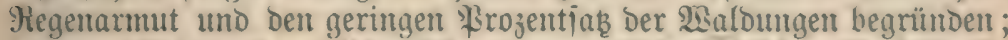
Dagegen jinto unjere jüboeutiden, namentlid) Babijden serbältniīe mit einem groben Ueberma

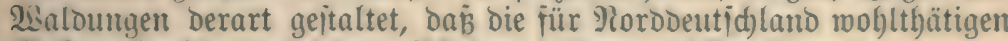
Wiabregeln Gier unbedingt Edjaben bringent muitien."

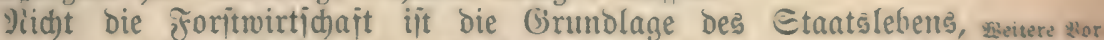

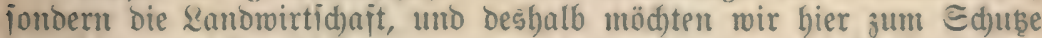

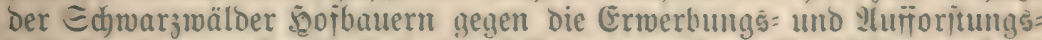
hejtrebungen mand)er F̧oritwirte nodh jolgenbe meiteren R'oridbläge mad)en :

Einnal jollte man zut Eridjwerumg Des 2luffaujes Ber Bdauern=

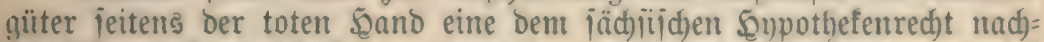

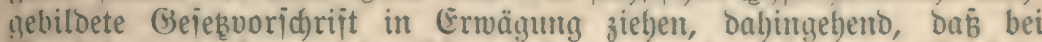

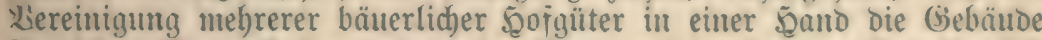
jür jebes (siut erbalten werbent muifien, wie and) jebes (Gut für jid)

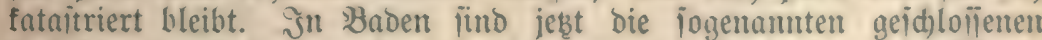

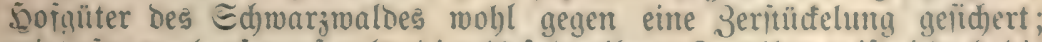
mindeitens ebenjogrok als bie (jejejabr ihrer Berteillmty ift jeood) bie

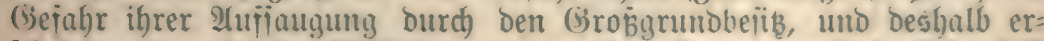

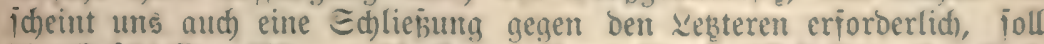

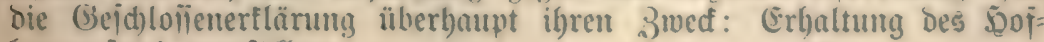
bauernitandes erfüllen.

đusือbnung bes 28 albes

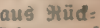
fid. ten aup bas Rlima. Ebuse des fropleatern: itanbes geqen

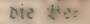
itrebansen jut Hitis= bebrung bes walbes 


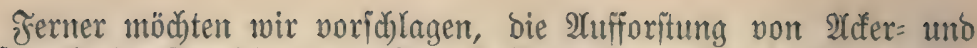

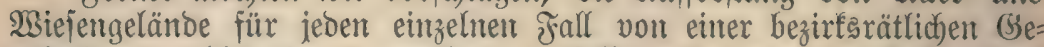
nefmigung abbängig zu machen; biefelthe wäre mur int Falle eitres

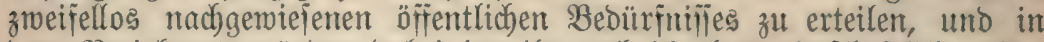

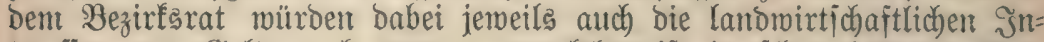
terefien zur Geltung fommen; ungefehrt ift ja fobon jebt zur 2(tus=

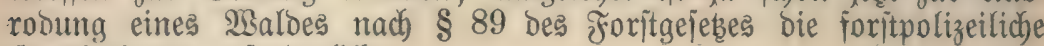
Genebmigung erforberlich.

Der Exrmäguna wert märe ferner ber Gébanfe, ber GSemeinbe für alle Berfäufe von Banernbäfen an bie tote Şand (mit Ausnafme von

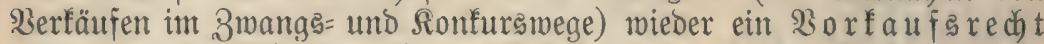

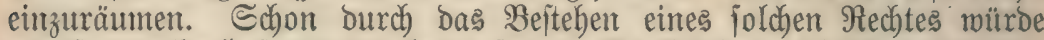

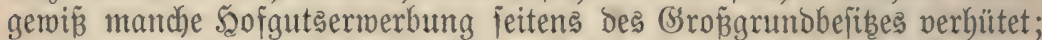
audi) wäre es im allgemeinen Sinterefife immerhin befier, bie Gemeinbe erwïrbe ein Sofgut, als basjelbe gebt an Den Staat, eine Stiftumg

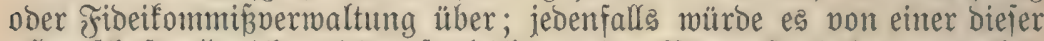

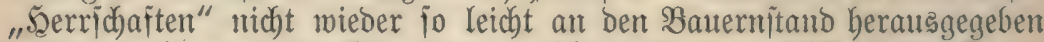
werben, als von ber (Şemeinde, welche boch das nächfte Sinterelie an Dem (Gebeiben ihrer Bürger hat und fich) bei ber (Gittsperwaltung ge=

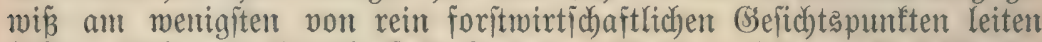

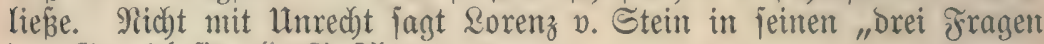
bes Grounbhefitkes", S. 35 :

,2iegt es nicht nahe, einmal banüber emithaft nadyzubenfen,

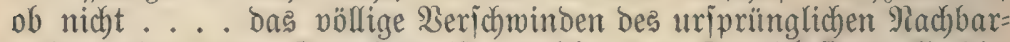

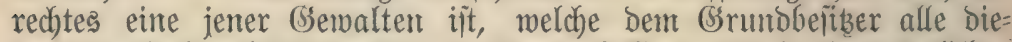
jentigen Erriftenzbebingungen in Frage jtellen, bie in Der örtlicken

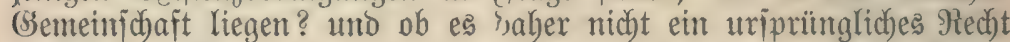
beritellen hieß̉e, menn man ber Gemeinde jentes alte Sorfanfsred)t wieber eitrräumt, gegenüber Dem Zwangs= wie bem freien Serfaufe."

3um Salluije biejes 26 fidnittes verweijen wir megen ber jonjtigen

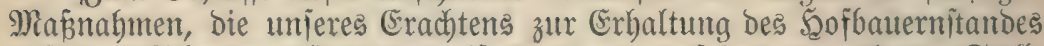
auf Dent Edjwarzmald zu ergreifen wären, auf Das an anderer Stelle Diejes Edriftchens (Beiagte: in eriter Sinte ericheint uns eine veränberte

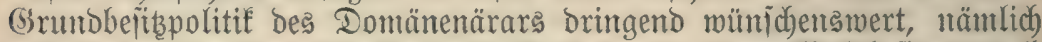

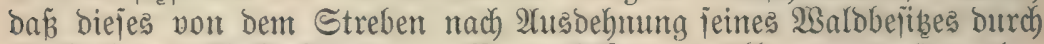

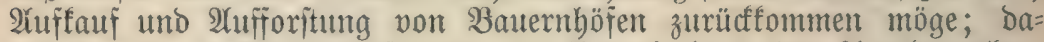
nebent wäre weiter insbejontoere bie Mengeitaltung bes 2Anerbenredtes in Betradft zu ziehen, um ber fteigenden Serichuldung Der 5ूofbautern entgegenzumirfen, utno ferner bie Erridytung eines ländlichen 5zypothefar=

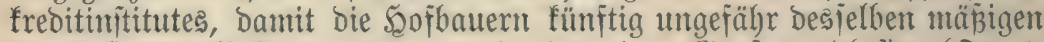

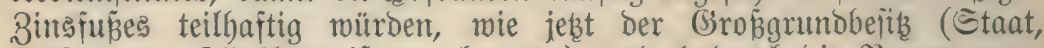
Etiftungen, Fibeifonumiß̄perwaltungen) und Daburd) bie Bevorzugung

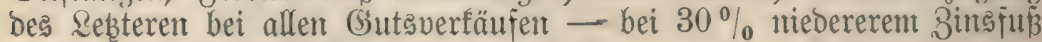
fant and eitr $30 \%$ Göberer Saufpreis geboten werben - bejeitigt wirtbe. 


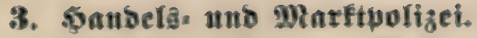

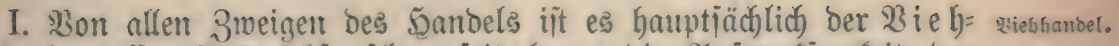

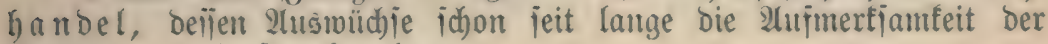
Segierung in 2 niprud nebmen.

jeber, der eimmal längere 3eit unter unjerm Rleinbauernitand gelebt hat, weiż, wie häü̈ig ber fleine Miann in Wiehbandel übervor=

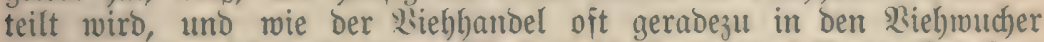

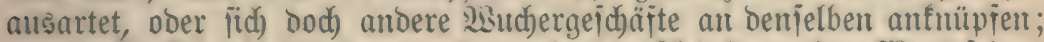

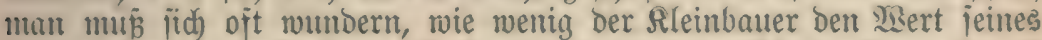
Silebes, Das er verfaufen will, femt, und wic er fid bariber oft erit

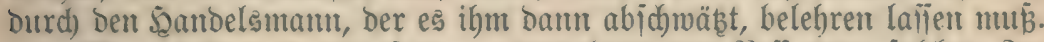

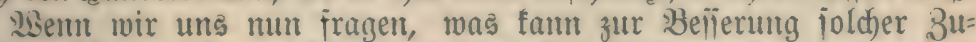

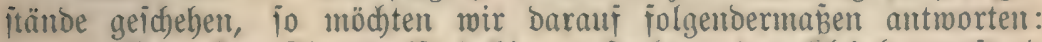

1. Wor allen Dingen ijt babin zu itreben, Den Rlembauerntand allgemein in Bildung und Charafter emporjubeben, bantit er jelbjt= ftänbiger mo mabbängiger in jeinen (biejchäten twerbe als bisher; aud)

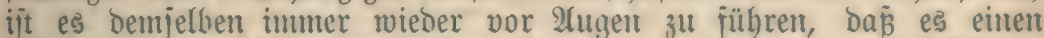
Berrat an jeinent Etandesgentolien bedeutet, went Jemtum cin Stüd Bieh, bas aud ein গlad)bar ober jontiger Befannter gern ermerben möd) zum jelben \$reis ober gar nod) billiger an einen Dandelsmann ver= äuBert, damit erjt biejer nod) jeinen Geminn Davon babe.

Tie Aleinbanern fund ferner inmer mieber barauf Ginzumeijen,

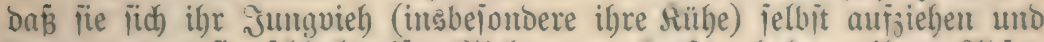

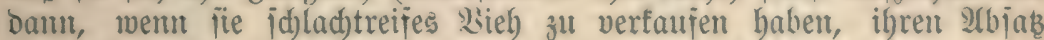

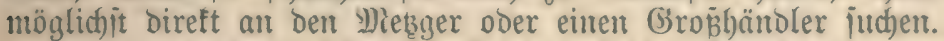

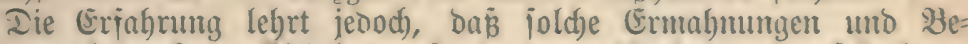
lebrungen bei unjerem Sleinbautermitand, wenu überbaupt, mur jebr lang= jan und allmählid) wirfen, un jo wiro bie Hegierung wobl audb bier mit

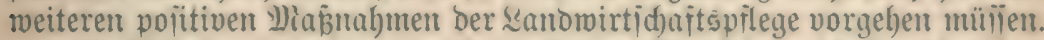

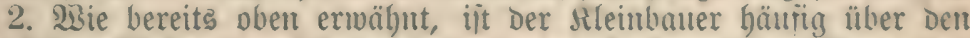
2bert jeines Biebes mur jebr ungenau unterrid)tet, und Der (ismo da= von liegt, abgeicben von Den bäuerlidben Charaftereigenjdgaiten, mieres

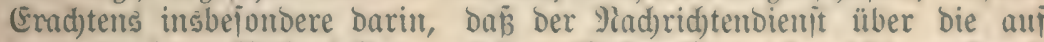

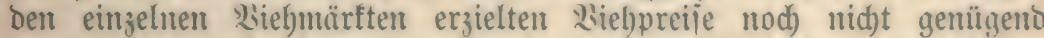
oryanijert ijt; bei bent einten Wartte swerden bie sielypreije nad) biejen, bei ben andern mieber nad) ganj anderen (innundäben Feitgeitellt, io

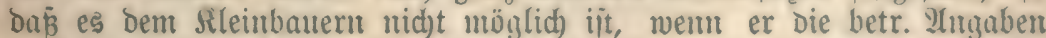
in der 3eitung liest, daraus fluy zu werden; es ijt deshalb bringento

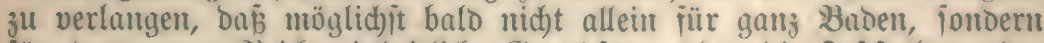

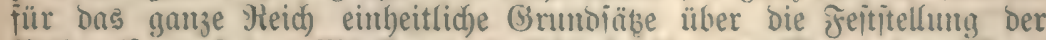
Siel)preije ani ben Diärtten uno Edblad)thöjen im siege einer öffent= liden Berorbnung aufgeitellt werbent. 


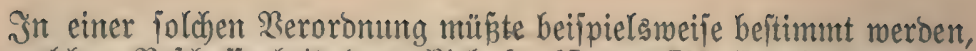
von weldyer Bejd)affentheit bas Bieh I., II. und III. Dualität zu jein

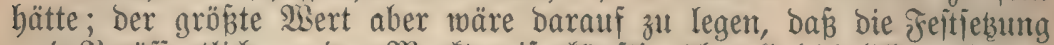
unto Seröfiffentlichung Der Marftpreije fünftig überall lesiglid) nad) Dem Zebend gewicht bes verfauften Biehes erfolgte, - wobei bie Berwiegung nad) einem Şungerzuitand von 10-12 Stunden zu geichehen hätte -

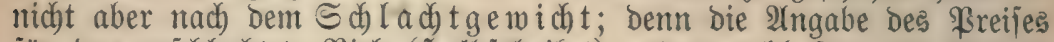

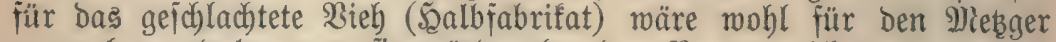
angenehnt und bequem; fie würbe aber ben SBauern nidets nüben, uno

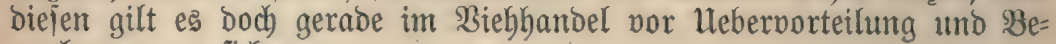
wutcherung zut fichern.

Die Preisfommififion, welder bie Alufgabe zufäme, bie an ben einzelnen Tagen wirflich) gezahlten Preife feitzuitellen uno baraus ben

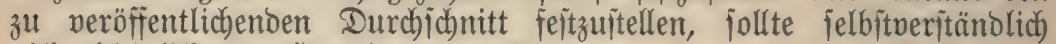

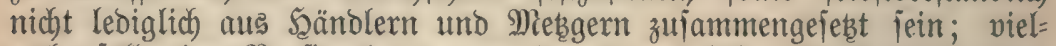
mehr jollte ber $\mathfrak{B}$ orifibende, wenn irgend möglidh, ein ftatlid) ange= ftellter Iierarzt jein, und es jollten ber Romunifition ebenjopiele Rano= wirte als 5̈ändler und Mebeger angehören; benn nur bann ijt eine umparteitiche Feititellung ber \$reiīe zu erwarten.

Sefr empiehlen würoe e马 fïd unter 2 Anderm aud einige Mebger für hohe \$reisfejtitellung zu interejifieren; fo fodwer bies im eriten 2lugenblidé erjocheinen möchte, fo fönnte es boch leicht in ber $23 e i f e$ ge=

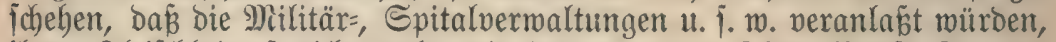

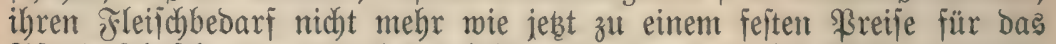

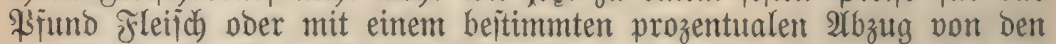
jetweiligen öffentlicten Flleifcdbetailpreijen zu vergeben, fonbern zu einem

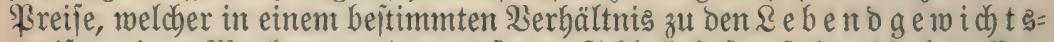
preifen eines Miarftortes ober größ̈eren Sajlachthofes fitht; bie betrefifen=

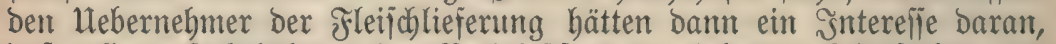

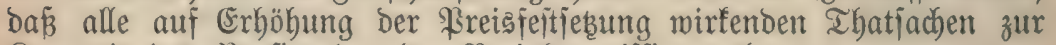

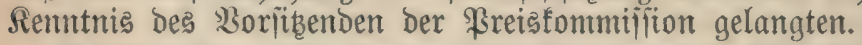

$\mathfrak{A} n$ merług: Wie übrigens bie Mebger burch bie $\mathfrak{B}$ ergebung ber Fleijc)= lieferunget feitens ber grö̈eren $\mathfrak{B}$ erwaltungen unter befinmten prozentualen $\mathfrak{A} b=$ zïgen gerabezu geztwungen werben, bie Detailpreife für das \$3ribatpublifum hod) zu balten, hat fich bet bem bom Stabtrat Freiburg bor einigen Monaten gegen bie

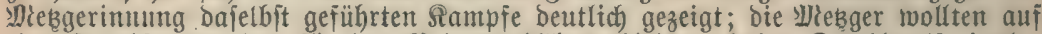
cine Şerabjebung der für bas \$ribatpublifum üblichen bohen Detailpreije inabe= fonbere beshalb nidht eingehen, weil fie bann infolge ber zugeftandenen prozen= tualen $\mathfrak{A b z u ̈ g e ~ a u d ~ b i e ~ F l e i j d ) p r e i j e ~ f u ̈ r ~ b i e ~ g r o ̈ B e r e n ~ ß e r w a l t u n g e n , ~ b i e ~ i h n e n ~}$

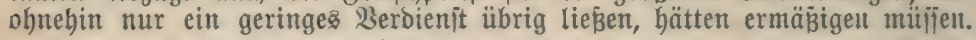

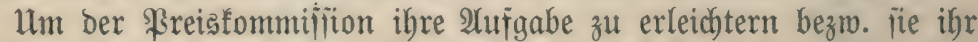
üherhautpt erit zu ermöglichen, jollte jebem Miarftbejucher bezw. jebem Das Schlachthaus benukenten Mekger bie wahrheitsgemäß̈e 21ngabe ber be= treffenden Biehpreife nach) Rebentogewicht zur 2luflage gentad)t werben,

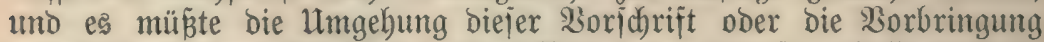
wabrheitswioriger $2(n g a b e n$ ausbrüđflich) unter Strafe geitellt werben,

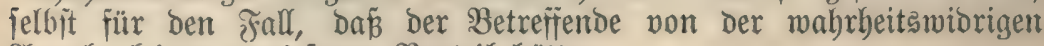
2ntrgabe feinen erwiejenten $\mathfrak{B}$ orteil bätte.

3. Damit ein Baner fich ben $\mathfrak{B e r t}$ eines Stücfes $\mathfrak{B i e h}$ beredynen 
faum, muti ifm vor allem (abgeiehen etwa non Rühen) bas Sebents= nemidht Desielben befant jein; es jollten beshalb die Bürgermeiter=

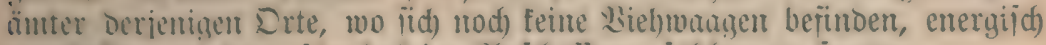

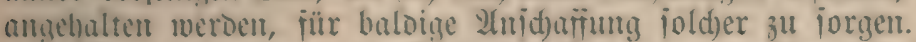

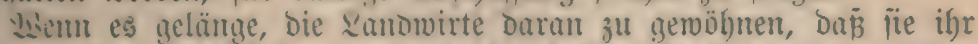

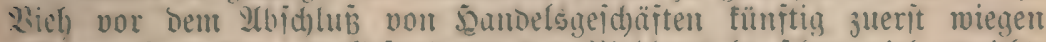

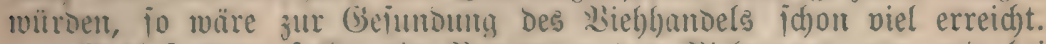

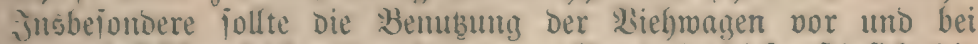

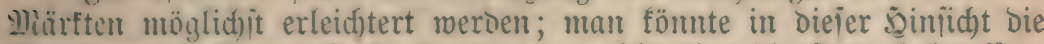

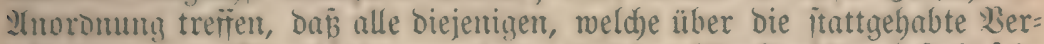

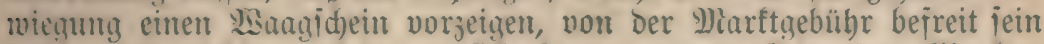
follen. (Empiehten würde es lid) Ferner, gegen Entoe Des Diarttes

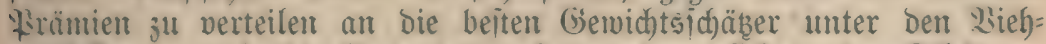

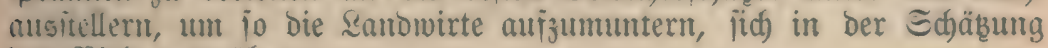
Des Siehes zu über.

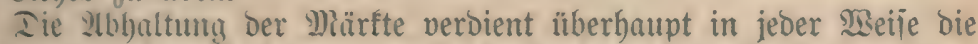
Itnteritübutg Der Plegierung, weil bie Ranomirte burd) fie in Etanto

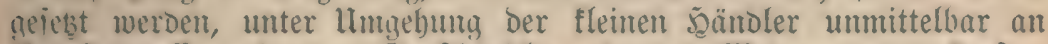

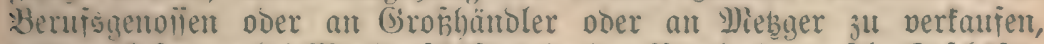

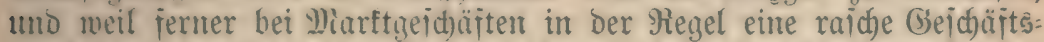

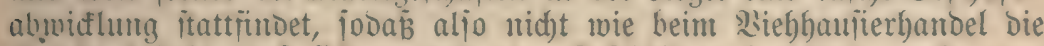

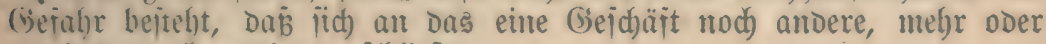
weniger wuderartige anjobliéen.

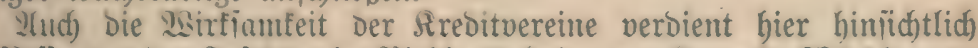
Der Befierung ber Buitünde im Siefhandel eine anerfentende Dem Dndurd) Daß̉ jie Den Banern Die Whittel voritrecten, ein notwendig

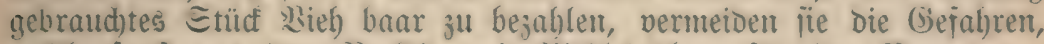

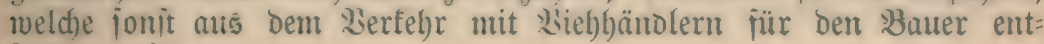
ipringen fönnen.

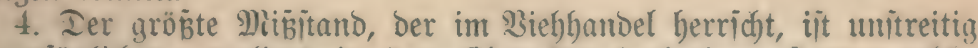
ein periönlicjer; er liegt in Dem Eforafter Derjenigen Sente, weldye

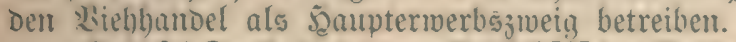

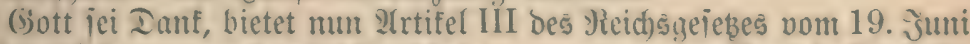

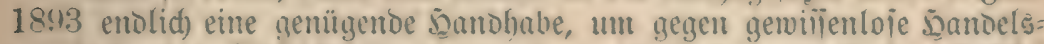
gebräud)e Der Skiehgänoler vorjugehen; Durd) Den erwäbnten Irtifel

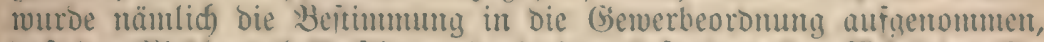

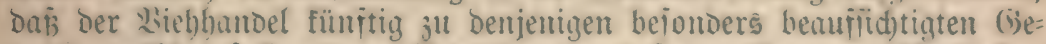
werben zäblen ioll, "Deren Betrieb 3u unteriagen it, wenn Thatiadjen

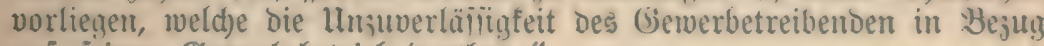
auf jeinen Gemerbebetrieb barthun."

Misohlgenterft! nidjt etwa eine Beitrajung wegen Diebitahles, Be=

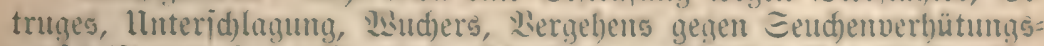
vorid)riften u. i. w. iit erjoroerlid), iontern lediglid) Bemeiie Der lin=

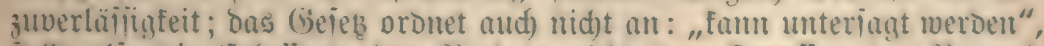

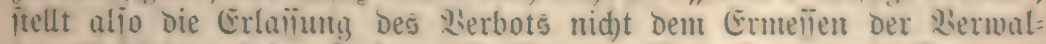

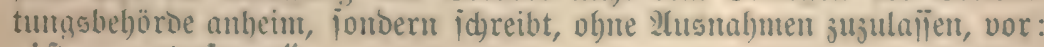
"i it zll unteriagen".

Jut Jntereile ber sanbovirtidajt idjeint uns mun eine entergijde 


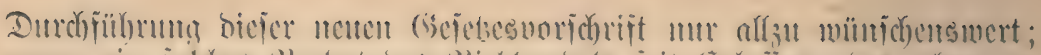

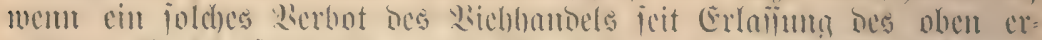

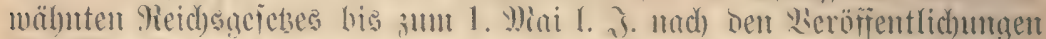

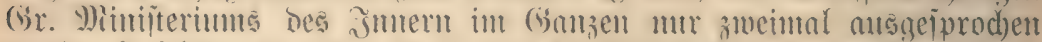

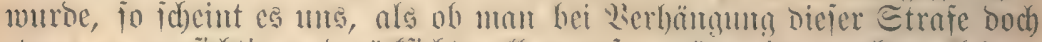

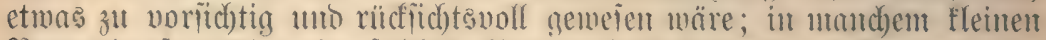

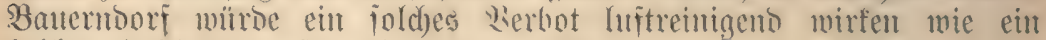
fübles Gewitter in idjwiller Sommerhibe.

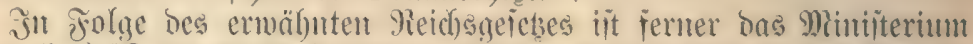

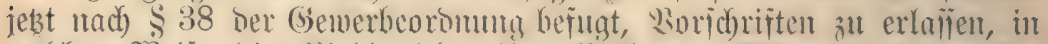

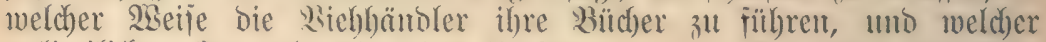

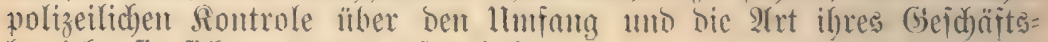
hetriebs fie fich zul unterwerfen haben.

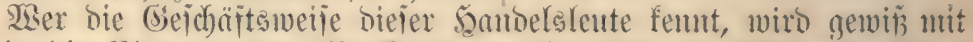

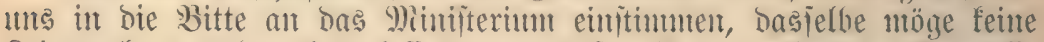

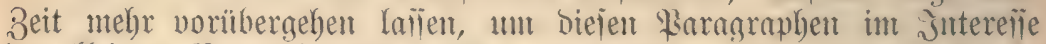
Des fleinen Banternitandes gehörig auszumben uno jo ben sieb= handel uter die gejeblid) zuläjige, leiber jo febr not=

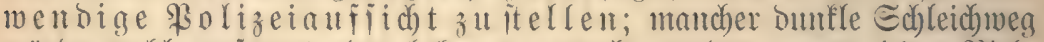

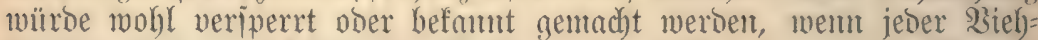

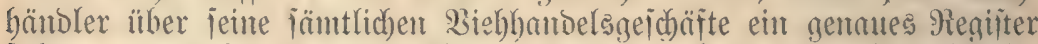
fübren und diejes in renelntäbigen Ierminen (nid)t etma blos bei be=

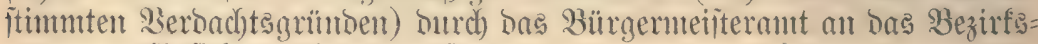
ant zur einficbt vorlegen müß̈te.

5. Bon allen Prten bes Riehhandels ijt bie Riehverfiellung (Biebverleibung) bie für ben Bamernitano gefäbrlichite; an verbreitet=

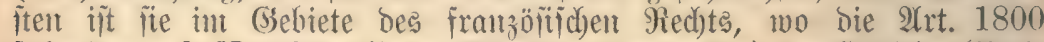
folg. bes code Napoleon (hezw. Babiichen Sambrechts) Den 5änoler (2Sieb=

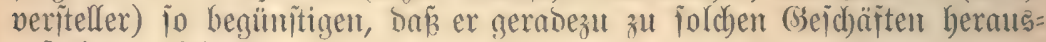
geforbert wirb.

In ber Miegel findet bie Rielyneritelfung burch ben Sänoler unter

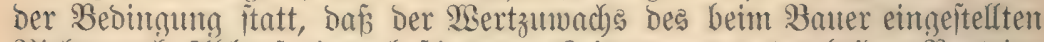

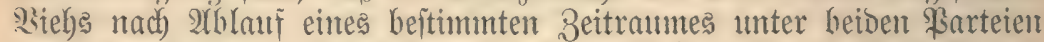
nad) einem gewiifien Serbältıis (z. B. Gälf̈tig) geteilt merbent inll; ber

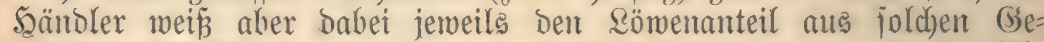

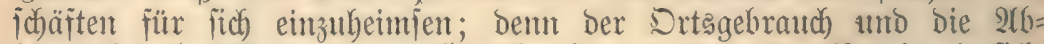

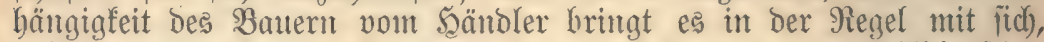

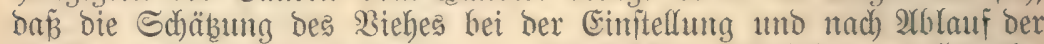

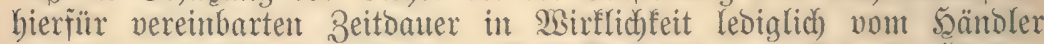

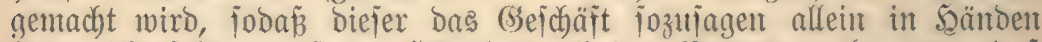

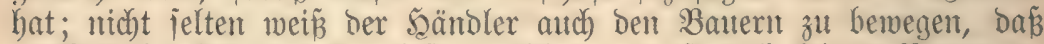

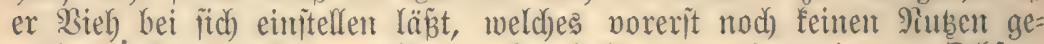

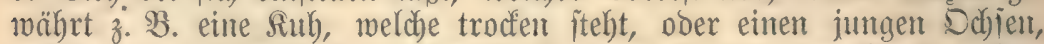

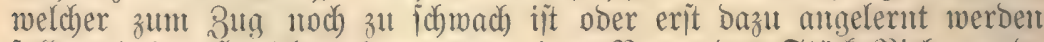

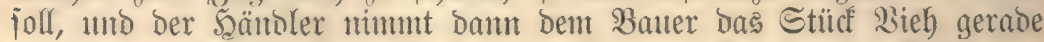

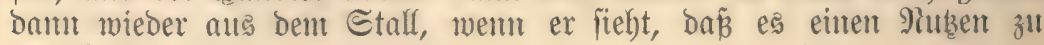
gewähren anfängt.

Sas gegen joldbe Miß̄itände geideben fönte, barüber jeien hier 


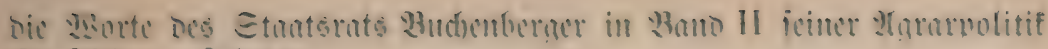
5. 226 antueintitst:

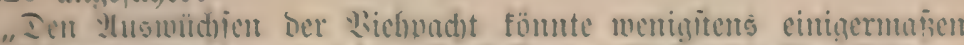

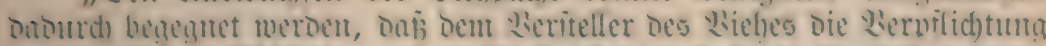

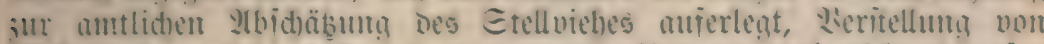

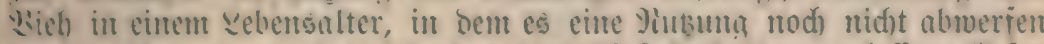

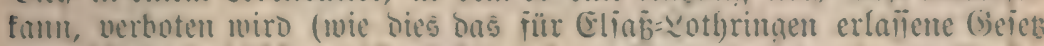

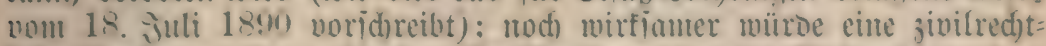

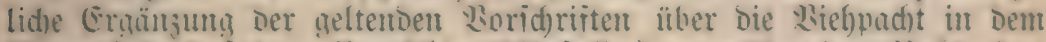

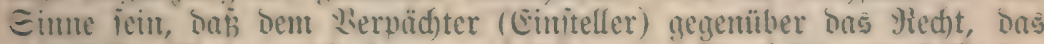

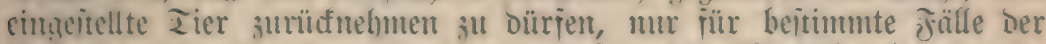

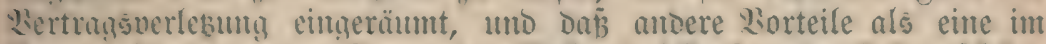

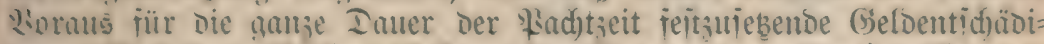

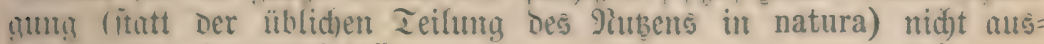
bebungen werben bürien."

II. TEem Der Baner in Bitehbandel of̈t im Rleinen übervorteift

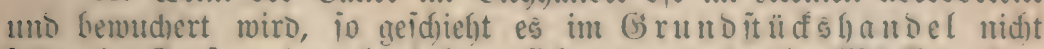

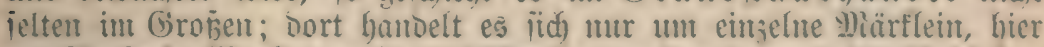

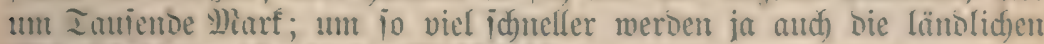

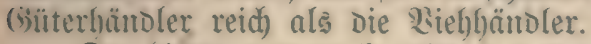

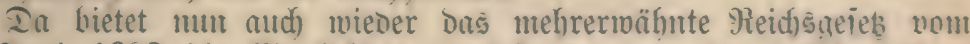

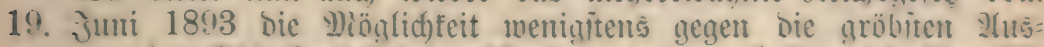

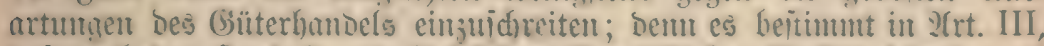

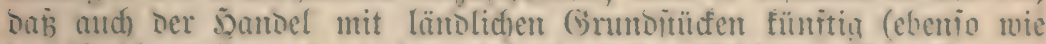

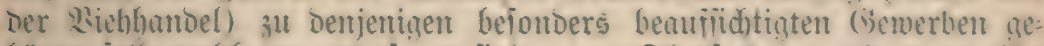
bören ioll, weldhe su unteriagen jün, wenn Ihatiatben vorliegen, meldes

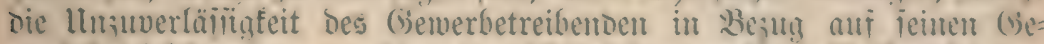

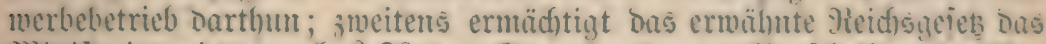

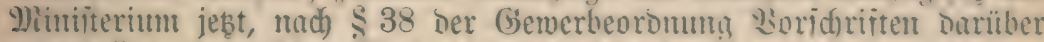

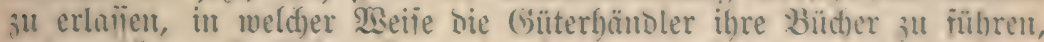

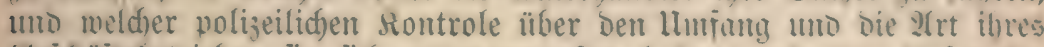

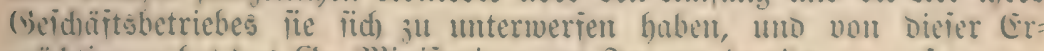

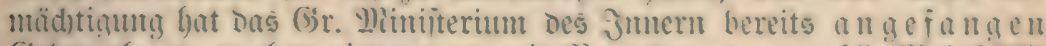
(isebrand) ju madjen, intom es mit veroromm wom 15. Whit 18\%.

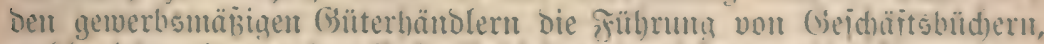

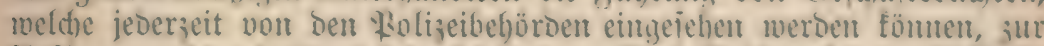

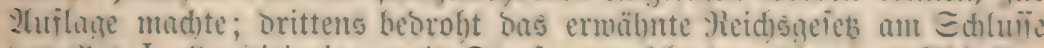

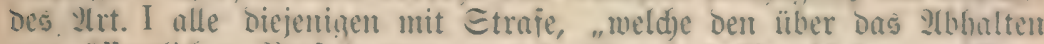

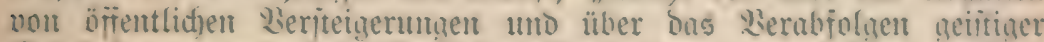
(Getrünte vor uno bei öftentlid)en sieriteigermugen erlailenten polizei= lid)en :Horomunen suviderbanoeln."

sebtere (isejebesbeitimmung follte unieres Eradtents unbedenflid)

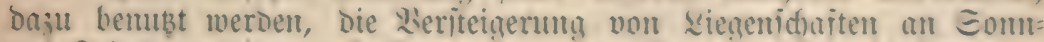

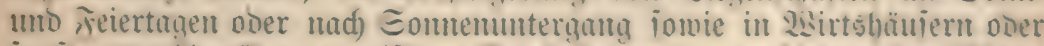

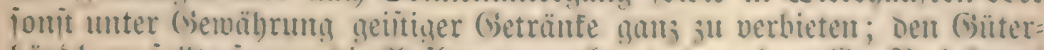

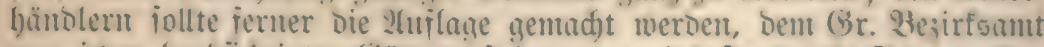

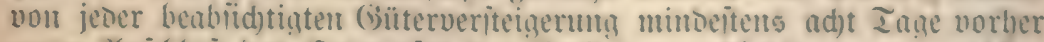

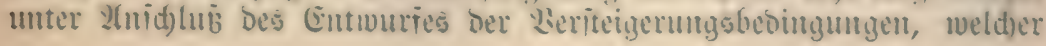




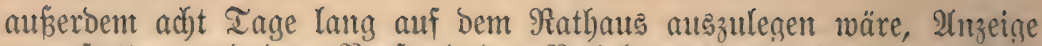
zul eritatten, und bem Boritand bes Bezirfsamts wäre bann Das Hecht einzuräumen, bei ber Beriteigerung jelbit zugegen zu jein ober fich) hierbei burd einen anberen Beanten vertreten zu laijen; bie vorgelegten Beriteigerungsbebingungen follten jeitents Des 3 ezirf'samtes jemeils einer gentauen Frifing und Durdjididt untermorfen werben, ob feine gegen Die Strafgejeßze oder gegen bie guten Sitten verítoß̈enden Bejtimmungen barin entbalten find. (Gejejäbe bies 2 trles, fo müroe es gewip nicht

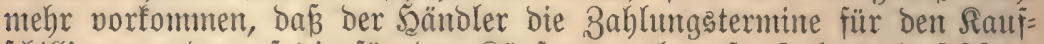
ichilling gerabe auf bie für ben Räufer ungelegenite Sabreszeit feitīest,

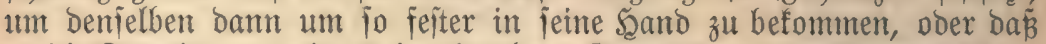
ex die Termine - wie es in einzelnen SSrenzorten vorgefommen ijt -

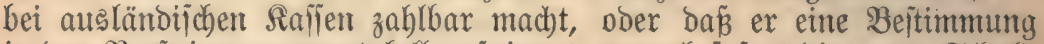
in bas 3eriteigerungsprotofoll aufninunt, wonad) fofort bie ganze Echuld ober gar nod) eine Sonventionalitraje bazu fällig merben poll, und bie biskerigen Ieilzahlungen als nidht geleijtet angejehen werben pollen, menn nur ein Iermin um ein paar Tage verjäumt wirb $4 . j$. w.

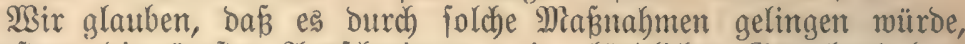

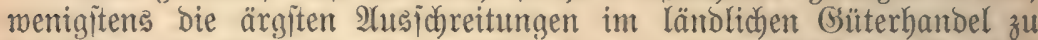
bejeitigen, zumal wenn man - wie roir in unjerem 2tbichnitt über bas

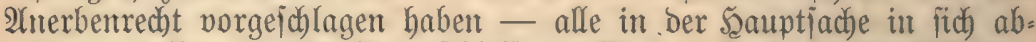

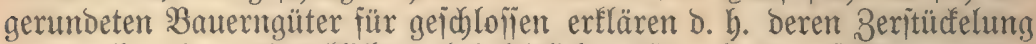
nur noch mit ausorücflicher obrigfeitlicher Erlaubnis gejtatten mürobe.

III. Inter ben Maannahmen, weldhe ergriffen werben fömten, um Den Rlagen ber sandwirte über zu geringe Gietreibepreije abzubelfen, verbient in eriter Rinie bie Reorganijation bes frudthandels (und Frudctabjazes) in nähere Ermägung gezogen zu merben.

Sis viel vollfommener ijt boch in IUmerifa ber Albjab bes Ge= treides organifiert als bei uns! 2ullerbings ijt bie volfsmirtichaitlicke

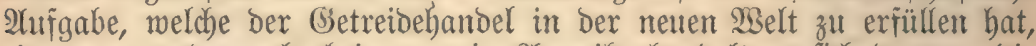
eine ganz andere als bei uns: in IImerifa handelt es fich barum, bie auf ben einzelnen Farmen erzeugten (Setreibemengen in einen einzigen grożen 2lusfugritrou zujammenzuleiten, welcher fïch bann von den europäif chen Einfubritellen aus auf bie veridfiebenen fionjumtionsgebiete verteilt; biejem Zwedfe find bie amerifanijhen Einrictungen bes (se= treibeabiakes (Elevatoren mit Reinigungmmaichinen, Bewertung bes Getreibes nad) Standarbmuftern, 2Uusftellnng von Setreibelagerideinten

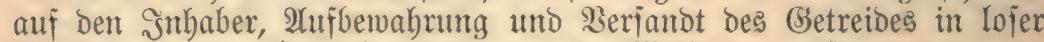

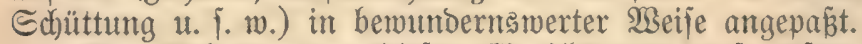

Eine Ulebertragung biejer Einrichtungen auf unjere Berbältnijie wird aber trobbem nidjt ohne \$Beiteres und in Bauja uno Bogen ftattfinden fömen: in Baben fönten eben bie Ranowirte nicht einmal

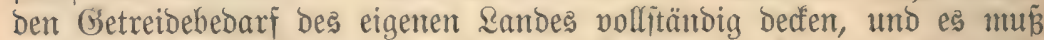
beshalb eine Einfultr von aupen her itattinton; ichon baraus geht hervor, Daß̄ eine Bentralifierung bes Frïchtehandels in einen einzigen Etrom mie in 2Umerifa bei ung nidjt am \$labe uno überbaupt nicht möglich ift.

Die \$erwaltung eines Ellevators würbe ferner bei uns mit bedentend 


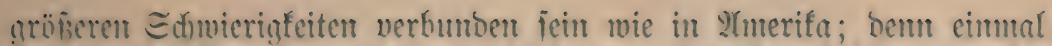

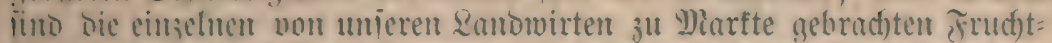

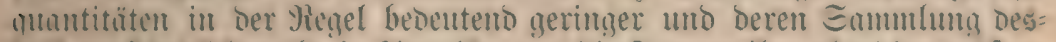
halb amitänolidjer als in 2tmerifa, wo bie Farmer ibre obnedies gröbere

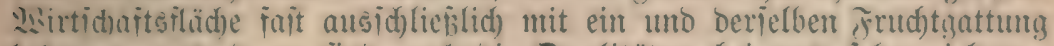

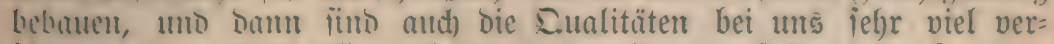
idficoenter als "brïben", weil Dort jeber fyurmer fait gerabe jo wirt=

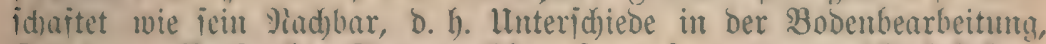

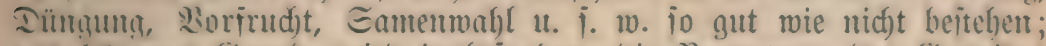

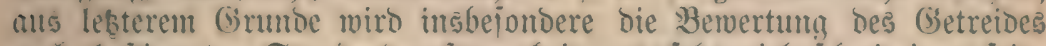
nad) lieitimmten Etandarbmutern bei um jebr viel idfmieriger jein.

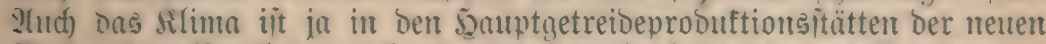
Widt allen Beridsten nad) ein anderes als bei uns; es ijt ein mebr fontinentales, uno Deshalb herrid)t zur Erntezeit in Der Pegel trocfene

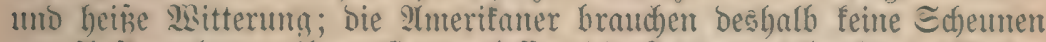
;ur Ifufhewabrumg ifrer Ente, lailen bie Sebtere vielmehr in Freien

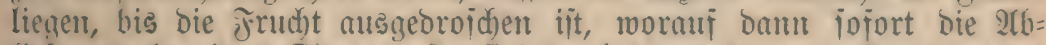
lieienung in einen Elevator itattrübet; bei ums Dagegen it wegen bes büutian regneriid)en Erntemetters bie Bemubutg von Ed)eunen (ins=

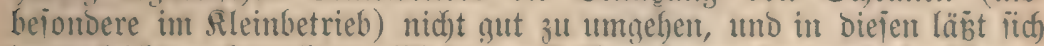

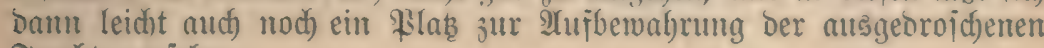
frudht vorieben.

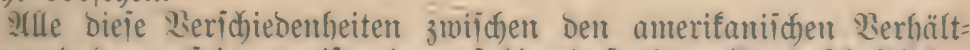

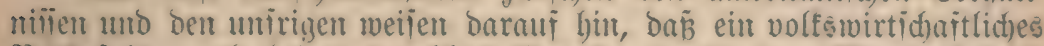
Beoürinis, aud) bei une alles Getreide Durd) einten (Elenatorbetrieb finturdgehen au lailen, feintesmege heiteht; aber andererieits iit es

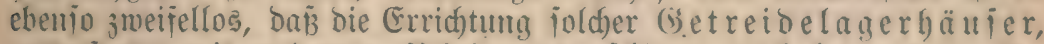

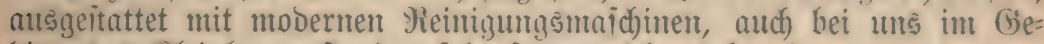
bicte des Rleintbauernitandes iehr iegensreid) wirfent fömte, unb zroar

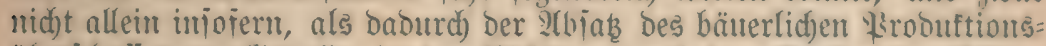
ïherid)uiles an (Śetreibe in Der Pridtung nad) Den Romiuntionsitütten

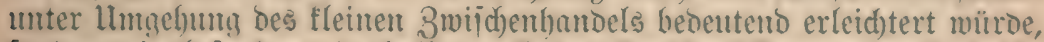

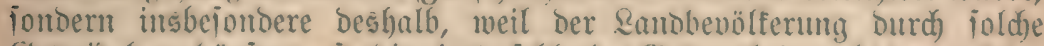
(isetreibelagerbänier erit bie jekst fehlembe (Belegenheit geboten mitroe,

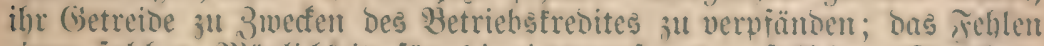
einter jold)en 9)iöglidffeit für bie jebt ieritreut auf fleinen Eveid)ern

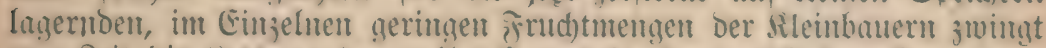
jutr Seit bie sebteren dazu, ifor Ergengnis furz nad) Der Ermte, wo iie ja bie meiten 3ablungsverpflichtumgen zu erpüllen hahen, зu jesent Preije Inşuidhlagen, uno es pileat bann gemöhnlid) ber (Setreibepreis chen wegen bicies eiligen Angebots bebentento berabingehen, un viel= leidgt erit ipäter, went bie Ernte non bem Zwija)enhandel aufgefunit iit, wicder $3^{\prime \prime}$ iteigen. Iie Erbaumg öffentlid)er (isetretbelagerhäuier wäre aber iicherlid) geeigntet, bierin zum Eegen unjeres Bamernitanbes

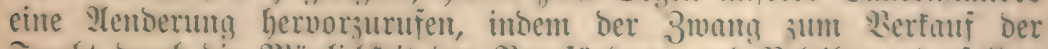

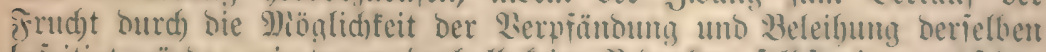
bejeitigt witrde; wir tragen beshalb feime Bedenfen, jelbit eine mä Bige Unteritüung jolder Eilobauten aus $\Xi$ tatsmitteln- 
etwa in berjelben $\mathfrak{B}$ eije, wie jebst ber Bau von Sofalbabnen unteritübt wiro - zu empfehlen.

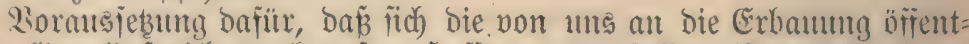
licher (Betreibejpeidjer gefinupten \$ofïmugen erfïllen, ijt es allerbintge,

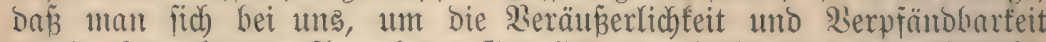

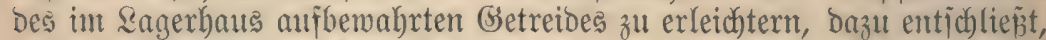

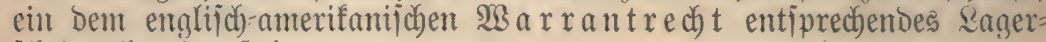
jocheinredtet einzufiuthren.

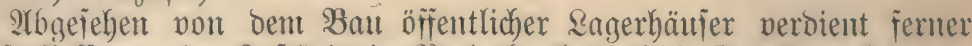

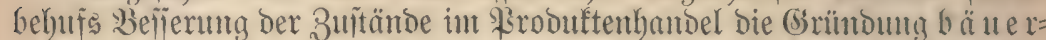

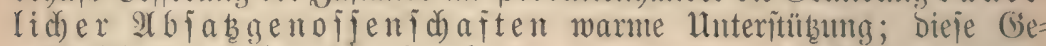
moliemichaften haben ben Bweck, ben Ranbwirt in ber Umgefuntg Des

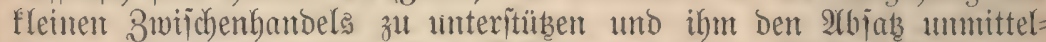
bar an Die (Setreideverbrautjer (Militärnermaltumg, Miülfer, Bierbrauer

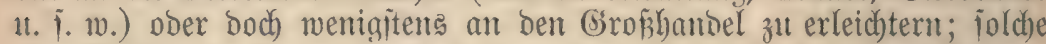
(Genolienichaften fömen inshejonbere bann Érfolg haben, menn fie mu forgfan gereinigtes und portiertes Betreide, wie es im Grophlyandel ge= wïnidat wiro, zu Marfte bringen.

Biel wäre ferner für unjere fleinen Sanbwirte erreidgt, wem auf̃

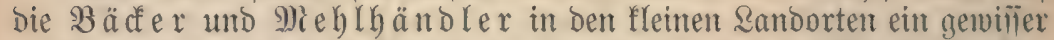

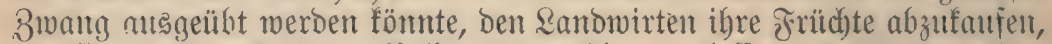

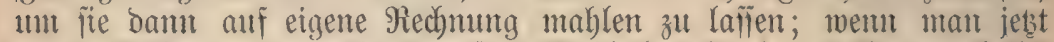
einen $\mathfrak{B a ̈ c f e r ~ f r a g t , ~ w o h e r ~ e r ~ j e i n ~ 9 ) i e h l ~ b e z i e g t , ~ j o ~ e r b a ̈ l t ~ m a n ~ i e l b i t ~}$

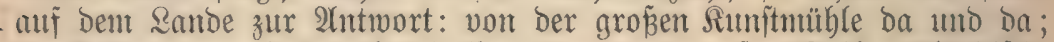
bie Rebtere verarbeitet aber bod wieder zum gropen Ieil auslänoifche

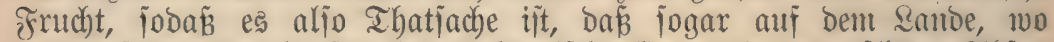

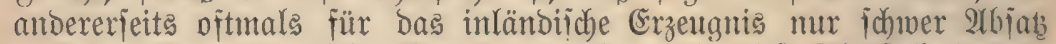
zu finden ijt, ausländiiches (Setreide verzebrt wiro; bieje Ifatjache brängt von jelfit zu bem Sorjoblag hin, allen Miïhlen bie Sermah)lung eines

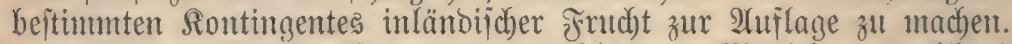

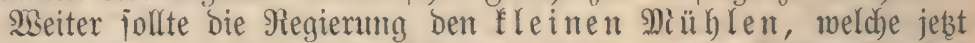
bent Untergang nabe zu jein icheinen, wieder mebr atifmerfianteit

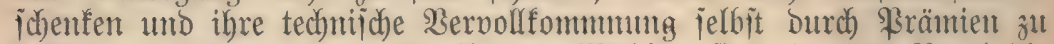
bef̈̈rbern juct)en; Denn bie fleinen Mïblen find in ber Fiegel bie ficheriten Albnefmer bes inländiichen Getreibes.

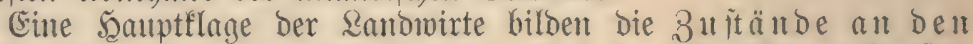

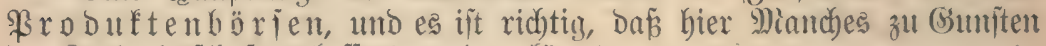
ber Ranbwirtichaft gebeffert merben fömute.

Bor allent jollte babin gejtrebt werben, bie jebt an den eirtzeluten Froduftenbörjen hejtehenben perjobiebenartigen "sörjeniliancen", weldhe

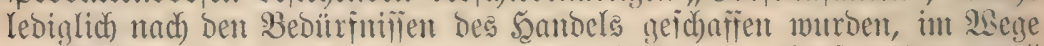
Des (iejebes ober ber Sierorommutg burd) gleichartige "Börjenorommtgen"

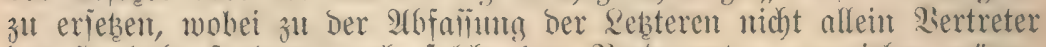

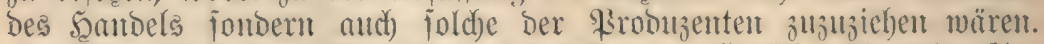

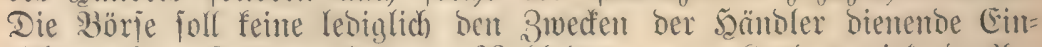

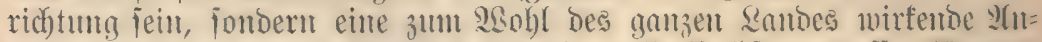
jtalt, wo fich bas reelle 2 fingebot mo bie reelle Siad)frage treffen fömten;

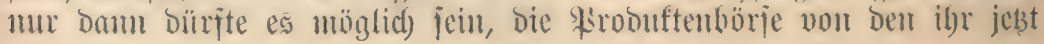




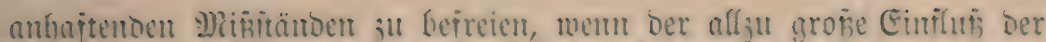

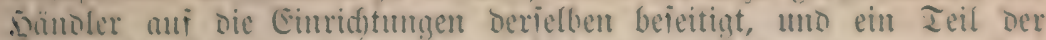

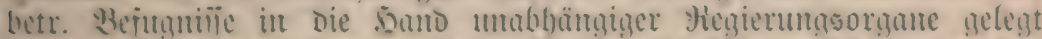

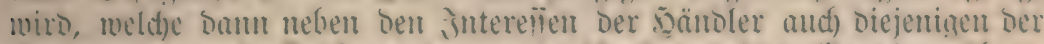

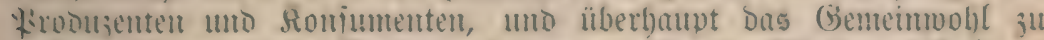

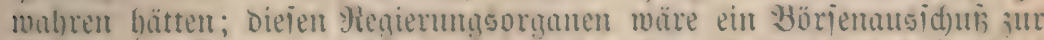
Ecite su itellen, in weld)en aber nidjt allein Nertreter des sandels

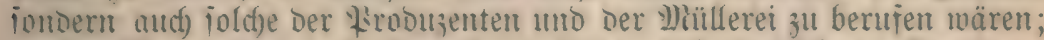

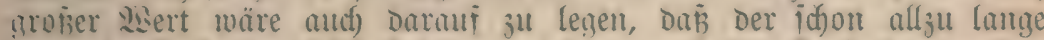

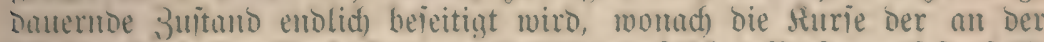

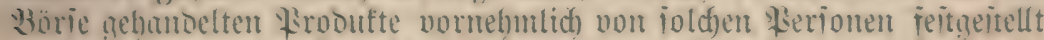

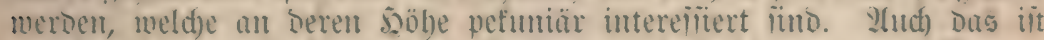

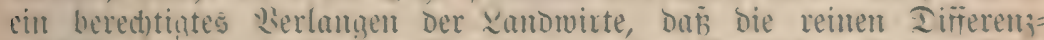

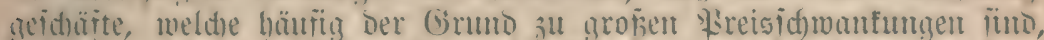

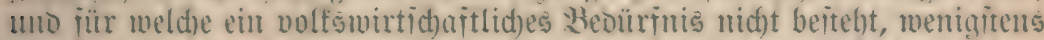

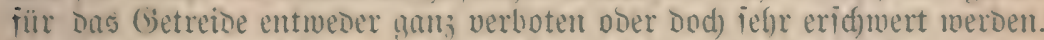

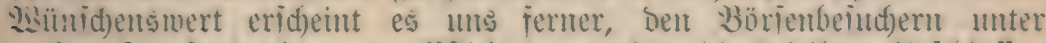

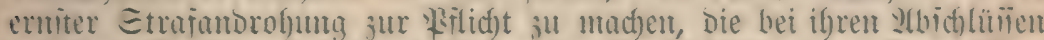

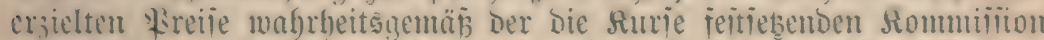

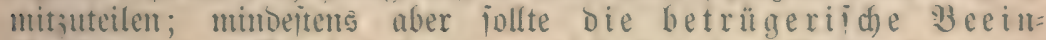
iluiiun a des Ruries landwirtidaftlider Frodufte unter

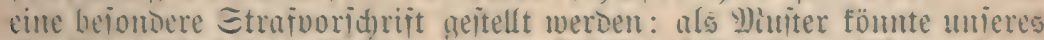

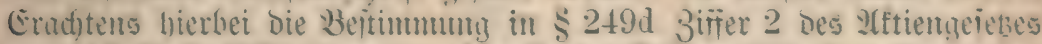

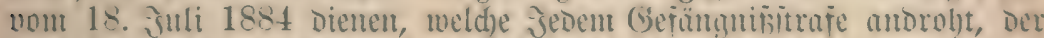

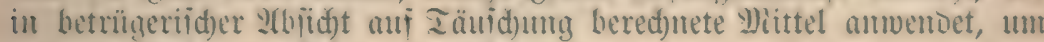
auj ben Surs von $\mathfrak{A}$ ftien cinzuwirfen.

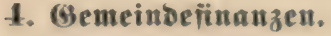

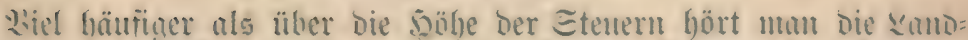

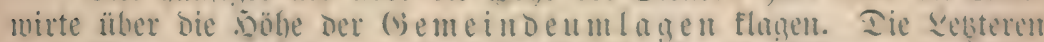

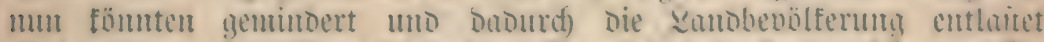

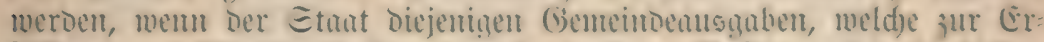

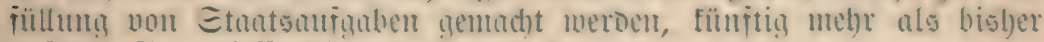
aur bie Stantafalie ïberuebuten witroe.

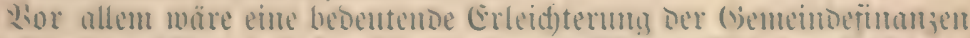

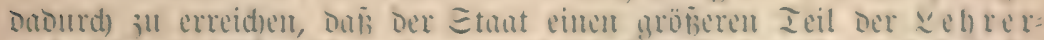

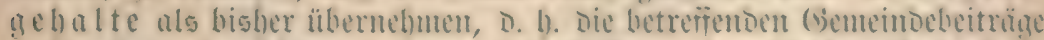

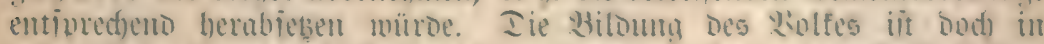

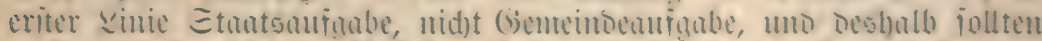

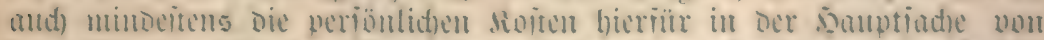

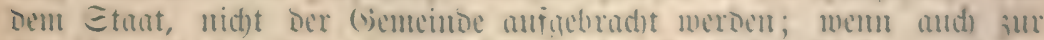

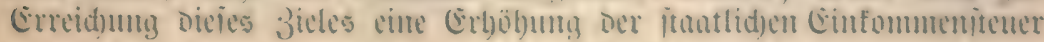




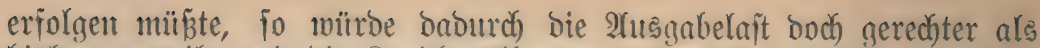
bisher verteilt and bie Ranbbenölferung wejentlic) entlaitet, weil eben bie Einfommenitenterfapitalien alif bem Ranbe verbältnismäß̈ig viel ge= ringer finto als in ben Stäbten.

Der Billigfeit würbe es ferner entipredten, ben Gemeinden jeitens Des Etants Entichäbigungen zu leijten, für bie Thätigfeit ber Ġe meindebeamten in ber Erfullung oon Etaatsanfaben.

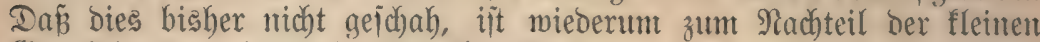
Gemeinden uno Damit ber Ranoheölferumg: in ben gröferen Gemeindent

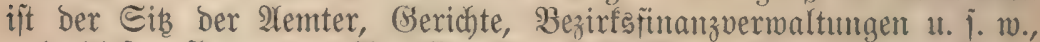

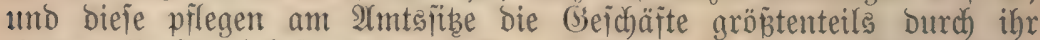
eigenes \$erional bejorgen zul laijen, währeno fie für bie fleinen Drte

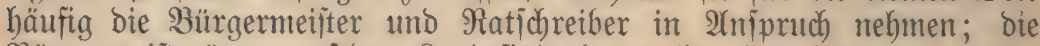
Bürgermeifterämter auf Dem Rano find eben nicht allein Drgane ber (Ge= meinbe=, jonbern aud Srgante ber Staatsvermaltung, mähreno bies in Den Etäoten, wo die Staatgftellen ifren Sit hahen, in viel geringerem Maßze bet Fall ift.

Da num ber Staat bis jebt bie Gsemeinden für bie Snaniprutd)= nahme ber Gemeindebeamten zu Etaatsgeichäiten nicht entichäbigt, iit

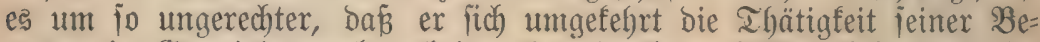
amten in Bemeindeangelegenheiten in einzelnen Fällen bejonbers be=

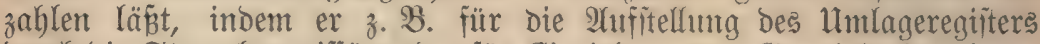
Durch bie Etenterfommiffäre ober für Einziehung von Gemeindeeinnahmen Durd) bie Steuererbeber (Umlagenad)träge, Sumbstaxanteile, Frorititraí= anteile u. 1. m.) bejondere Gebühren in Die Stantsfajle erhebt. Anderer= jeits it es jeboch danfbar anzuerfennen, da in in biejer Sinficht bejonders in Folge ber befannten 2Unträge, bie ber voritorbene Freiherr v. Sorn= itein=Bieningen 1. 3t. in Der eriten Rammer geitellt hat, in ben lebten Sabren bereits eine bedeutende Beflerung eingetreten ijt; jo werben jebst beipielsmcife nach $\$ 18$ ber Farrenichaunronuma vom 26. \$)iai 1890 menigitens bie Roften bes Sorfikenden ber Farrenichaufoumififion (bes Bezirfistierarztes) aus ber Staatsfaije beitritten uno in 2 trt. I Biif. II und VIII bes Sermaltuntggebührengejekes nom 15. Sunt 1894 murbe neueroings beitinmt, baß̄ in Ângelegenheiten ber Etantsaufiticht über Die Gemeinben Eporteln nidgt mehr erhoben merben jollen, und dá aud bie in joldjen Angelegenteiten an Beamte Des Bezinfenmts zu ge= währenden Dienitaufmantosentichäbigungen von ber Staats̆faje zu über=

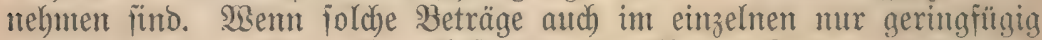
waren, fo waren fïe Dody insbejondere ben fleinen Ranbgemeinsen mit nur wenigen Taufend Marf Steuerfapital mohl füblhar, mäbrend fie andererjetts von ben Stabtgemeinden verbältnismäß̈ig viel jeltener in Inforberung zu bringen waren.

Sn Der Entlajtung ber Randgemeinden von foldhen in Einzelnen fleinen fojten jollte man aber noch meiter gehen als bisher unb ferner ut. 2 . noch) auf bie Etaatgfaije übernefunen: Die Gebühren ber beiden bäuer= licken Mitalieber ber Farrenichaufommifition, bie Roften ber Bor = und

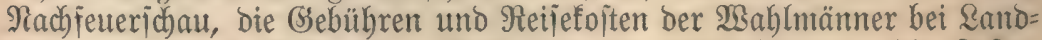
tagswahlen, bie Rojten ber $\mathfrak{M a} \tilde{\beta}=$ und Semichtsvifitation, bie Rojten 


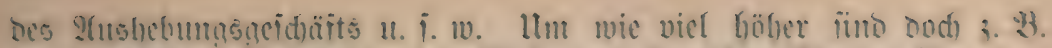

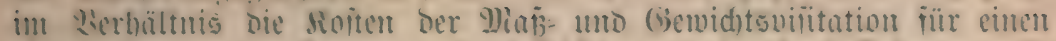
abuelegenen armen samDort mit vielleid)t zmei ober brei Rrëmern, als fir eine fleine ober größere Stabt!

Sur llebernabme ani die Etmatsfaile mürben fïd) fermer bie io=

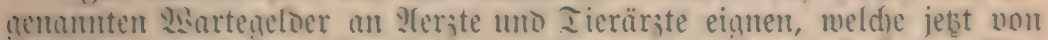
cinjelnen abgelegenen (isemeinon gejahlt merben, Die ionit feinen $\mathbb{A r} \mathrm{r}_{3} \mathrm{t}$ oner Iterarjt in erreidbure Viäbe befommen fömten; ehenjo ericheint

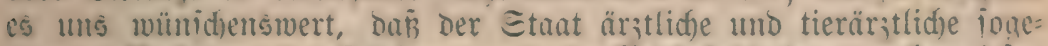
namte IIntòtage in Iöriern, wo ein Beburinis bazu nadgemicien wiro, cinrid)ten uno bie Roiten bafür anj bie Etantófaije übernebnten mödhte.

HInd Durd) Erhöhung Der itantlichen Iotationen an bie Sireiie und

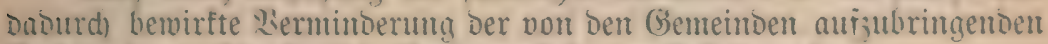
Rirets̆umlaụen fömten Die Eanogenteinden entlaitet meroen.

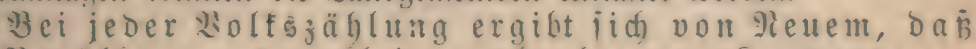
bie Bevölferung ber fleimen abgelegenen sanoorte su= rüdaeft, und eit hauptiäd)lides mittel, bieier be= banerliden Erideinung entgegenzuwirfen, ijt unieres (Eradtensebendie Entlaitung Der tleinensandgemeinden von allen benjelben nidt unbebingt zuzumeijenden \& $u s g a b e n$.

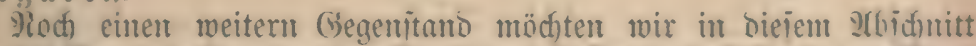

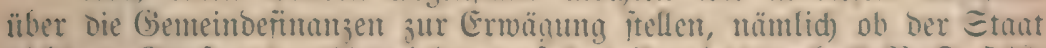

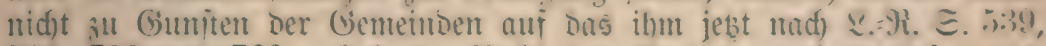

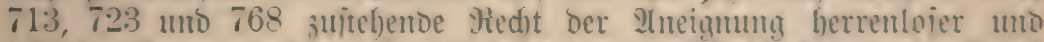

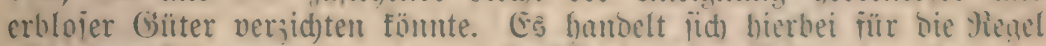

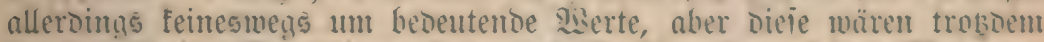
Den hetreffenten (Semeinoen als unverhorite Eimuhmen iehr willfommen, uno iie fönnten ban zu Dem einen ober Dent antorn gemeinmïsigen Bwede vermentiet werden, sit weldben man nidjt gerane llmlagen er:

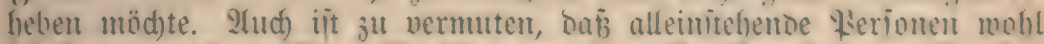

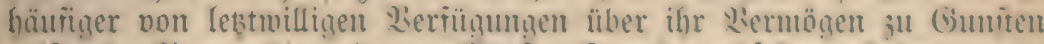
entiernter Nerwandter ober 3 (Sunten Fremoer abiehen müroen, wem

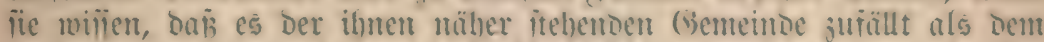
entienteren Ettuat; Dem Die 2Hthänglid)teit Der Bürrger an ihr (i)e= meinmeien it ond) hei Wielen bis ju einem gemiiten (Brnoe um io gröper,

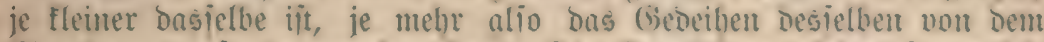
Einselnen empfunden merben fann. Die Gemeinden würoen fermer die Wermaltung ber berrenlos newordenten Siegenidajten, beren śaue uno

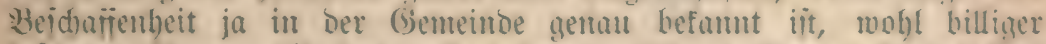
beiorgen fömen als Das mebr ober mentger entfernt gelegene Io: mänenamt.

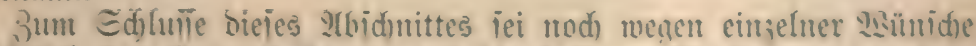

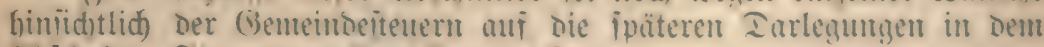
:lbid)nitt "Etuerverwaltuty" verwiejen. 


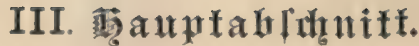

\section{Domänenverwaltung.}

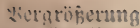
bes arorifónt

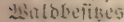
sutrut) :tutant und 2 ituffor: jtulti! von Bauetll= ๆütem.

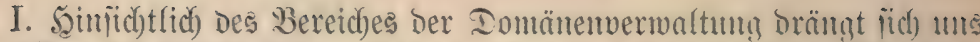
vor allem bie Frage ant: "Riegt es im allgemeinen Etaats= interefie und inbejondere im Suterefie bes buateru=

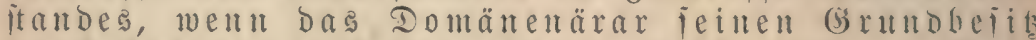

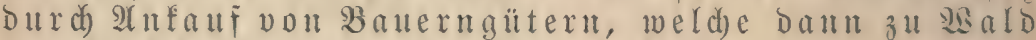
angelegt werden, ju vermebren jud t?"

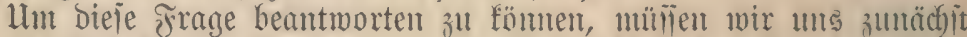
über bie Urjache ber bisherigen vielen Gintsantäufe bes Iontäutuärars ill ben lekten Sabrzelnten flar zu werben juchen uno zu biejent 3wecte

1) einte Beitummung Der in Der Scantiache aud jebt mod) gelten= Den Beroronung Der ehentaligen Direftion Der Foritbontänen แแb Berg= werfe vom 24. Juli 1846 itber bie Bejorgunty ber Santgeichäfte it 2Bald uno staloboden einer Bejprechung unterziehen.

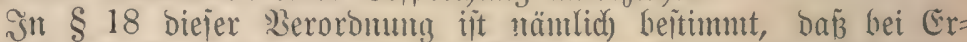

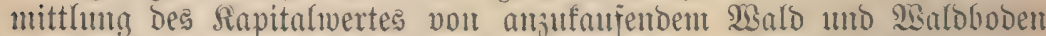
in Der Fiegel $3 \%$ Bins und $2 \%$ Binjeşits ju berechnen find.

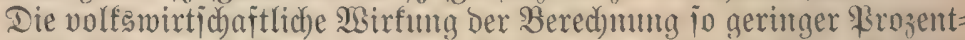

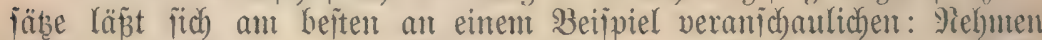
wir an, ein S3anterntgut int Edymarzwald mit zugebörigen fleinem SBalo habe bisher eiten jäbrlichen Reinertrag von 1500 Mlarf abgemorjen,

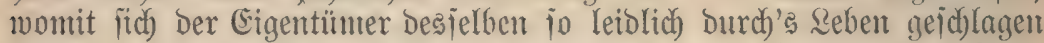
lätte; ans biejer Rente ergiebt jich unter Bugrunbelegung eines Bins= funes von $4 \%$ ein Rapitalwert Des Gittes für ben betr. Banter von 37500 Marf.

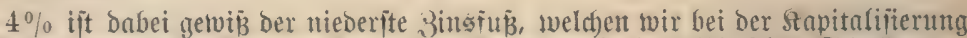

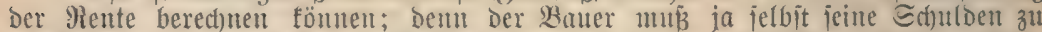

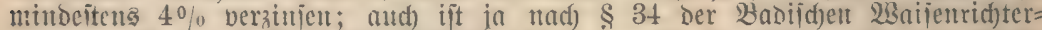

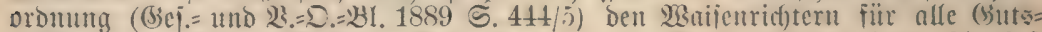

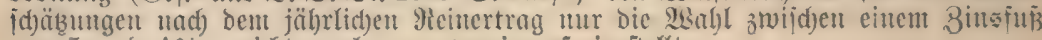
bon 5 und $4 \%$, nidft aud bon weniger freigejtellt.

Siun gerällt abex bas (sint and ber Foritbebörbe und bieje be=

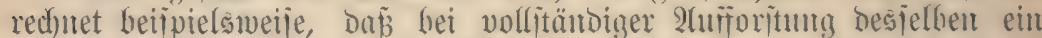
jäbrlicher Siemertrag vou 1400 M) Mrf barans Geranszunirtidgaften jei,

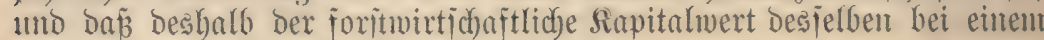
Binsfú von $3 \% 46667$ Miarf betrage.

Dis Foritbeböroe wäre alfo iu ber sage, beul $B a u e r$

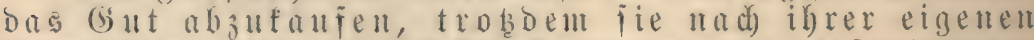

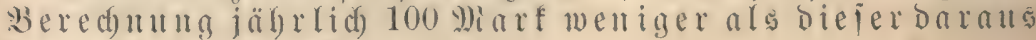
berausbrillgeli wärbe. 


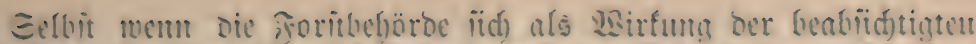

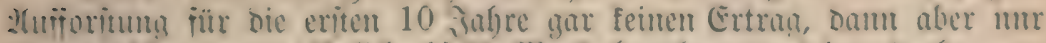

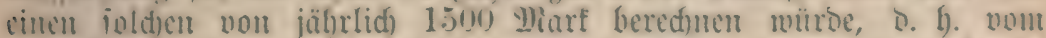

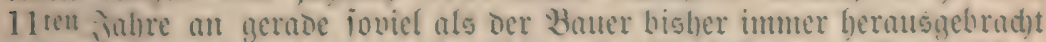

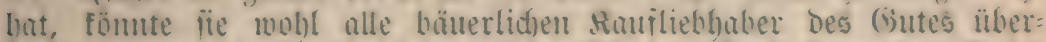
bieten; Den bie Forjtbehörbe würoe fid) Den Rapitulwert Des Guttes

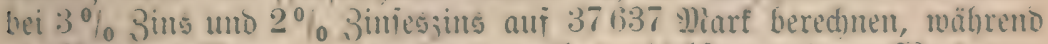

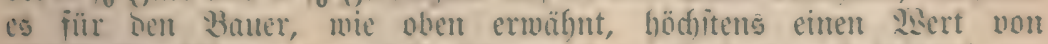

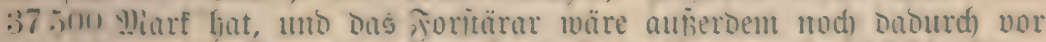

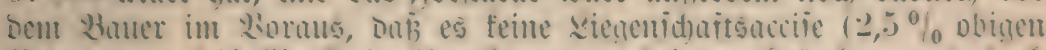

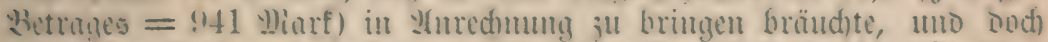
murne bas Fehfen eines Ertranes für Die eriten lo jabre bei $4 \%$, Sins

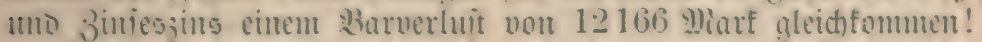

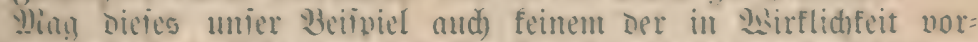

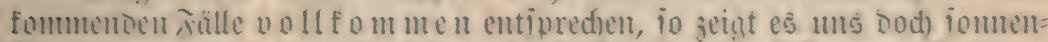

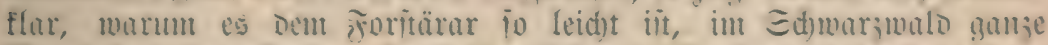

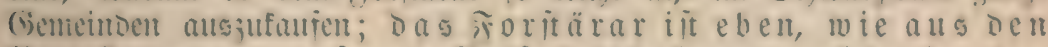

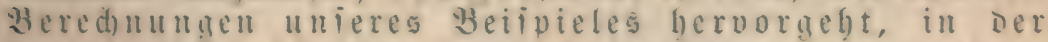

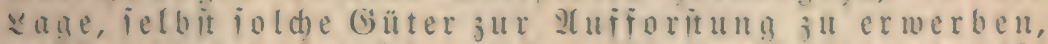
welde bisher bei bäuerlider bewirtidaftungweife cincu aroberen Ertrag abgeworien baben, als Dies uad)

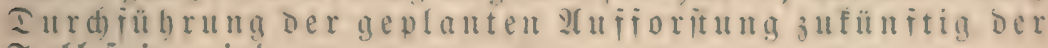
Fall pein wirb.

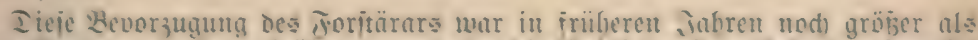

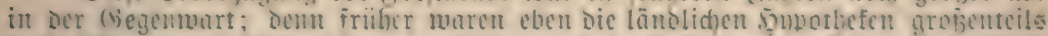

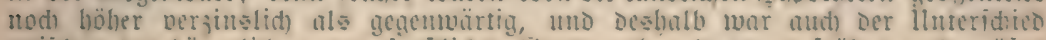

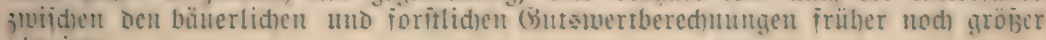
als iebt.

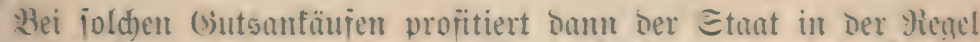

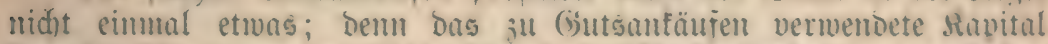

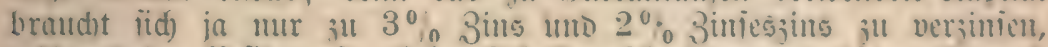
mähreno ben Beübern itautlidher Edhulowerid)reibungen gröstenteils nod) $4 \%$, minbeitens aber $3 \frac{1}{2} \%$, Bins gezahlt werben mub, itatt; and aud) beim

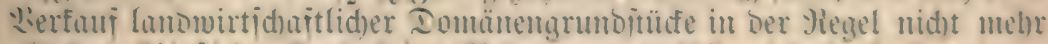
als - Das $3 \frac{1}{2} \%$, ige Ranital bes Heinertrays erlöt wiro (vol. Iomänen= Reroromungeblatt 1894, 5. 162).

ll nter oiejen sierbätnifien erideint es uewib uid) ungeredifertigt, weun wir im intereife Der Ërbaltung

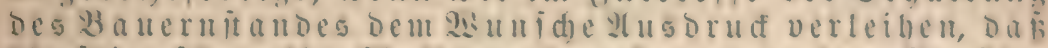

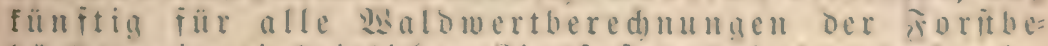
börden ein cinbeitlider Singfuis onn 4 ober ond min:

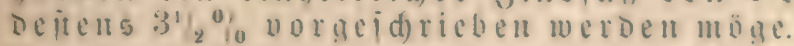

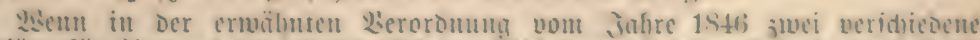

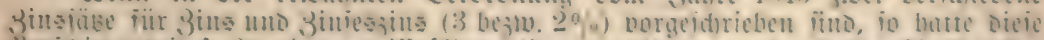

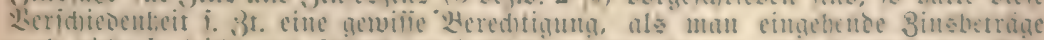

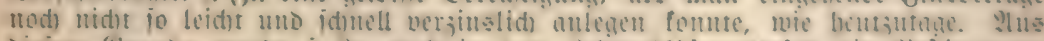

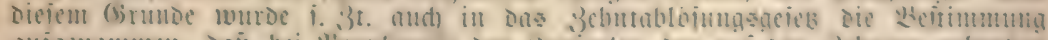

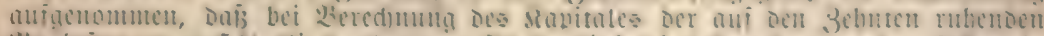

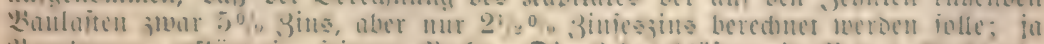

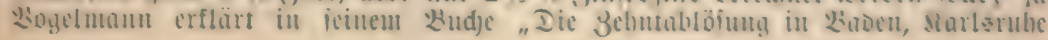


1838", Dǟ Die Binfeszinfen bon $2^{1 / 2} \%$ nach bem bomaligen Stande ber Dinge

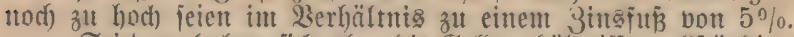

Eeitben baben fith) aber bie (Seldverbältniffe bollftändig geändert; jedermann

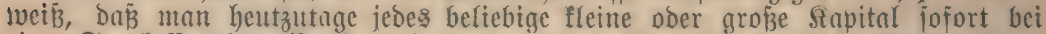

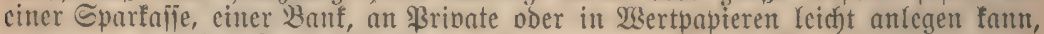

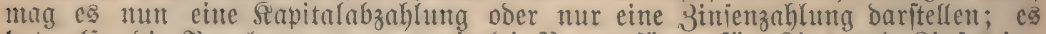
hat aljo bie Bered)nung bon zmeierlei \$̧rozentiäzen für Bing und Binicszing

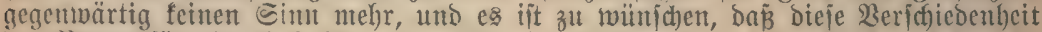

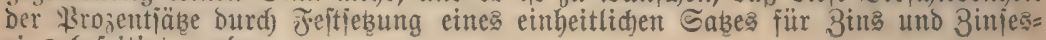
zinz bejeitigt twerbe.

Unjerer Befürmortung eines Binsfǘes pon 4 ober $3^{1} / 2 \%$ miro

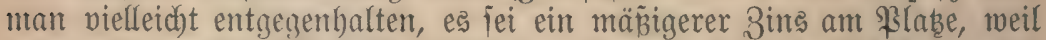

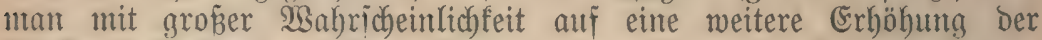
Joritproduftenpreije rechnen fönne; nir möhten jeboch dieje cinrede

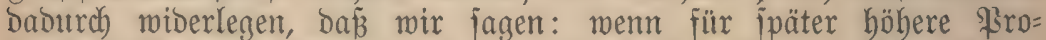
Duftenpreije mit Beitimutheit ermartet werben fönnen, jo gebören bieje föberen Freije bei ber Bered)mung Des Gelowertes ber jäbrlichen Forjtrenten berïdïchtigt, nidgt aber pon vornberein in einer nach blofier

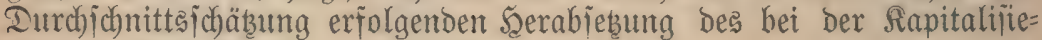

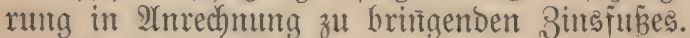

(5) jei uns geitattet, noch auf ben $\$ 14$ Der mebrermähnten Ber= oromung vom sabre 1846 aufmerfian zu madben, monad bas Betreff= nis Der Befolbung ber Forjtbeamten fïr Bemirtichaftumg Der einzu=

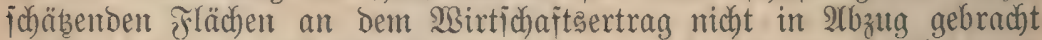
werben joll, und boch pflegen andererieits gerabe bie ben Foritbehörben burd) BergröBerung Der Sỉirtjchaftgfläd)en entitebenden vermebrten Ge=

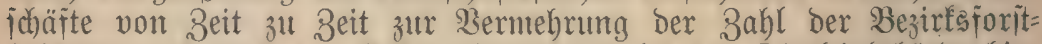
behörben uno anch der Rolleaialmitglieber bei ber Direftivbebörbe hin= 3แDrängen. Eeßt man diejes erwähnte Beioldungsbetrefinis gleich Dem

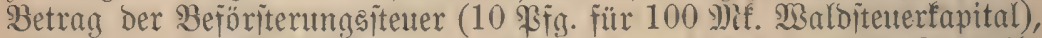

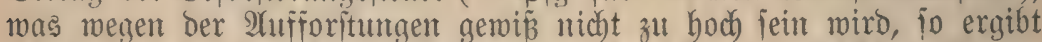

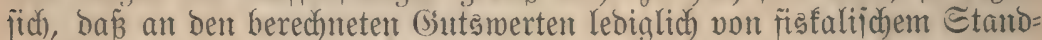
punft aus 2,5\% (bie erwäbnten 10 \$rg. $344 \%$ fapitalifiert) in $\mathfrak{2 b}_{z} u g$ zu bringen find. Ebenjo wäre ferner eiu entiperedender arbzug für Die bei Den Domänenämtern Durch Sinzug ber Foritprobuftenerlöje

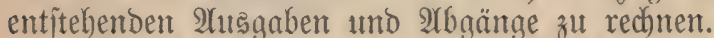

Ylle bieje Ermägungen lajien es gewí̈ als bered)=

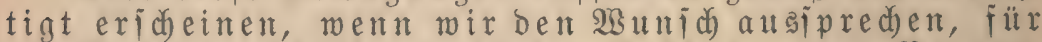
bie $\mathscr{B}$ alomertbered gütern möge fünftig bie Beredrung von mindeiteng $3 \frac{1}{2} \%$ für zing und Binjeszing vorgejdrieben werden.

Siur bei Berechnung eines Binsfunes von minbejtens $3{ }_{2} \%$ fömnte ïberbaupt von einer Rentabilität Des zu Giutsanfäufen vermendeten itaat=

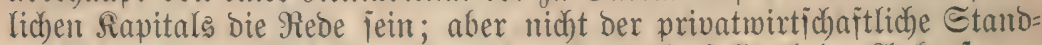

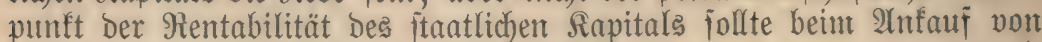
Bauerngütern Den 2(tsid)lag geben, fondern böher als diejer Etanopuntt

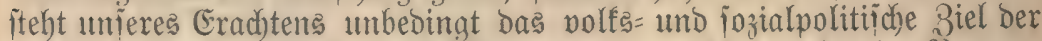
Erhaltung ber jelbititändigen Exijtenzen bes 9)ittelitandes, Gier Des Sauern= ftandes; Froduftion und Pentabilität ijt für Den Staat Doch nidbt Gelbit=

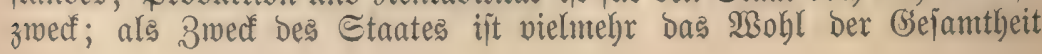




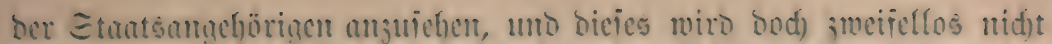
lefordert, mem Durd) Das Whlfumen von Bumemaütern jeitens der

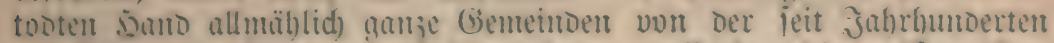

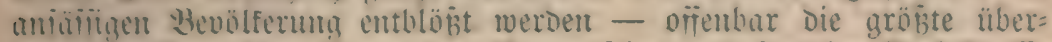

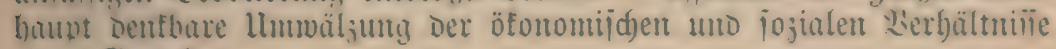
einer Gegend.

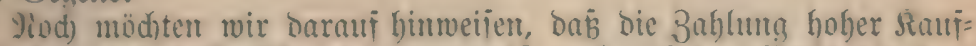
preije ietens Des foritärars maturgemtäb aud) auf Den Preis Der Dem Bunemitund verbleibenden Giöter iteigerno eimuirft.

Viebnten wir an, Der Etmat babe Das in unierem Fritheren Beipiel crmähnte (jut in Der Dofinm ani einen jährlid)en Feinertrag vont

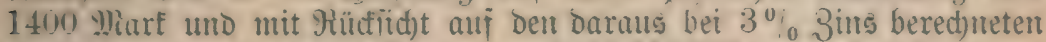
Rapitalmert von 461667 Dif. ju nut 45000 Dif. erworben D. h. 4m

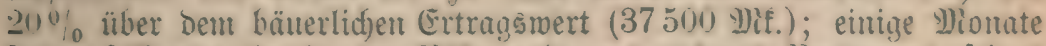

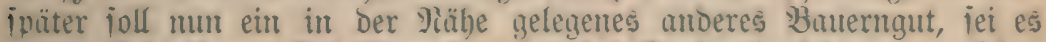

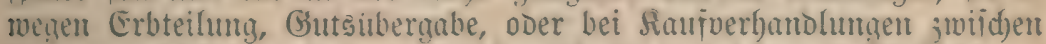

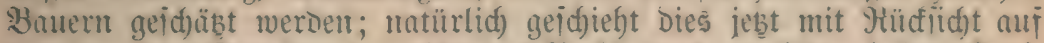

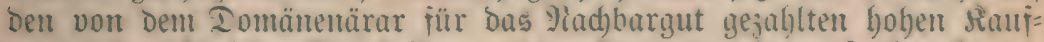

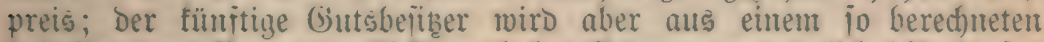

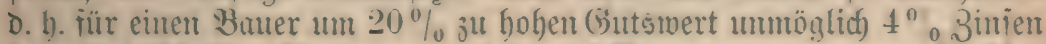

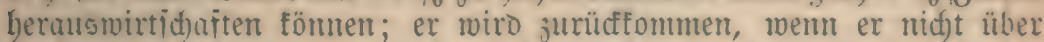
grobe Dittel veriügt, und nad) wenigen jafhren wiro ifjm vielleid)t nidgts anberes übrị bleiben, als iein (Gut gleid)falls Der Foritbehörbe anjubieten. Thatiache ijt es jebenfalls, was aud bie im jahre 1883 juttuebabten Lambuirtichajtlid)en Erbebumben ermieien haben, Das zu hohe Gutsüber=

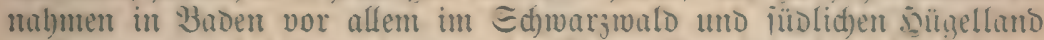
vortomuth, viel ieltener Dagenen in Doenualo, wo andererieits Gitts = antäuje jeitents Des Domänenürars fait nid)t itattründen.

24ud) von bieier Betrad)tungsweije aus erid)eint es uns Dringend

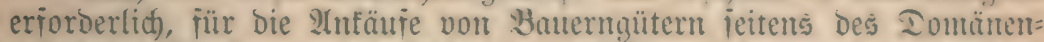

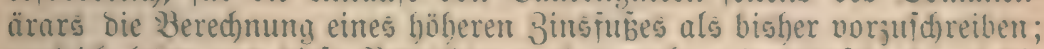
jugleid) (el)rt uns Dieje Betrad)tung aber aud), wie winnid)ensmert Die Gründun einer (srumbfrebitbant auj genolienid)artlid)er (smunolage iit, un anbererieits and) Dem Banernitumb bie jebt blos Dem Groburumb=

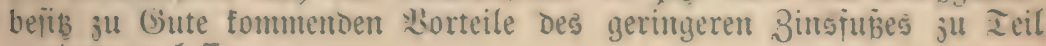
werben zu lailen.

2) Ẽ sueiter Gேrund, welder bas Iomänenärar

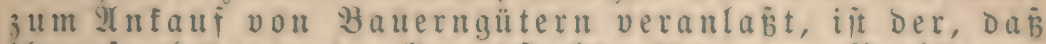
ibm io bedeutende (is runditodgelder zur berfügug iteben, welde zum $\mathfrak{A}$ tauf von bauermböfen gerabeju hin๖rängen.

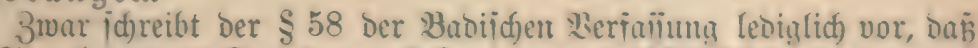
Die Einnabmen ats Iontänenverüusernngen, einid)Lieblid) Derjenigen ans

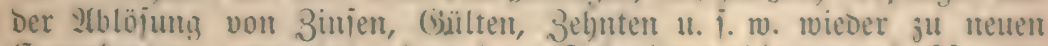
Ermerbungen nerwendet ober ber $\Xi$ duldentilgungs faije jur Sersiniung ïberwieien werden jollen; es wiro alio nidat unbedingt

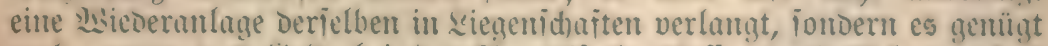
and), svent Das (jelo bei ber Amortifationstaije verjinslidg angelegt 


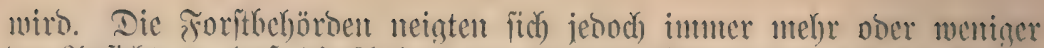

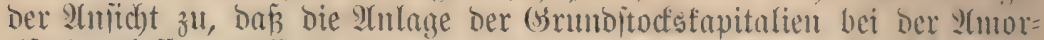
tijationsfafle gewijierntanen mur als ein vorïbergehender Potbehelf an=

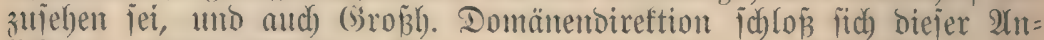

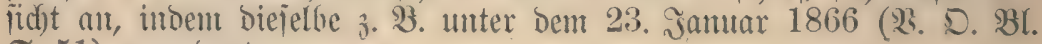
ङ. 51) verorbnete:

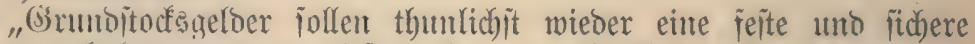

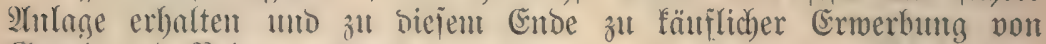

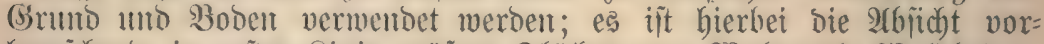

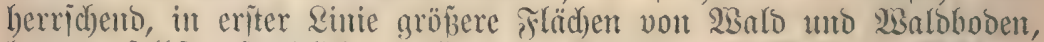

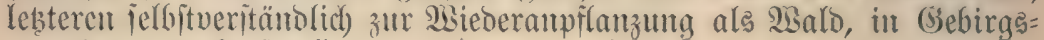
gegenten anzuffaufen.".

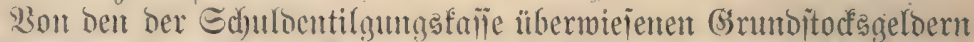
Des Dontäneuärars ijt der Sictrag von $12000000 \tilde{f l}=$ ruto 20571428 Miart, welcher als iogenamite "tobte Edhullo bes Domäntenärars be=

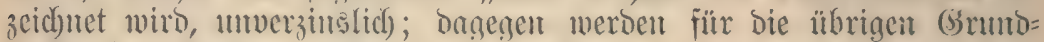
itoctsgelder Bimjen gered)net anto ber Etant biejer verzinslid)en Edhuld betrug am 1. Jannar 1860 (eimid)liejblic) ber bantals bei Der 3ebnt=

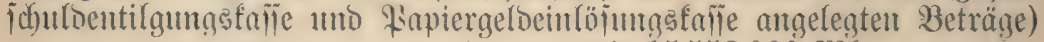

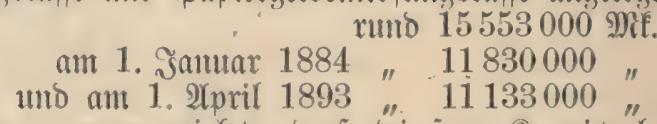

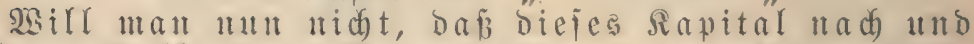

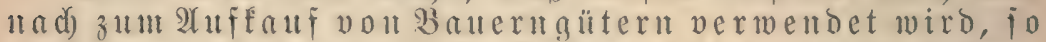

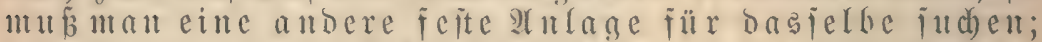

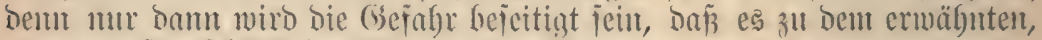

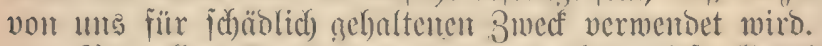

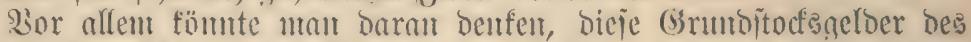

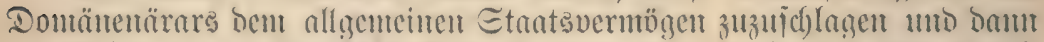

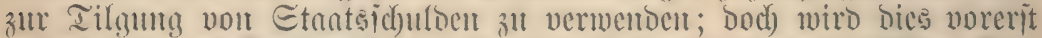

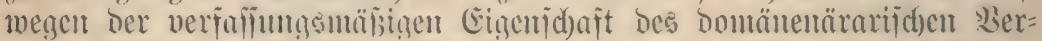

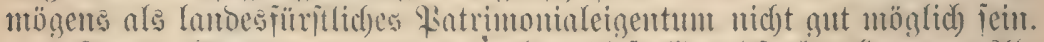

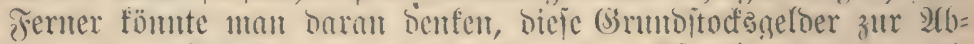

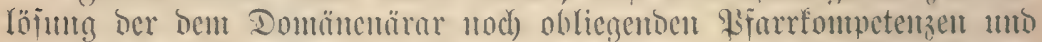

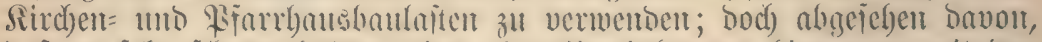

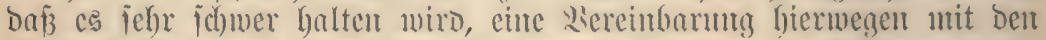
Sirchentheböroen zu Etanto zu bringen, jo mürben bie Sebteren, went

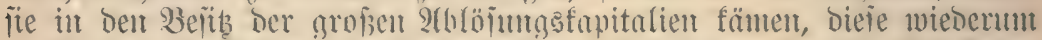

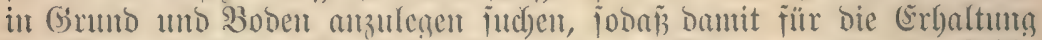
Des Banternitantoes nidat viel gethant wäre, mollte man nicht eine joldhe

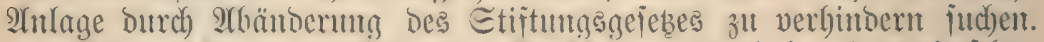

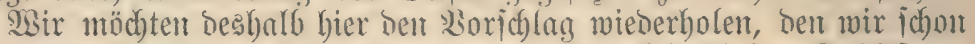
an anberer Etelfe bei Bcipred)ung ocr Innomirtichaftlidben Rrebitfrage

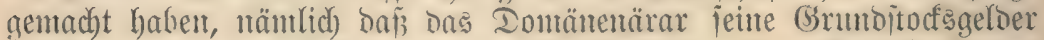

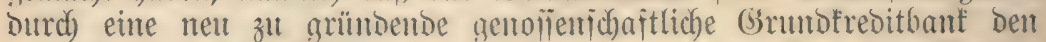

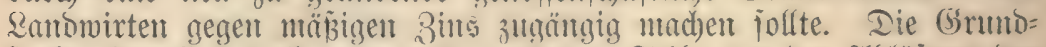
jtodfsgeloer furo bod) zum nid)t geringen Teile auts ber Arthlöintg ber 3ebnter, Bimjen, Gíilten u. i. w. angejanmelt, aljo i. 3t. von ber land= 


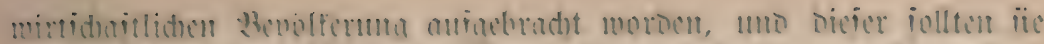

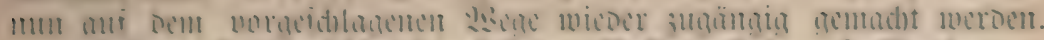

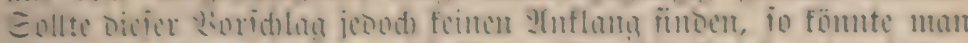

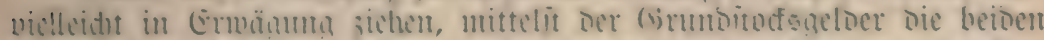

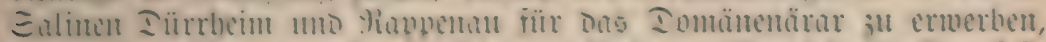

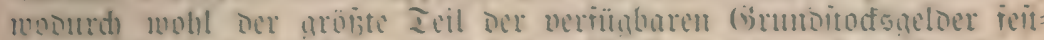

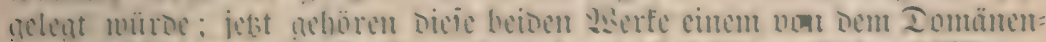

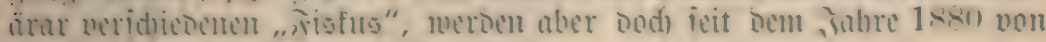
Grö̉. Domänenbireftion vermaltet.

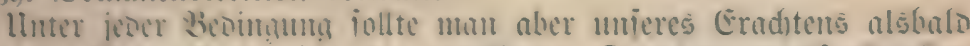

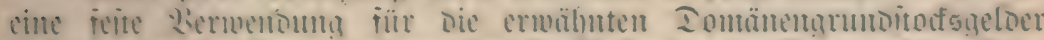

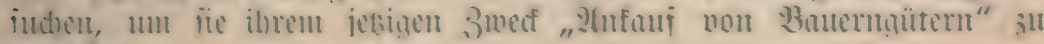
entivichen.

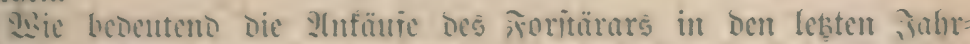
sehnten aemeien ïns, acht Darus bervor, Dab Der foritmirtiduatlide

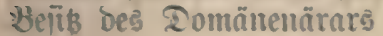

$$
\text { im Jahre } 184887607 \text { ha }
$$

betranen hat; Derielle hat alio in Den iathen 18488.2 im 15.54 ha uno in Den juhren 188.29:3 m 270.5 ha sugenommen.

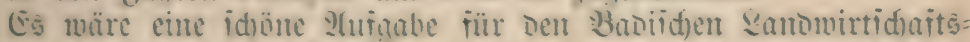

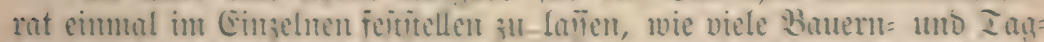

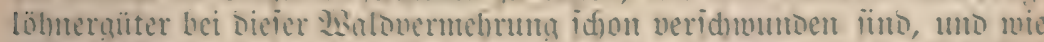

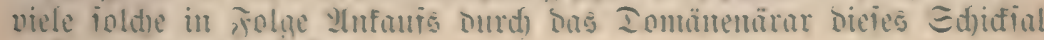
nod) ju ermarten bulen.

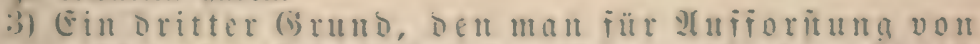
Bauernaüteru Dur (t) Das Domänenärar gelteno mad) $t$, $i$ it

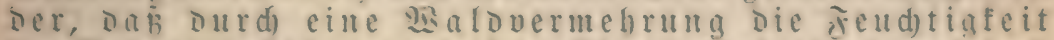

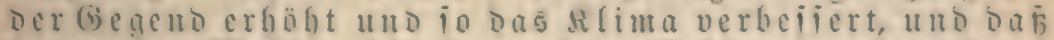
fermer ber 28 aiferablub an Dem Gebirge verlangiamt und io gleidmäbiger auf oie veridiedenen jabresjeiten verteilt werde.

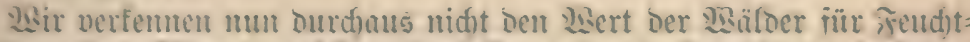
crhaltutạ Des Rlimtas, môt)ten Denielben aber Dod) nidut io bod) (an=

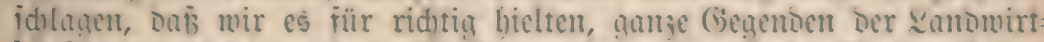

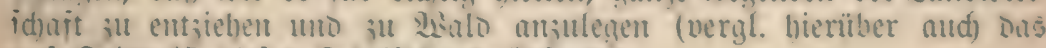
auj Eeite 45 Diejes Ed)riftd)ents (isejante).

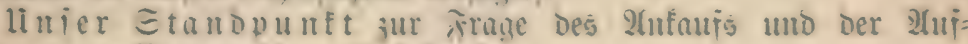
iorimu von Bamernutern it folgender:

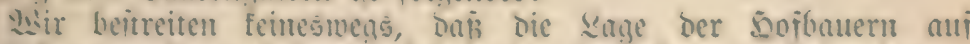

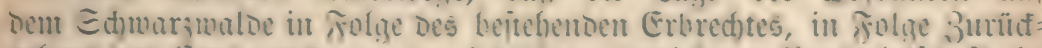

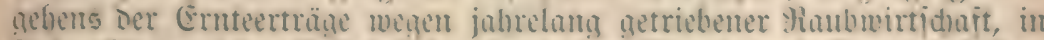

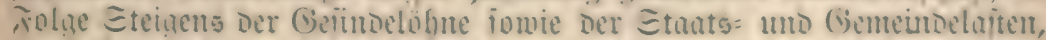

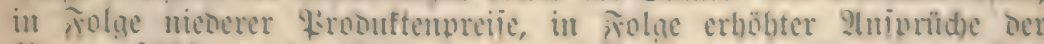
Whatem ielbit an Bas Seben u. i. w. jid) recht untainitia neitaltet bat.

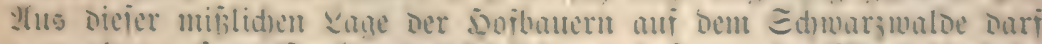
man aber unieres Erad)tents nid)t jolgern, Dab̉ m Der Etaat Die betr. 


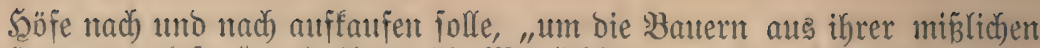

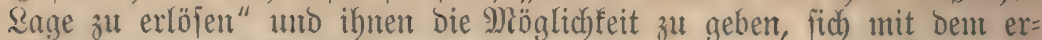
löiten Gelbe in beljerer Gsegend nen anzufitedeln; benn wir wilien wohl,

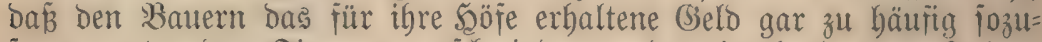
fagen unter ben Fingern veridywindet, uno wir halten auBerbem Den Untergang jebes felbititänigen Bauernbofes für eimen nidft leidht zu erjebenden 3 erluft für ben Etaat. Alus ber ungüntigen Rage ber Şofbauern auf dem Echwarzwald folgern

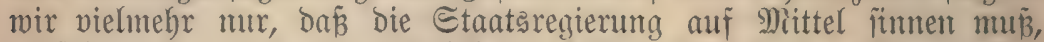

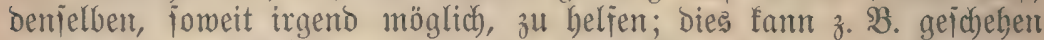

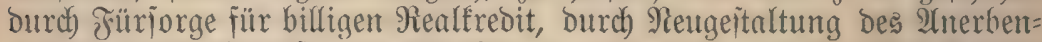
rechtes, Durch Ermäfigung der Steuter= und Umlagenlaft, Berbelierung

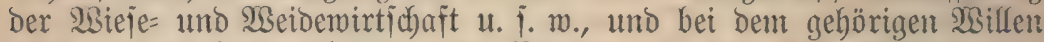

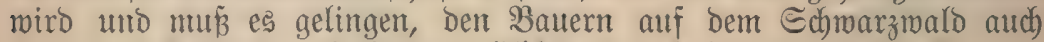
für bie Zufunft eine Erritenzmöglichfeit zu erhalten; benn Der Bauern= jtand bildoet bod bie Gínundage des ganzen Staatsmejens.

Un nicht miß̄peritanden zu werden, fügen wir bier noch bei, baf́s wir jelbjtweritänolich bagegen feine Eimwendungen zu macken haben, wenn das Domäntenärar bei fïh bietender Gelegenheit z. 33. von einer Grumbherrichaft eimen gröferen $\mathfrak{B a l b f o m p l e x ~ e r w i r b t ; ~ D e m ~ d i e ~}$ Sinterefien ber Rantobevölferung witrben burd. foldhe Erwerbungen wir möd)ten jagen: von einer tobten Şand an bie andere - nicht be=

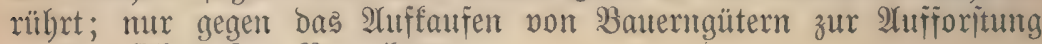
wenden fich unjere Setradytungen.

Bewirtiduaf tung bes lambirt=

id)aftlidien (Sirutio=

befitses deas

รomänen= ส̈rarรื.
II. : Domänenärarijojen Bejïbes anbetrifft, fo haben wir vor allem bie vom (5)r. Finanzminiterium in vorigen Jabre erlafienen ?ormativbejtum= mumgen über Die Seräıв̋erung und ßerpachtung Des bomänenärarijchen

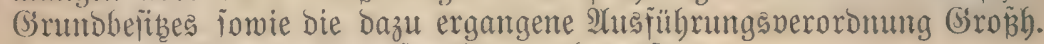

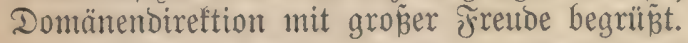

Dá̉ für bie fleinen $\mathfrak{P a d h t g r u n b j t u ̈ c f e ~ b e s ~ D o m a ̈ n e n a ̈ r a r s ~ n o c h ~ m e h r ~}$ als bisher (Gelegentheit zur Beräußerung gejucht werben joll, uno zmar momöglich an bie bisherigen \$ächter uno eventuefl auch gegen 2tumui=

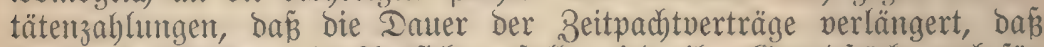

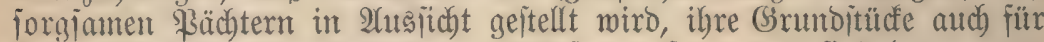
ipötere \$achtperioden bebaltes zu bürfen u. . w., das find lauter vom rid)tigen jozialen Geijt getragene Alnoronungen, bie Den Snterelien ber lantwirtichaftlichen Bepölferung wohl entiprechen.

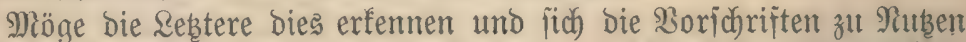
machen, Damit beren 3wed voll uno ganz erreicht wiro, uno möchten

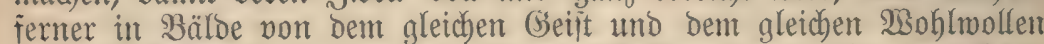

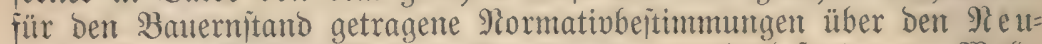

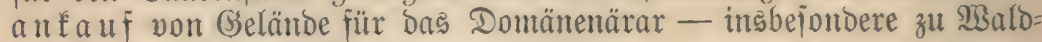
anlagen - erlafien weroen!

A(ud) bei ber Bewirtichaftung Des landwirtichaftlichen Beländes ift bie Domiänenverwaltung in ihren Maknahmen ficherlich nicht allein an

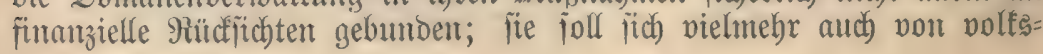




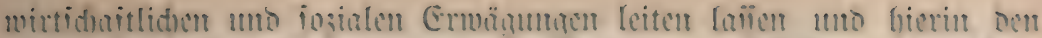

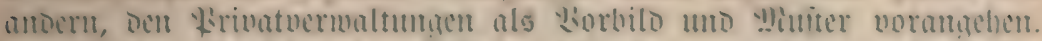

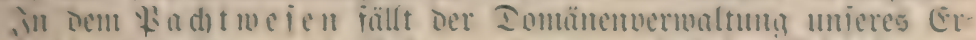

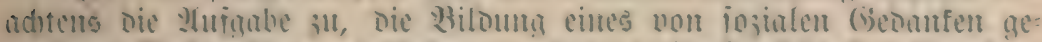

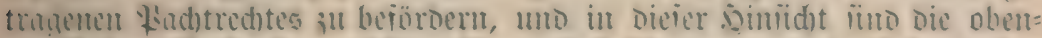

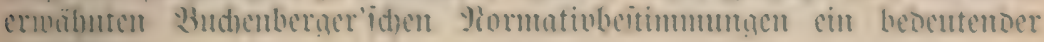
Fortidritt.

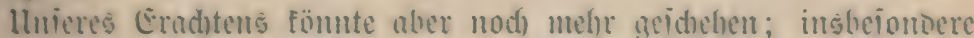

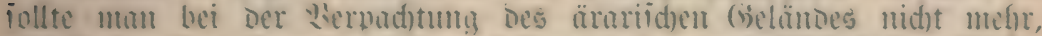

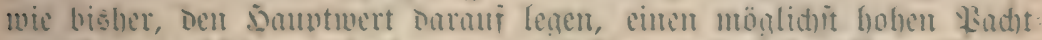

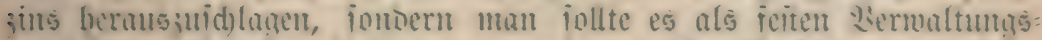

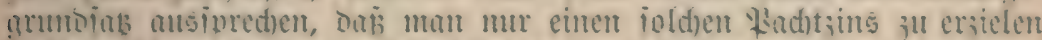

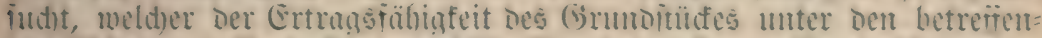

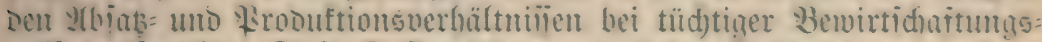

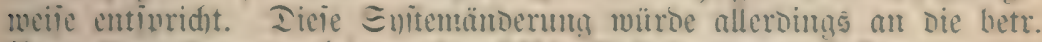

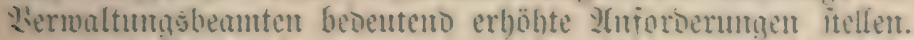

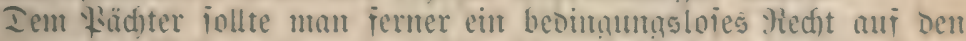

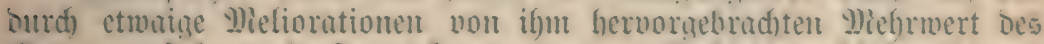

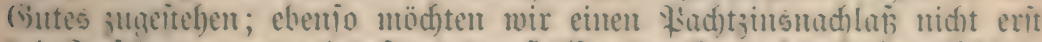

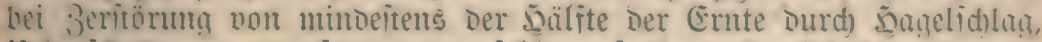

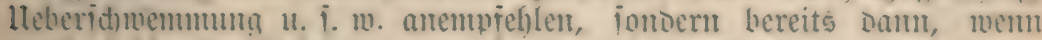

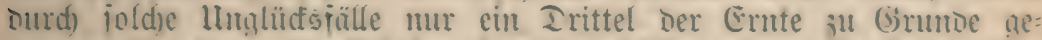

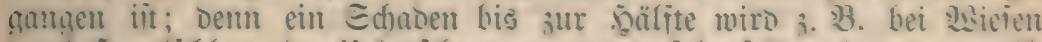
Durd) sonelichlag noer lleberid)memmung mur iehr ielten eintreten, meil, menu aud Die Denternte sum gröjern Teil vernid)tet wird, Dod) Der

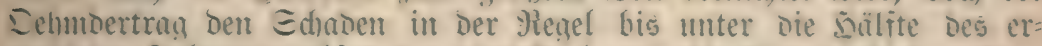

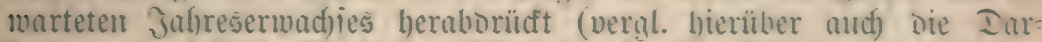

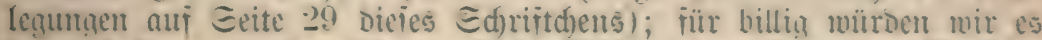

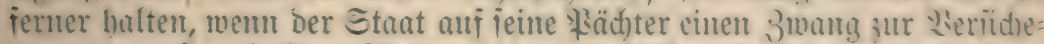

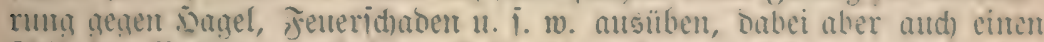

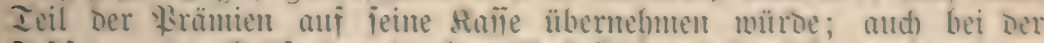

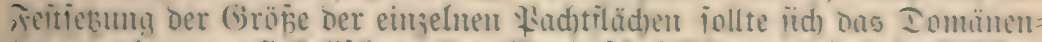

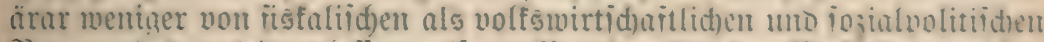

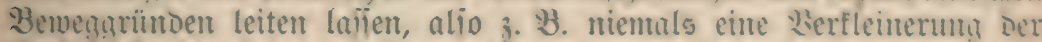
Find)titide lesiaglich) Deshalb vornehmen, un Die Ronturren; unter Ben

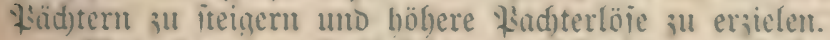

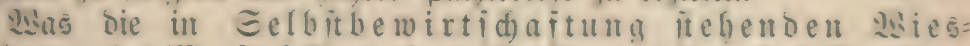
fläd)en anthetrifit, io iollte unieres Erad)tens ieitens Des Inuänen=

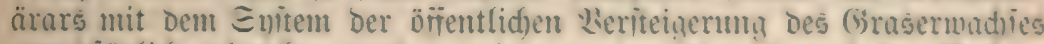
armoniäslid) gebrodsen merben, wie man ja jest and) mad) Den Bindsen= bernerid)en Viormatinbeitmumugen für emen yroken Teil ber pud)tirei

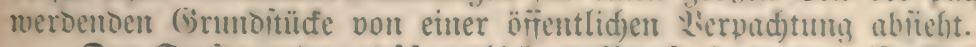

Ias $\Xi$ it em ber öfientlid)en Beriteigerung if allerdinns für bie Rermaltung Das bẹtuemite unt eimpadite; es erforbert von Dem betr. Beamten fojulagen gar feine geiitige Ibätigfeit, jonbern mur bie med) niqde Arbeit ber Protofollamsfüllumg; bajür iit es aber um io mad)= teiliger für biejenigen sanowirte, weld)e auf bie regelmäbige Tcilmalme

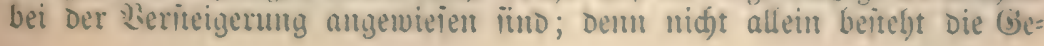




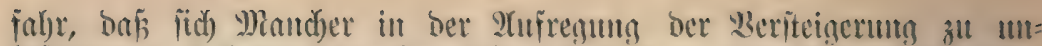

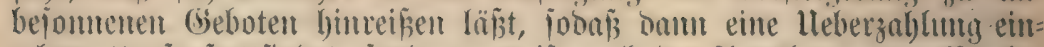

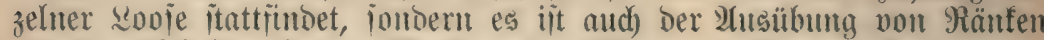

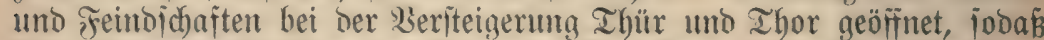
feut Steigenutgshitiger im Borats minīen fann, zut meldhem \$reife er ein oder zmei Rooje erbalten wird, wenn er muda) antererieits vielleidst im

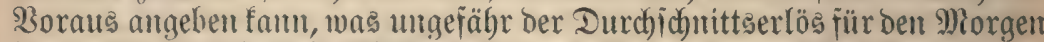
jein wiro. Durch bieje 2l(bhängigfeit bes Steigerunggerlöjes für bie ein= zelnen Sonie von Buffall fommt etwas Intridgeres uno Sdywantendes in

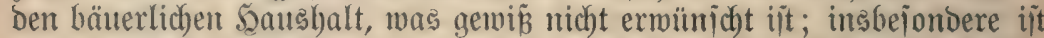

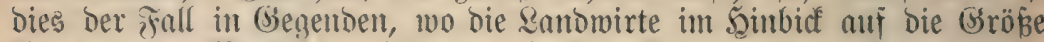

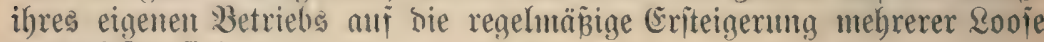
angemiejen find.

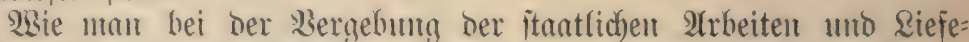

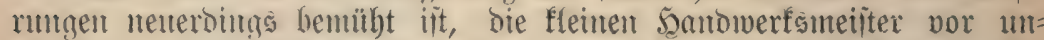

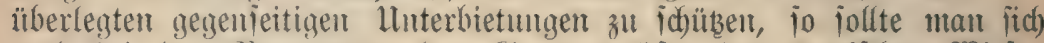

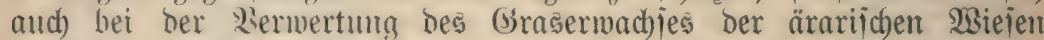

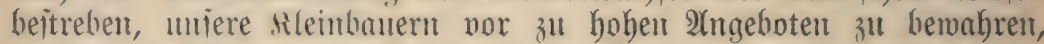

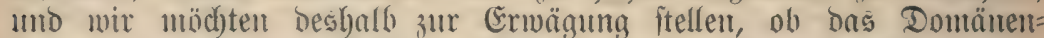
ärar bie erwähnten ofientbaren Miängel bes Beriteigerungsmeient nidht

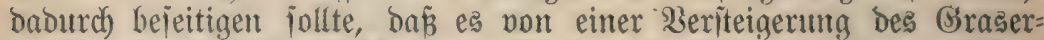

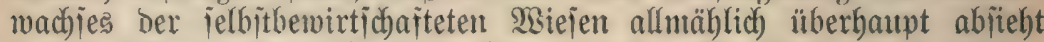

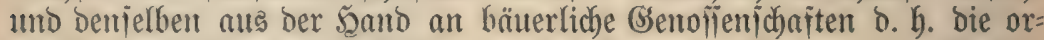

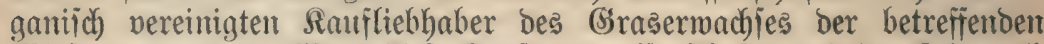

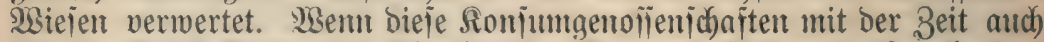

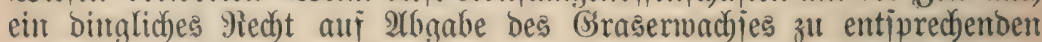
Freijen erwerben unto fich io zu eigentlident realen sisiejengentoijen=

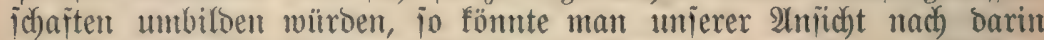

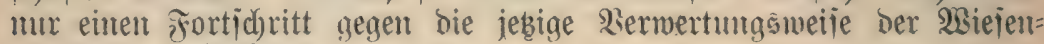
erträgninīie erblicten.

2utauf von

(Gitern burd) bas

Tomåneก=

äraน วutm

Buecte bex sisieder:

verïuperung.

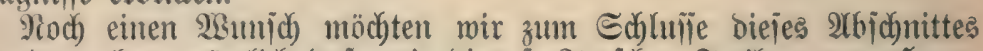

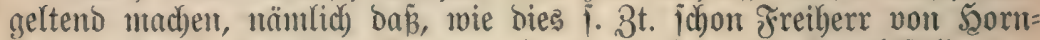
itein in ber I. Babijchen Ranmer beantragt hat, bie Bezirfajtellent ber Domänenverwaltung Dazu bemukst merben jollen, Bauterngüter, beren

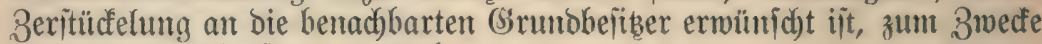
bes $\mathfrak{B}$ ieberverfaufs zแ ermerben.

Selbjtweritünolich Gat biejer Borichlag weniger bie jogen. ge= ichlofienen 5ुofgüter im 2utge, Deren Bertbeilung ja nur in jeltenen Fö̈llen eittem volfgwirtidjaftlichen Bebinrinis entipredjen wiro, als viel=

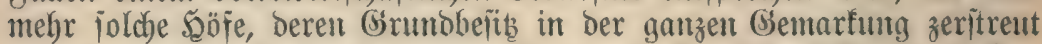
iit, und weldhe aus irgend einem Grumbe $(3.9 B$. Iodesfall oder Heber= jd)uldoung) nicht mebr zujammengebalten werben fönnen; bem verfaujs=

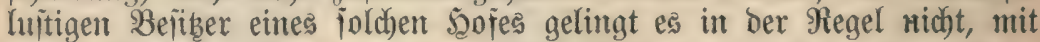
Den Riebhabern feiner einzelnen Grunditüfe bandelseinig zu werben;

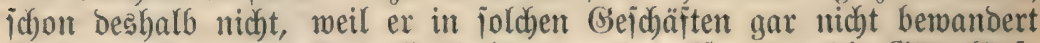
iit; Da muß bann erît ein Şandelsmann eingreifen, um bie Gsüterfäufe

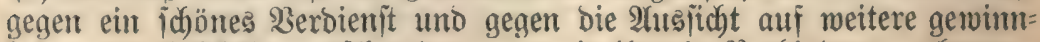
bringende Géldärite zwichen ben mum mit igm in Berbindung gefomme= 


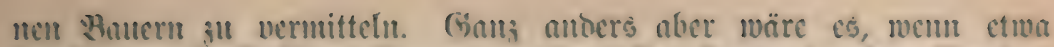

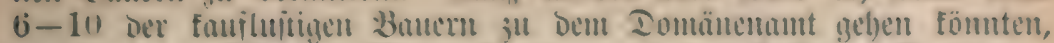
um bier su erflären: "2isir wollen ben uno ben bo jum \&iseije von io uno io viel Mharf fanfen uno unter uns verteilen, baben aber Diejent Setrag natürlich nicht sur jojortigen Beriügumu; wir bitten beshalb Dieien Betrag für uns an Den bisherigen Beitker Des bojes und Dellen

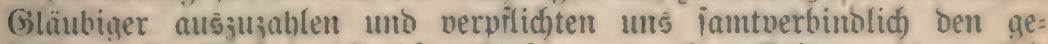
leiteten zueritatten."

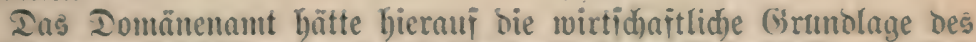
beabiidhtigten (Seichäjtes jowie, ob bie faurlujingen (sejuchiteller zmeirel=

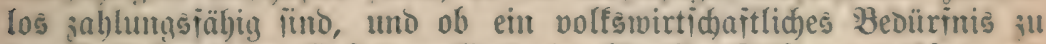

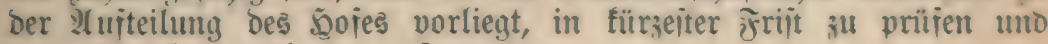
Dann Beriddt bierüber fu erftatten.

Gewis wäre bei eintem jold)en Beriabren die (Sejahr eines Ber= luites für bas Iomäntenärar mur einte gany geringe, bagegen fömte

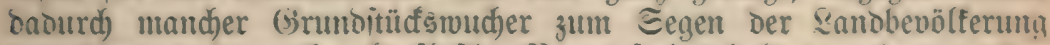
vermieben, uno mandjer faufluitige Bauer frei gebalten wersen von Der

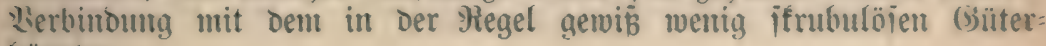
bänoler.

\section{Eteuer: un๖ 3ollverwaltung.}

Bezunglid) ber (G)

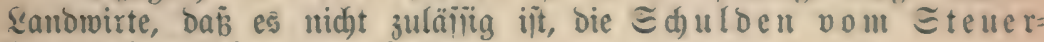
fapital in $\mathfrak{A b} z \mathfrak{g} z$ u bringen.

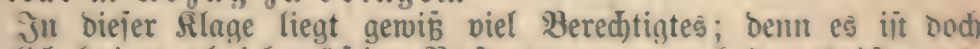

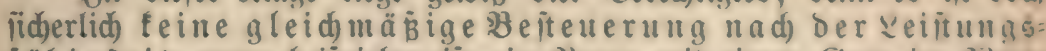
fähigfeit, wenn beipielsmeije ein Bamer mit einen Bute in Livirte von 50000 Miarf uno 30-40000 Diarf Ed)ulden Darani Denielhen Betrag an Grunditener zahlen joll, wie ein antherer Bhater mit cintem gleid) wertvollen, aber ganj ober nabezu idduldenireien Gut; bie (sirumi: itenern rübrent ebent aus eitrer Beit her, wo mant eine Sierid)uldunţ Des

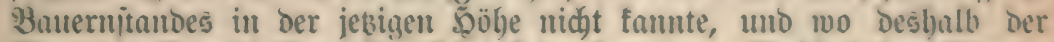

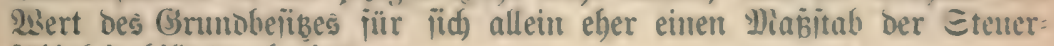
jäbigfeit bilbete alo jest.

Zndere Beiten bringent aber aud andere झnfordenungen an bie Etenerverwaltung mit iid): Inter ben gegenwärtigen Lierbältniiïen

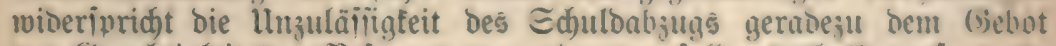
Der (Beredotigfeit ber Bejtentenung, uno man iollte Deshalb umio mebr eine Itenterung fierin eintreten lainen, als bie bermalig̣e Viotlange der Santhenölferung gebieteriich eine weitere 2ierminberung ibrer Belaitum mit Etetern, llmlagen u. i. w. verlanght.

Allerdinge iit bic (s) it a t tu 


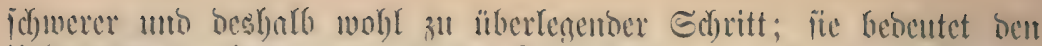

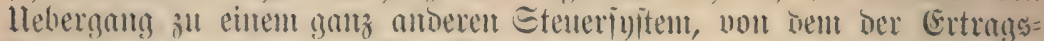

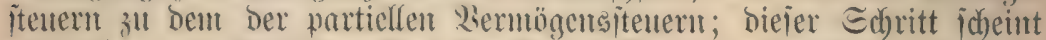

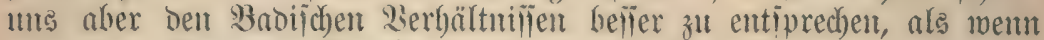
mtan, bem Siorgange Prenzens folgento, die Grumbitener ganz an bie

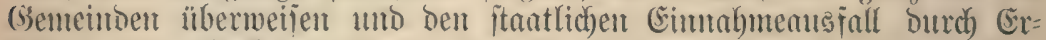

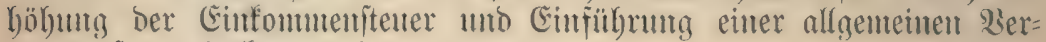
mögensfteuer becfen mitroe.

Der Saanteinmurf, Den man bei ber (Srmmoitenter gegen bie Bse=

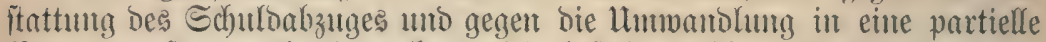
Nermögensjtener geltento machen wirb, bejteht wohl - abgejehen von der

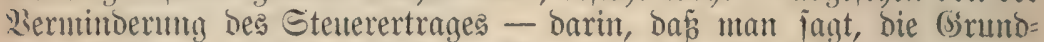

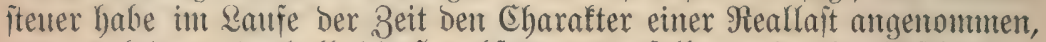
Itno es bcoente beshalb bie Serabjebung berielben rein ein Gejchenf an bie \&anbuirte in Betrage bes fapitalijierten Stenernad)(anjes; wer jebod

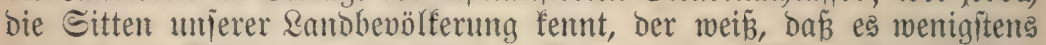

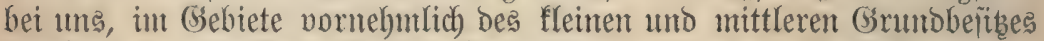
Durdhaus unutreffeno iit, bie (ssumojtener mit einer Peallaft zu ver= gleidben; uniere Bauern pflegen befauntlid) bei $2(n=$ un 2 Serfäufen von Ğrumbjtitcen feineswegg eitre genaute Ertraggmertberechnutg vorzunehmen, uno vollents bavon, Daż fie hierbei bie auf Dem Raufgegentanto rubenbe

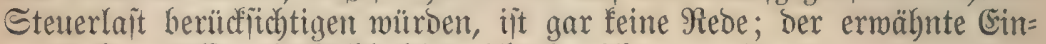
wand faun aljo als itichlyaltig nicht bezeichnet weroen.

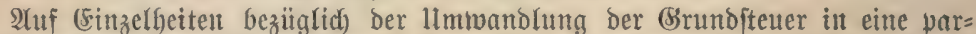
tielle 2 'ermögensfteuer einzugehen, ift hier nidht ber geeignete Drt; bodh lei ea ung erlaubt, folgentes zut bemerten:

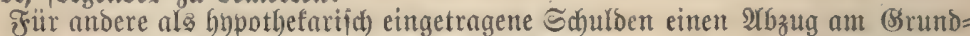
fteuerfapital zut geitatten, ericheint ung menigitens vorerfit nicht notwendig und

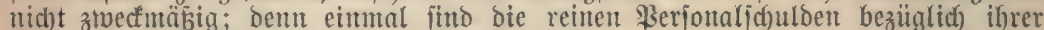

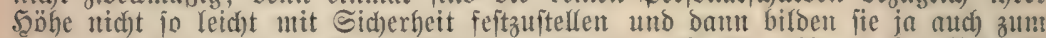

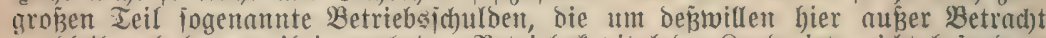
zu bleiben haben, weil ja aud) bas Betriebafapital ber Ranbwirte nid)t bejonders

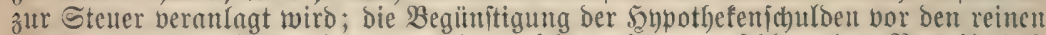

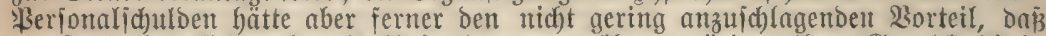

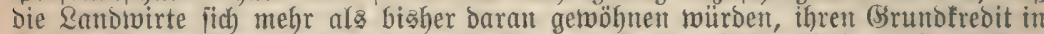
2Aiprud zu nehmen, amitatt fich) mit oft zweifelhaften (Seloberleihern einznlafien,

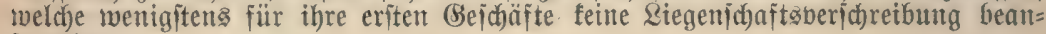
ipruthen.

(sine weitere Frage ift $\mathrm{es}$, ob bet ber vorgejdlagenent lumbandlung ber

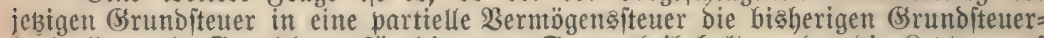
fapitalien ala (Srunolage für bie nette Steuer beibehalten ober Die Restere auf

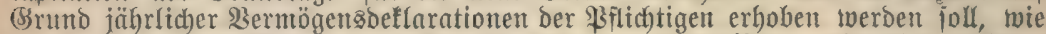

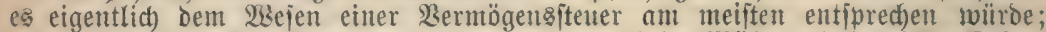
wir mödten jebod) befürtworten, fich bie mit fo bieler Miübe und io vielen foften nach ben Berfehrsmerten veraulagten (Srunditeuerfapitafien aud) fernerhin nukbar

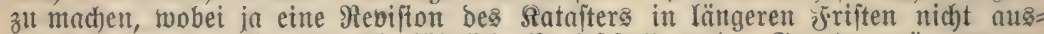

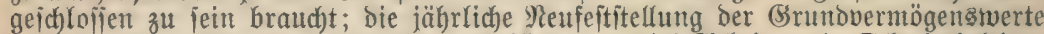
wiibe unieres (Erad)tens ber Steuerbehörbe zu viel Arbeit und Ed)wierigfeiten

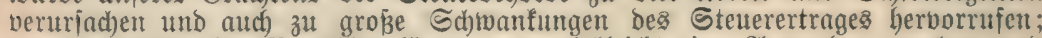

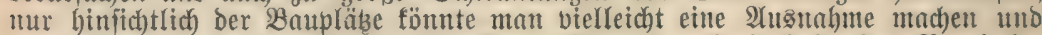
Deren 2ermögentwerte, die ja bag betr. (Srumbitenerfapital in Der Regel be=

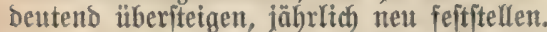

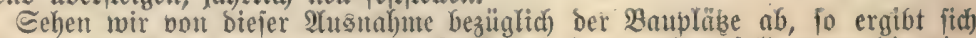
uns ferner bie Frage, wie es in beut Jalle gehalten werben ioll, wenn bie ein= 
netragenten Edfulben bem Etcuerfapital nalse ober gleichlommen ober es gar lifer=

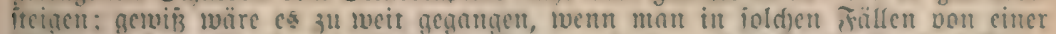

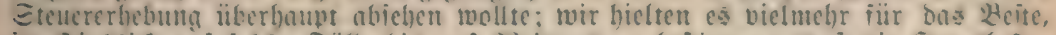

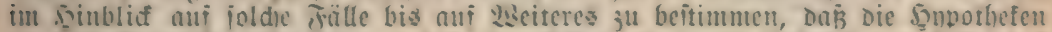

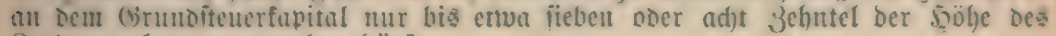
Rebterent abgezogen twerben bürfen.

Bei Der llmmanolung Der Grumbiteuer in eine partielle Lermögents= irener fömte man and die ifreilaifung eines agrarifon Eritensminimums in Enö̈gum zieben; wir balten jebod) bie genentuärtige 3cit ju einemt jold)en Ed)ritt nicht jür geeigntet uno zmar

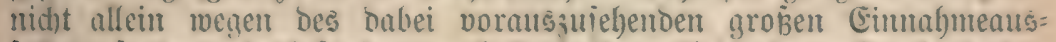
ialles, jondern inshejontere and) Deshlalb, weil die bermalige lantwirt=

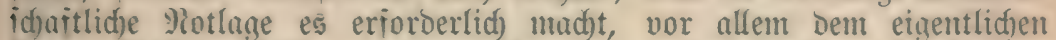
Whaternitano ju helfen, währeno für bie grumbheitbenden Taglöhner,

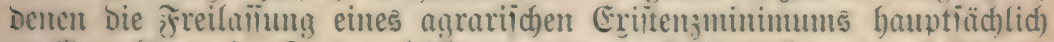
jul Gute fäme, eine Etenererfeid)terung gegentwärtig viel wentiger Dringento eridgeint.

Dagegen jodeint uns andererieits eine mä̈ige Progreijion

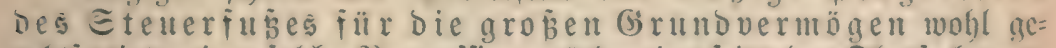
rechtiertigt; eine ioldhe Progreition witrbe eimerieits ber Thatiadhe ent=

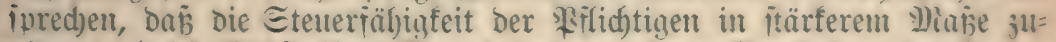

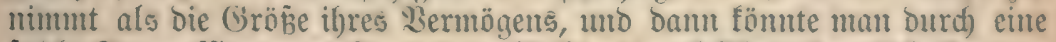

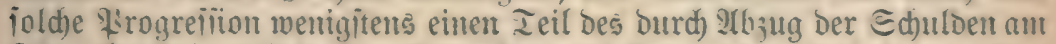
Etenterfapital entitehenden Eimafhmeausfalles wieder einbringen; Den Tुauptoorteil mürben wir aber barin erbliden, Da baburd) Der sati=

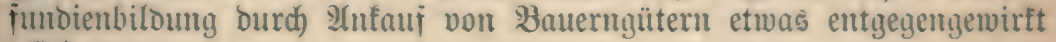
wirtre.

Ferner jei hier nod) die Freibeit bes Domänenärarg vou

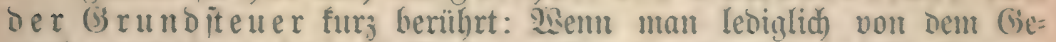
Danfen anşgeht, Daj bie Cinfünțte bes Domänenärars in bieielbe Etauts=

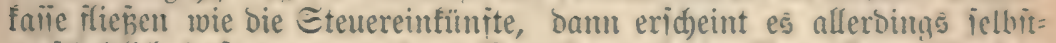

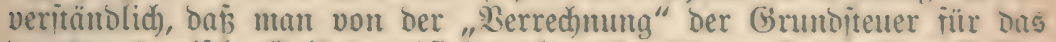

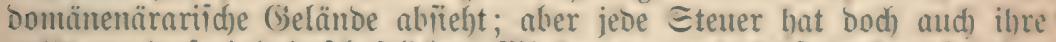
volfs= und jozialwirtid)aftlidjen Wirfungen, und bieje gehen bei Der Intterlaijung einer iold)en Pierred)untg fïr bas Iomünenïrar verloren;

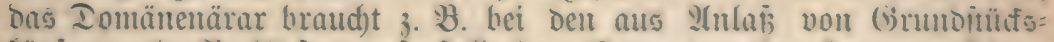

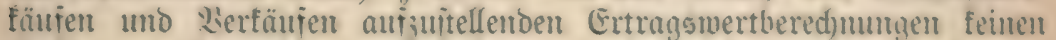
Bletrug an Grumbitener einjuitellen, uno io wirft bieie Etenerireibeit

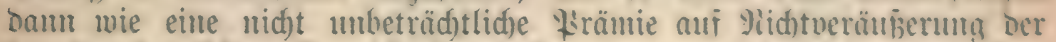

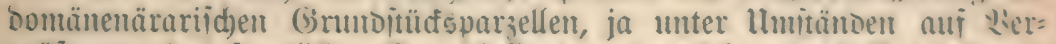

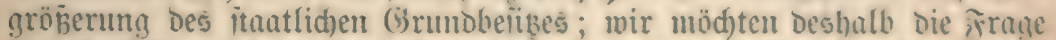

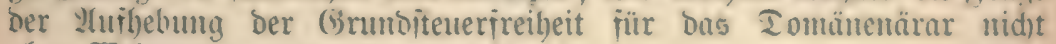

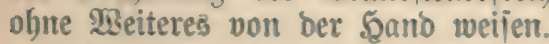

Einen beionberen Beitanoteil ber (G̈nundenter bilDet in Baben Dic Eteuer vou dem bewaldeten (iselänbe; belien Ratuitritum

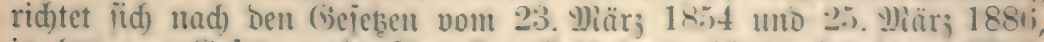

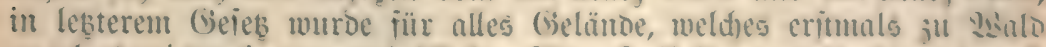
angelegt wiro, eine jwanjigjäl)rige Etenerfreibeit angeoronet, was mad)

Beiteueturg ber sialbungea. 
ber beitebenben Gemeindeoromtng eine ehenfo Iange Utmlagejreibeit zutr Folge hat.

Der (S)rumb biejer 20 jährigen Stenerfreiheit it eimmal ber (Ge=

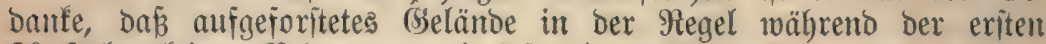
20 Jabre feinen Reinertrag abmirft (eine Thatiache, aus ber allein mant itbrigens unferes Erachtens nur eine 20 jährige Befriftung ber Stener folgern fam, ba ja nad) Umlauf ber 20 Sabre ber burdjigntitt=

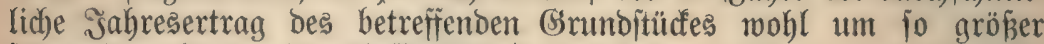
jein wiro als vor ber 2fufforftutg), und bann wollte man burch bieje

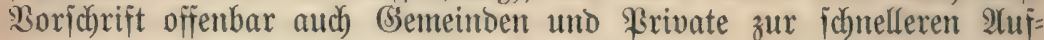
foritung ihrer "Deolänbereien" veranlafien.

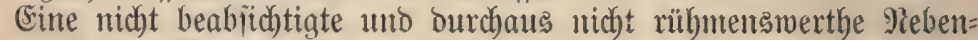
mirfung biejer Stenterbefreiung ijt es aber, baß bierourch bem $D 0=$

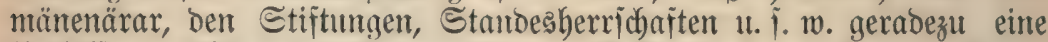

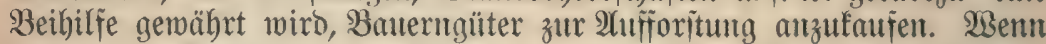

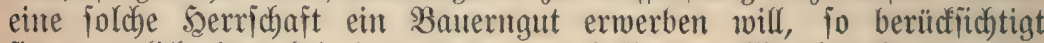

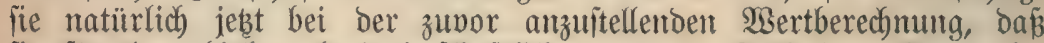
fie für ben bisher lantowirtichaftlich) genutbten Teil des (Šutes bei Durchfiulfrung Der geplanten 2hufforitung 20 Jahre lang feine Steuern

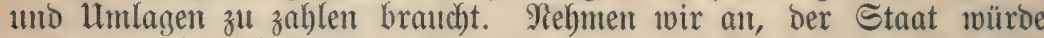

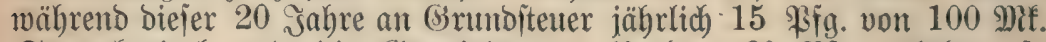
Stenterfapital uno bie Gsemeinde an Umlage 60 \$íg. erheben, fo fommt bie eriparte Steuter und $\mathfrak{U m l a g e}$ bei Bered)mung eines Binefunes von $4 \%$ einem baren Rapitalvorteil von 10 Mif. 19 Pfg. für je 100 Mef. Stenerfapital gleidy, und jeben wir bas Stenerfapital gleid) Dem Gutsmert, jo beträgt alio ber bare $\mathfrak{B}$ orteil in solge ber Steuer= und $\mathfrak{l}$ mlagebefreiung megr als $10 \%$ bes (b) uts=

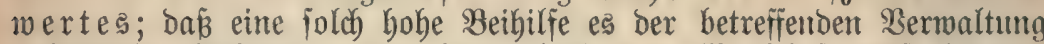

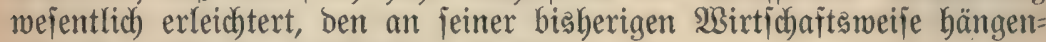
Den Bauernitano auszufaufen, ijt flar.

Sino nut im Raufe eintiger Эabre mehrere Sö̆fe einer (Semeinto

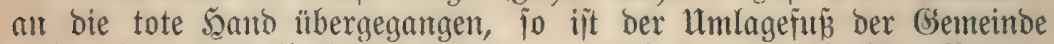
micht allein beshalb böber gemorben, weil bie ausgefautten Bauern utbit Familien zum größten Ieil fortgezogen fino, umo feine Umlage von ihrem Einfommentsanjohlag mehr eingeht, jonbern aud beshalb, weil bas lanbwirtichaftliche Gelänbe berielben, weldhes jebt aufgejoritet

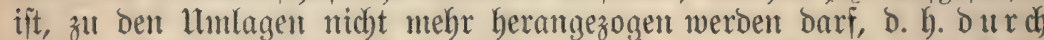

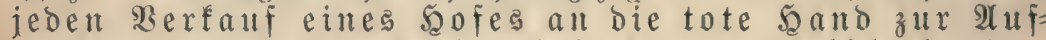
foritung wirb bie umlagelaft ber zurü deleibenden Bauern utr um jo gröper ut beren Exiftenz um jo fibieriger.

Eine batternfremtolidje Regierumg jollte eine (sejebgebung, welche folde Folgen hat, balothunlidyit beridytigen! Unjer Woridalag in

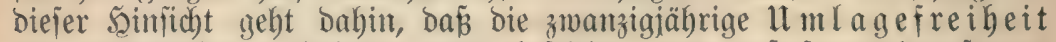

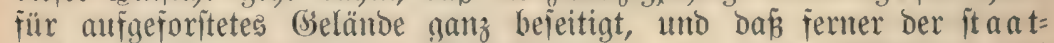
liche Miad)la

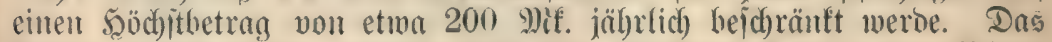

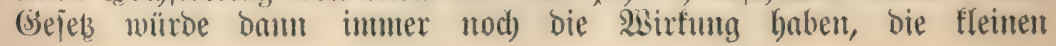




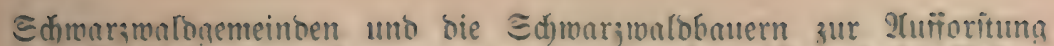

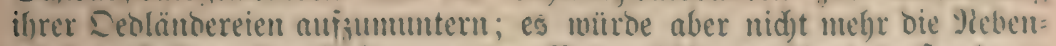

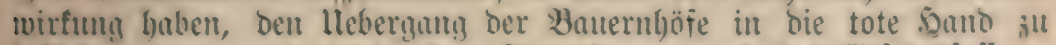

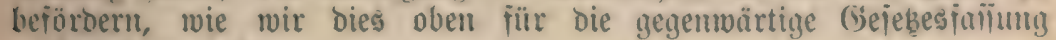
nadjgeviejen baben.

Erforberlidenfualls fönnte man ja bie 2ufijoritung ber "Iedlän=

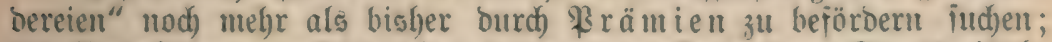
sie Llnteritübung voüroe aber bant ans allgemeinen Etatemmitteln itattfiutben unto nidgt vie bisher burdh bie llmlageireiheit auf Roiten Der betrefienton Gemteintefaile bejw. Der zur sebteren jernerbin llm= lage zahlenten Bemeinbegentifien.

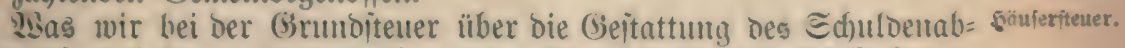
zuges geiagt hahent, gilt mutatis mutandis aud f̈̈r bie bänieritenter.

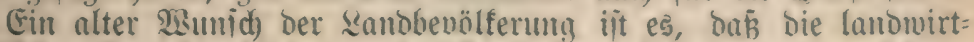

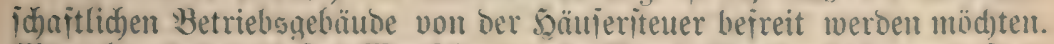

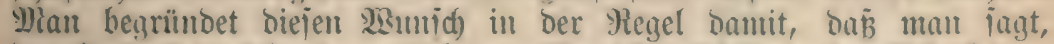
Der Lanbwirt ziehe in ants ieinen Betrielisngeböuton eignentlid) feinen

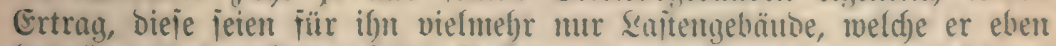
braude, um Den Ertray feiner Hecfer zu verwerten; da mu ber lestere Ertrag bereits vollitäntoiy zur Etenter herantuezoyen iei, jo jolle man

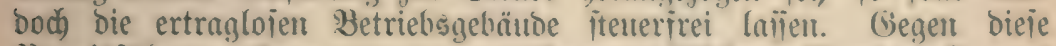

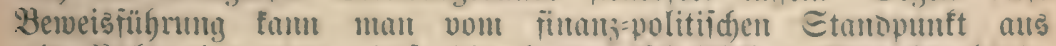

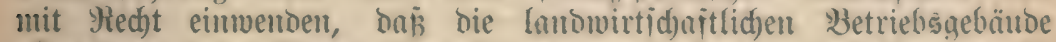
allerbings einten Ertrag abmerien, wemu aud) feinen (Jieldertrag, jo boch eitten Platuralertray; wäre es antoers, jo wuirshent jie ja von Der santobevölferung nid)t weiter unterbulten uno gätten aud) feinen

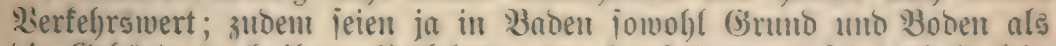

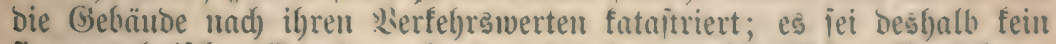

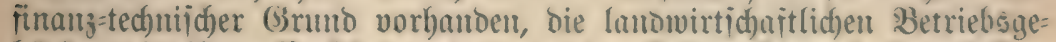

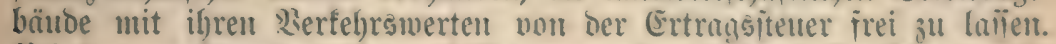

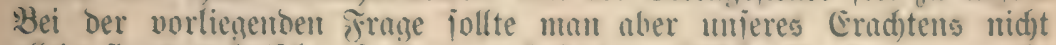

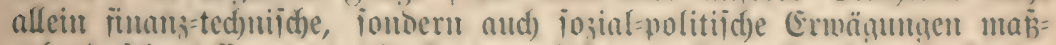

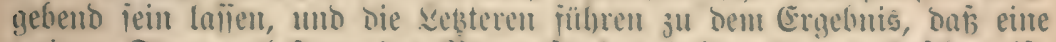

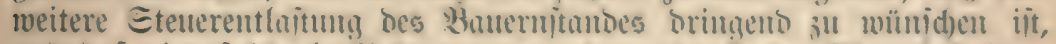

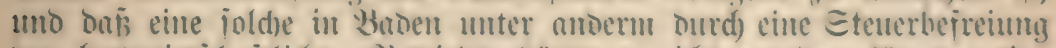

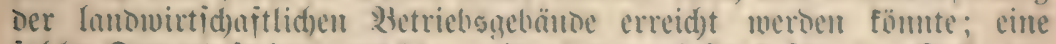

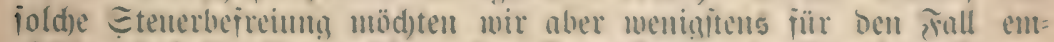

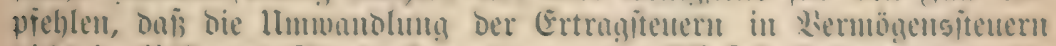

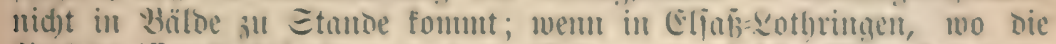

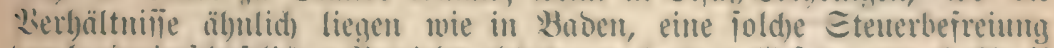

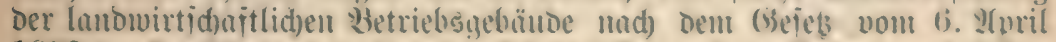
1892 Durchgejül)rt miro, jo wiro jid) biejel(be and) in Baben ermögltid)en laijent.

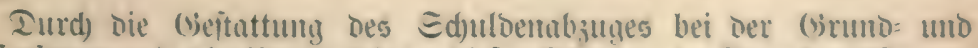

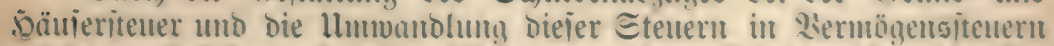

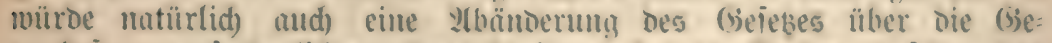
merbeitener erjorberlid) werben; ülurigens bat dic sebtere ja jidon jest viel von einer Liermögensjenter an ïd). 
Sinfichtlich) Der (Semerbejtener bejteht int Interefie ber santhe= völferung vor allem ber 93 unjch nach einer böheren Bejtetterung bes

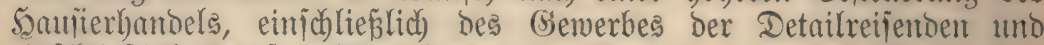

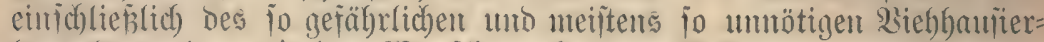

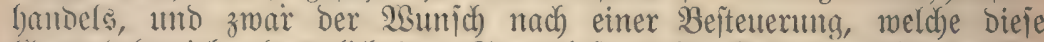
(isemerbebetricbe bezüglich ber Stenerlait nicht allein ben übrigen (Se=werben vollitänoig gleid) ftellt, fonbern weldbe - Darüber hinaus= gel)ento - biejelbe möglichît erjânert uno eimichränft.

WBas Den Beizug Der eingetragenen (Senofienichaften - bieje be= iteben ja großzenteils auf bem sande uno in ben fleinen Stäbten -

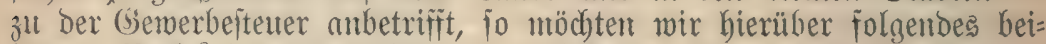

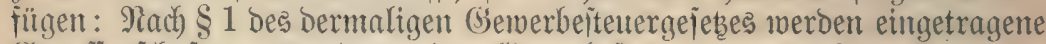

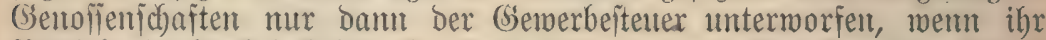

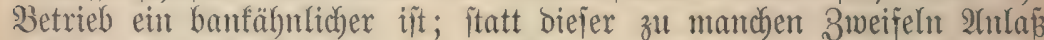
gebenben Sorjobrift witroen wir vorichlagen, zu bejtinmen, Daß̉ fünjtig mu biejentigen Gentofienfobaften vou ber Gewerbeftener frei bleiben jollen, welche hödjiteng joviel Frozent Giewimn an ihre Mitglieber verteilen, als ber 3itsfinß fïr gute \$ypotgefen in ber betreffenden Gegend beträgt;

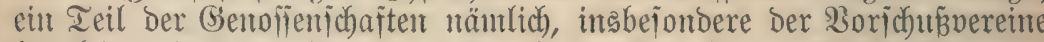

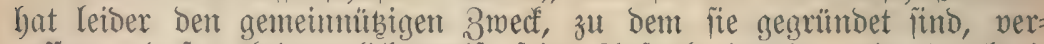

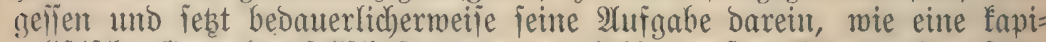
taliftijche Ermerbsgejellichaft einen möglichit gropen Geminn für jeine

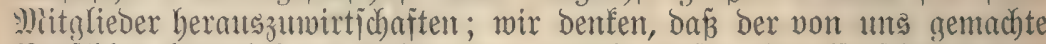

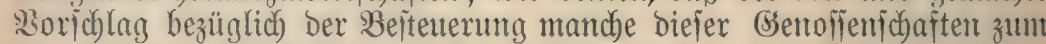
Eegen Der Ranbbevölferung auf Den ridhtigen $\mathfrak{I S e g}_{3}$ urüdbringen wïrbe.

Eirtormuten= fteuter.

Son allen Etentern ijt mohl bie Eimfommtenitenter biejentige, welche

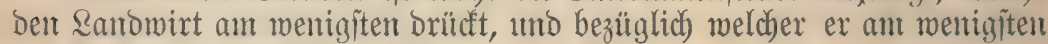
geredbtfertigte Wümiche gelteno machen fam.

Megen ber Bejtenerung Der eingetragenen (Benofienichaften erlunben wir uns dabei auf dos eben bei Der Bemerbeitener Gejagte Bezug zu mebmen.

\$seinftener. Sicht allein von allen indireften, fonbern überbantht von allent Etenern, meldye in Baben beiteben, entipricht mohl bie siseinitener ant

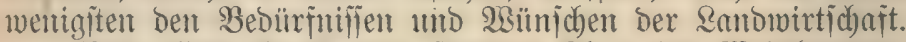

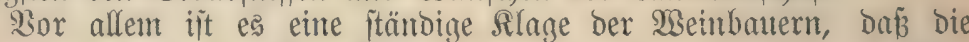
gerintgeren Reine Demjelben Etenerjab mnterworfen feien, wie bie wert= volleren; wir minfen jedod) offen befenten, Daß̉ wir feinen gangliarent

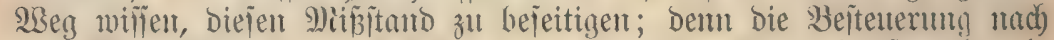
ben sisert ericheint 1 ms jelbjt hei ben itrengften Sontrolutapregelu als faum burchfiulbrbar.

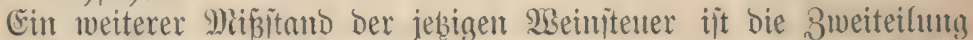

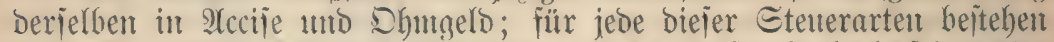
wieber Gejontere Siontrolvoridriften; bieje äuberit beläjtigende

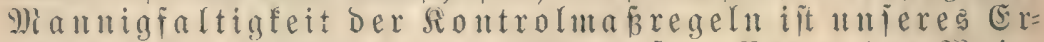

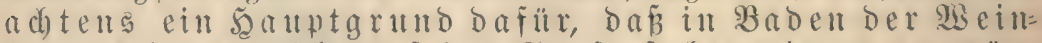

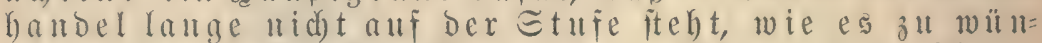
f(d) nebon ibren ssintid)aftsgewerbe angleid) nod) einen eigentlid)en ssem= 


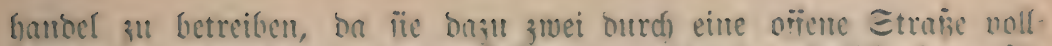
itünig von cintuber getrennte Beller nötị bätten, näntlid) einen fïr

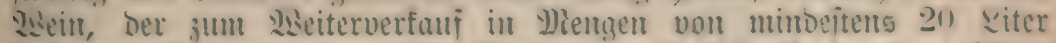

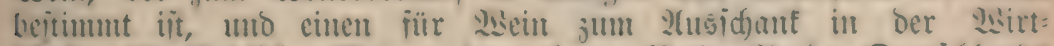

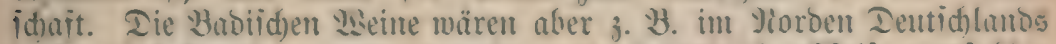

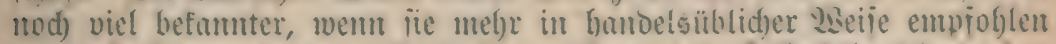

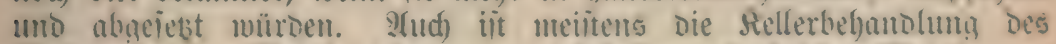

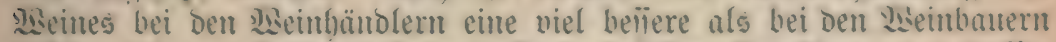

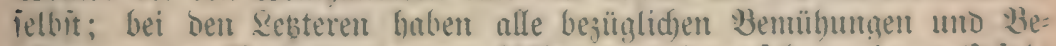
lebrutgen ber ßegierum

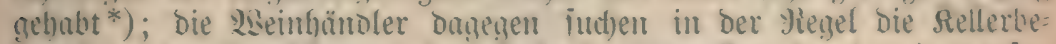

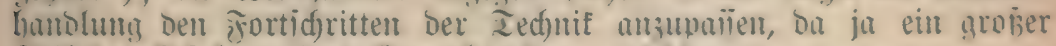

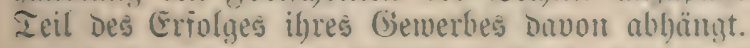

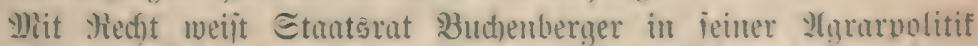

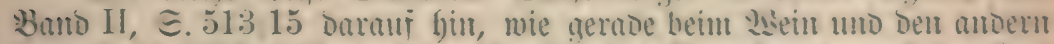

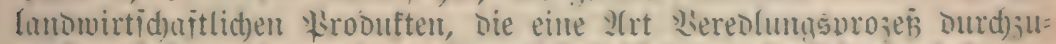

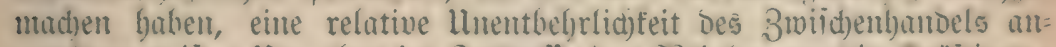

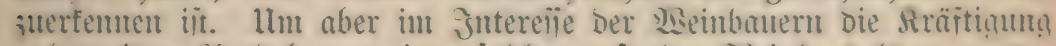

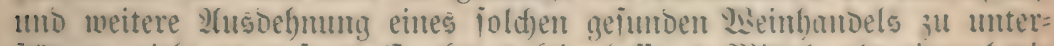

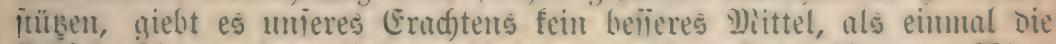

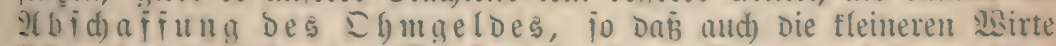

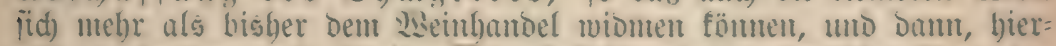

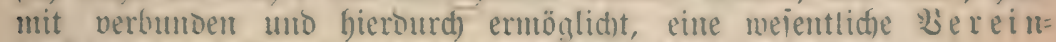
fad) ung Der Rontrole bei Der beitebenbleibenten DEeinacite.

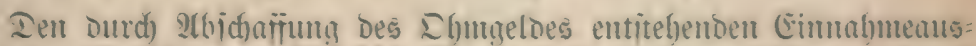
fall von jährlid etwa 250000 Diarf mitrien wir vorichlajen, Durd) eine allomeme

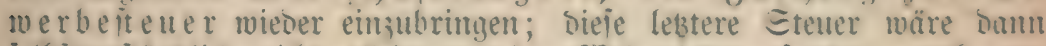
ielbitneritünolid) nid)t allein von ben sieinuirten, fondern and non

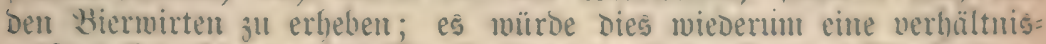

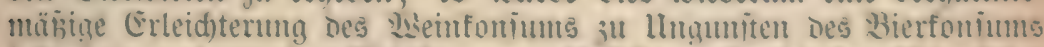

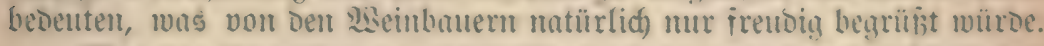

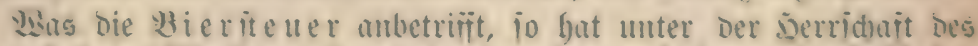

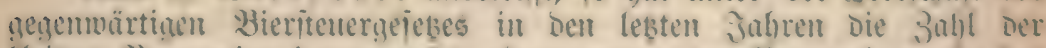
fleimen Brmereien immer mehr abgenommen, Das Bramereigemerhe hat

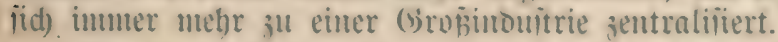

(iserade bie fleiten Brater find è aher, Deren Fortheitano für bie

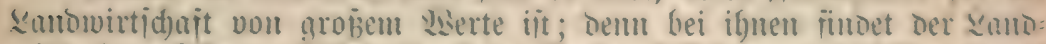
wirt einen fidgeren stbiab jür ieme Gerite, ielbit mem bieiclbe cimmal

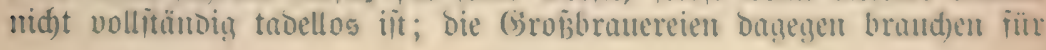

*) Eogar den Stüfern in den fleinen Sandorten fehlt es böupig an den

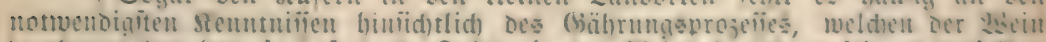

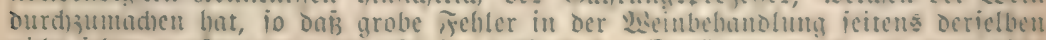

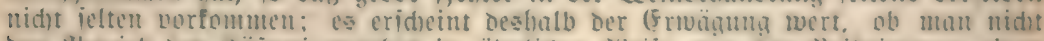

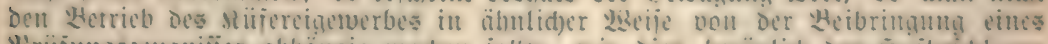

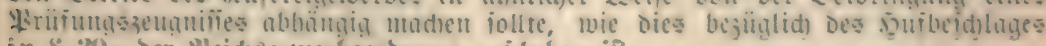
in $\$ 30$. Der Heid)sgnerbeorbnung geidhehen ift. 


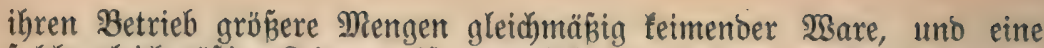

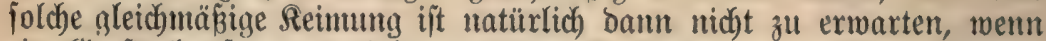
eit Sieritenhaufen aus vielen geringen Berfaufsmentgen fleiter Bauern

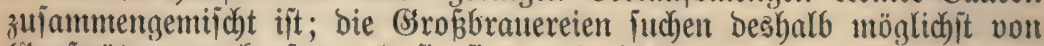

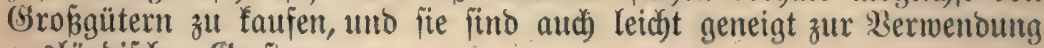
autąländijcher Bserite.

Sm Snterelle ber fleinbäuerlichen Ranomirtichaft ijt es beshalb oringeno

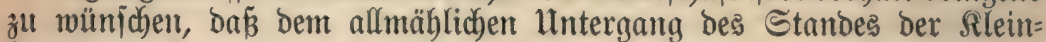
brauer burch eine 2)enderung ber Bieriteuergejebgebung entgegengemirft merbe, Into am bejten wïrbe bies geicheben burch Eriebung ber ver=

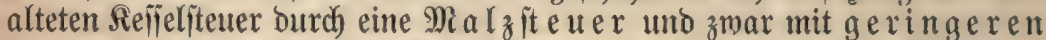
Steueriäben für bie Rleinbrauer uno insbefondere biejenigen unter benjelben, welde ibren Malzbebarf jelbit erzeugen (Lanbwirtichaftliche Brauereien uno Mälzereien).

Die Malzitener follte babei nicht nach bem $\mathfrak{M} a \tilde{\beta}$ (wie in $\mathfrak{B a y e r n}$ ) fondern nady bem (S) widyt (wie in Mürttemberg) erhoben werben; denn bas eritere Enjtem bränat zur Bermenoung möglichit idoweren Malzes, wodurd bie (Gerfte Der Rleinbauern wieberum zurïdgejekt milroe.

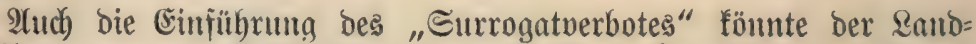
bevölferung mur erwünidit jein; Denn in ihrem sorteil liegt eg jeben=

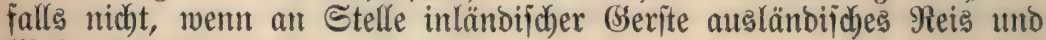
Diais nerwendet wiro.

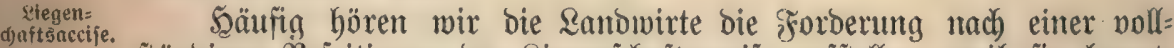
itänoigen ßeleitigung ber Riegenidaftaccife aufitellen, weil fie haupt= jäcblich bie Ranbwirticjaft belaite.

Das Rebtere ift jeooch nicht ridjtig; benn ber Riegenjodjaftsuerfebr ijt befanntlich allf bem platten Ranbe ein viel geringerer als in ben Stäbten; aus ben lebteren, wo fich zubem bie mertwolliten Riegen= ichaften (insbejondere (Gebäube) befinden, geht beshallb audh ber gröpere

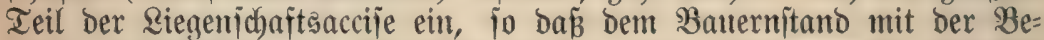
jeitigung Derielben und Eriebutu burdh andere Stentern nidjt geholfen würbe. Aludh hat bie Riegenichaftsaccife immerhin ben bodhanzuichlagen=

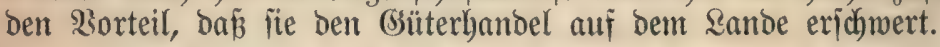

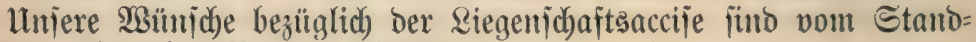
punft ber Rantbevölferung folgende:

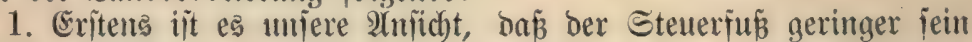

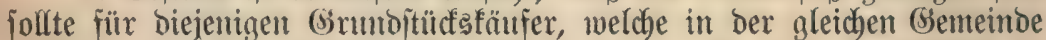
wohnen, wo bas gefaufte Srumbitid gelegen ift, ober wenigitens in einer an bieje angrenzenden Gemeinde.

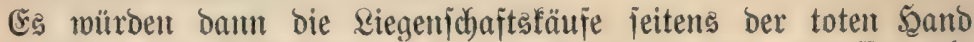

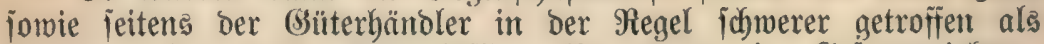
biejenigen jeitens ber ortsanjäjïtgen Bauern - eine Gejebeswirfung,

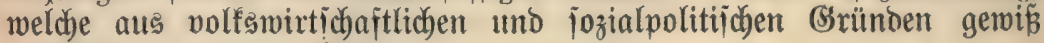
geredhtfertigt werden fann.

2. Dagegen jollte zweiteng bie Stener in boppelten Setrage, näm= lich jowohl vom Sin̈ufer als SBerfäufer erboben werben, wenn feit ber 


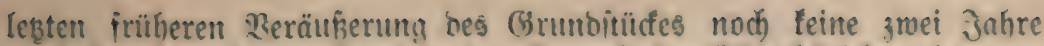

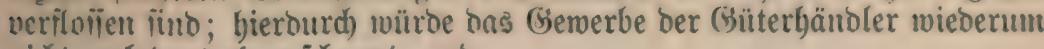
nidgt unbebeuterí eridjwert, uno

3. Follte bie Steuer erbohen werben nidyt alleir, renn es iid) um

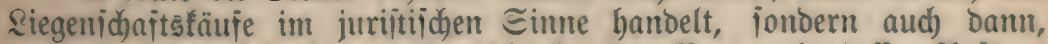
wenn cin Güterhändler bie Grunditüde eines Bauern in belien Aujtrag uno Manten veriteigert ober jonit veräusert, babei aber ausgemad)t iit,

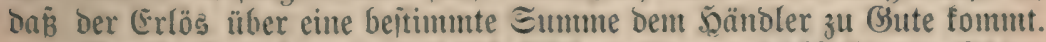

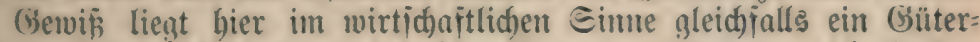
verfai an ben Sänder vor; ber betr. Nertring mutbe mur nidgt in ber Frorm bes Sintes uno Lierfaupes abgeid)lolien, meil man bie \$iflidgt

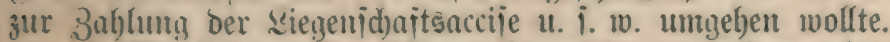

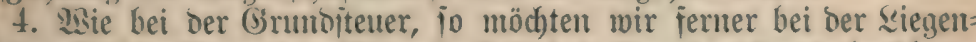

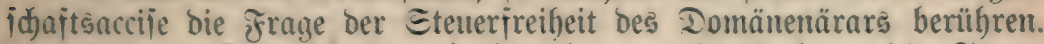

And) bie Sienenid)aitsaccije hat eben - wie ïberbaupt jebe Eteuer - auber Der Becinfluïuty ber betreffenben jtenerpiflictigen Einzelmirt=

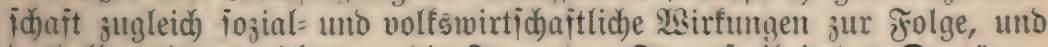
Deshall geht es nidht an, bie Frage ber Eteuerireibeit bes Domänen= ärars lesialid, vom Etmo bunft bes itaatlidjen औechmutgsweiens zu be= trad)ten, etwa inbem man jagt, es jei Dod) einterlei, ob eine Etaatsfalie Der antoern einen Betrag erjebt ober nidjt; vielmehr hat man iid) jut vergegenmärtigen, Dá் man bent Domäıttärar durç bie Befreiung von ber Siegenichapitsaccije ein nidjt untheträd)tliches ßoraus vor allen

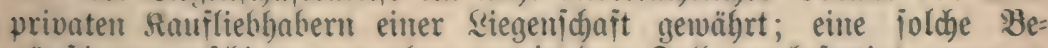
güntigung erichiente uns aber mur in bent frall geredtfertigt, merut es

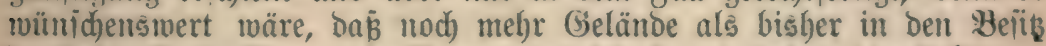

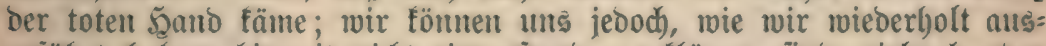
gejührt bahen, hiermit nidgt einveritanden erflären, fïn vielmebr ber

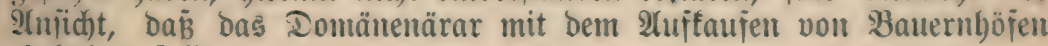
einbalten jollte.

Elhenjogut wie bas Domänenärar bei Dem Betrieb jeiner einen Bierhrauerei ber Bieriteuerpflidft unterworfen iit, uno bie Diilitürvermal=

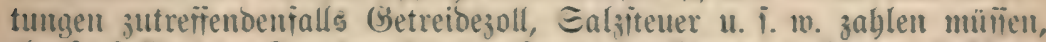
ebenjo iollte bas Domtänenärar mijeres Eradotents aud zur Bahlumị Der Siegenichaitsaccije für jeine (3ïterermerhungen angebalten werden.

Die gleide Betradtumysmeije nilt ielbitweritänolid aud) für Die

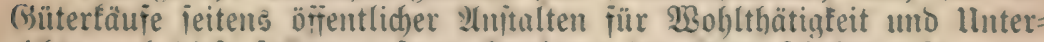
ridt; aud bieje jollten unieres (Erad)tens ber siegenid)aitsaccije unter= worfen werben, jojern bie Erwerbungen nicht aur Erfüllung ber betr. Stiftung 5 zwe de gemndyt wurbert.

Die bisherige (Sewidhtşitener vom Hohtabaf laitet idjwer aü Dem Iabafbauer, weld)em in eriter Sinie bie \$iflidbt zur Eteuerzablung ob=

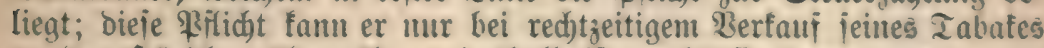
an ben ફändler überwälsen; beşbalb iit er häurig gezmungen, unter

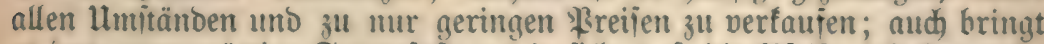

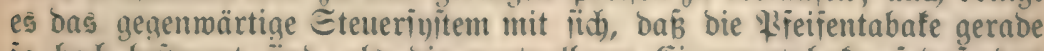
io hoch beitemert ïno als bie mertwolleren Cigarrentahafe, jobaß̉ bas \$ijeifenrauden imuer mebr burd) baș Eigarrenraudben verorängt wirb, 


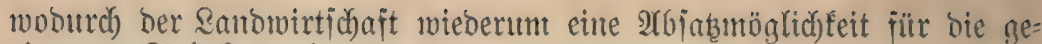
ringeren Iabafe verloren gebt.

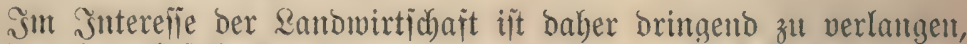
Daß̧ Das jekst bejtebende Steuerinjtent Durd) eine Tabaffabrif́atitener, womtöglich abgefauft nad) Dem MSert ber Fabrifate, erjebt und jo bie Stener: Iajt anitatt ben $\mathfrak{I} a b a f b a u e r n$ in eriter Rinie ben $\mathfrak{I} a b a \mathfrak{E}=$ und Cigarren= fabrifanten anferlegt werbe. Fjür wünichenswert würben wir es babei Galten, went bie Iabaffahrifatitener für biejenigen Betriebe, welde im Sommer itilliteben, äbnlich wie bei ber Branntweinteuter, in geringerent Betrage erboben witrde, als für bie, welche bas sanze Jahr hindurd

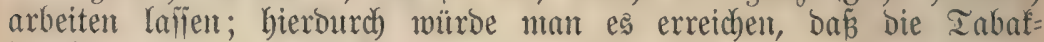
indultrie gerade wie bie Branntweinprobiffion fich mebr alf Dent platten

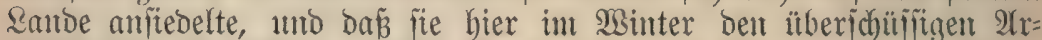
beitsfräften Beichäftigung böte, wäbrento bieje in Sonmter in ber Ranto= wirtichaf̣t thätig jein fönnten.

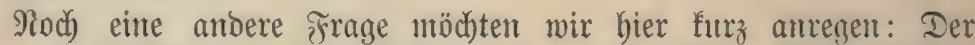

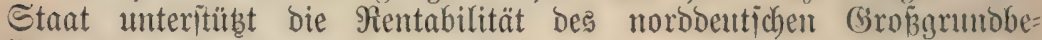
fitzes burcty Exportprämien für Bramutwein แnto Bucter; wie wäre es, wenn er mun aud Den in Der Regel von Rleinbantern betriebenen Tabafbau, weldher ja in Den lebeten Salyrent in Feinter Rentabilität zweifelsohne bebeutend zurürgegangen ift, burch Exportprämien auf

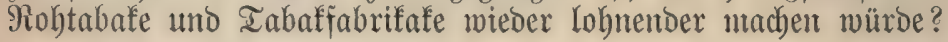

Getreibezölle. Bei ben Getreidezöllen ift e马 naturgentä́p hauptiäd)lich bie Frage nach Der Şöhe Derjelken, weldbe in Den Tagesblättern uno der

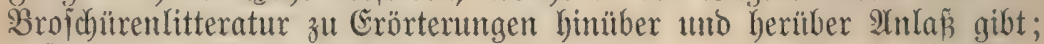
mijererjeits foll jeboch hier von Beipredyung biejer Frage abgejeben werben, weil wir uns mur mit Exreid)barem beidbätigen wollen, Die (Setreidezölle aber burch bie Scandelsverträge auf Jahre hiutats Feit= gelegt fino.

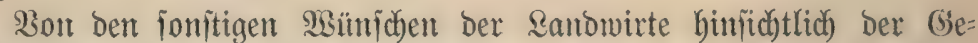
treisezölle wirb netterbings insbejonbere ber häufïg wieberbolt, bie 3oll= vermaltung möge bie jogenanten gemijoten Privattraniitlager

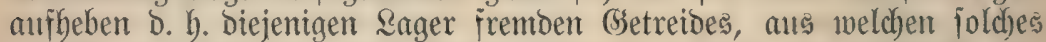
fowohl in bas Sntland nach itattgebabter Berzollung als tunerzollt in's

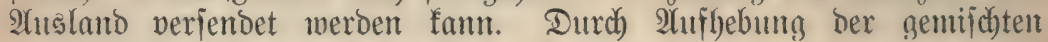

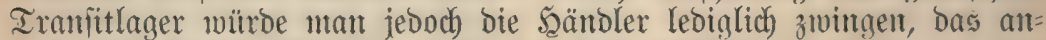
fommente frembe (Ssetreibe gleich allf zwei perichiebene Räger zu ver=

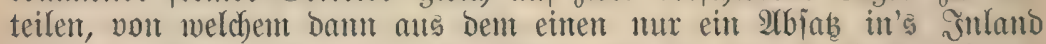
unto aus bent andern mur eine Miederantsfuthr in's 2Atsland gejtattet wäre; es wïroe aljo bem Ragerinhaher bie Möglichfeit genommen, je nach ber Weltmarftstourjuntur ïber bas Getreibe balo zur Eimfubr bald

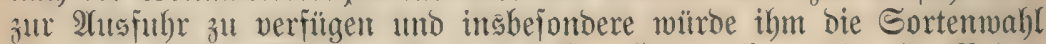

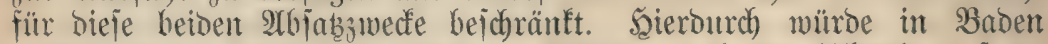
jweifellos ber Sambel mit frembem (Şetreibe nady ber Sdyweiz 11. 1. w.

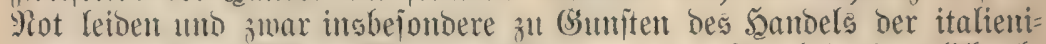

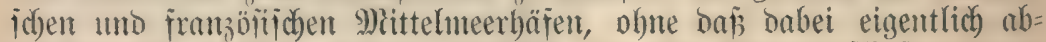

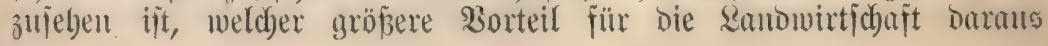




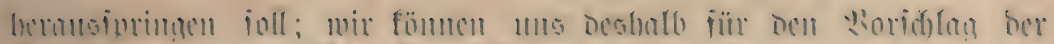

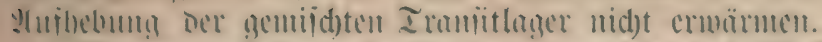

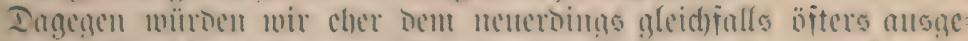

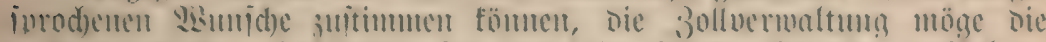

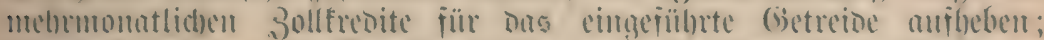

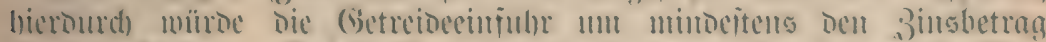

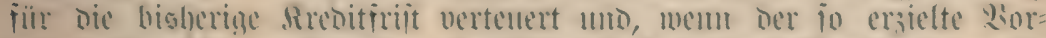

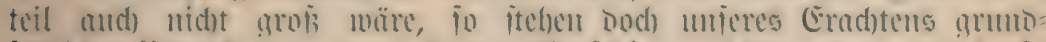

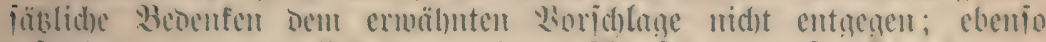

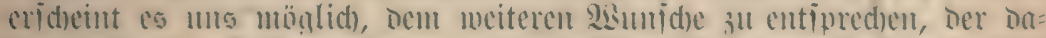

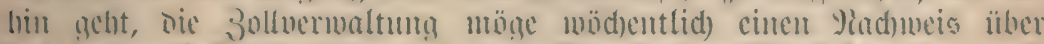

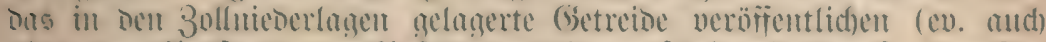

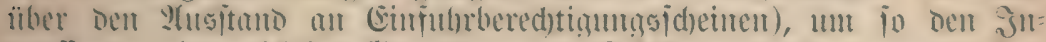

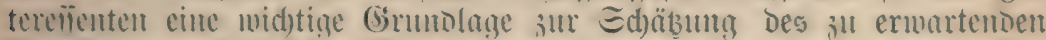

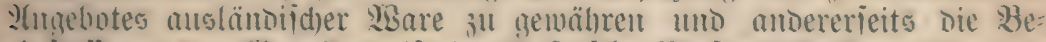

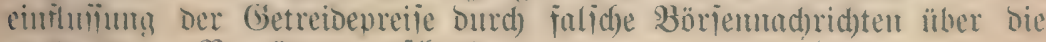
norbarbenen Borräte zu erjabueren. 


\section{IV. 祖 $\mathfrak{n} \mathfrak{h} \mathfrak{a} \mathfrak{i t} \mathfrak{g}$.}

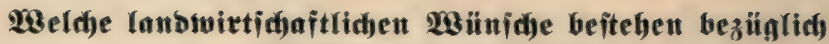 bez (Eijenbahnweien}

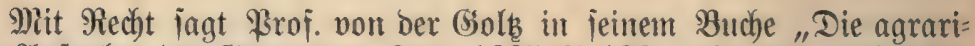

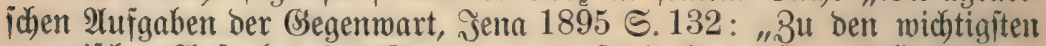
agrarifłen 2 Uufgaben ber Begentwart muß̈ bie Sorge fïr bie \$eritellung guter Berfebrsmittel gered)net werben".

Ullerbings murben in ben lekten Sabren bie Tarife für lanomirt= idaftliche $\mathfrak{B r o b u f t e ~ j o w i e ~ b i e j e n i g e n ~ f u ̈ r ~ D u ̈ n g e r = ~ u n o ~ F u t t e r m i t t e l ~ v i e l = ~}$

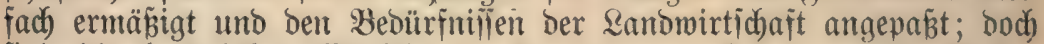

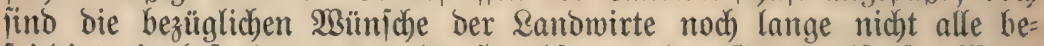
friebiat; insbejondere märe eine Scerabjebunt ber Bütertarife für Wein, Taliaf, Obĩt, Butter u. j.m. oringeno zu wünjchen; ferner jollten bie Tarife fïr Frucht billiger geftaltet merden als bie für 9 lehl, unt bie Einfulbr bes Rekteren aus ber Ferne (z. B. aus Moro= uno Dít=Deutid)land) zu

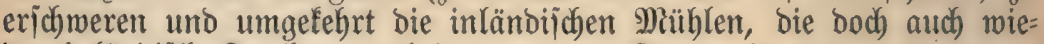
ber inländijabe Frudbt verarbeiten, zu unteritüben; bagegen wäre gegen bie Miedereinfïhrung ber Differenzialtarife für das oitpreußifiche (S)= treide und Mehl mit alfer Energie $\mathfrak{B i d e r i t a n d}$ zu leijter.

Biel geringeres Interefie als an ben Gsiltertarifen hat ber Bauer

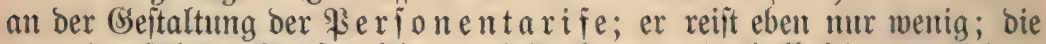
nell eingeïührten Iaujendfilometerbeite fomment beshalb feintesmegs bem

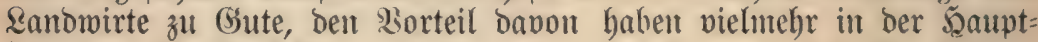

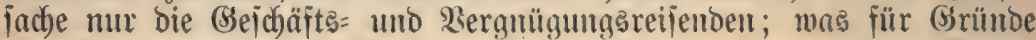
aber fann man bafür gelteno madjen, ba $\tilde{B}$ man eintem armen Batter,

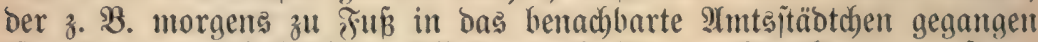
iit uno Dant nadh Sauje zurüdfabren will, für eine Stredfe, von - jagen

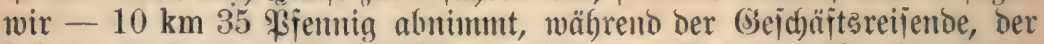

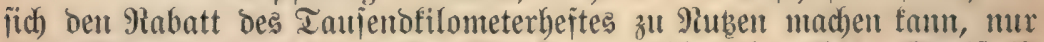

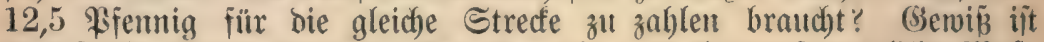
eine joldbe Iarifgeitaltung alles eher als eine bauernfremb(iche 9)ia nabme.

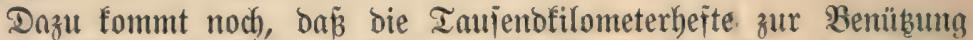

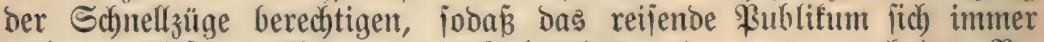
mehr an bieje gewöhnt, uno in Folge bavon bann mur noch bas $\mathfrak{B e}=$

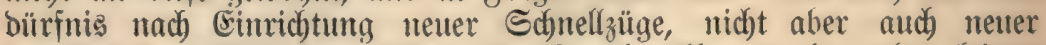
gewöhnlicher Büge hervortritt; die \&anbbevölferung hat aber feimen Borteil von ben Edynellzügen, weldbe, obne zu halten, an ben fleinen

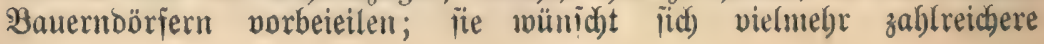




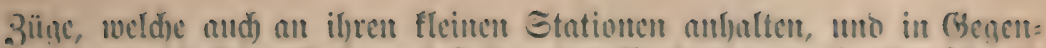
Den, wo nod) feitue Balmen beitelen, ben Yieubun normal= ober idmul= ipuriger Yofalbabnen. Beises - sablreidgere sofalgitge unt Bau neuer Sofalbahnen - wiro aber ım io idnwieriger zu erreidben jein, je mebr bie Bahmeinnahmen Durd) meitạehente Rerbilliguna ber Berjonentarife uno Regiall nes Ed)nellyugşuid)lạ̣s für bie jubaher von Tauiend= filometerheiten berabgeben: Deshall hat bie Ranblievölferumg burdjaus fein Interelie an Dieien Tarifberabiebuntuen; wenn ioldhe aber bennod

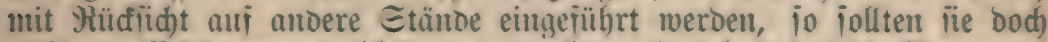
nid)t von Besingungen abbängig gemad)t merben (mie ję̧t die Benuß̨ung

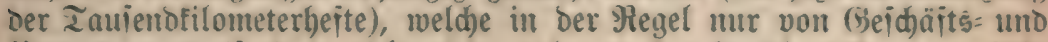

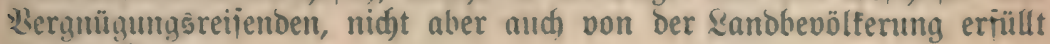
werben fönnen. 


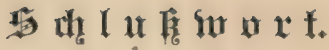

Mit ben voranggegangenen Attsfübrungen glanten wir in ber

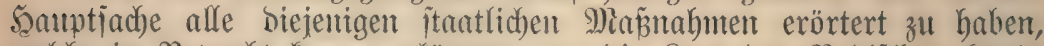

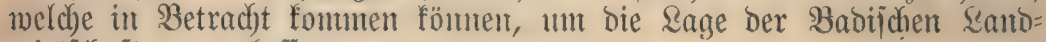
mirtichajt zu verbefiern.

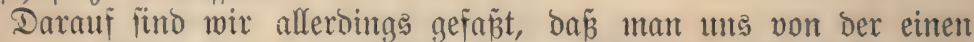
Seite vorwerjen miro, unjere 93orichläge enthielten zum groß̧en Teil

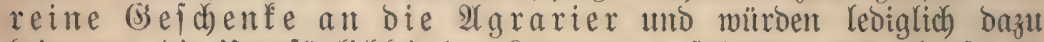

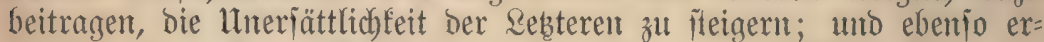
warten wir audd) umtgefehrt, bã gegengehalten werben wirs: , Mit iolden fleinen $\mathfrak{M}$ itteln $i$ ft ber \&andoirtidaft nidgt mehr zubelfen; wo bleiben unfere

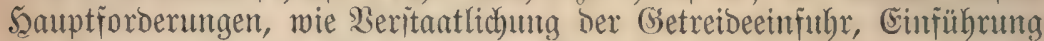
Der Doppetwährutg, 2tblöjunt Der Syypothefenichufden unter Staats= आni

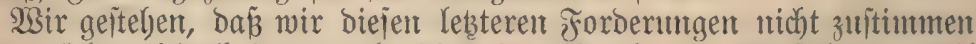

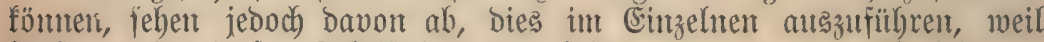

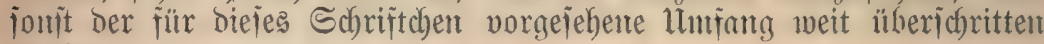
mitroe.

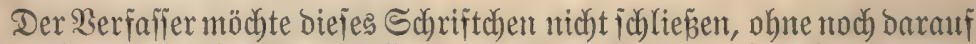

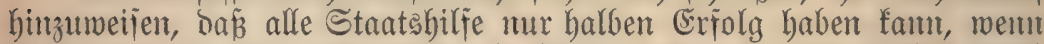
Die Rambmirte fich nidht mehr als bisher felbjt zul helfen juchent burd)

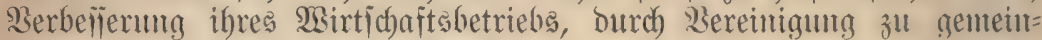

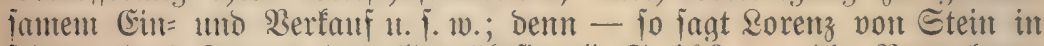

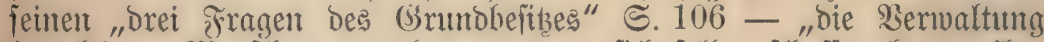

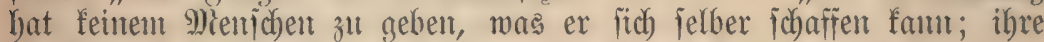
2lufgabe ift es allein, Dent Eintzelnent biejentigen Bebinguntgent feiner ge= jamten periönlichent Entwidflung zu bieten, bie er burch jeinte einzelnte wirtichaftliche oner periönlidge Rraft nicht heritelfen famm."

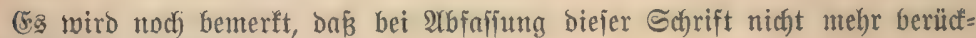
fidtigt werben fonten:

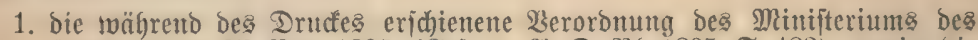

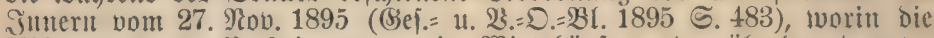
श्(bhaltung won Beriteigerungen in Wirtghäujern ober überbaut unter (Semährung geiftiger Betränfe verboten wiro (bergl. hierzu aud) Seite う1 biefes S(briftults);

2. Der Den Stänচen vorgelegte neue Bieriteuergejezentwurf und

3. Die Den Ständen vorgelegte Denfichrift über die औeform ber bireften Steuern itt Baben.

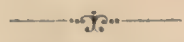





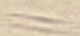


$\frac{6}{4}$

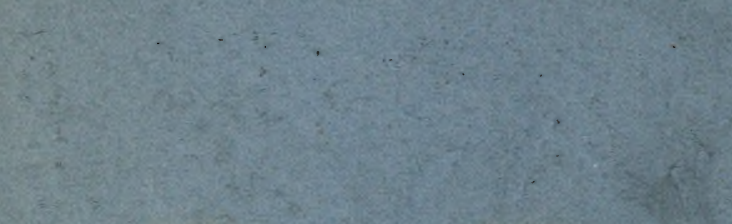

